Das

religiöse Leben der Juden nach dem Exil

ron

Rev. T. K. Cheyne, M. A., D. D.

Professor der Exegese zu Oxford, Kanonikns der Kathedralkirche zu lior anter

\author{
Deutsche Übersetzung \\ unter durchgängiger Mitwirkung des Tertasser- \\ roll \\ H. Stocks
}

Zweite wohlfeile Ausgabe

Alfred Tïpelmann

(rorm. J. Ricker'sche Verlagshuchhandlung,

Gieben 190j 


\title{
Die Religion des Volkes Israel bis zur Verbannung
}

\author{
von \\ D. Karl Budde
}

wr. Prolessol der Theologie an der Cniversitat Jarburg a. J.

\author{
Zweite wohlfeile Ausgabe
}

Oktar-Format - 224 seiten

Geheftet II. 2.51)

1905

Gebunden II. 3.30

\section{Einleitung in das Buch Jesaja} von

\section{T. K. CHEYNE}

Professor der Exegese zu Uxford. Kanonikus der Kathedralkirche zu Rochester

Unter durchgängiger Mitwirkung des Verfassers übersetzt von

\section{Julius Böhmer}

Lic, theol.. I)!. phil., Pfarrer in Raben

$$
\text { Groli-Oktav — } 448 \text { Seiten }
$$

Geheftet M. 5.-. 


\section{CHEYNE}

Das religiöse Leben der Juden nach dem Exil 
Amerikanische religionswissenschaftliche Forlesungen Vierte Reihe 1898-99

I)ie Religion des Volkes Israel bis zur Verbannung yoll

\section{I). Karl Budde}

Prof. d. Theologie a. d. Lniv. Marburg

Zweite wohlfeile Ausgabe

Oktar - 1905 - 224 Seiten - Geh. M. 2.50; geb. M. 3.30

Verlag con Alfred Töpelmann (rorm. J. Kicker) in Giessen 


\title{
Das
}

\section{religiöse Leben der Juden} nach dem Exil

von

Rev. T. K. Cheyne, M. A., D. D.

Professor der Exegese zu Oxford, Kanonikus der Kathedralkirche zu Rochester

\author{
Deutsche Übersetzung \\ unter durchgängiger Mitwirkung des Verfassers \\ Von
}

H. Stocks

Zweite wohlfeile Ausgabe

Alfred Töpelmann

(vorm. J. Ricker'sche Verlagsbuchhandiung)

Gieben 1905 
Alle Rechte vorbehalten

\author{
Amerikanische \\ religionswissenschaftliche Torlesungen \\ Dritte Reihe 1897-98
}

Diese Ausgabe bietet den unveränderten Text der ersten Ausgabe von 1899 


\section{Inhaltsverzeichnis.}

Vorrede des Übersetzers . . . . . . . . . . . . . VII

Torrede des Verfassers . . . . . . . . . . . . IX

\section{Erste Vorlesung.}

Das religiöse Leben in Judäa vor der Ankunft Nehemialıs 1

Zweite Vorlesung.

Nehemiah, Esra und Manasseh oder die Wiederherstellung der jüdischen und samaritischen Gemeinde . . . . . 37

Dritte Vorlesung.

Religiöse Ideale der Juden; Hindernisse für ihre volle Entfaltung . . . . . . . . . . . . . . . 83

Vierte Vorlesung.

Jüdische Weisheit; ihre Bedeutung; ihr Gegenstand und ihre Gestaltungen

Fünfte Vorlesung.

Orthodoxe und ketzerische Weisheit; gleichzeitige levitische Frömmigkeit . . . . . . . . . . . . . . . . 173

Sechste Vorlesung.

Das Judentum: Seine Anziehungskraft auf Fremde, seine Auffassung des Terhältnisses zu Gott als solchem, seine Beziehungen zu Griechenland, Persien und Babel . . 215

Noten . . . . . . . . . . . . . . . . 261

Übersicht über die Datierung der betrachteten Quellenlitteratur . 



\section{Vorrede des Coersetzers.}

Herr Professor D. Cheyne hat die Güte gehabt, mich zum Übersetzen des vorliegenden Werkes ins Deutsche zu ermächtigen. Er stand mir bei Anfertigung der Übersetzung sowie bei Lesung der Korrektur in mannigfacher Weise mit Rat und That zur Seite. Verschiedene Nachträge von grösserem oder kleinerem Umfange sind dieser seiner freundlichen Anteilnahme zu verdanken. Alle Nachträge, besonders die beiden am Schluss des Buches hinzugefügten über Sanballat und Tobiah sowie über Koh. 3, 11, werden anch die Kenner der Originalansgabe interessieren. Sie sind bis anf die genannten in eckige Klammern eingefasst. Die Verszählung in den Citaten des Originals weicht zuweilen etwas von der in unsern landläufigen hebräischen Texten ab, ich habe letztere im Einverständnis mit dem Herrn Verfasser in eckigen Klammern nachgetragen. V'ereinzelte Druckfehler des Originals sind stillschweigend berichtigt. Anderes, besonders Angaben ïber einschlägige dentsche Litteratur, habe ich selbst nachgetragen. Solche Nachträge sind durch eckige Klammern mit der Sigle S. bezeichnet. Litteratmrangaben sollten anf besondern Wunsch des Herm Verfassers sich in ganz bescheidenen Grenzen halten. Was also nicht genannt ist. 


\section{Vorwort des Übersetzers.}

ist farmm nicht ignoriert. Aus verschiedenen Griinden sind die Vorbenterkungen. die ausführliche Inlaltsangabe sowie die Indices des Originals weggeslassen worden und zwar die beiden letztgenanntrn besonders deshalb, weil das Buch selbst da, wo seine Aufstellungen zum Widerspruch herausfordem. gorlesen werden und nicht nur zum Nachschlagen dienen soll. Für die schöne Ausstattmug des Buches gebührt dem Herrn Verleger verbindlicher Dank.

H. stocks. 


\section{Vorrede des Verfassers.}

Das Bestreben des Verfassers ist ein doppeltes gewesen: einmal ein grösseres Publikum für die Geschichte der Stammmutter unserer Religion, der jücdischen, zu interessieren und daher solchen, die sich mit der nachexilischen Periode beschäftigen, eine $\mathrm{Zn}$ sammenstellung der sichersten gegenwärtig erreichbaren Resultate der Kritik darzubieten und so sie zu einem Urteil über deren Wahrscheinlichkeit in den Stand zu setzen. Vielleicht besteht die Eigentümlichkeit des vorliegenden Buches eben in der Vereinigung dieser beiden Zwecke. Man kann einerseits erfolgreich der Popularisierung der Wissenschaft dienen, ohne doch ein selbständiger Forscher zu sein, man kann anderseits wissensehaftlicher Forseher sein, ohne das gleichzeitig zu sein, was man interessant nennt. Inwieweit der Verfasser seinen doppelten Zweck erreicht hat, das zu beurteilen steht andern zu. Er ist jedenfalls von dem Wunsche erfüllt gewesen, nach dem Rat eines französischen Orientalisten ${ }^{1}$ ) ", sich nicht zu begnïgen mit zehn gelehrten Lesern, wenn man alle die um sich versammeln kann, welche die Vergangenheit des menschlichen Geistes interessiert und anzieht". Warum der Verfasser grade die Periode der per-

1) M. Barbier de Meynard. 
sisch-griechischen Herrschaft ins Auge fasste, das hat er in der ersten Vorlesung dargelegt. Er ist sich der Schwierigkeit des Themas wohl bewusst, aber er hoft zu ihrer Verminderung in etwas beigetragen zu haben und seitens des Lesers, ehe er an die letzte Seite gelangt, das Zugeständnis zu empfangen, dass die nachexilische Periode nicht so öde und monoton ist, wie er gefürchtet hatte. Selbstverständlich ist der Verfasser weit davon entfernt, alle seine Ergebnisse als abschliessend in Anspruch nehmen zu wollen. Kein Forscher kamn auf dem Boden der alten Geschichte das beanspruchen, am allerwenigsten wäre das angebracht, wo das Material so fragmentarisch, die Exegese so zweifelhaft ist, wie im vorliegenden Fall. Aber das: das hier gezeichnete Bild in den allgemeinen Zügen tren ist, das kann mit Zuversicht behauptet werden und viele 'Thesen, gegen welche der For:cher' auf einer früheren Stufe noch gewichtige Einwände erheben komnte, gehören zu denen, die jetzt mit dem besten Erfolge verteidigt werden können. Noch eine Versicherung darf ausgesprochen werden. Sollten Freunde der Religion dem Verfasser Mangel an Sympathie mit ihnen zum Vorwurf machen, so wären sie fast noch mehr in Irrtum als die, welche ihm kritische Willkür vorwerfen würden. Thatsächlich sind diese Seiten geschrieben worden, um zu einer allseitigeren Würdigung der jüdischen Frömmigkeit anzuregen. Eine solche Wiirdigung kann nicht ohne segensreichen Einfluss auf das religiöse Volksleben sein.

Welehes der Zustand des religiösen Lebens der 
Juden vor Ankunft Nehemiahs war, das wird in der ersten Vorlesung geschildert. Obwohl diese einen Überfluss an neuen Thatsachen darbietet, ist sie aus dem angeführten Grunde vom Standpunkt reiner Neugierde aus die am wenigsten interessante. Über die edelsten religiösen Ideale und Ideen des älteren Judentums mag man sich in der dritten und vierten Vorlesung Belehrung suchen. Die Geschichte der jüdischen Reform, eine auf kühner, wie wir hoffen, nicht allzu kühner Kritik beruhende Darstellung, ist in der zweiten Vorlesung zu finden. Die orthodoxen und skeptischen Spielarten dessen, was man in gewissem Sinne jüdische Philosophie nennen kann, treten in der vierten und fünften Vorlesung in den Kreis der Betrachtung ein. In der Schlussvorlesung hat der Terfasser neben einer neuen Behandlung der interessantesten Abschnitte der älteren jüdischen Theologie eine dem gegenwärtigen Stande der vergleichenden Religionsforschung, wie er hofft, entsprechende Skizze der Beziehungen des Judentums zu den andern grossen Religionen, die in der nachexilischen Periode in seinen Gesichtskreis traten, gegeben. Ein Inhaltsverzeichnis wird den Leser in den Stand setzen, dem Gange der Darstellung zu folgen.

Diese sechs Vorlesungen wurden zuerst in der Zeit vom November 1897 bis Januar 1898 in neun verschiedenen Städten der Vereinigten Staaten von Nordamerika unter den Auspicien des „Committee" gehalten. Sie werden hiermit in ziemlich erweiterter Form mit den notwendigsten Anmerkungen einem 
weiteren Publikum geboten. Sie bilden den vorläufigen Abschluss einer Reihe von eingehenden Untersuchungen. Der Verfasser hofft, dass ihre nicht schulmässige Form sie auch denen interessant macht, die für tiefer eindringendes Studium keine Musse haben.

T. K. C. 
Erste Vorlesung.

\section{Das religiöse Leben in Judäa vor der Ankunft Nehemiahs.}

Ich lege Thnen ein Thema vor, das vor noch nicht langer Zeit in ziemlicher Gefahr sich befand, in Misskredit zu geraten. Wer von uns denkt nicht mit Unbehagen an die schwierigen biblischen Geschichtsstunden seiner Jugend zurück. Ohne Zweifel hat das durch Reisen und archäologische Forschungen auf die Äusserlichkeiten der biblischen Eızählungen fallende Licht einen gewissen Fortschritt gebracht. Aber wie sehr ich auch die Lernenden unserer Tage glücklich schätze wegen der grösseren Interessantheit ihrer Studien: für befriedigt kann ich mich doch nicht erklären. Denn die Unnatürlichkeit der geltenden Auffassung der biblischen Geschichte besteht noch, und nur als Sammlung anschaulicher Erzählungen scheinen die Geschichten des Alten Testaments ihre Rolle in der gebildeten Welt weiter spielen zu sollen. Was ein moderner Mensch am liebsten aus dem Alten Testament kennen lernen will, das ist die zuverlässige Geschichte der jüdischen Religion, und diese kann allein dargestellt werden, indem man die Methode der modernen Kritik bei den alten hebräischen Urkunden in Anwendung bringt. Könnte diese Forschungsmethode 
angenommen werden nicht allein in gelehrten akademischen Werken, sondern auch in populären Vorträgen und Handbüchern, köunte das Alte Testament in gründlich modernem Geiste behandelt werden, zugleich mit warmem Interesse wie mit umsichtiger Kritik, damn glaube ich unbedingt, dass diese ehrwürdige religiöse Überlieferung ihren alten Zauber wiedergewinnen würde. In solchem Geiste trete ich nun in die Erörterung eiu. Kann ich auch nicht überall mit absolut feststehenden Thatsachen dienen, warmes Interesse und umsichtige Kritik wird man nicht vermissen.

Meine Leser werden es mir hoffentlich nicht übelnehmen, wenn ich dreierlei ihnen zumute. Einmal, dass sie Vertrauen um Vertrauen geben und mir glauben, dass ich nur das eine Ziel im Auge habe, die wiedererschlossene Geschichte der jüdischen Religion freimütig und anziehend zugleich zu schildern, soweit sie mir erkennbar ist. Nächstdem empfehle ich zugleich mit der Lektüre der vorliegenden geschichtlichen Skizze ein erneutes Studium des Wortlautes der biblischen Überlieferung. Und endlich bitte ich darum, dass man sich auf eigene Hand vertraut mache mit irgend einer guten Zusammenstellung ${ }^{1}$ ) der grundlegenden Ergebnisse der modernen Bibelkritik. Denn wenn ich mich beständig damit aufhalten sollte, Ausdrücke wie "Deuterojesajah" zu erklären oder die Fragen nach Ursprung und Verfasser zu erörtern, dann würde der Zusammenhang dieser Vor-

1) Die beiden Bibelworterbilcher, die bei T. $\&$ F. Clark bezw. A. $\&$ C. Black erscheinen werden, seien hier nur erwahnt. Auf einige Artikel des letztgenannten, zu dessen Herausgebern der Verfasser gehört, wird im weiteren Verlauf der Varstellung Bezug genommen werden. Der erste Band des erstgenannten ist erschienen. 
lesungen ernstlich bedroht sein und ihr Zweck, die Geschichte einiger Phasen einer wichtigen Religion zu erforschen, würde entsprechend verdunkelt werden.

Doch es soll mich nicht wundern, wenn einige meiner Leser über meine letzte Zumutung lächeln werden. Ich nehme bestimmt an, dass vorgeschrittene Jünger der Wissenschaft doch auch direkte Förderung der kritischen Arbeit von mir erwarten werden und nicht eine blosse Wiederaufzählung des Inhalts der Lehrbücher. Das Thema, welches ich mir ausersehen habe, starrt von kritischen Schwierigkeiten, und sogar eine lediglich darstellende geschichtliche Skizze wird nicht umhin können, etwas von dem kritischen Standpunkt ihres Verfassers zu verraten. Es war allerdings die Schwierigkeit des Themas auf der einen Seite, welche mich anzog; bietet es doch so reichliche Gelegenheit, die Forschung weiterzuführen. Auf der andern Seite aber sind doch, wie mir scheint, die erarbeiteten Ergebnisse zuverlässig genug, um als geschichtliche Grundlage dienen zu können. Ich erwog auch, dass solche, die sich mit dieser Periode befassen, froh darüber sein werden, das Gesamtbild vor Augen zu haben, welches später durch die Thatsachen der früheren Periode erklärt werden soll. Steht ihnen doch für jenen Zeitraum eine grössere Masse von Stoff zu Gebot. Sie haben ja nicht allein die biblischen Berichte, sondern daneben auch viele kostbare Belehrung durch die orientalische Altertumskunde. Bei der Erforschung der vorliegenden Periode werde ich mich dagegen im allgemeinen mit den nachexilischen religiösen Schriften 
zu begnügen haben. Freilich darf ich glücklicherweise annehmen, dass wir sie heutzutage besser verstehen als früher. Die Kritik fährt ständig fort, Resultate von dauerndem Werte zu Tage zu fördern. Resultate, welche ich für meine historischen Zwecke zusammenzustellen und $\mathrm{zn}$ erläutern bestrebt sein werde durch gemeinsame Thätigkeit zweier verwandter Geistesgaben: Verstand und Phantasie (Divination).

Man spotte nicht über divinatorische Kritik; der Nutzen der Phantasie wird wohl gewürdigt durch die bedeutendsten unter unseren Naturforschern und Geschichtsschreibern $^{1}$ ). Sogar in der Exegese lässt ein glücklicher „Einfall" oft eine Flut von Licht auf eine dunkle Stelle fallen, und eine ähnliche Beobachtung lässt sich noch mehr anwenden auf die aufbauende Thätigkeit des Geschichtsschreibers. Diese .. Einfälle" sind nicht rein zufällig. Sie beruhen in der Exegese auf Seelengemeinschaft mit dem Terfasser und einem Gefühl dafür, was er gresagt haben kann und was nicht, in der Geschichte dagegen auf einem emsig gepflegten divinatorischen Blick für das Altertum, der durch umfassende Beherrschnng der Thatsachen unterstützt wird.

Ein Punkt muss ausserdem noch bestimmt hervorgehoben werden. Es ist meines Erachtens für den, der mit dem hebräischen Altertum sich beschäftigt, merlässlich, anf Grund kritisch bearbeiteter Texte zu arbeiten. und selbst für den Jünger der Wissenschaft,

1) „Die Phantasie... die Mutter aller Geschichte sowohl als aller Dichtkunst." Mommsen, Rüm. Gesch. V s. 5. 
der auch nur die bescheidensten wissenschaftlichen Ansprüche an sich stellt, wenigstens so viel, dass ibm Übersetzungen (womöglich mehr als eine) solcher kritisch bearbeiteter Texte zu Gebote stehen. Ein amerikanischer Professor macht jetzt den dankenswerten Versuch, mit einer Schar von Gehilfen diesem Mangel abzuhelfen. Allerdings ist mir von den Ergebnissen dieser Arbeit bisher nicht viel bekannt geworden. Ich habe daher oft eine neue Übersetzung eigener Arbeit geben müssen auf Grund eines von mir selbst kritisch ermittelten Textes. Indem ich Sie noch bitte, denselben später mit dem der Hauptschen Bibel$^{1}$ ) zu vergleichen, gehe ich nunmehr zu meinem Thema über.

Es herrscht noch viele Ungewissheit über den Anfang der nachexilischen Periode. Dass Cyrus geneigt gewesen sein sollte, Glieder des jüdischen Volkes von der Heimkehr in das Land ihrer Väter abzuhalten, widerstreitet allem, was uns über seinen Charakter und seine Grundsätze bekannt ist. Die vor kurzem entdeckte Keilinschrift des Cyrus wirft allerdings kein klares Licht auf unsere Frage; aber der Geist, welcher dort dem grossen Eroberer zugeschrieben wird, ist milde und duldsam. Dass die Schüler Ezechiel̀, der, Gesetzgeber und Prophet in einer Person, die

1) Die Polychrome Bible (Regenbogenbibel), herausgegeben ron Prof. Paul Haupt [dem bekannten Assyriologen - S.], John Hopkins Lniversity Baltimore. Die im rorliegenden Buche gegebene Jesajahubersetzung stimmt im allgemeinen mit der des genannten Werkes überein: die der Psalmen mit einer auf einem durchgreifend verbesserten Text basierenden Übersetzung, welche der Verfasser bald herauszugeben hofft mit erläuternden Noten. Die im vorliegenden Buch acceptierten Textkorrekturen für Hiob und die Proverbien findet man im Expositor (Juni und Juli 1897) und im Jewish Quarterly Review (eitiert als J Q R) Juli nnd Oktober 1897 . 
Idee der Volksgemeinde zuerst ins Auge fasste, um nicht zu sagen, sie begründete - keine Neigung gehabt und nicht den Versuch gemacht haben sollten, ihres Meisters gesetzliche Grundsätze im heiligen Lande selbst in die Wirklichkeit umzusetzen, ist kaum glaublich. Und für diejenigen, welche in der Lage und gewillt waren, die Reise zu machen, bot sich Gelegenheit, als Šešbazzar oder richtiger Sanabassar (wie die besten griechischen Zeugen den Namen geben), ein Jude aus Babylon vom Geschlecht der Davididen, durch Cyrus, in Verfolg seiner die Gegensätze ausgleichenden Politik, nach Jerusalem gesandt wurde, als Gouverneur vonJudäa. Denn dieser hohe Beamte musste naturgemäss von einem Gefolge begleitet sein. Einer seiner Begleiter war sicherlich sein Neffe Zerubbabel, und es ist sehr wohl möglich, dass die andern Personen, welche mit Zerubbabel zusammen in einer gewissen vielcitierten Liste $^{1}$ ) als "Häupter" der Juden in der „Provinz" genannt werden, thatsächlich historisch sind. Von diesen andern Führern (elf an der Zahl) ist der bekannteste Ješua oder Jošua, der der erste Hohepriester im nachexilischen Sinne des Wortes wurde. Wir müssen natürlich annehmen, dass die „Häupter" mit ihren Familien und ihrem sonstigen Anhang hinaufzogen, so dass sie in ihrer Gesamtheit eine beträchtliche Schar bildeten, obwohl sie ziffernmässig nicht stark genug

1) Esr. 2, 2: Neh. 7, 7; Esdr. A 5, 8 (wo der Grieche den Begriff ,Häupter ausdruckt). (Der Nime Nahamani wird hinzugefugt Neh. 7, 7; Esdr. A 5, 8. Er findet sich auch in der Lukianischen $\mathrm{LXX}$ (ed. de Lagarde) zu Esr. 2, 2; so ergiebt sich mit Einrechnung Zerubbabels die Zahl zwolf.] 
waren, den Charakter der jüdischen Volksgemeinde zu bestimmen. Dass thatsächlich in diesem Sinne die Schar keinen Einfluss ausübte, glaube ich mit Notwendigkeit aus den Prophetien des Haggai und $\mathrm{Za}-$ chariah folgern zu sollen.

Diese Propheten haben ihr Augenmerk darauf gerichtet, das Volk zum Wiederaufbau der Tempelruinen anzufeuern. Sie hatten Erfolg. Aber aus den Berichten ergiebt es sich klar, dass die Erbauer, jedenfalls ihrer Mehrzahl nach, nicht aus dem Exil Heimgekehrte, sondern solche Judäer waren, welche Nebukadnezar nicht nach Babel weggeführt hatte.

So habe ich in kurzen Zügen festgestellt, was meiner Meinung nach der Thatbestand betreffs viel umstrittener Vorgänge ist. ${ }^{1}$ ) Die herkömmliche Anschauung ist, ich bedauere das sagen zu müssen, in vieler Hinsicht unrichtig. Die Überlieferung hat teilweise Thatsachen erdichtet, wo keine solche vorlagen, teilweise wirklich feststehende Thatsachen umgebildet. Ich darf mich nicht dabei aufhalten, die Gründe zu entwickeln, auf welche hin ich zu Werke gegangen bin; denn mein eigentliches Thema ist nicht die äussere, sondern die innere Geschichte des Judentums und die von mir so sorgsam wie möglich aufgestellten Thatsachen sind mir jetzt nur insoweit von Wichtigkeit, als sie den Hintergrund für gewisse Er-

1) Vgl. den Artikel , Israel, History of ${ }^{\star}$ in Blacks demnächst erseheinender Encyclopaedia Bibliea und den Prologue zu C'heyne's Introduction to the book of Isaiah. [E. Heser, Die Entstehung des Judentums. I896. Stade-Holtzmann, Geschichte des Volkes lsrael. Kosters, Het herstel van Israel. I894 u. a. Von anderm Standpunkt aus: Klostermann, Geschichte des Volkes Israel. 1896. Die einschlägigen Artikel in Herzog-Hauck, Realeneyklopaedie u. a. - S.] 
scheinungen des religiösen Lebens der Juden bilden. Nummehr gehe ich sofort über zu der Frage: Welches war die religiöse Stimmung des unglücklichen Restes des alten judäischen Volkes?

Die Antwort anf diese Frage giebt der Prophet Haggai, welcher, wie wir sahen, sich mit Zachariah zu einem praktischen Aufruf an das Volk von Jerusalem verband. Die Antwort, welche er erhielt, war keineswegs ermutigend, und die Lauheit der Bürger erschien ihm tadelnswert. Er lässt jedoch durchblicken, dass sie über die Sache nachdachten und für ihre Haltung eine Entschuldigung zu haben glaubten. Sie waren Landleute. Eine Reihe von Plagen hatte sie betroffen, welche nur zu deutlich zu zeigen schienen. dass Jehovah ihnen zürnte. Sie haben keine Lust, den Tempelbau aufzunehmen, ohne ein klares Zeichen seiner ihnen wieder zugewandten Gunst. „Die Zeit ist noch nicht gekommen ", so sagten sie, ,den Tempel Jehovahs zu bauen". Jehovah selbst sollte ihrer Meinung nach den passenden Zeitpunkt bestimmen durch die Sendung des Messias. Es waren lediglich Haggai und Zachariah. welche ihrer eigenen Meinung nach die Zeichen der Zeit richtig verstanden. Sogar Zerubbabel (der um das Jahr 520 v. Chr. seinem Oheim als Gouverneur gefolgt war) und Ješua, der neueingesetzte Hohepriester, mussten mit den übrigen ermuntert werden, das Werk des Wiederaufbaus des heiligen Hauses zu unternehmen. Eine Art "Haus" (der Ausdruck "bêt" ist in den semitischen Sprachen vieldeutig) mag allerdings seit langer Zeit dort bestanden haben. Sie 
waren ohne Zweifel von dem allgemeinen Kleinmut angesteckt und bebten zurück ror der Arbeit und den Kosten eines wirklichen Tempelbans, bis es gewiss war, dass die Zeit gekommen sei. Obgleich sie aus Babel. dem Mittelpunkt jüdischer Frömmigkeit. gekommen waren, besassen sie nichts von dem religiösen Eifer und dem zielbewussten Enthusiasmus der Schüler Ezechiels.

Es thut mir leid. dass ich keine farbenreichere Darstellung geben oder die berechtigten Erwartungen derer, welche sich mit Deuterojesajah ${ }^{1}$ ) beschäftigen. befriedigen kann. Am Anfang unserer Periode bildeten die Juden in Judäa eine geringe Gattung der religiösen Menschheit. and die Ereignisse ihrer Geschichte sind an sich wenig interessant. Aber trübe Zeiten sind notwendig als Übergänge zu glänzenden, und sicherlich haben unter die Fürse getretene Tölker die ihnen zugetriesene Rolle zu spielen. Pflicht des Geschichtsschreibers aber ist es. sie anziehend zu schildern. Ich bitte daher den Leser, wohl zu beachten. dass in dem heruntergekommenen Reste Judas ein gewisser echt religiöser Geist herrschte. wie unbefriedigend er auch Haggai erscheinen mochte. Wir können kaum bezweifehn. dass fast beständig während der traurigen Jahre der Tergangenheit ${ }^{2}$ ) Opfer an heiliger Stätte dargebracht worden waren, wie dürftig die Quantität. wie regellos das Ritual auch immer sein mochte. Da-

1) Denterojesajah ist der dem Verfasser der Wiederherstellungsweissagung Jes. 40-66 gegebene Name. - -2) Das Schweigen unserer dürftigen Lrkundea ist kein Beweis für das Gegenteil. 
neben thut eine unserer Quellen beiläufig der Thatsache Erwähnung, dass lange vor 520 v. Chr. Fasten ${ }^{1}$ ) regelmässig geübt worden waren. Der Beweis liegt vor im 7. Kapitel des Zachariah. Die Stelle verdient wohl unsere Aufmerksamkeit; sie enthält einige bemerkenswerte Angaben, und der geschichtliche Hintergrund (ich werde unten darauf zurïckkommen) zieht allerdings den Blick des Geschichtsschreibers auf sich.

„Im vierten Jahre des Königs Darius am vierten Tage des ,neunten Monats Kislev kam ein Wort Jehovahs an Zachariah. „Dies war die Gelegenheit. Belsarezer und Raam-melech hatten „Boten gesandt, Jehovah zu begiitigen (und) den Priestern rou „Jehovahs Haus und den Propheten diese Frage vorzulegen: „Soll ich weinen im fünften Monat mit Fasten, wie ich sehon "so viele Jahre gethan? Da geschah es, dass dieses Wort Jenhovahs zu mir kam: Also sprich zu allem Volk des Landes „und zu den Priestern."

Ich breche hier ab, um drei Punkte von einiger Bedeutung hervorzuheben. Der erste ist die angesehene Stellung des Zachariah. Die Tage des prophetischen Ansehens sind gezählt und doch tritt hier ein Prophet auf, dessen Worte noch Gesetz sind für Laien so gut wie für Priester. Der zweite ist die Einmütigkeit zwischen Jehovahpriestern und eingeborenen jüdischen Laien betreff's des hohen religiösen Wertes des Fastens. Und der dritte ist die Thatsache, dass die Absender der Deputation ${ }^{2}$ ) (deren

1) Fasten war der am meisten gesehătzte Weg, eine gelöste Verbindung mit der Gottheit wiederherzustellen. - " Sie sind zwei von den zwölf .Häuptern“, welche Sansbassar begleiteten. Vgl. die Artikel .sarezer und . Regem melech ${ }^{*}$ in der Enc. Bibl. Naturlieh begrundet der geschichtliche Charakter des Ješ̀u sowie Bilǩan (Belsarezer) und Ramiah (Regem-melech) nur eine $A \mathrm{nnabme}$ betreffs der Geschichtlichkeit der anderen 
Namen nachweislich Belsarezer und Raammelech sind) uns in der Ansicht bestärken, dass bis zu diesem Zeitpunkt (d. h. 518 v. Chr.) das harte Los der Juden keine fühlbare Erleichterung erfahren hatte.

Der durch Zachariah geschilderte Vorfall zeigt mit ziemlicher Klarheit, dass religiöse Gesinnung in Jerusalem nicht erstorben war. Wir dürfen auch überzeugt sein, dass die kleine Schar religiöser Sänger ilhr Bestes that, dieser Gesinnung Ausdruck zu leihen. Sehr wohl möglich ist es, dass die sogenannten Klagelieder, mit Ausnahme des dritten, auf den an den Fastengedenktagen gesungenen Elegien beruhen, auf welche die an Zachariah gesandte Abordnung anspielt.

Höher darf ich diese interessanten Lieder nicht hinaufrücken. Wie packend das Bild des auf den Trümmern von Jerusalem sitzenden und Klagelieder singenden Jeremiah auch immer sein mag, es ist zu romantisch, um geschichtlich treu zu sein. Wir müssten uns glücklich schätzen, wenn wir wenigstens fünf Werke eines wirklich vorexilischen Dichters besässen, aber wir dürfen uns darüber nicht hinwegtäuschen, dass aus inneren Gründen die Klagelieder in ihrer jetzigen Ge-

\footnotetext{
Namen. [Es muss betont werden, dass die bier vertretene Ansicht von der in den jetzt am meisten eitierten Kommentaren (siehe Wellhansen, Nowack, G. C. Smith und

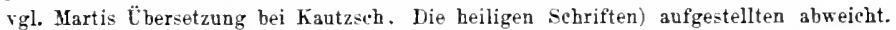
Dort wird angenommen, dass das „Bethel* dadurch in den hebräischen Text geraten sei, dass ein Schreiber das .Bel- missverstand, indem er es als hurzung ron -Bethel ${ }^{4}$ auffasste. Ferner muss betont werden, dass Regem-melech keineswegs der Fuhrer der Abgesandten war, sondern einer der beiden Absender der Deputation. Regem-melech hat man als ,Freund des hünigs" erklärt. Raam-melech. die richtigere Form. bedeutet wahrscheinlich, der (gottliche) Künig ist der Donnerer-. Der Verfasser hofft in der Eac. Bibl. ausführlicher darauf zurlickommen zu können.]
} 
stalt aus einem nicht allzufrühen Abschnitt der nachexilischen Periode stammen.

Somit sind unsere einzigen Quellen für die religiöse Stimmung der nachexilischen Juden frühester Zeit die Weissagungen Haggais und des Proto- oder echten Zachariah. Obgleich jedes litterarischen Reizes bar, sind sie von grosser geschichtlicher Bedeutung, weil sie auf der Grenzmarke zwischen dem exilischen und nachexilischen Zeitalter stehen. Es ist eine irrige Annahme, dass das nachexilische Zeitalter mit dem sogenannten Edikt des Cyrus (537 v. Chr.) beginne. Wenn es überhaupt ein nachexilisches Zeitalter gab, müsste es vielmehr von Vollendung des zweiten Tempels (516 v. Chr.) ab gerechnet werden. Denn das wahre Exil der Juden bestand in dem Gedanken der Verbannung von ihrem Gott hinweg, und dies schmerzliche Bewusstsein begann alsbald sich zu mildern, als man den Bau eines Hauses zur Wohnung Jehovahs vorzubereiten begann. ..Es ist jetzt keine Zeit zum Bauen", sagte das Volk des Landes; aber die Propheten glaubten, der Glaube und die Liebe, welche die Arbeit am Tempelbau voraussetzte, würden einen moralischen Zwang auf Jehovah ausüben. Zu irgend einer Zeit, nachlem der Schlussstein des Tempels eingesetzt war, musste doch an Ende der König der Ehren einziehen. Daher behaupte ich. dass Haggai und Zachariah das nathexilische Zeitalter einleiten.

Wir dürfen die prophetische Begabung dieser Männer nicht unterschätzen. Sie sind noch, kraft ihres Amtes, die tonangebenden Gestalten in der Ge- 
meinde, und sie besitzen in gewissem Grade noch jenes Bewusstsein einer einzigartigen Stellung zu Gott, welches die grossen Propheten der alten Zeit bezeichnete. Sie hätten mit Amos sagen können: "Der Herr Jehovah thut nichts, ohne zuvor sein Geheimnis seinen Dienern, den Propheten, zu offenbaren". ${ }^{1}$ )

Und gerade jenes Zeichen von Jehovahs wiedererworbener Gnade, welches das Tolk ersehnte, die Propheten Haggai und Zachariah glaubten es selbst gesehen zu haben: es war das Zeichen allgemeiner Gährung unter der Bevölkerung des Perserreichs.

Sehen wir zuerst vor allem, was Haggai, mit dem sein Amtsgenosse Zachariah vollkommen übereinstimmt, zu verkündigen hat:

"Noch eine kleine Weile, spricht Jehovah der Heerscharen, "und ich will erschüttern die Himmel und die Erde, und das „Meer und das Trockene; und ich will erschüttern alle Na"tionen, und die Schätze aller Nationen werden ankommen, "und ich will anfüllen dieses Hans mit Pracht, spricht Jehovah "der Heerscharen (Hagg. 2, 6 f.)."

Zwei Monate darauf kommt eine zweite Rede oder Offenbarung zu ihm:

„Sprich also zu Zerubbabel, Gouverneur von Juda: Ich "will erschüttern die Himmel und die Erde; ich will Königs"throne umstürzen und die Stärke der Königreiche unter den "Völkern zerstören... An jenem Tage, spricht Jehovah der "Heerscharen, will ich dich nehmen, Zerubbabel, meinen nKnecht, und will dich machen zu einem Siegelring, denn „ich habe dich erwählt, Spruch Jehovahs der Heerscharen "Hagg. 2, 21-23)."

1) $A \operatorname{mos} 3,7$. 
Die Meinung Haggais ist nicht zu verkennen. Jener politische Scharfblick, mit welchem die Propheten über die Regungen des Geistes sich klar werden, erkennt in den Wirren der Völker das Anfangsstadium des grossen Gerichtstages. Die Geschichte dieser Wirren ist für uns durch die Keilschriftforschung enthüllt worden. Gerade zu der Zeit, als Haggai und Zachariah auftraten (es war eben nach dem Regierungsantritt des Darius), brachen Aufstände aus in verschiedenen Teilen des Perserreiches ${ }^{1}$ ).

In Babel hatte beispielsweise ein Mann Namens Nidintu-Bel (d. h. Geschenk des Bel) im Jahre 521 die Krone Nebukadnezars an sich gerissen; er nahm dessen Namen an und gab sich für seinen Nachkommen aus. Nun kann Haggai an diesem Pseudo-Nebukadnezar kaum ein persönliches Interesse genommen haben. Aber als Anzeichen des Zusammenbruchs des Perserreiches mag er sehr wohl das Auftreten des Prätendenten mit Begeisterung begrïsst haben, und als nun 519 (bald nach den kühnen Weissagungen Haggais und Zachariahs) der Aufstand der Babylonier niedergeworfen und um 515 ein zweiter unter Führung eines andern Prätendenten ${ }^{2}$ ) erloschen war, da konnte man es den Führern der Juden nicht verargen, wenn sie den Schmerz der Enttäuschung empfanden. Hatte es doch ausgesehen,

1) Persien, Susiana. MIedien und Rabylonieu werden besonders erwunt. - 2) Dieser zweite Pratendent behauptete ebenfalls Nebukadnezar Nabu-na'ids Sohn zu sein. „Es ist klar", bemerkt Ir. J. P. Peters, ,dass ler Name Nebukadnezar zueinem Sehlagwort in Babylonien geworden war, so dass, weun jemand einen Aufstand zu erregen suehte, er Anspruch auf diesen Namen erhob, als sicheres Mittel, die Volksseele zu seinen Gunsten zu entflammen" (Journal of Biblicil Litterature 1897 p. 113). 
als ob ein neuer Tag heraufdänmern sollte, wenn nun die Herrlichkeit Jehovahs wieder seinen Tempel erfüllte, und Zerubbabel, der messianische König, sogar den Glanz des alten David überstrahlte!

Es ist eine bemerkenswerte Thatsache, dass ein Beleg dafür in der Bibel selbst sich findet. Der Prophet Zachariah erwähnt die Ankunft von vier Juden (wahrscheinlich Führern einer Partei) in Jerusalem, welche Gaben an Silber und Gold von den reichen babylonischen Kolonien mit sich brachten. Der Schatz wurde, gemäss göttlicher Anweisung, zu einer Krone für Zerubbabel ${ }^{1}$ ) verwendet. Es sei daran erinnert, dass dieser davididische Prinz schon den messianischen Titel Zweig oder Spross ${ }^{2}$ ) (der Ausdruck ist vielleicht durch Jeremiah gemünzt) erhalten hatte; es erübrigte nur noch, ihn zu salben und vor dem Volke zum Könige auszurufen. Ob letzteres jemals erfolgte in einer Form, welche man als Hochverrat bezeichnen kounte, das ist uns unbekannt. Aber es ist nicht unwahrscheinlich, dass ein späterer Herausgeber, der die Stelle nicht verstand und den Schein einer geschichtlichen Beziehung einzutragen bestrebt war, den Namen Josuas statt Zerubbabels in den Text gebracht hat.

Es liegt noch eine andere geschichtliche Thatsache vor, welche Erwähnung verdient. In Esr. 5 wird erwähnt - und ich sehe keinen Grund das zu beanstanden - , dass 'Tatnai oder Sisines, der Satrap von

1) Zach. 6, 9-12, woselbst in $r .11$ zu lesen: "mache Kronen und setze sie auf das Haupt Zerubbabels*. Der Text ist verderbt. Siehe Artikel ,Zerubbabel- in Blacks Enc. Bibl., woselbst eine andere mögliehe Ansicht vorgetragen wird. 3) Zach. 3, 8; vgl. 6, 12. 
Syrien, dem Tempelban Einhalt zu thun strebte; ich möehte diese Thatsache auf das plötzliche Verschwinden Zerubbabels beziehen. Dieser Prinz war ohne Zweifel ein persischer Gouverneur. aber er war nicht minder nach Geburt und Glaube ein Jude. Man müsste nun doch erwarten, ihn, und nicht Belsarezer und Raammelech, bei Absendung der von Zachariah erwähnten Abordinung nach dem Tempel genannt zu finden. Die Thatsache, dass zwei untergeordnete Beamte genannt werden und nicht Zerubbabel, nötigt uns anzunehmen, dass letzterer des Hochverrats bezichtigt und von Darius abberufen worden ist. Überdies zwingt die Thatsache, dass der Satrap Tatnai dem Tempelbau Einhalt zu thun bestrebt war, gleichfalls zu der Annahme, dass man die Juden wegen Untrene im Verdacht hatte. Diese Auffassung wird weiter dadureh belegt, dass wir finden, wie Sanballat Nehemiah warnt, er soi in Gefahr, verklagt zu werden wegen prophetischer Verkündigungen, es sei ein König in Juda (Nel. 6, 7).

Ich kann nicht umhin, ein ehrfurchtsvolles Mitleid mit der Enttäuschung Zachariahs zu empfinden, zugleich aber auch seine Aufrichtigkeit zu schätzen, da er es nicht unterlïsst, seinen Missgriff zu erwähnen. Freilich, es ist nicht ganz unmöglich, dass er seinen Irrtum unterschätzte. Er mag gedacht haben, er habe sich nur betreffs des Zeitpunktes der Erfüllung der Weissagung versehen und mag festgehalten haben an seinem Glauben betreffs Zerubbabels messianischen Charakters. Aber das Bewusstsein auch nur eines teil- 
weisen Missgriffs muss peinlich gewesen sein, und wir sind daher nicht befremdet über den Mangel an Begeisterung, der seine der Abordnung gegebene Antwort kennzeichnet. Der Bericht über die der Gesandtschaft gegebenen Aufträge führt gleichfalls dazu, niedergeschlagene Gemüter vorauszusetzen. Ein Auftrag bestand darin, „Jehovah zu begütigen", was voraussetzt, dass Jehovah als nicht allzufreundlich gesinnt angesehen wurde, und ein anderer, eine Frage wegen Fasten vorzulegen, augenscheinlich bestimmt, aus dem Munde der Propheten irgend ein ermutigendes Wort für die Zukunft zu vernehmen. Die Laien würden, wie es scheint, froh gewesen sein, die Fastengedenktage aufzugeben, wenn sie nur hätten sicher sein können, dass "der Herr, den sie suchten", schnell „zu seinem Tempel kommen " werde. Die Frage wurde vorgelegt vor dem Fasten des fünften Monats, aber Zachariah schob sein Antwortsorakel bis nach Vollendung des Fastens des siebenten Monats auf. Augenscheinlich empfand er die Schwierigkeit der religiösen Lage. Die innere Ruhe, deren ein Empfänger der prophetischen Eingebung benötigt war, kehrte ihm eben nur langsam zurück. Als er seine Antwort gab, war sie eine doppelte. Zuerst antwortete er dem Volke im Geiste Jesajahs, es läge Jehovah nichts daran, ob man fastete oder nicht. Sodann verkündigte er, dass Jehovah eifrigen Anteil nehme an seinem Volk und sicherlich zurückkehren werde; daran knüpfte er die Mahnung, den sittlichen Vorschriften der alten Propheten, wie z. B. Jesajah und Jeremiah, zu gehorchen. Er selbst 
betonte jedoch dabei nicht genïgend, dass nach den alten Propheten einem unbekehrten Volke kein Heil widerfahren liönne, und von Haggai wird überhaupt nicht berichtet, dass er eine solche sittliche Ermahnung gegeben habe.

Grosse Propheten sind sie sicherlich nicht! Ihr litterarischer Stil lässt zu wünschen übrig, und ihr Geist zeigt einen traurigen Rückgang im Vergleich zu dem der älteren Propheten. Zachariah ist der bedeutendere von beiden, aber sogar ihm fehlt die sittliche Energie, und er zeigt Spuren einer Lehre, welche in Munde eines weniger bedeutenden Sittenlehrers verletzend wirkt: ich meine seinen Dualismus. Fr meint, dass an dem furchtbaren Schicksal Israels die Thätigkeit eines himmlischen Wesens Namens Satan, dessen Aufgabe es ist, Gott an menschliche Sünden, die er sonst gerne vergessen würde, zu erinnern, die Schuld trägt. Dieser Begriff würde harmlos gewesen sein, wenn er verbunden gewesen wäre mit dem Glauben, den wir in dem in das Buch Hiob eingeschobenen grossen Elihuepos finden, dass es noch ein anderes engelartiges Wesen gebe, dessen Beruf es sei, Sünder zu retten, indem es sie zur Busse leitete (Job 33, 23 f.). Da er aber damit nicht verbunden war, so führte er zu einer flacheren Anschauung von sittlicher Verantwortlichkeit und Notwendigkeit sittlicher Erneuerung. Wir bemerken auch, dass Zachariah die dichterische Freiheit der Personifikation in sonderbar abgeschmackter Weise verwendet. Er hält die Bosheit seiner Landsleute für zu gross, als dass sie das Werk der menschlichen 
Natur allein sein könnte. Daher muss es seiner Meinung nach ein böses Princip, Gottlosigkeit genannt, geben, das diesen ganzen Überfluss an Ungerechtigkeit hervorbringt. Und in einer Vision (Zach. 5, 5-11) erblickt er thatsächlich dieses Princip, in Gestalt eines Weibes, welches in einem Gefäss von einem Epha Inhalt sitzt und dann plötzlich niedergeworfen wird, während der Deckel geschlossen wird. Darauf wird es durch zwei Franen mit Storchflügeh in das Land Sinear (d. h. Babylonien) getragen, um dort zu wohnen und so das Verderben, das es jetzt über das Land der Juden zu bringen droht, ïber Babylonien zu bringen.

Doch nach dieser Zeit bemerken wir noch eine bestimmte Erwartung vom Kommen Jehovahs zum Gerichte, und die Mängel Zachariahs als Sittenprediger werden ergänzt durch einen späteren Propheten, der nicht nach dem Ruhm der Nachwelt gestrebt hat, da er ohne Namen schrieb. Nachfolgende Geschlechter gaben ihm infolge eines wunderlichen Missverständnisses den Namen Maleachi.

„Siehe der Tag kommt", ruft er aus, „brennend wie ein "Feuerofen; alle Stolzen und alle Übelthäter werden wie „Stoppeln sein: der Tag, der da kommt, wird sie mit Spross "und Schoss verbrennen. Aber über euch, die da meinen nNamen fürchten, soll aufgehen die Sonne der Gerechtigkeit „mit Heil unter ihren Flügeln; ihr sollt fortgehen und fett

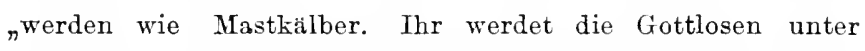
ndie Füsse treten; sie werden Asche werden unter euren Fuss.

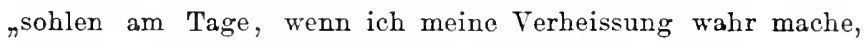
"Spruch Jehovahs der Heerscharen (Mal. 4, 1-4)." 
Dann, augenscheinlich als Vorbedingung für die vorangehende Verheissung, fügt er hinzu:

${ }_{n}$ Gedenket des Gesetzes meines Knechts Mose, dem ich am "Horeb befohlen habe Satzungen und Rechte für das ganze "Israel (Mal. 4, 3 [3, 22])."

Offenbar hatte die Flut angefangen, zurückzustauen; der Wiederaufbau des Tempels bezeichnet einen geschichtlichen Wendepunkt. Wie mangelhaft die Volksreligion auch immer sein mochte - und Maleachi kann sich in seinen Anklagen gegen dieselbe nicht genug thun - es herrschte mehr inneres Leben in der Gemeinde als zu Haggais Zeit. Es waren wohl nicht wenige, welche das deuteronomische Gesetz strenge beobachteten und durch ihre Gewissenhaftigkeit die Oberflächlichkeit der grossen Menge wieder gutmachten. Alles, was diese Leute brauchten, um ihr Zeugnis wirksam zu gestalten, waren begabte Führer, in denen theoretische Einsicht mit praktischer Fähigkeit vereinigt war. Solche fähige Leute waren in der That zu finclen, aber in den Ländern der Diaspora, nicht in Judäa. Wie kommt das? Warum blieben sie an ihrem fernen Wohnort? Warum kehrten nicht mehr Israeliten zurück?

Einige, das halte ich für zweifellos, kehrten zurück. Aus Zachariah geht klar hervor, dass babylonische Juden manchmal zum Besuch der heiligen Stadt kamen, und es ist kaum glaublich, dass niemand unter ihnen sich hätte veranlasst sehen sollen, seinen Pilgerstab niederzulegen und in Jerusalem zu bleiben. Solche 
Einwanderer schlossen sich natürlich an die „Gottesfürchtigen" an, die sie dort schon vorfanden: das heisst an jene strengen Anhänger des Deuteronomiums, die sich, wie uns Maleachi $(3,16)$ erzählt, zu einer Gemeinschaft zusammengethan hatten. Aber der allgemeine Charakter des Volkes wurde durch diese wenigen Einwanderer nicht merklich bestimmt. Die Juden waren, wie ein späterer prophetischer Schriftsteller sich ausdrückt, gleich einem armseligen Traubenbüschel, das der Weingärtner nur hängen lässt wegen der wenigen guten Beeren, die daran hängen (Jes. 65). So werfe ich wieder die Frage auf: Warum kehrten nicht mehr Juden zurück?

Man kann darauf drei Antworten für möglich halten. 1. Seit dem Fall des alten Staatswesens klafite ein tiefer Abgrund zwischen babylonischen und judäischen Israeliten. Jeremiah wie Ezechiel bedienen sich der verächtlichsten Ausdrücke gegen die Juden, welche das Schicksal Jojachins nicht teilten, und Deuterojesajah kümmert sich um die Juden in Judäa überhaupt nicht. 2. Starke jüdische Kolonien in anderen Teilen des Reiches spielten eine Rolle, indem sie sowohl den Einfluss der Rasse stärkten, als auch das Silber und Gold für religiöse Zwecke lieferten. das der bedürftigen judäischen Bevölkerung fehlte. Keinesfalls darf die religiöse Bedentung ihres Zeugnisses für sittlichen Monotheismus ausser Acht gelassen werden. 3. Die Weissagungen Deuterojesajahs setzen voraus, dass die Kräfte Himmels und der Erde vereint werden sollten zwecks Israels Wiederherstellung, während doch 
gegenwärtig die himmlischen wie die irdischen Zungen, wie es schien, beharrlich schwiegen.

Im Lauf der Zeit gab Gott es einem der jüdischen Priester in Babylonien ins Herz, an der Spitze einer Schar nach Judäa zu zichen. Aber es gab auch Leute verschiedener Schule, welche vorher, wie es scheint, sich bemüht hatten, die babylonischen Juden in Bewegung zu bringen. Wir haben höchstwahrscheinlich eine Nachricht über diesen Versuch in Jes. 49-らう. Es scheint das ein Anhang an die ursprüngliche Wiederherstellungsweissagung zu sein, den ein Verrhrer Deuterojesajahs in Babylonien abfasste und nach Jerusalem überbrachte. Fast überall in diesem Abschnitt ist der Blick von Babel und den Exilierten weg Zion und seiner streitenden Gemeinde zugewandt. In der That, ohne die Schönheit des Stils und die Feinheit der Kunst, wodurch diese Kapitel sich von den unleugloar in Jerusalem angefügten (Kap. 60-62) nnterscheiden, und ohne den Mangel an Bestimmtheit. ja ich möchte sagen die Abgeschmacktheit in der Beschreibung der Zionsgemeinde, könnten wir uns veranlasst fühlen zu der Vermutung, dass sie in Judäa abgefasst wurden. Die Merkmale können am besten miteinander vereinigt werden durch die Annahme, dass diese Kapitel abgefasst wurden in Babylonien, teils $n$ mabylonische Juden zum Aufbruch nach Judäa zu veranlassen, teils um die hartbedrängten Streiter in Jerusalem zu ermutigen.

Es sei mir gestattet, eine sehr bekannte Stelle anzuführen, die jedoch allzuoft missverstanden wird, 
Das religiöse Leben in Judiia vor der Ankunft Nehemiahs. 23

weil ihr geschichtlicher Hintergrund nicht klar erfasst wird. $\left.{ }^{1}\right)$

"Auf! alle, die ihr durstig seid, geht zu den Wassern,

„Und ihr, die ihr keine Kraft habt, esset!

"Geht, kauft Korn ohne Geld,

"Wein und Milch ohne Entgelt.

"Warum bezahlt ihr Geld fïr das, was kein Brot ist,

„Und lasst euch sauer werden um das, das nicht sättigt?

(Jes. 55, $1 \mathrm{f}$.)"

Hier bedeuten "Wasser", "Korn", "Wein" und "Milch" alle jene Segensgaben sittlicher wie materieller Art, deren Empfang die Wiedergeburt eines Volkes bewirken kann. Die Existenz einer organisierten Gemeinde im Lande Israel wird voransgesetzt, und es ist der Wunsch des frommen Redners, gottesfürchtige Leute in Babylonien zum Anschluss an Leben und Werk dieser Gemeinde anzuregen. Wenn sie nicht, sei es mit ihrem Sehnen, sei es, was das Beste von allem ist, in Wirklichkeit nach Jerusalem ziehen, dann werden sie seiner Meinung nach auch ferner den „dürren Knochen" einer anderen prophetischen Vision gleichen. Sie mögen Geld auszugeben haben zum Kaufen, aber es ist kein Brot da für sie zu kaufen. Sie mögen ,frühe aufstehen und hernach lange sitzen" "); aber sie werden ihres Gewinns nicht froh werden. Sie sind nach eigener Wahl „dem israelitischen Gemeinwesen fremd". Weit besser wäre es, zu den Reihen der Bekenner Jehovahs zu stossen:

1) Siehe Jesajah in der Polychrome Bible und vgl. des Verfassers Introduction to Isaiah; siehe auch Artikel „lsaiah" in der Ene. Bibl. - 2) Ps. 127, 3 [2] [Luther. Übersetzung - S.]. 
denn solche sind nach der irrigen Annahme des Verfassers die judäischen Juden geworden; weit besser wäre es, den Spott der Menschen zu erdulden, der doch nur einen Augenblick dauern wird, und in Zion auf jenes Ausstrecken des Armes Jehovahs zu warten, der die Wunder der Tage der Vorzeit ernenern wird. Heftig sehnt das vereinsamte Zion sich nach seinen Kindern; wann werden die Exilierten in heiligem Zuge in einer Gesamtschar aufbrechen von Babel: nicht flüchtig, wie Deuterojesajah vorher verkündigt, sondern in ernster, erhabener Feierlichkeit, mit Jehovah an der Spitze und beim Nachtrab? ${ }^{1}$ )

Von den beiden sehr verschiedenartigen Gaben, welche Jerusalem seit kurzem Babel zu verdanken hatte: dem zu einer Krone für Zerubbabel verarbeiteten Schatze und dem ersten Anhang zur Wiederherstellungsweissagung, liess sich die erste viel leichter nutzbar machen als die letzte. Die goldene Krone wurde zweifellos eingeschmolzen und in irgend ein notwendiges Zierstück für den Tempel verarbeitet. Aber die neue prophetische Rhapsodie war zu idealistisch, als dass sie in Jerusalem hätte hoch geschätztwerden können. Ezechiel hatte zu jener Zeit viel grössere Aussicht, die ..Freunde des Fortschritts" zu beeinflussen. Seine Auffassung der "Heiligkeit" und sein Abscheu vor der Berührung heiliger Dinge mit unreinen finden sich bei Zachariah wie bei Maleachi (Zach. 3, 7; Mal. 2, 11). Ebenfalls wird ron Ezechiel die Unterscheidung zwischen

1) Jes. $51,7-10 ; 54,1 ; 52,12$. 
Priestern und Leviten, von der man eine Spur in der alten Liste der "Kinder der Provinz" bemerkt (Esr. 2; Neh. 7) hergeleitet, und Ezechiel ist es gewesen, der einige der hauptsächlichsten Teile der vielleicht ältesten unter den Weissagungen im dritten Teil des Jesajah (Jes. 56, 9-57, 13a) nach Stimmung und Wortlaut beeinflusst hat.

Die genannte Weissagung gehört zu denen, welche viel verlieren, wenn man sie in dürftiger Übersetzung aus einem verderbten Texte liest. Die genaue Bedeutung dieser und die der verwandten Stellen in Jes. $65 ; 66,1-22$ verdient besser bekannt zu werden. Die Leute, welche seitens der prophetischen Schriftsteller so zornmütig angegriffen werden, siad die Mischlingsjuden Mittelpalästinas, welche man gewöhnlich Samariter nennt, und jene Juden in Judäa und Jerusalem, welche sich in religiöser Hinsicht mehr oder weniger zu ihnen hingezogen fühlten. Wie es möglich war, dass die bittere Gesinnung, die diese Stellen zum Ausdruck bringen, jemals dem sanftmütigen und friedliebenden Deuterojesajah hat zugetraut werden können, ist schwer zu begreifen. Selbst einer von den nachexilischen Propheten, wie z. B. Haggai oder Zachariah, könnte solche zornige Strafreden nicht geschrieben haben. Denn es steht fest, dass wir für irgend eine schärfere religiöse Fehde zwischen Juden und Samaritern in der älteren Zeit keinen Wahrscheinlichkeitsgrund besitzen. Die Samariter standen zweifellos der Gesetzesorthodoxie ferner als die Juden; aber sogar unter den Juden kann der Durchschnittsstand der 
Orthodoxie kein sehr hoher gewesen sein, besonders in den Landgebieten, wo in Ermangelung einer starken centralen Autorität roher Aberglaube sich noch breit machte. Und es liegt kein Grund vor zu der Annahme, dass die Samariter, bevor sie dazu gezwungen wurden, ihr Interesse an dem grossen Heiligtum in Juda aufgaben. Es wird erzählt. dass nicht lange nach dem Tempelbrande eine Schar von achtzig Pilgern aus Sichem. Silo und Samaria nach Mizpah kam mit Opfergaben für das dortige alte Heiligtum ${ }^{1}$ ), und zweifellos würden sie den Tempel zu Jerusalem lieber aufgesucht haben als das Heiligtum in Mizpah, wenn jener nicht in Trümmern gelegen hätte $\left.{ }^{2}\right)$. Wir dürfen daher nicht daran zweifeln. dass, als 520 die Juden sich zum Wiederaufbau ihres Tempels entschlossen, die Samariter ein lebhaftes Interesse an dem Unternehmen hegten. Mochten sie zunächst auch keine Sorge dafür getragen haben. den Juden die. Last des Wiederaufbaus ihres Tempels zu erleichtern (die Geschichte von ihren Verhandlungen mit ilıren Stammverwandten. wobei sie den Wunsch, am Bau sich zu beteiligen, erheuchelt haben sollen, ist rein erfunden), aber als durch Zachariahs hinreissenden Enthusiasmus das Werk vollendet war. da mussten sie naturgemäss bestrebt sein. ihre Terbindung mit einem so heiligen Platze aufrecht zu erhalten. Mit Unterstïtzung der priester-

1) Jer. 41,5. Thie tragisehe Geschichte der Pilger ist kaum weniger sehauerlieh als die ron dem Brunten zu cawnpore in Indien [zur Zeit des furchtbaren indischen Aufstandes in den Fünfiger Jahren un.. Jahrh. - S.]. - ") Viele Gelehrte glauben, dass des _Haus Jehorahs", woranf Jeremiah liezug nimmt, thatsachlich die Ruinenstatte des Tempels in Jeraralem bedeute. 
lichen Aristokratie gelang ihnen das, bis Nehemiah anf Grund eines persischen Edikts einschritt.

Die Art des Vorgehens. welche dieser hohe Beamte beliebte, reizte die Samariter bis zmm äussersten und inderte ihre Beziehungen zu den Juden von Grund aus. Man könnte geneigt sein, Nehemiah zu tadeln, wenn man nicht bedenkt, dass die religiöse Sonderstellung der Juclen auf strenger Gesetzesgrundlage für die höhere Religion eine Lebenstrage war, und dass seitens orthodoxer Juden schon ein Bekehrungsversuch an den Samaritern gemacht war. Über diesen Versuch scheinen einige aufklärende Worte von nöten. Er wird meines Erachtens crwähnt in der folgenden. Stelle aus dem Werke einesder orthodosen Schule angehörenden prophetischen Schriftstellers aus der vornehemianischen Zeit ${ }^{1}$ ):

"Ich bot Zugang zu mir denen, die nicht nach mir fragten; "ich bot meine Offenbarung denen dar, die mich nicht suchten; "ich sagte: Hier bin ich! zu einer schar, die meinen Namen "nicht anrief. Ich habe meine Hänle den ganzen Tag ans,gestreckt nach einem unbändigen und ungehorsamen Tolke, "das einen Weg verfolgt, der nicht gut ist, nach seinen eigenen „Anschlägen (Jes. 65, 1 f.).."

Dies scheint mir zu besagen. dass einige der orthodosen Führer der Juden die fortdauernde Zulassung der Samariter zu religiösen Rechten (und zu allem, was dazu gehörte) abhängig zu machen wünschten vom Verzicht derselben auf ihre wesentlichen Eigentümlichkeiten und ihrer Annahme des jüclischen Gesetzes und der jüdischen Überlieferung. Mit einem Worte.

1) Es war Professor Duhm in Basel, der dies zuerst erkannte. 
man versuchte aus den Samaritern Konvertiten zu machen, aber der Versuch ergab einen Fehlschlag, ziemlich wahrscheinlich deshalb, weil man Fehler auf beiden Seiten beging. Die Juden liessen es an Duldsamkeit fellen, wie Augustin von Canterbury, als er vergebens Engländer und Walliser zu einer einzigen christlichen Kirche zu vereinigen suchte. Die Samariter besassen ihrerseits bis jetzt keine religiöse Empfänglichkeit. Und jetzt tritt uns eine ganz seltsame Erscheinung vor Augen, obgleich nicht seltsamer, als viele, die wir in der späteren Litteratur antreffen werden, nicht seltsamer als z. B. die Thatsache, dass ,Maleachi" trotz seines energischen Widerspruchs gegen eine Völkermischung auf dem jüdischen Boden den von Grund aus umgestaltenden Gedanken, dass Gott unser Vater sei, aufgreift und die Allgemeinheit einer wahren Jehovahverehrung ${ }^{1}$ ) aufstellt. Die Erscheinung, welche ich im Auge habe, ist folgende: dass (wahrscheinlich) derselbe Schriftsteller, der soeben so scharf ron den Samaritern gesprochen, weil sie die Anmahme des jüdischen Gesetzes abgelehnt, jetzt dieselben Leute tadelt, weil sie ein Centralheiligtum für sich zu bauen wünschten und diesen Tadel auf ein Princip gründet, welches, logisch genommen, genau ebenso den Ansprüchen des jerusalemischen Tempels widerspricht. Er sagt:

"So spricht Jehovaln: Der Himmel ist mein Stuhl und die „Erde meiner Füsse Schemel. Welches Haus wolltet ihr für "mich bauen und welchen Ort zu meiner Wohnung? Denn

1) Mal. 2, 10 f.; 1, 11 . 
nalles dieses hat meine Hand gemacht, und mein ist das alles, nSpruch Jehovahs (Jes. 66, 1 f.)."

Die Erklärung dafür ist, dass die nachexilische jüdische Religion zum grossen Teile eine Mischung von unvereinbaren Elementen ist, beziehentlich prophetischen und priesterlichen Ursprungs. Auf der einen Seite weiss sich dieser Schriftsteller, wie mancher andere, mit Propheten wie Jeremiah von Herzen eins; auf der andern mit den Priestern. Die Erfahrung bewies, dass es aussichtslos war, die judäische Gemeinde auf rein prophetische Vergeistigung zu begründen; überlieferte Formen mussten festgehalten werden und soweit als es anging als harmlos oder als Symbole innerer Wahrheit betrachtet werden. Und so rechtet dieser Schriftsteller, obwohl er dafür hält, dass nicht einmal der Tempel zu Jerusalem des göttlichen Schöpfers würdig ist, doch mit denen, welche die Errichtung eines anderen Tempels an anderer Stätte planen. Nur allein in dem kürzlich wieder aufgebauten Tempel findet man die wahren Anbeter, nämlich die demütigen und gehorsamen jüdischen Gläubigen. Mögen doch die Samariter ihre selbst zurechtgemachten und oft abscheulichen Sitten ablegen und sich dem Gesetze unterwerfen, dann wird man ihnen erlauben, Gott in einem Tempel zu verehren, der mit Händen gemacht ist.

Auf die eingehende Darstellung der Sitten, welche den Gegnern der Orthodoxie (nämlich den Samaritern und den einen Fortschritt ablehnenden Elementen des alten judäischen Volksrestes) eigentümlich sind, sich 
einzulassen ist nicht nötig (s. Jes. 65.3 -5. 11; 66, $3 \mathrm{f}$.), aber es ist interessant zu beobachten, wie orthodoxe Juden dieser Zeit ihre Abneigung solchen Gegnern im heiligen Liede ausdrückten. Ich citiere ans einem Bruchstück eines alten nachexilischen Psalms, der später erweitert worden zn stin scheint: es ist der Kern unseres jetzigen 16. Psalms ${ }^{1}$ ).

„Bewahre mich, Gott; denn zu dir nehme ich meine Zuflucht! "Ich bekenne dem Jehovah: Du bist mein Herr;

„Dir zu nahen ist mein Glück,

"Und an deinen heiligen Zeiten ist meine ganze Wonne.

"Die, welche einen andern auserwählen (als Jehovah), machen sich viel Schmerz;

"Ihre Blutopfer will ich nicht ausgiessen;

"Ihre (Götter-) Namen will ich nicht auf meine Lippen nehmen, „Jehovah (allein) ist meines Bechers Teil und mein Los

(Ps. 16, 1-5)."

Um die Anspielungen zu verstehen, müssen wir verschiedene Stellen im dritten Teil des Jesajah heranziehen. Sie sind zur Zeit Nehemiahs geschrieben, höchstwahrscheinlich kurz vor seiner Ankunft. Der Sprecher ist die personifizierte Gemeinschaft frommer Israeliten, welche, wie klein sie auch sein möge, als Jehovahs Bannerträger sich fühlt und ihr eigenes inneres Glück und die ihr verheissene Herrlichkeit dem gegenwärtigen Zustand geistlichen Vorderbens und der zukünftigen Strafe derjenigen, welche den abschenlichen Bräuchen der Samariter anhängen, gegenüberstellt.

Doch man mag vielleicht der vorstehenden Skizze

1) Ich aborsetze nach einem rerbesserten Text. 
des anfänglichen Verhältnisses zwischen Juden und Samaritern entgegenhalten, dass sie Geschichtskonstruktion sei. Gewiss ist sie das, und sie muss es sein. Dass für einen solchen Versuch der rechte Zeitpunkt gekommen ist, das kann niemand bestreiten, der von der Entwicklung der neneren Kritik eine Ahnung hat, und Kenner der Geschichte werden hoffentlich zugeben, dass die hier gegebenen Resultate beträchtliche Wahrscheinlichkeit für sich haben. Es ist mit ziemlicher Bestimmtheit nachgewiesen, dass der Zusammenstoss zwischen Juden und Samaritern sich wahrscheinlich später und allmählicher entwickelt hat als man angenommen hatte und dass der Plan, einen samaritischen Tempel zu erbanen, lange vor der Zeit Alexanders des Grossen entstand, wo nach Josephus das Garizim-Heiligtum errichtet wurde. Aber daraus erwächst nun die Frage: Konnte vielleicht Josephus in der Datierung dieses Ereignisses sich irren $\left.{ }^{1}\right)$ ?

Nun ist allseitig zugestanden, dass er die Austreibung des Manasseh, Sanballats Schwiegersohn (auf den ich später zurückkommen werde), etwa 100 Jahre zu spät ansetzt. Was zwingt uns denn zu der Annahme, dass er zuverlässiger ist bei einer Angabe, die damit eng verknüpft ist? Allerdings wiederholt er die Angabe betreffs der Datierung des Tempels in anderem Zusammenhange; aber kann denn nicht ein Schriftsteller beharrhich ungenau sein? Die Chronologie der

1) Jos. Ant. XI 8, 2-4. Der Fehler bei dem Ansatz wird natürlich verringert, wenn es, wio einige annehmen, der zweite und nicht der erste Artaxerses war, unter dessen Schutz Esra und Nehemiah nach Jerusalem kamen. 
Perserzeit war zu Josephus' Zeit schon derartig verblasst, dass man ihm einen solchen Irrtum nicht übelnehmen kann.

Eine Bemerkung darf wohl noch zum Schluss betreffs Manassehs hinzugefügt werden. Die Geschichte dieses jüdisehen Priesters wird in ihrem Zusammenhang später dargestellt werden. Er zog sich das persönliche Missfallen Nehemiahs zu, weil er unter erschwerenden Umständen eine Mischehe eingegangen war. Aber wir dürfen Manassehs Charakter nicht zu niedrig einschätzen. Bei seiner Zugehörigkeit zu der alten jerusalemitischen Priesterschaft hatte er seine eigenen Ansichten über die Verhältnisse eines Priesters und seine eigene Weise, das Gesetz zu verstehen, und obwohl Maleachi auch von ihm hätte sagen können, er habe durch seine Gesetzesdeutung "vielen Anstoss gegeben" (Mal. 2, 8), so werden wir doch gleich sehen, dass die strengen Ansichten Esras und Nehemiahs unter den ernstgesinnten Juden nicht in alleiniger Geltung waren. Gewiss ist es, dass seine Religiosität eine ganz andersartige war, als die seiner Freunde, der Samariter, und dass Nehemiah der rivalisierenden Gemeinde einen thatsächlichen Gefallen erwies, als er Manasseh zwang, zu ihr seine Zuflucht zu nehmen. Manasseh wurde, wie man annehmen darf, der religiöse Reformator der Samariter. Höchstwahrscheinlich nahm er bei seiner Vertreibung nicht nur das Buch Deuteronomium, sondern den ganzen Pentateuch in seiner damals bestehenden Gestalt mit sich. Wir dürfen annehmen, dass er auch die Errichtung des Tempels 
Das religiöse Leben in Judäa vor der Ankunft Nehemiahs. 33

auf dem Garizim durchsetzte und so die Centralisation des samaritischen Kultus vollendete.

So wurde der flüchtige jüdische Priester Manasseh der grösste Wohlthäter der samaritischen Gemeinde. Ihm allein verdankt sie ihre Lebensdauer. Der (wie ich glaube) von ihm erbaute Tempel wurde durch den hasmonäischen Machthaber in Judäa Johannes Hyrkanos 130 v. Chr. zerstört. An seine Stelle trat ein Tempel in Sichem, der zweifellos unterging bei der Zerstörung Sichems durch Vespasian. Aber die Samariter bewahrten fortdauernd die Anhänglichkeit an ihren heiligen Berg, und der eine oder der andere von uns mag den alten Passahbräuchen beigewohnt haben, welche an einer geheiligten Stelle des Garizim begangen werden, welche vielleicht einst innerhalb des Manassitischen Tempelbezirks sich befand. Die Samariter mögen vom Standpunkt eines modernen Theologen aus lediglich eine jüdische Sekte sein; aber versetzen wir uns in ihre Auffassung hinein, dann dürfen wir nicht überrascht sein, dass sie ihre Lokalüberlieferung als stärksten Beleg für ihre religiöse Orthodoxie betrachten. Sie mögen eine geringfügige Minderzahl der Anbeter des Gottes Jakobs bilden, aber ein Zeichen aus der übernatürlichen Welt würde mit einem Schlage das Verhältnis zwischen Juden und Samaritern ändern, wie denn in der That das altgläubige Judentum selbst lehrt, dass ein übernatürlicher Eingriff eines Tages die Beziehungen zwischen Juden und Heiden umkehren werde. Jahweh Nissi (Jehovah ist mein Panier) kann daher als Motto in Anspruch genommen werden eben- 
sowohl von der zertretenen Gemeinde von Nablus wie von der fast über die Welt verbreiteten Körperschaft: der jüdischen Kirche.

Denn nach allem haben Juden und Samariter in gleicher Weise eine Ahnung von der Wahrheit: wir trennen mns lediglich von ihnen oder von einigen unserer Mitchristen, insofern sie die Wahrheit mit anmassenden und ungeistlichen Annahmen vermischen. Von ihrem Glauben leiten sie ihre Daseinsberechtigung her. und Glaube ist allerdings der einzige Felsen, der Gemeinschaften wie Einzelne im Wellenspiel des Wechsels festhält. Ich wage das Recht zu diesen IVorten sogar in einer geschichtlichen Untersuchung für mich in Anspruch zu nehmen; denn es erscheint mir als nutzlose Spielerei, über Religionen Untersuchungen anzustellen, ohne das Wesen der Religion an sich selber erfahren zu haben. Glaube ist das Wesentliche an der Religion anf ihrer himmelan gerichteten Seite, und der Chronist erfasst richtig das Bindeglied zwischen der Religion der vorexilischen Propheten und der der nachexilischen Kirche, wenn er den König Josafat die versammelte Gemeinde in der Wüste zu Thekoa so anreden lässt:

„Hört mich, o Juda und ihr Einwohner von Jerusalem! "Glaubt, dass Jehovah euer Gott sei, dann werdet ihr bleiben; nglaubt seinen Propheten, daun wird es euch wohlgehen "(Chron. B 20, 20)."

Denn der vorexilische Prophet hatte schon, was dem Chronisten später selbstverständlich war, lange vorher ahnend entdeckt, als er zu Ahab und seinen 
Höflingen sagte: "Glaubet ihr nicht, so bleibet ihr nicht!" 1) (Jes. 7, 9). Und auf diesem festen Grunde, nicht auf irgend einer kleinlichen Ansicht von der Natur der Inspiration oder der Erklärung von Glaubenssätzen begründe ich mein eigenes persönliches Recht, so tief ich es vermag in die Bibelkritik hineinzudringen, und mein Eintreten für ein zuversichtlicheres und weniger zurückhaltendes Vorgehen, als es in der Belehrung der Studenten bisher gebräuchlich gewesen ist $^{2}$ ). Ein solches Vorgehen kann dem religiösen Gefühl keines Menschen Anstoss erregen und geschieht meines Erachtens im Geiste dessen, den ich zu nennen nicht würdig bin, der aber der Lehrer und Leiter aller derer ist, welche bestrebt sind, die sittlichen und religiösen Gedanken der Kirche oder Gemeinde zu läutern.

Es ist die Haltung ihres Herrn gegen das jüdische Gesetz, welche christliche Kritiker (zu deren Verteidigung ich dies schreibe) rechtfertigt in ihrer freien, aber ehrfurchtsvollen Haltung gegenüber den geschichtlichen Urkunden der Kirche, unter denen die des Alten und Neuen Testaments obenan stehen. Wieviel die Religion der Menschheit der pietätvollen, aber unvergleichlich kühnen Stellung des Herrn zum jüdischen Gesetz verdankt, das tritt schon jetzt ein wenig hervor und wird in einem späteren Zeitabschnitt der Weltgeschichte noch klarer zum Bewusstsein kommen. Und der Leser wird mit Recht annehmen, dass meine Behandlung der Samariter in der vorliegenden geschicht-

1) Oder: "Wenn ihr nicht festhaltet (d. h. am lebendigen Gott), dann werdet ihr nicht festgehalten werden ${ }^{4} .-{ }^{2}$ ) [Der Herr Verfasser redet hier im Hinblick auf englische Verhältnisse $-\mathrm{s}_{\text {.] }}$ ] 
liehen Skizze teilweise unter dem Eindruck jener verständigen Milde steht, mit der der Herr jenes Volk ansah. Wie die alten Juden jene verachteten, ist wohl bekannt. Aber der Herr selbst stellte bei zwei Gelegenheiten ${ }^{1}$ ) die sittliche und religiöse Handlungsweise der Juden und Samariter zum Vorteil der letzteren einander gegenüber. Wenn das billig und recht war in der römischen Periode der jüdischen Geschichte, dann kann man uns nicht zu der Annahme zwingen, dass die Samariter zu Nehemiahs Zeit gänzlich der wesentlichen Eigenschaften menschlicher Sittlichkeit entbehrten.

1) Lk. 10, 33;17, 16. 


\section{Zweite Vorlesung.}

\section{Nehemiah, Esra und Manasseh,}

\section{oder die Wiederherstellung der jüdischen und samaritischen Gemeinde.}

Wir haben, wie ich hoffe, schon einige wertvolle Ergebnisse erarbeitet. Dass ein flüchtiger jüdischer Priester der Reformator der samaritischen Religion wurde, ist nicht das am wenigsten interessante darunter, und demgemäss werde ich mich bemühen, diese Thatsache in die rechte Beleuchtung zu rücken. $\mathrm{Zu}$ allererst aber darf ich Thre Aufmerksamkeit hinlenken auf einige patriotische Unternehmungen babylonischer und jüdischer Israeliten, welche der Vertreibung Manassehs vorangehen. Gewiss hatten die in Babylonien gebliebenen Juden keineswegs Jerusalems vergessen. Obwohl sie selbst nicht alle nach Judäa zogen, müssen sie doch einen derartigen Plan als im Werke befindlich gekannt haben; denn die Besten ihrer Körperschaft widmeten sich der schwierigen Aufgabe, die überlieferten jüdischen Gesetze zum Abschluss zu bringen. Auf dies wahrhaft patriotische Unternehmen muss ich später zurückkommen. Ein nicht weniger wichtiges Werk, das ebenfalls in Babylonien in Angriff genommen wurde, bestand darin, die Bruchstücke der früheren Weissagungen zu ergänzen und sie den Bedürfnissen der Gegenwart 
anzupassen. Wie schon erwähnt, bemühte sich der Verfasser des ersten Anhangs an die Deuterojesajanische Weissagung (Kap. 49-55), babylonische Juden zu persönlicher Mitarbeit am Werk der jüdischen Reformer anzufeuern. Dieser fesselnde Schriftsteller stand augenscheinlich in enger Fühlung mit jenen glaubensvollen Arbeitern. Er kannte die Schwierigkeiten, die ihnen im Wege standen, und hatte mit Bedauern bemerkt, dass sie Anwandlungen von Mutlosigkeit ausgesetzt waren. Gleich ihnen ersehnte er eine allgemeine Rückkehr der jüdischen Exilierten, aber er fïhlte dentlich, dass, um diese zu ermöglichen, Jehovah selbst mit seiner mächtigen Hand den Völkern einen Wink geben müsste ${ }^{1}$ ). Zu diesem grossen Ereignis rüstete er seine Leser mit Zuversicht aus.

Aber ein weit praktischerer Gedanke drängte sich einem judäischen Israeliten namens Hanani auf. Möglicherweise war er ein Beamter irgend einer Gattung, jedenfalls bekleidete er nachher ein sehr wichtiges Amt in Jerusalem (Neh. 7, 2). Glücklicherweise war er mit Nehemiah, einem der Mundschenken des Königs Artaxerxes ${ }^{2}$, verwandt. Er bewog eine Schar Juden, ihn zu einem Besuch bei seinem einflussreichen Landsmann zu begleiten. Nach seiner Ankunft in Susa (der Winterresidenz der persischen Könige) schilderte er auf Nehemiahs Erkundigung den jämmerlichen Znstand, in dem sich Jerusalem befand, und erzählte zugleich von einem Unfall, der uns als soeben

1) Jes. 49, 22. $-{ }^{2}$ ) Artaxerxes Langhand (466-445), nach Ansicht der meisten kritiker. 
erst geschehen anmuten könnte, wenn im übrigen Teil der Urkunde Belege für eine solche Annahme zu finden wären. Hier folge der Wortlaut von Frage und Antwort, wie sie Nehemiah in seiner gedrungenen Weise uns überliefert:

"Ich fragte sie nach den Juden, die entronnen und von der "Gefangenschaft übrig geblieben waren, und nach Jerusalem. „Und sie sagten mir: Die von der Gefangenschaft dort übrig „geblieben sind, die werden schr gekränkt und verhöhnt; der "Wall zu Jerusalem ist niedergerissen und ihre Thore ver"brannt (Neh. 1, 2f.)."

Nehemiah wurde es klar, dass eine Krisis eingetreten war, und dass es ihm oblag, eine äusserste Anstrengung zum Besten Jerusalems zu machen. Er war kein reiner Theoretiker und nicht gewillt, sich mit der Abfassung von Ansprachen voll hochfliegendem, aber unpraktischem Idealismus zu begnügen. Was er that oder wenigstens über seine Thaten uns wissen lassen will, lesen wir in seiner Autobiographie. Diese Urkunde ist eine unserer besten Quellen; dass sie erhalten blieb, ist das Werk eines einzig günstigen Schicksals. Freilich bleiben dem Geschichtsforscher noch manche Fragen übrig, auf die er keine Antwort von derselben erhält. So unterlässt sie z. B. Aufklärung darüber zu geben, wie Artaxerxes dazu kam, freundlicher gegen die Juden zu sein als Cyrus oder Darius. Angenscheinlich gab es für die Grossmut des Königs politische Beweggründe. Anfgabe des Geschichtsforschers ist es, das zu erraten. Ich wage daher eine Vermutung aufzustellen. Im Jahre 448 v. Chr. wütete 
in Syrien ein sehr gefährlicher Aufstand des Satrapen Megabyzos. Es ist mehr als wahrscheinlich, dass die Juden eine Beteiligung an demselben ablehnten, und wir dürfen annehmen, dass Artaxerxes sie für ihre Treue zu belohnen wünschte. Ich glaube, dass Nehemiah diesen Zusammenhang kannte und sogar annahm, dass er seine Stellung bei Hofe, welche in früheren Zeiten hochgeborne persische Adelige bekleidet hatten, der Judenfreundschaft des Artaxerxes verdankte. Nicht unwahrscheinlich ist es überdies, dass einige einflussreiche Lente in Jerusalem das ebensogut wussten wie Nehemiah, so dass die Ankunft Hananis und der Seinen nicht ganz so zufällig war, wie Josephus in seiner romanhaften Erzählung das darstellt $^{2}$ ) (Jos. Ant. XI 5,6 ).

Eins ist jedenfalls sicher, dass Nehemiah Urlaub erhielt, als Gouverneur nach Jerusalem zu gehen, mit dem besonderen Auftrag, die Mauern auszubessern. Mit königlichem Reskript und militärischem Geleit eilte er nach der heiligen Stadt. Dort angelangt, zeigte er sofort sein bezeichnendes Selbstbewusstsein. Er hätte die Notabeln berufen und sie um ihre Meinung über die Möglichkeit, die Wälle auszubessern, fragen können. Aber es gab tiefe Spaltungen unter der Bürgerschaft. Einige, sowohl Angehörige der Priesterklasse als Laien, waren mit den Führern der Samariter eng verbündet. Nehemiah war das olıne Zweifel bekannt;

1) Die Juden mögen schon lange den Wunseh gehegt haben, die Mauern ihrer Hauptstadt auszubessern, aber der Gunst des Hofes sich nicht sicher genug gefühlt hahen, um die Erlaubnis dazu zu erbitten. 
er mochte nicht Gefahr laufen, dass seine eigene Meinung abgelehnt wurde. In der dritten Nacht nach seiner Ankunft ritt er daher teils und teils ging er mit wenigen zuverlässigen Begleitern rund um die Stadtmauern $^{\mathbf{1}}$ ). Bei einer ähnlichen Gelegenheit (obwohl höchstwahrscheinlich 100 oder mehr Jahre später) schrieb ein Psalmist folgende Worte als passenden Ausdruck für Nehemiahs Gefühle:

"Denn deine Diener finden Wohlgefallen an ihren Steinen "Und sind bekümmert, sie im Staube zu sehen (Ps. 102, 14 [15])."

Bis in die Tiefe seines Herzens bewegt, rief der Gouverneur jetzt die Notabeln zusammen. Er zeigte ihnen, wie offenbar die Hand (d. h. die Vorsehung) Gottes über ihnen gewaltet hätte. Widerspruch war unmöglich. Eljašib, der Freund eines samaritischen Führers, stand in allererster Reihe unter Nehemiahs Bundesgenossen. Es war wie bei dem Wiederaufbau der athenischen Mauern nach dem Persereinfall. In 52 Tagen war die Mauer wiederhergestellt ${ }^{2}$ ).

Die geschichtliche Treue dieser Erzählung kann nicht angezweifelt werden. In der That haben wir eine teilweise Parallele dafür in der Geschichte eines nicht weniger selbstbewussten und nicht weniger verdienstvollen Beamten in persischen Diensten, des ägyptischen Priesters Uza-Hor. Unter den beiden letzten einheimischen Königen von Ägypten war dieser Mann Flottenbefehlshaber gewesen; nach der Eroberung Ägyptens durch Kambyses hatte er das Amt eines Obersten der Ärzte empfangen. Jedoch war er

1) Neh. 2, 11-15. $\left.-{ }^{2}\right)$ Neh. 2,17 f.; 3,$1 ; 6,15$. 
mehr als das. Sein Vater war Oberpriester der erhabenen Mutter des Sonnengottes, der Göttin Neit, gewesen, deren Haupttempel in Sais stand. Uza-Hor benutzte seine Stellung am persischen Hofe, um dem König einen hohen Begriff von der Würde seiner Gotheit beizubringen sowie von der Pflicht, ihren Tempel zu reinigen und ihren Kult in seiner Schönheit herzustellen. Kambyses erkannte die Pflicht an und befahl, den Kult der Neit wiedereinzuführen. Er selbst bezeigte sogar, wie alle frommen ägyptischen Könige vor ihm, der grossen Gottheit seine Verehrung. "Er that das", sagt Uza-Hor, "weil ich ihn mit der hohen Bedeutung der heiligen Gottheit bekannt gemacht hatte". So geschickt verband Uza-Hor seine Pflicht als Hofmann mit seinen religiösen Obliegenheiten. Und dass er kein blosser Anhänger des Formelwesens war, das beweist die Förderung, welche er den im alten Ägypten so hochgeschätzten Werken der Barmherzigkeit angedeihen liess. "Ich beschïtzte das Volk", sagt er, "bei dem sehr schweren Unglück, welches sich ereignete im ganzen Lande. Ich beschirmte den Schwachen ror dem Mächtigen. Ich schenkte dem, der ohne Sarg (dahinschied), ein gutes Begräbnis; ich ernährte all ihre Kinder und baute ihrer aller Häuser wieder auf". Dann kam die Thronbesteigung des Darius, der dem Uza-Hor seine Gunst in demselben Masse zuwandte und ihn nach Ägypten sandte, um die heiligen Schreiber der Tempel vollzählig wiederzuernennen und alles Verfallene wieder herzustellen. "Ich that, wie mir befohlen war." sagt Uza-Hor. "Ich 
nahm Kinder, ich vertraute sie für alle Zweige der Wissenschaft erfahrenen Meistern an. Die, welche sich auszeichneten, versah ich mit allem, dessen sie bedürftig waren als Schreiber. O ihr Götter von Sais! Gedenkt all des Guten, das Uza-Hor, der Oberste der Ärzte, gethan hat! O Osiris, bringe über ihn alles Gnte, gleichwie er es gethan, der Schirmer deines Schreines in Ewigkeit"1).

Diese ägyptische Inschrift ist in mehrfacher Hinsicht von grosser Wichtigkeit. Zuerst bezeugt sie die Achtung, die die persischen Könige vor den Religionen unterworfener Völker hegten. Die Dynastie der Achämeniden wurde erst gegen das Ende ihres Bestehens religiös unduldsam, auch waren sie nicht bestrebt, Propaganda zu treiben in Ländern wie Ägypten, Babylonien und Palästina, welche altehrwürdige Religionen besassen. In der That zeigen die Denkmäler, dass Cyrus den Babyloniern ausdrücklich Gunst erwies sowie Kambyses und Darius den Ägyptern. Dafür lagen wichtige Gründe der hohen Staatspolitik vor. Ich habe angedeutet, dass die Begünstigung der Juden seitens des Artaxerxes ähnlich erklärt werden muss. Aber natürlich war der Einfluss wohlwollender Beamten eine unerlässliche Hilfe. Es war ein Segen für die Ägypter, dass Uza-Hor den Posten eines Obersten der Ärzte bekleidete, und nicht minder für die Juden, dass Nehemiah königlicher Mundschenk war. Wir können gewiss sein, dass letzterer Sorge

1) Brugsch, Gesehichte Ägyptens S. $7 \pm 8$ fí. 
trug, das Räderwerk der Politik in Gang zu erhalten, indem er die Juden als zuverlässige Unterthanen und als Verwandte der Perser hinsiehtlich der Reinheit und Erhabenheit ihrer Religion hinstellte.

Ferner ist die selbstbewusste Sprache des ägyptischen Hofmanns des Darius bemerkenswert, insofern sie uns an die des jüdischen Höflings des Artaxerxes erinnert. Der Untersehied zwischen beiden besteht in folgendem. Nehemiahs Selbstbewusstsein ist eine Eigenschaft, die unter Israeliten bis dahin unerhört war, während Uza-Hor auf die Überlieferung ägyptischer Hofleute seit vielen Jahrhunderten zurüekblickt. Thatsächlich war Ägypten Israel in sittlicher Entwicklung voraus. Die Wertschätzung des Einzelnen welche das hebräische Buch der Proverbien (Sprüchwörter), das nachexilischen Ursprungs ist, bezeichnet, findet sich in den Vorschriften des ägyptischen Prinzen Ptah-hotep lange vorher. Kein Wunder daher, dass das Selbstbewusstsein des Nehemiah viel ältere Parallelen in den Inschriften ägyptiseher Standbilder hat. Es liegt nahe, Sie daran zu erinnern, dass die Ägypter seit der grauen Vorzeit auf ein Gerieht nach dem Tode mit Lohn und Strafen für den Einzelnen gerechnet hatten. Die Inschriften auf den Standbildern (welche in den Grabkapellen sich befinden) sind hauptsächlich an die Götter gerichtet. Wir können kaum das Gleiche sagen von Nehemiahs Bericht über seine guten Thaten. Aber er bewegt sich augenseheinlich im Gedanken an eine zukünftige Belohnung, wenn er im Fluss seiner Erzählung Pause macht, um den Seufzer auszustossen: 
„Gedenke meiner, mein Gott, zum Guten!" 1 ) Ist dies bloss eine "Bitte um Ruhm nach dem Tode?" Dechant Stanley hielt dafür $\left.{ }^{2}\right)$. Aber sicherlich müssen diese Worte erklärt werden durch folgenden anziehenden Ausspruch eines Psalmisten:

"Gedenke meiner, Jehovah, wenn du deinem Volke Gunst erzeigst, "Siehe mich an, wenn du Erlösung wirkst,

"Dass ich meine Augen richte auf das Glück deiner Auserwählten, „Mich freue an der Freude deines Volkes,

"Teilhaben möge am Triumph deines Erbteils (Ps. 106, 4f.)."

Nehemiah hofft thatsächlich, die messianische Zeit um ein gutes Stück näher gerückt zu haben durch die Mühe, die er sich gegeben hat, und träumt davon, dann ebenso hervorragend dazustehen, wie es in dieser schweren Zeit in Jerusalem der Fall gewesen war.

Gewiss war der Mundschenk des Artaxerses der einzige bedeutende Mann in Judäa. Obgleich nicht ganz unberührt geblieben vom Idealismus, zeigte er eine Energie im Rat sowohl wie in der That, welche uns an Napoleon erinnert. Dass er ungeduldig und herrisch war, zeigt nur an, dass er äusserst fähig und seiner Fähigkeit sich bewusst war. Die Zeitläufte verlangten einen solchen Mann, und irgend ein anderer der damals lebenden Juden würde wahrscheinlich nicht zum Ziele gekommen sein. Wenn ich hinzufüge, dass er die Gegner der orthodoxen Religion mit einem Eifer hasste, der uns verletzt, und dass er sie der Gemeinheit nicht minder als des religiösen Irrtums verdächtigte, so wird das keinen nachdenkenden Forscher

1) Neb. 5, 19; 13, 14. 22. 31. - ${ }^{2}$ ) Lectures on the jewish charch III, 120. 
überraschen. Es war schwer, wenn nicht unmöglich, in jenen frühen Zeiten Gott inbrünstig zu lieben, ohne einen grossen Teil von Gottes Geschöpfen zu hassen. Wie Nehemiah gesinnt war gegen die ausserpalästinensischen Völker, das können wir nur ahnen, aber wir wissen mit Bestimmtheit, dass er drei Personen verabscheute: Sanballat den Horoniter, Tobiah den Ammoniter ${ }^{1}$ ) und Gešem oder Gašmu den Araber.

Dieser Abscheu war natürlich Nehemiah nicht allein eigentümlich. Kurz vor seiner Ankunft hatten Propheten in den bittersten Wendungen gegen die Samariter geschrieben ${ }^{2}$ ). Die Beziehungen zwischen den beiden verwandten Gemeinschaften wurden mehr und mehr gespannt. Sanballat und Tobiah, Verehrer desselben Gottes wie die orthodoxenJuden, waren zu der Einsicht gekommen, dass die Unterschiede, die sie trennten, bedeutender waren als die Ähnlichkeiten, die sie vereinten. Und als Nehemiah ankam, „da that es ihnen sehr wehe, dass ein Mann gekommen sei", um - wie es schien - der rechtgläubigen Partei in Jerusalem endgültig zum Siege zu verhelfen oder, wie Nehemiah selbst es ausdrückt, .. die Wohlfahrt der Israeliten zu suchen"3). Und sie hatten guten Grund dazu. Die Propheten, die gegen die Samariter geschrieben hatten, thaten das anonym. Es war Nehemiah, der die erste offizielle Kriegserklärung erliess. "Wir sind die Knechte des Gottes vom Himmel, aber ihr habt kein Teil, noch Recht, noch Namen in Jerusalem*4). - Ich fasse zu-

1) [Vgl. Nachtray über Sanballat und Tobiah am Schluss des Bucbes.] - ") Jes. $57,3-13 ; 65$ f. $-{ }^{3}$ ) Noh. 2, 10. - ${ }^{4}$ ) Neh. 2, 20. 
sammen. Es waren ursprünglich nicht die Samariter, welche von den Juden loszukonmen wünschten. Gerne würden sie dem Heiligtum von Jerusalem auch weiter angehört und nach dem Tode jener schattenhaften Unsterblichkeit sich erfreut haben, die darin bestand, in der heiligen Stadt ein Denkmal zu haben. ${ }^{1}$ ) Aber Nehemiah und die exklusive Partei duldeten nur ihre eigene Meinung und gaben ihrer Feindseligkeit gegen ihre Nachbarn dadurch Nachdruck, dass sie die Mauer von Jerusalem herstellten, nicht so sehr als Schutz gegen gewöhnliche Feinde als um die Samariter fernzuhalten.

Die Samariter ihrerseits stellten sich erstaunt, dass Nehemiah es wage, einen Akt offenkundigen Abfalls von Persien zu begehen ${ }^{2}$ ). Einige unter den jüdischen Propheten hatten ihnen aller Wahrscheinlichkeit nach einen gewissen Anhalt für dieses kühne Missverständnis gegeben. Die Behauptung wird dem Sanballat zugeschrieben, aber es liegt kein genügender Grund vor zu der Annahme, sie sei von dem samaritischen Führer schlankweg aus den Fingern gesogen worden. Wir wissen, dass Haggai und Zachariah Zerubbabel als messianischen König ausgerufen hatten, und es ist ziemlich wahrscheinlich, dass andere Propheten zu Nehemiahs Zeit diesen grossen Mann (er war wie gesagt der einzige grosse Mann) für den Messias erklärten. Freilich war Nehemiah kein Abkömmling Davids. Aber es steht nicht fest, dass Jere-

1) Vgl. Jes. 56, 5: „ein Gedächtnis and ein Name besser als Söhne und Töchter“. - 2) Neh. 2, 19. 
miah und Ezechiel, wo sie von David oder vom Davidsspross als dem idealen König der Zukunft reden, auf thatsächliche Abstammung von dem Isaisohn glaubten Gewicht legen zu sollen. Wenn ein Held, der im Geist und in der Kraft Davids erschien, ihnen vor Augen gestellt worden wäre, dann würden sie wahrscheinlich in ihm einen echten Davidssohn erkannt haben, gerade so wie Jesus in der Erscheinung des Täufers Johannes die Erfüllung der wohlbekannten Maleachistelle erkannte. ${ }^{1}$ ) Die Samariter besassen somit thatsächlich den Schein eines Vorwands, die Geschichte über Nehemiah in die Welt zu setzen. Jüdische Propheten hatten für einen Augenblick den Namen des Gouverneurs verknüpft mit der überlieferten messianischen Hoffnung. Aber Nehemiah selbst ${ }^{2}$ ) war zu klug und zu aufrichtig, solche Agitation zu dulden und trügerische Hoffnung auf jüdische Unabhängigkeit zu erregen. Und ich vermute, dass Sanballat das wohl wusste. Es ist kaum begreiflich, dass des Gouverneurs vornehmlichster Zweck bei dem Mauerbau Sanballat ein Geheimnis geblieben sein sollte.

Was das für ein Zweck war, haben wir schon gesehen. Nehemiah wünschte Jerusalem zu verteidigen vor dem Angriff, den die Samariter (unter dem Vorwand des Aufstandes Nehemiahs gegen seinen königlichen Herm) wahrscheinlich auf die Stadt machen würden, nachdem das Recht der Anbetung im Tempel und der

j) Mft. 11, 14: Uk. 9, 13, rgl. L.k. 1, 17. - ") Sen. 6, 7 . 
Eheschliessung mit den Juden ihnen entzogen war. Ein Punkt jedoch, der für Sanballat spricht, muss erwähnt werden. Bevor die Thürflügel in die Stadthore eingehängt waren, machte er einen letzten Versuch, ein Abkommen mit Nehemiah zu erzielen ${ }^{1}$ ). Der Gouverneur erklärt freilich in seinen Erinnerungen, dass die Samariter einen Anschlag gegen ihn geplant hätten. Aber die Thatsache, dass Sanballat, unbeirrt durch Nehemiahs anfängliche Weigerung, einen viermaligen Versuch machte, eine Zusammenkunft zu ermöglichen, spricht zu seinen Gunsten. Die Sprödigkeit des Gouverneurs war ausreichend, auch den Versöhnlichsten zu reizen und trägt in etwas dazu bei, den endlichen Vorstoss Sanballats zu entschuldigen. Jener kühne Mann äusserte nur öffentlich Zweifel gegen Nehemiahs Zuverlässigkeit als Vergeltung für wiederholte Abweisungen verletzendster Art; seine früheren Bemühungen um ein Übereinkommen waren in gutem Glauben angestellt. Dass Nehemiah dies nicht glaubte, ist kein entscheidendes Argument zu seinen Gunsten. Sein Argwohn war ungewöhnlich leicht erregt. Er witterte überall Verrat und mochte seinen nächsten Nachbarn nicht trauen. Ein Prophet drängt ihn, im Heiligtum Zuflucht zu suchen. Sofort schliesst er daraus, dass der Prophet in Sanballats Solde stehe (Neh. 6, 10 -14). Die Edlen in Jerusalem unterhalten einen Briefwechsel mit Tobiah dem Ammoniter, ihrem alten Freund, der einigen unter ihnen verwandt ist. Sofort schliesst Nehemiah, dass ihre Briefe voll boshafter Verleumdungen gegen ihn selbst $\operatorname{sind} .^{2}$ )

1) Neb. 6,1-9. - 2) Neh. 6,17-19. Statt „meine Worte ${ }^{4}$ lies nüble Nachreden uber mich ${ }^{*}$. Cbejne, Religiöses Leben der Juden. 
Ich bitte meine Leser, nicht zu glauben, dass ich es mit den Samaritern und ihren jüdischen Freunden gegen Nehemiah halte. Allerdings bin ich der Meinung, dass erstere ein Recht hatten, sich beeinträchtigt zu fühlen bei der Aussicht, ihrer bürgerlichen und religiösen Vorrechte in Jerusalem beraubt zu werden, und dass die konservativen Juden sich ganz naturgemäss zu den Samaritern hingezogen fühlten, bei denen sie ein sympathisches Verständnis für ihre ererbten Anschauungen fanden. Einige Anerkennung schuldet man meiner Meinung nach auch den jüdischen Adligen für den Beistand, den sie Nehemiah (dessen letztes Ziel sie vielleicht nicht klar erkannten) bei der Wiederherstellung der Stadtmaner leisteten. Bei alledem halte ich es für sehr wohl möglich, dass sie Nehemiah in ihren Privatbriefen etwas schwarz malten, und dass sie den Propheten Šemajah anstifteten, Nehemiah zu einer Handlung offenbaren Misstrauens zu vermögen. Und dann war die Sache Nehemiahs eine bessere als die ihrige. Eine das Volk abschliessende Politik war zu diesem Zeitpunkt notwendig, damit eines Tages eine liberalere und weitherzigere möglich werden könnte. Ausserdem waren, wie es scheint, den Samaritern die Bedingungen gestellt worden, auf Grund deren ihnen ihre religiösen Vorrechte weiter bewilligt werden konnten, und diese Bedingungen hatten sie verworfen. Sie lratten sogar Widerwillen gezeigt gegen die beste jüdische Frömmigkeit (Jes. 66, 5), und nun, da ein tiichtiger Führer der Orthodoxen erschienen war, thaten sie ihr Äusserstes, seine Thätigkeit zu hindern. Sicher- 
lich mag dieser Widerstand gegen das, was Nehemiah als wahre Gerechtigkeit erkannte, vom Standpunkt des Gouverneurs aus als störrische Gottlosigkeit e1schienen sein, welche keine Höflichkeit oder Beachtung verdiente.

Kehren wir zu Nehemiahs persönlicher Geschichte zurück. Das Werk, wofür er vom Hofe Urlaub erlangt hatte, war vollendet. In dem uns vorliegenden Text des Buches Nehemiahs steht, dass er zwölf Jahre in Jerusalem als Gouverneur blieb (Neh. 5, 14). Aber ohne anderweitigen selbständigen Beleg dafür müssen wir Anstand nehmen, das als zuverlässig zu betrachten. Die biblischen Texte erlitten mannigfache Veränderungen, besonders im Punkte chronologischer Angaben, ehe sie an die letzten Herausgeber kamen. Der Text von Neh. 5, 14 kann kaum genau überliefert sein. Nehemiah muss doch wohl zu Artaxerxes zurückgegangen sein, sobald das Werk, worauf sein Reskript Bezug nahm, vollendet war. Der König hatte ihm nur für eine bestimmte Zeit Urlaub gegeben, und der Königin war ebenfalls an seiner Rückkehr gelegen. Eine interessante Thatsache habe ich jedoch noch zu erwähnen, welche über jeden Zweifel erhaben ist. Vor seiner Abreise bezeigte Nehemiah eine Herzenssympathie mit den niedergetretenen Armen. Die Erzählung von ihrem "bitteren Geschrei" folgt unmittelbar auf die vom Mauerbau. Gerade dieses grosse öffentliche Werk brachte die arge Not, worïber sie klagten, schliesslich auf ihren Gipfel. Denn die armen Juden, welche so unablässig an der Mauer arbeiteten, konnten unmög- 
lich Zeit erübrigen, ihre Felder und Weinberge zu besorgen. Die Folge war, dass auf der einen Seite der persische Steuererheber sie drängte, und auf der anderen die Hungersnot sie in ihren furchtbaren Krallen hielt. Das einzige Mittel war, sich an die Geldausleiher zu wenden. Aber diese harten Menschen wollten nicht zufrieden sein, ehe ihre Klienten ihnen ihre kleinen Besitztümer verpfändet hatten, ja gar ihre Söhne und Töchter in die Sklaverei gehen liessen. „Ein lautes Geschrei erhob sich unter dem gemeinen Volk und seinen Weibern gegen ihre jüdischen Brüder." "Wir sind von demselben Fleische wie unsere Brüder," so riefen sie in der Angst ihres Herzens aus, "und unsere Kinder haben dieselben Züge wie die ihrigen." Der Schrei traf die Ohren des Gouverneurs in seinem Palast, und leidenschaftlicher Zorn ergriff ihn. Er war auf diesen sittlichen Mangel nicht vorbereitet. Er war der Hoffnung gewesen, die judäischen Juden im Besitz nicht geringerer Bruderliebe als die der Diaspora zu finden. Hielten diese es doch für ihre heilige Pflicht, jüdische Gefangene aus ihren Banden loszukaufen. Die Vorstellung eines reichen Juden, der auch nur duldete, dass ein Armer sein eigenes Kind verkaufte, ja es wohl gar selbst kaufte, war für Nehemiah unfassbar. Das war nicht bloss unmenschlich, das war gottlos, und eine solche Unthat setzte die ganze Gemeinde dem schnöden Spott der Samariter aus. Er berief eine Versammlung, und mit dramatischen Gesten, welche er anschaulich schildert, nahm er den Wucherern den Eid ab, die Pfandbriefe zu vernichten 
und den übermässigen Zins, welchen sie eingetrieben hatten, zurückzuzahlen.

Die Erzählung lässt kein günstiges Licht fallen auf das religiöse Leben in der Gemeinde. Sie erinnert uns an eine anonyme, etwa dieser Zeit entstammende Prophetie, wovon eine Probe beigebracht zu werden verdient. Der Verfasser führt die reichen Juden dramatisch ein, indem er sie mit Jehovalı wegen seiner Unthätigkeit als Beschützer Israels rechten lässt:

„Warum haben wir gefastet, und du siehst es nicht? Uns selbst „kasteit, und du achtest nicht darauf?

"Sicherlich treibt ihr an' euren Fasttagen euer Geschäft und „treibt alles Geld ein, das ihr auf Pfand ausgeliehen habt. „Ist nicht dies das Fasten, das ich ansehe, Spruch Jehovahs: „Zu lösen die Fesseln der Ungerechtigkeit, zu lockern die „Bande der Gewalt,

„In Freiheit zu setzen die Bedrückten, zu lösen jedes Joch?

„Solltest du nicht dem Hungrigen dein Brot brechen und den „Heimatlosen in dein Haus bringen,

„Wenn du den Nackenden siehst, ihn bekleiden und dich nicht ,zurückziehen von deinem eigenen Fleisch?

„Dann wird dein Licht hervorbrechen wie die Morgenröte, deine "Wunden werden schnell geheilt werden;

,Deine Söhue werden die Wüsteneien der Vorzeit aufbauen, du ,wirst die lange verwüsteten Wohnplätze wieder aufrichten, „Und die Menschen werden dich nenren: Erbauer der Wüsteneien, „Hersteller der verwüsteten Wohnplätze

$$
\text { (Jes. 58, 4. 6-8. 12)." }
$$

Wir ersehen daraus, dass Nehemiah nicht der einzige war, der gegen die Unmenschlichkeit der Aristokraten auftrat. Hätte er nachgeforscht, dann würde er diese Grausamkeit auch schon vorher an- 
getroffen haben. Denn es war nicht der Wiederaufbau der Mauern allein, der den Wucherern Gelegenheit geboten hatte, den Bürgerstand zu quälen. Er forschte nicht nach, weil er zu sehr mit wichtigen Angelegenheiten beschäftigt war, als dass er hätte nach unbedeutenden Einzelheiten sehen können. Hätte nur sein Freund Hanani ihn auf die Notwendigkeit einer gründlichen socialen Reform aufmerksam gemacht; aber Hanani war ganz aufgegangen in der Idee von der Notwendigkeit, die religiöse Abschliessung zu vollenden. Und so trieb denn Nehemiah, der diese Aufgabe ebenfalls als wesentlich ansah, diese armen Leute aus ihrer ländlichen Heimat weg, um am Manerbau zu arbeiten, ohne für ihre Entlohnung gehörige Sorge zu tragen. Hat er sich darüber nachträgliche Vorwürfe gemacht? Seine Autobiographie erwähnt davon leider kein Wort.

Ebensowenig geschieht der iibrigen Massnahmen Nehemiahs während seines ersten Besuchs Erwähnung. Es: ist möglich, dass der letzte Überarbeiter seines Werkes einige Partien ausgelassen hat, weil sie in seinen eigenen Plan nicht passten. So kennen wir auch nicht Namen und religiöse Gesinnung des Tiršatha (d. h. königlichen Bevollmächtigten), dem Nehemiah die Zügel der Verwaltung übergab. Doch gleichviel, wer auch immer der Tiršatha war, er hat nicht den Mut besessen, mit den jüdischen Aristokraten zu brechen. Sie erscheinen zu späterer Zeit mit den Führern der Samariter so vertraut, als ob die Mauer nie ausgebessert worden wäre. Ja, es bestand noch ein Abgrund zwischen babylonischer und judäischer Rechtgläubigkeit. 
Dürfen wir daran zweifeln, dass das in den babylonischen Judenkreisen viel Unzufriedenheit erregte oder Anstand nehmen, das mit der ersten grossen geschichtlichen Rückkehr jüdischer Verbannter nach Palästina unter Esra dem Schriftgelehrten zusammenzustellen? Dieser grossen Rückwanderung musste natürlich eine Reise seitens einiger einflussreicher Juden, darunter Esra, an den persischen Hof mit der Bitte um königliche Erlaubnis vorangehen. Zum Glück erhebt eine authentische Äusserung seitens Esras selbst das über allen Zweifel und setzt uns in den Stand, auf den Inhalt der dem Artaxerxes vorgetragenen Bitte einen Schluss zu ziehen. Folgendes sind die bezüglichen Worte:

„Gelobt sei Jehovah, der Gott unserer Väter, der dem König „eine solche Sache wie diese ins Herz gegeben hat, Jehovahs "Tempel in Jerusalem zu zieren, und mich hat Gnade vor dem „König und seinen Ratsherren und vor allen mächtigen Fürsten „des Königs finden lassen (Esr. 7, 27 f.)."

Es erhellt daher, dass der Beweggrund Esras und seiner Partei lediglich religiöser Art war. Es war keine blosse nationale Wanderung, wozu er vom König die Erlaubnis erbat, sondern ein Versuch im grossen Stil, den Weg für die noch hinausgeschobene Rückkehr Jehovahs in sein Land zu bereiten. $\mathrm{Thm}$ wie Haggai und Zachariah vor ihm galt ein prächtiger Tempel als eine unerlässliche Bedingung, Israel die göttliche Gnade wieder zuzuwenden. Das angebliche königliche Edikt aber, das vor den eben angeführten Worten Esras eingefügt ist, ist viel bestimmter in seinen Ausdrücken. 
Es erklärt, dass Esra der Priester ${ }^{1}$ ) und Schriftgelehrte vom König und seinen Räten entsandt wird, um auf Grund des in seinen Händen befindlichen Gesetzes eine Prüfung der jüdischen Religion vorzunehmen. Es ermächtigt sogar Esra Korporationen und Richter zu bestellen, um das Volk in der Provinz jenseits des Euphrat in Gemässheit dieses Gesetzes zu richten. Sollte jemand da sein, der sich Ungehorsam herausnimmt oder die Belehrung ablehnt, über den ist ein strenges Urteil zu fällen; von einfachem Gefängnis kann es bis zu Einziehung der Güter, Verbannung und Tod verschärft werden ${ }^{2}$ ). Das alles ist sehr auffällig. Eine gewaltsame Einmischung in die Religion ihrer jüdischen Unterthanen würde ein unerhörter Vorgang in der Politik der persischen Könige gewesen sein. Esra nimmt auf keine andere Anordnung des Königs Bezug als auf die betreff's der Ausschmückung des Tempels. Er sagt überdies ausdrücklich, dass er den König um ein militärisches Geleit nicht bat, weil er so viel über göttlichen Schutz gesagt hatte (Esr. 8, 22). Das sieht kaum danach aus, dass er den Gedanken gehegt hätte, seine Reformen mit Hilfe der Regierung durchzudrücken. Dass das Reskript mit Geschick abgefasst ist, das bin ich am allerwenigsten geneigt $\mathrm{zu}$ bestreiten. aber es in seiner vorliegenden Form als geschichtliche Urkunde zu verteidigen, dazu bin ich ausser stande ${ }^{3}$ ). Ich bin über-

1) Einige Gelehrte zweifeln an der geschichtlichen Beglaubigung des priesterlichen (harakters des Esra. - 2) Esra 7, 11-26, rgl. Chron. B 15, 13. - 3) Daruber und über andere Dunkelheiten des Lebenslaufs Esras und Nehemiahs vgl. Specialartikel in Blacks 
haupt nicht sicher, ob das Esr. 7, 8 f. gegebene Datum richtig ist.

Doch steht fest, dass ein beträchtlicher Teil der babylonischen Juden unter Esra in Jerusalem ankam. Gewiss ist die Thätigkeit Esras wie die Nehemiahs nötig, den späteren Verlauf der jüdischen Geschichte zu erklären. Aber worin sie wirklich bestand, das kann nicht in allen Fällen mit Bestimmtheit festgestellt werden. Der Bericht, den der Chronist in den Büchern Esra und Nehemiah liefert, mag auf zeitgenössischen Berichten beruhen, aber auch zeitgenössische Berichte sind nicht immer streng zuverlässig. Ich weiss wohl, dass ich damit das Grenzgebiet einer sehr schwierigen Frage anrühre, aber es ist das eine solche, um die der Forscher nicht herumkommen kann, und über die ich meine eigene Meinung zu sagen verpflichtet bin. Niemand setzt gern die Autorität einer alten Urkunde beiseite, aber hier scheint es mir ganz unvermeidlich. Wie wir auch immer die Ansichten des Erzählers beurteilen mögen, die Geschichte wird die Feuerprobe der geschichtswissenschaftlichen Kritik nicht bestehen. Die einzige mögliche Ansicht ist die, dass Esra bei seiner Ankunft mit Reskript und Gesetzbuch das erstere infolge der Stimmung des Volkes ganz nutzlos fand und 13 Jahre lang wartete, bevor er das letztere öffentlich einzuführen wagte. Andere nehmen an, dass der Erzähler etwas ganz anderes sagen wollte d. h. dass Esra es nicht für so wichtig hielt, zu son-

Enc. Bibl. und die Übersetzung der Bticher Esra und Nehemiah (mit Anmerkungen) von Guthe in Professor Haupts Bibel. 
dieren und seine Überredungskunst zu versuchen, sondern dass er mit einem Schlage das Gesetz einführte, mitten zwischen den Jubel der Menge hinein. Ich für meine Person denke, dass die letztere Ansicht über die Meinung des Verfassers die natürlichste ist, aber doch finde ich es mit nicht weniger Schwierigkeiten verknüpft, sie als treffend anzuerkennen, als die erstgenannte. Wie Esra unmittelbare Annahme für sein Gesetzbuch erreicht haben sollte, ausser durch Berufung an die Gewalt, das kann ich nicht begreifen. Machte er laut der Urkunde eine solche Berufung? Nein. Es wird angegeben, dass „das ganze Volk.... redete zu Esra dem Schriftgelehrten, das Buch des Gesetzes Moses, das Jehovah Israel befohlen hatte, zu bringen" (Neh. 8, 1), und dass am nächsten Tage die Häupter der Familien die Priester und Leviten zu einem Besuch bei Esra, dem grossen Gesetzeskenner, beriefen, um Laubhütten auf strenggesetzliche Weise feiern zu lernen. Nun leugne ich nicht, dass zu dieser Zeit aufseiten der führenden Juden eine aufrichtige Anhänglichkeit an das ältere Gesetz bestand, und ich erkenne den sittlichen Einfluss, der durch die neuen Ansiedler aus Babylonien ausgeübt sein muss, voll und ganz an, aber ich bezweifle, dass ein Gesetzbuch, das so sehr von dem älteren sich unterschied (ich werde auseinandersetzen, was Esras Gesetzbuch damals enthielt), auf einmal von dem ganzen Volk und zumal von der aristokratischen Klasse angenommen worden sein kann. - Freilich die andere Ansicht erscheint mir nicht weniger bedenklich. Wie kann Esra 13 Jahre 
lang gewartet haben, ehe er, und noch dazu recht unvollkommen, dem gemessenen Befehl des Artaxerxes gehorchte? Ich muss überdies gestehen, dass die Ereignisse, welche gemäss den überlieferten Berichten dieser angeblichen Veröffentlichung und feierlichen Annahme des Gesetzes folgten, mich in meiner zweifelnden Haltung bestärken. Ieh kann teilweise die Geschichte von der Einführung des älteren Gesetzbuchs unter Josiah verstehen, aber die äusserst verwandt klingende Erzählung Neh. 8 kann ich ganz und gar nicht begreifen. Wir werden nicht fehlgehen, wenn wir einen gesehichtlichen Kern zulassen, aber die Erzählung wie sie dasteht ist leider wahrscheinlich ungesehichtlich.

Nicht minder voll von Unwahrscheinlichkeiten ist die Erzählung von der Ehereform Esr. 9 f. Eine so schwierige Sache, wie die Abänderung von Ehesitten kann nicht so sehnell und so im Handumdrehen zu Wege gebracht sein. Dass der Anblick Esras, wie er mit zerrauftem Haar in Ekstase dasass, und dann die Anhörung eines feierlichen liturgischen Gebets die Leute, welche nichtjüdische Weiber geheiratet hatten, hätte so knicken sollen, dass sie mit einem Schlage einwilligten, Weib und Kinder zu entlassen, und dass drei Tage hernach eine noch grössere Versammlung unter freiem Himmel bei kaltem, regnerischem Wetter sich zusammengefunden und in die Bestellung einer Kommission gewilligt haben sollte, um die Widerstrebenden zu zwingen, diesen Beschluss auszuführen, das ist ganz unglaublich. Dass etwas geschah, was 
einer allgemeinen Austreibung nichtjüclischer Weiber und ihrer Kinder ähnlich sah, das zu glauben verbieten uns nicht allein psychologische Erwägungen, sondern auch gewisse wichtige in unsern Urkunden ${ }^{1}$ ) erwähnte Thatsachen.

Doch man glaube nicht etwa, dass ich Esra nun in ein Muster von Menschlichkeit verwandeln wolle. Im Gegenteil, ich halte es für wahrscheinlich, dass er zuerst bei weitem zu hitzig in seiner Sprache und zu strenge in seinen Anforderungen war, und ich muss der Befürchtung Ausdruck geben, dass es Leute gab, die allzu fügsam auf seine Ideen eingingen. Wenn die oben abgewiesene Vermutung richtig wäre, dann wäre der Schriftgelehrte Esra einer ausdrücklichen Leugnung der Vorstellung von Gott als dem Vater überführt - eine Vorstellung, die sich schon im ersten Kapitel der sein Gesetzbuch einleitenden Erzählung findet. Ich fühle mich verpflichtet, das eben so gut festzustellen, wie ich die ganz verschiedene Haltung des Apostels Paulus billige und bewundere. Auch kann ich nicht umhin, in diesem Zusammenhang auf die Segnungen hinzuweisen, welche den englischen Volke aus der Verbindung eines heidnischen Königs von Kent mit einer christlichen Prinzessin von Frankreich erwuchsen. Schon aus Dankbarkeit für diese Segnungen würde ich mich genötigt sehen müssen, mich mit Schaudern von dem Vorgehen Esras abzuwenden, wenn es zu einem Bericht wie dem in Esr. $9 \mathrm{f}$. hinreichenden Anlass gab.

1) Vgl. Esra 10, 15; Neh. 13, 23-27. 
Und doch, selbst wenn Esra insoweit tadelnswert ist, so darf ich das Bestehen von mildernden Umständen nicht übergehen. Diese Energie und Strenge (soweit sie geschichtlich sind) sind nur der Ausfluss eines religiösen Patriotismus. Sie gingen hervor aus der Angst vor den nur zu wahrscheinlichen unheilvollen Folgen von Mischehen. Ein Kind wird in allen Fällen nachhaltig beeinflusst entweder zum Guten oder zum Bösen durch die Religion der Mutter. Es gab eine Zeit, wo die Religion des alten Ägyptens teilweise semitisiert wurde durch die Zwischenheiraten zwischen Ägyptern und Syrern, und einige von den unerfreulichsten Eigentümlichkeiten der Religion der alten Israeliten wurden wesentlich durch ihre Zwischenheiraten mit Kanaanitern verursacht. Das war hauptsächlich der Grund, weshalb Esra und Nehemiah gegen die Mischehen eingenommen waren. Die Religion, die sie zu verbreiten wünschten, war eine Buchreligion, welche in ausgedehntem Masse von den Gesetzen der Entwicklung abhing, diejenigen der Samariter und der andren kleinen palästinensischen Nationen waren örtlich-konservativer Art und auf alte Sitten begründet. Ohne Zweifel stand Esras Vorgehen in Widerspruch mit der Anschauung von Gottes Vaterliebe, die Gen. 1 zum Ausdruck kommt. Aber wir können auf Grund des Buches Maleachi ${ }^{1}$ ) zeigen, dass viele von denen, gegen welche Esra gerne so barbarisch vorgegangen wäre, sich ebenso unleugbar mit jener grossen Lehre in Widerspruch gesetzt

1) Nal. $2,10-16$. 
hatten. indem sie die jüdischen Weiber. die sie in der Jugend heimgeführt hatten. fortgetrieben hatten, $1 m$ fremde Weiber zu heiraten. "Haben wir nicht alle einen Vater? Hat nicht ein Gott uns geschaffen?" das sind die Worte, mit denen Maleachi sie unwillig tadelt. Er thut auch der tramigen Familienverhältnisse Erwähnung, welche infolge dieser hartherzigen Ehescheidungen entstanden waren. da die Kinder sich augenscheinlich anf die Seite ihrer verstossenen Mütter gestellt hatten. Und er scheint seine eigene Unfähigkeit, diese Missstände abzustellen, schmerzlich empfunden zu haben, denn er selbst (oder irgend ein noch späterer Verfasser) hat folgenden Anhang seiner Prophetie hinzugefügt:

.,Siehe, ich sende euch den Propheten Eliah, ehe denn da ,kommt der grosse und schreckliche Tag Jehovahs. Er wird ,die Herzen der Väter den Kindern zuwenden und die Herzen ,der Finder ihren Tätern, damit ich nicht komme und das "Land mit einem Fluche schlage (Mal. 4, 5 f. [3, $23 \mathrm{f.j}$ ). "

Mit anderen Worten: Maleachi sieht aus nach rinem grossen religiösen Reformator, der das Tolk wieder an seine socialen Verpflichtungen und an Jehovahs [Jahwe's] Hass gegen jeden nichtisraelitischen Wandel erimnern sollte. Jehorah hatte seinen Bund mit Israel ganz allein gemacht. Diejenigen. welche irgend einen Bund abschlossen, sei es mit Halbjuden wie Samaritern oder mit Nichtjuden wie Philistern, Ammonitern und Moabitern, und die zu diesem Zweck ihre jüctischen Weiber entlassen hatten. erregten sein Missfallen. Derartig müssen wir uns auch 
die von Esra eingeschärfte Anschanung über die Ehe vorstellen.

Bleibt somit dem kritischen Geschichtsforscher von den Einzelheiten der Erzählung in Esra 9 f. sehr wenig übrig, so kann ein etwas günstigeres Urteil wenigstens meiner Ansicht nach gefällt werden betreffs des Berichts über die Entstehung der sogenannten Gemeinde, oder um einen dem Griechischen entlehnten passenderen Ausdruck zu verwenden, der Ekklesia ${ }^{1}$ ). Diese Erzählung scheint ursprünglich auf jene in Esra $9 \mathrm{f}$. gefolgt zu sein, deren Schlussworte nach dem richtigen LXXText lauten: "Und sie entliessen sie (d. h. ihre fremden Weiber) mit ihren Kindern." Diese Erzählung setzt ebenfalls unzweifelhaft voraus, dass Esras Gesetzbuch nun allerseits angenommen war und zu Recht bestand. Denn sie spricht von einer langen Verlesung aus dem Buch des Gesetzes Jehovahs, die dem von den Leviten gesprochenen liturgischen Sündenbekenntnis vorangegangen sei. Der Inhalt des Gesetzbuches war der Zuhörerschaft zum Teil ganz neu. Nun steht so viel fest, dass dies nicht der geschichtliche Hintergrund der Bildung der Gemeinde sein kann. Die Mischehen können nicht in irgend beträchtlicher Zahl gelöst worden sein, und das Gesetzbuch Esras kann nicht allgemein oder in öffentlicher Versammlung Annahme gefunden haben. Aber die Scene im Vordergrund des Gemäldes mag noch geschichtlich sein. Die babylonischen Juder, welche mit Esra heraufgezogen waren, betrachteten

1) Vgl. Hort, The Christian ecclesia 1896. 
sich selbst sicherlich als die wahren Israeliten, und es war nur natürlich, dass sie sich zu einer Gemeinschaft zusammenschlossen, die den Anspruch erhob, eine nationale Kirche oder Versammlung zu sein, indem die Vorstellungen von Kirche und Volk fortan untrennbar miteinander verquickt waren ${ }^{1}$ ). Und zu dieser Kirche oder Versammlung mussten sie zunächst natürlich alle die zulassen, welche in den verflossenen bösen Tagen gegen das Halbheidentum protestiert hatten und wach den Worten Maleachis $(3,16)$,sich oft mit einander besprachen ${ }^{2}$ " " und ferner diejenigen, welche unter dem Einfluss der Kolonisten ihre nichtjüdischen Gewohnheiten abgelegt oder, um in der Sprache eines Zeitgenossen ${ }^{3}$ ) zu reden, sich "von der Übertretung in Jakob bekehrt hatten" (Jes. 59, 20). Diese Gemeinschaft ist das "Zion" der späteren Kapitel Jesajahs, und ihre Glieder sind die "Armen", die „Demütigen ", die "da leid trugen in Zion", die „da zitternd Jehovahs Worte hörten", von welchen wir in späteren Psalmen, Prophetien und Erzählungen lesen ${ }^{4}$. Diese Gemeinschaft ist auch der zarte Keim der grossen jüdischen Kirche, und die Abmachung oder der Bund, den ihre Mitglieder nach feierlicher Verlesung des neuen Gesetzbuches wahrscheinlich unterschrieben, muss die hauptsächlichsten Verpflichtungen enthalten haben, welche die Bedingung der dem wahren Israel ver-

1) Nach der nachexilischen Liste in Esra 2 (Neh. 7, Esdras A 5) betrug die Zahl der Manner in der Gemeinsehaft 42360 , d. h. etwa 125000 Seelen. - ${ }^{2}$ ) d. h. die sich enge zosammengesehlossen hatten. -- $\left.{ }^{3}\right)$ Siehe Jesajah in der Polychrome Bible. 4) Jes, 61,$3 ; 66,2$; Esra 9, 4; 10, 3; P's. 9, 12 [13]. 18 [19]; 10, 9 f. 12 u. s. w. 
heissenen Rechte bildeten, Rechte, die in folgenden wichtigen Worten des dritten Teils des Jesajah zusammengefasst sind:

,Und ich, diesen Bund mache ich mit ihnen, Spruch Je„hovahs: Mein Geist, der auf dir (d. h. auf dem wahren Israel) „,ruht, und meine Worte, welche ich in deinen Mund gelegt „habe, sollen nicht weichen von deinem Munde, noch von dem "deines Samens oder von dem der Nachkommen deines Samens, „von nun an bis in Ewigkeit (Jes. 59, 21)."

An diesem geschichtlichen Wendepunkte verschwindet Esra der Schriftgelehrte plötzlich. Die Hauptrolle in der Erzählung übernimmt noch einmal Nehemiah, den die Kunde von Esras verhältnismässigem Misserfolg von seiner Heimat in Susa fortgetrieben zu haben scheint ${ }^{1}$ ). Wahrscheinlich kam er mit Urlaub als zeitweiliger Gouverneur oder hoher Specialbeamter. Es ist bemerkenswert, dass sogar Nehemiah Esra in dem kurzen zweiten Teil seiner Erinnerungen nicht erwähnt. Er beschränkt sich auf eine geschäftsmässige Darstellung seiner eigenen Massnahmen. Es sind dieselben, welche in der überlieferten Erzählung von dem Bunde der Gemeinde gegeben werden, nämlich Abschaffung der Mischehen und des Sabbatverkehrs und Beschaffung regelmässiger Einkünfte für den Tempeldienst und für die Priester und Leviten.

Betrachten wir zuerst den letzten dieser drei Punkte: Nehemiah fand, dass die Besoldung der Leviten so arg vernachlässigt worden war, dass sie ihren Posten verlassen und sich auf ihre Landbesitze zurückgezogen

1) Neh. 13, 6 .

Cheyne, Religiöses Leben der Juden. 
hatten $\left.{ }^{1}\right)$. So seltsam es klingen mag: der Priester Eljašib (nach meiner Vermutung der Hohepriester desselben Namens) hatte, indem er dem Verfall der gottesdienstlichen Ordnung freien Lauf liess, die Benutzung einer grossen Vorratskammer, die früher für die Leviten bestimmt gewesen war, Tobiah dem Ammoniter eingeräumt ${ }^{2}$ ). Hier in der Nïhe seines priesterlichen Freundes hatte sich wie es seheint Tobiah, als Verwalter des Tempels, mit seinem Hausgerät wohnlich eingerichtet. Nehemiah schritt naeh seiner Weise ohne Zögern ein. Er liess das gesamte Eigentum des Tobiah ans der Kammer entfermen und dieselbe dann reinigen, gerade als wenn Tobiah ein Heide wäre ${ }^{3}$ ). Eljašib gegenüber hat er, soviel wir vernehmen, kein Wort des Tadels gehabt; dagegen den bürgerlichen Machthabern, welche das Volk hätten antreiben sollen, seine Opfergaben zu bringen, gab er einen kurzen, aber seharfen Verweis: "Warum ist das Haus Gottes verlassen ${ }^{4}$ ?" Die Wirkung erfolgte auf der Stelle. Die Leviten wurden wieder versammelt, und die rüekständigen Zehnten eingefordert ${ }^{5}$ ). So trat dieser Staatsmann mit seiner wohlthuend gebieterischen Weise da ein, wo Propheten wie Maleachi und priesterliche Reformer wie Esra gescheitert waren.

Es war eine viel schwierigere Aufgabe, die Beobachtung des Sabbats nach der nenen gesetzestreuen Weise durehzusetzen. Das Denteronomium hatte lediglich

1) Neh. 13, 10. $-{ }^{2}$ ) Neh. 13, 4f. $-{ }^{3}$ ) Neh. 13, i-9. - 4) Diese Worte tragen die Farbe der Lage. Sie sind nicht aus Nieh. 10, 39 entnommen, sondern wurdert angenscheinlich ron dem. der lie Geschichte ron dem angeblichen Bund verfasste, abgeschrieben. - 5) Neh. 13, 11. 
Ruhe von der täglichen Arbeit der Landwirtschaft gefordert; der Priestercodex forderte Enthaltung von aller irdischen Arbeit und stellte sogar Holzsammeln am Sabbat als ein Vergehen hin, das Todesstrafe verdiene $^{1}$ ). Nehemiah, ein Anhänger dieses Codex, entschloss sich, der späteren Fassung des Sabbatsgebots Geltung zu verschaffen. Er verliess sich nicht auf fremde Berichte, sondern sofort nach seiner Ankunft in Jerusalem ging er darauf aus, Beobachtungen für sich selbst zu machen ${ }^{2}$ ).

Es war ein Sabbat, und die Dörfer waren belebt von dem heiteren Frendengeschrei derer, welche die Trauben in der Kelter traten. Sie waren arglos genug, zu denken, dass diese angenehme Beschäftigung keine Verletzung des Sabbatgesetzes bedeute. Er wandte seine Augen anderswo hin und bemerkte Dorfbewohner, die ihre Esel mit Korn, Früchten und Wein beluden, um rechtzeitig zum nächsten Markttage in Jerusalem einzutreffen. Nehemiah verschwieg seine Absicht, aber als der Markttag herankam, riet er den Verkäufern, nicht wieder am Sabbattage aufzubrechen. Der Sabbathandel mit Fischen erregte ebenfalls seinen Unwillen, obgleich er die Schuld weniger auf seiten der Tyrier fand, die die Fische verkanften, als anf seiten der Juden, die sie kauften ${ }^{\mathbf{3}}$ ). Nehemiah erteilte den angesehenen Juden eine ernste Rüge, indem er sie daran erinnerte, dass Sabbatschänden in der Vergangenheit das Verderben gebracht habe, und dass noch grösseres

1) Num. 15. 32-36. - 2) Neh. 13, 15-22. - 3) Es waren gesalzene und getrocknete Fische vom Mittelmeer. 
Unglück die Folge solch ungesetzliehen Thuns sein werde. Er gab Befehl, die Stadthore den Sabbat ïber vollständig verschlossen zu halten und niemanden, der Waren herzuführte, einzulassen. Die Handelsleute sahen keinen andern Ausweg. als die vierundzwanzig Stunden ausserhalb der Mauern zuzubringen. Aber sogar das erregte den Unwillen des Gouverneurs. Die Juden, welche am Sabbat hinausgingen auf das Land, moehten sich zu einem Versuch, das Gesetz zu umgehen, veranlasst sehen. So drohte Nehemiah den Handelsleuten, er werde sie mit Gewalt aus der Umgegend der Stadt vertreiben, wenn sie nicht sämtlich des Handels sieh enthielten.

Es ist ein Bild aus dem täglichen Leben, das wir vor Augen haben, und es hilft uns den Übergang von dem nachsichtigen deuteronomisehen Codex zu dem unerbittlich strengen Gesetzbuch Esras begreifen. Wir besitzen interessante Äusserungen von Anhängern Nehemiahs in dem Teil des Buches Jesajah, den ich den Nehemianischen nennen möehte: ich habe natïrlieh die wohlbekannten Äusserungen über den Sabbat Jes. 56, 2-6; 58, 13 im Auge. Die Stellen sind nicht erhaben genug, sie wörtlich anzuführen; thatsäehlich hatte die Poesie des Sabbatgedankens lange Jahrhunderte auf einen vollgültigen Ausdruck zu warten.

Und nun kommt die Wendung in der dritten grossen Aufgabe der Reformer, der Beseitigung der Mischehen. Zwei merkwürdige Thatsachen fallen uns auf. Die erste ist Nehemiahs Milde gegen das gemeine Volk, das er nieht zwang die philistäischen oder 
ammonitischen oder moabitischen Weiber zu entlassen. Mit fast fanatischer Erregung liess er die Übertreter schwören, nicht fürder solche Ehen in ihren Familien zu dulden. Damit begnügte er $\left.\operatorname{sich}^{\mathbf{1}}\right)$. Die zweite ist seine Strenge gegen die Priester. Ein Enkel des Hohenpriesters Eljašib hatte eine Tochter Sanballats geheiratet. Ohne Zweifel ist das derselbe Manasseh, von dem, wie ich schon angedeutet, Josephus uns erzählt. Nehemiah erzählt, dass er dem Übertreter den Aufenthalt in Jerusalem unerträglich machte. Er floh Hals über Kopf. "Gedenke es ihnen und nicht mir", sagt Nehemiah, ndass ich priesterliche Würdenträger angerührt habe". "Anderseits", fährt er fort, "habe ich die Priesterschaft von allen Fremden gereinigt und jeden im Dienst der Priester und Leviten beschäftigt $\left.{ }^{2}\right)^{4}$. Daher dürfen wir annehmen, dass Manasseh Gefährten in seiner Verbannung besass. Wir haben ja schon gesehen, dass Nehemiahs Ansicht von seinem Charakter nicht die einzig zutreffende ist. In der That bringt der Gouverneur keine andere Anklage gegen ihn vor, als dass er einen geheiligten Stamm in verbrecherischer Weise entweiht habe. Manasseh mag ein guter Mann gewesen sein, sicherlich war er in gewissem Sinne ein grosser Mann. Dass er die samaritische Gemeinde reformierte, war ein Ereignis von hoher Bedeutung für die jüdische Religion.

Dürftig genng sind die Berichte über Nehemiahs zweiten Besuch, aber sie reichen aus zu zeigen, dass sein hauptsächliches Augenmerk zu dieser Zeit kirchlicher

1) Neh. 13, 23-27. - ${ }^{2}$ ) Neh. 13, 28-30 (Neue Übersetzung). 
Natur war. Vielleicht gab er sich mit der bürgerlichen Verwaltung nicht ab; diese mag in den Händen des Mannes, den er im Amte fand, geblieben sein. Seine Hanptaufgaben waren die des Esra. Es war sein grosses Verdienst, Erfolg zu haben, wo der priesterliche Schriftgelehrte gescheitert war; nicht bloss deshalb, weil er die königliche Autorität für sich hatte, sondern wegen seiner grossen persönlichen Fähigkeiten. Doch dürfen wir uns nicht herausnehmen, Esra zu unterschätzen. Wenn die überlieferte Darstellung seiner Thätigkeit nicht völlig geschichtlich treu ist, damn liegt es uns ob, die Lücken der Überlieferung durch verständige Kritik zu ergänzen. Wir müssen bedenken, dass Esra nach seiner Erziehung ein Theoretiker war, und dass er in seine praktische Laufbahn mit unvollständiger Kenntnis der Lage der Dinge eintrat. Unter diesen Umständen ist es begreiflich, dass er zuerst zu hitzig and willkürlich verfuhr. Aber es ist psychologisch wahrscheinlich, dass er, nachdem sein erster unïberlegter Anlauf gescheitert war, sich in einem angenehmeren Lichte zeigte. Das Bild des Knechts Jehovahs in einigen schönen Liedern, auf die ich zurïckkommen werde, scheint allerdings nicht im Hinblick auf Esra entworfen worden zu sein, aber es scheint das Ideal der Klasse, zu welcher Esra gehörte, zu verkörpern. Ich glaube, dass sein Leben in der Verborgenheit jener Jahre, die seinem Misserfolg im öffentlichen Leben folgten, gross gewesen ist in Gottes Augen. Ich glaube, dass er zu der Einsicht gekommen ist, wie wenig das Gesetzbuch in seiner ursprünglichen Form für die Bedürfnisse der 
Juden passte, und dass er sich mit anerkennenswerter Gründlichkeit der Abstellung einiger seiner Mängel

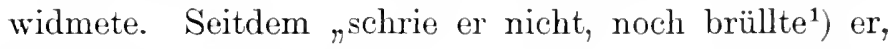
noch liess er seine Stimme hören auf den Gassen". Mit alten und neuen Freunden arbeitete er daran, die Forderungen des neu redigierten Gesetzes Jehovahs etwas nutzbarer zu gestalten, und obwohl ich nicht annehmen darf, dass er Psalmen verfasste, so kann ich mir doch vorstellen, dass er in den Gesang von Worten, wie den folgenden, von Herzen eingestimmt haben wird:

„Lass dein Angesicht auf deinen Knecht scheinen

,Und lehre mich deine Satzungen.

,Thränenströme rinnen aus meinen Augen hernieder, „Weil die Menschen dein Gesetz nicht halten

(Ps. 119, 135 f.).:

Es giebt noch einen andern Grund, weshalb Esra in Ehren gehalten werden muss. Er ruht wahrscheinlich auf festerem Grunde als die vorstehende Vermutung. In einer Urkunde, die ziemlich früh anzusetzen ist - ich meine das angebliche Reskript des Artaxerxes (Esr. 7, 12. 21) - wird er bezeichnet als der "Schreiber des Gesetzes des Gottes vom Himmel" d. h. des Gesetzes, das Esra mit sich nach Jerusalem brachte, und das das Reskript an anderer Stelle "das Gesetz deines Gottes, welches in deiner Hand ist", nennt. Ich meine, dass der Urheber des Reskripts mit diesem Titel andeuten wollte, Esra sei Verfasser oder Herausgeber des genannten Gesetzbuchs. Denn

1) Siehe die C̈bersetzung von Jes. 42. 2 (mit Anmerkung) in der Polychr. Bible. 
wenn „Schreiber" lediglich "Abschreiber" bedeutet, weleher Grund sollte dann vorliegen, Esra den Titel beizulegen? Es würde für einen Priester sicherlich keinen Zuwachs an Ehre bedeuten, Abschreiber genannt zu werden. Das Reskript kann allerdings nieht als vollgültiger Ausdruck der Ansichten des Artaxerxes betrachtet werden; aber die Wendung "Schreiber des Gesetzes des Gottes vom Himmel" (d. h. Jehovahs) besagt wahrseheinlich, was Esra bei seiner Reise nach Jerusalem für sich in Ansprueh nahm. Es wird uns erzählt, wie der Hohepriester Hilkiah zu Josiahs Zeit, als das Deuteronomische Gesetzbuch vor den Kanzler des Staates gebracht wurde, angab, was er über die Geschichte der Urkunde wusste ${ }^{1}$ ). Ebenso wurde ohne Zweifel Esra von den Vorstehern der jerusalemischen Gemeinde in dieser Hinsicht befragt, und er sagte wahrscheinlich, dass er dureh den Geist Jehovahs das Gesetz Moses vollständiger als seine Vorgänger aufgezeichnet habe ${ }^{2}$ ). Ein späterer Schriftsteller, dessen Worte Esr. 7, 6-10 erhalten sind, wusste davon nichts. Er stellt Esra lediglich hin als einen bewährten Kenner des Gesetzes Jehovahs, der sich das Vortragen der göttlichen Satzungen als Aufgabe gestellt habe.

Das Gesetzbuch Esras war ohne Zweifel ein Werk von kleinerem Umfange, als das, welches jetzt den Kritikern als Priestercodex geläufig ist. Auch können

1) Reg. I, 22, 8. - 2) Esra D 14, 44 ist natlirlich eine willkürliche Erdichtung. Für 204 lies 94 (siehe Ball Variorum apoerypha [ef. Fritzsehe, Libri apocryphi Veteris Testamenti p. 639 zu Esra D 14, 44. - S.]). 
wir nicht der Ansicht beipflichten, dass es ausschliesslich Esras Werk war. In der babylonischen Periode sowohl als in der frühpersischen scheinen verschiedene Priesterschulen sich mit Wiederzusammenstellung, Sichtung und Ergänzung der früheren Gesetze und gesetzlichen Überlieferungen beschäftigt zu haben. Der Zustand der jüdischen Religion um die Mitte des 5. Jahrh. legte es nahe, diese Arbeiten zu vorläufigem Abschluss zu bringen, und es war wahrscheinlich Esra, der die Anweisung für die Redaktion des Stoff's gab. Es war vermutlich seine Aufgabe, den litterarischen Stoff, den seine priesterlichen Kollegen vorbereitet hatten, auszuwählen, zu verarbeiten und zu ergänzen.

Es wird Thnen jetzt klar sein, in welchem Sinne ich von Esras Gesetzbuch als einem neuen gesprochen habe. Es war neu im Vergleich zum Denteronomium, gerade so wie Deuteronomium seiner Zeit (zur Zeit des Josiah) neu war im Vergleich zum Bundesbuch, welches vielleicht in die Zeit Jošafats gehört. Aber es wollte die alten mosaischen Gesetze und Satzungen in einer dem Zeitalter Esras angepassten Form darbieten, und sein Anspruch war nicht unbegründet. Denn es war den Theisten jener Tage vollkommen klar, dass Gott den Willen und die Macht habe, auserwählte Männer mit dem Geiste und der Kraft eines Mose auszustatten, gerade so wie er nach Maleachi in zukünftigen Tagen einen auserlesenen Propheten mit dem Geiste und der Kraft des Elias ausstatten wollte. Ich verstehe daher unter dem Ausdruck ,ein neues "Gesetzbuch" nicht ein Buch, das damals erst durch 
den produktiven Kopf eines Enthusiasten hervorgebracht wurde.

Um Esras Gesetzbucl zu verstehen, muss man seinen Zweck sich vor Augen halten. Dieser bestand nicht darin, ein in der Luft sehwebendes Ideal von persönlicher Frömmigkeit zu pflegen. sondern einen Damm anfzurichten gegen den Wiedereinbruch des grossen nationalen Unglücks der Vergangenheit. Die alte Religion Israels mit all ihrer anziehenden Mannigfaltigkeit von örtlichen und Familienriten hatte sich als unzureichend erwiesen. Die Gegenwart des göttlichen Königs unter seinem Volke war fortwährend unterbrochen worden. Usurpatoren hatten oft die Herrschaft an sich gerissen; wie aber konnte man in einem eroberten oder gar tributpflichtigen Lande von einer Gottesherrschaft reden? Und ferner hatte eine fortdauernde Verdunkelung des Begriff's der Theokratie durch die Einrichtung eines menschlichen Königtums bestanden. Daher die Notwendigkeit eines vollkommenen göttlichen Gesetzes, dem Priester und Laien, Reiche und Arme gleicherweise unterworfen sein sollten: eines Gesetzes, das den unermesslichen Unterschied zwischen Gott und Mensch in Betracht ziehen und keine Mühe sich sparen sollte bei Bestimmung der Punkte, durch welche ein übernatürlicher Gott notwendig zum Zorn gereizt werden musste d. h. es waren die Grenzen zwisehen heilig und unheilig, geweiht und profan zu bestimmen. Und da die ursprüngliche Termischung des Materiellen und Sittlichen noch nicht überwunden. und es bei weitem 
einfacher war, mit materieller als mit sittlicher Verletzung der göttlichen Heiligkeit zu rechnen, so ergab sich, dass der Hauptgegenstand des jüdischen Gesetzes ebenso wie des zoroastrischen in der Unterscheidung zwischen rein und unrein, sowie der Möglichkeit, verlorne kultische Reinheit wiederzuerlangen, bestand. Es waren nur die kunstgemäss (technisch) Reinen, die vor Gott zu erscheinen in der Lage waren, und der Zweck des ausgeklïgelten Opfersystems war nicht, Herzensfrieden für den Einzelnen zu erwerben, sondern die Gemeinde als solche anf dauerhafter religiöser Grundlage zu vereinigen, so dass ihr geweihter Charakter unverletzt blieb. Der Einzelne, welcher freiwillig oder unfreiwillig irgend eine Vorschrift des Gesetzes übertrat, verletzte die Heiligkeit der Gemeinde. So lange daher diese Übertretung nicht gesühnt war, bedeutete der Unreine eine Gefahr für jenen Gesamtorganismus, dessen Glied er war. Es that nichts zur, Sache, ob das Gebot sittlich oder rituell war; die göttliche Heiligkeit war verletzt worden, und Genugthuung musste gegeben werden; sei es durch kultische Mittel, sei es, dass man den missfälligen Zweig vom Mutterstamme abschnitt ${ }^{1}$ ).

Den gewichtigsten Beweis dafür, dass die Gesetzgebung der Esraschule auf das Interesse der Gesamtheit, nicht auf das des Einzelnen zugeschnitten war, liefern die Bräuche des Versöhnungstages. Der Zweck derselben war, jegliche Unreinigkeit, welche die Sühn-

1) Eine Strafe, welche wegen der thatsächlichen Abschaffung der Clanverbände den ihr Verfallenen in eine wahrhaft schreckliche Lage brachte. 
akte des verflossenen Jahres noch in der Gemeinde oder im Heiligtum belassen haben mochten, zu entfernen. Dass sie schon zur Zeit Esras geübt wurden, kann jedoch nicht nachgewiesen werden, und sie grehören zu den spät in die Levitische Gesetzgebung eingeschobenen Stïcken ${ }^{1}$ ). Eine der Einzelheiten des Rituals ist so seltsam und wirft so helles Licht auf den niedern geistigen Bildungsgrad der grossen Masse unter den Juden, dass ich bei derselben verweilen muss. Es besteht thatsächlich eine enge Verwandtschaft derselben mit Bränchen, welche nach Mr. Frazer (Verfasser von The golden Bough) noch in Teilen von Indien, Borneo und andern Ländern beobachtet werden. Die Eingebornen dieser Gegenden sind fest überzeugt, dass die Dämonen, welche Unglück und anderes Missgeschick bringen, vertrieben werden können durch lautes Geschrei, das sich gegen irgend ein opferfähiges Tier z. B. eine Ziege richtet. Wir wissen aus der Mišnah, dass ebensolches Geschrei zu demselben Zweck gegen den sogenannten Sündenbock am jährlichen Versöhnungstage ausgestossen wurde. Dieses Unglückstier wurde in die Wildnis getrieben, wobei es alle von den Juden während des Jahres begangenen Sünden mit sich nahm. Es war Brauch, dasselbe über eine gewisse unweit Jerusalem gelegene Klippe hinunterzustossen. Der Felsen ist wieder aufgefunden. Es wurde auf demselben empfangen von Azazel, einem der gefallenen Engel, für den dieser Name, übrigens

1) Sie werden einigermassen rorweggenommen durch eine sehr einfache seitens des Ezechiel eingeschar lte Caerimonie (Ez. 45, 10-20). 
von ganz junger Bildung, erfunden worden war ${ }^{1}$ ). Gewiss war es auffällig, dem Volksaberglauben ein solches Zugeständnis zu machen, aber das brachte zugleich den Vorteil, dass es der Sitte, den "Satyrn" genannten Wüstenkobolden zu opfern, Abbruch that ${ }^{2}$ ). Wir müssen ja im Auge behalten, dass die Juden nicht für sich selbst allein überkommenen Aberglauben hatten, sondern inmitten einer Bevölkerung lebten, die noch abergläubischer war als sie selbst, und dass man vom Standpunkt eines Kirchenpolitikers aus thatsächlich nicht umhin konnte, der Schwachheit menschlicher Natur einige allerdings sorgfältig abgegrenzte Zugeständnisse zu machen. Ob Esra ein so weitgehendes Zugeständnis wie das betreffs des Sündenbocks gebilligt haben würde, scheint mir zweifelhaft. Und ich denke mir, dass es in der Folgezeit viele gegeben haben muss, welche gegen die traurige Caerimonie mit dem Sündenbock lauten Widerspruch erhoben haben.

Ein anderer Grund, weshalb es von Wichtigkeit ist, den Zweck des Gesetzes festzustellen, ist der, dass Protestanten naturgemäss geneigt sind, die Gesetzesreligion vom paulinischen Standpunkt aus zu beurteilen. Nun ist freilich der Judaismus als solcher durchaus nicht ganz dem Formendienst verfallen: er hat echte Heilige unter seinen Anhängern; aber das Gesetz, über das er so weit hinausgeht, kann der kritischen

1) Vgl. s. v. "Azazel ${ }^{*}$ in Blacks Enc. Bibl. - 2) Vgl. "Satyrn ${ }^{*}$ in derselben Encyclopaedie. Azazel mag nach den Ausfihrungen des Verf. d. B. daselbst an die Stelle eines Erzkoboldes des jüdischen Volksglaubens getreten sein. 
Probe, welcher paulinische Christen es unterwerfen, nicht stand halten. Das Gesetz mag in der That eine tiefe Ehrfurcht vor Gott erregen, aber diesen Dienst kann es nur denen leisten, welche zu einer solchen Gemütsstimmung schon vorbereitet sind. Natürlich rede ich von der Wirkung des Gesetzes an sich, solange sie eben nicht durch das Studium der prophetischen Schriften und durch den Einfluss der sanften Töne des Psalters gefärbt ist. Und ich bedaure, dass durch unbewusst ungerechte Verurteilung einem der bemerkenswertesten Erzengnisse des religiösen Geistes in etwas mrecht gethan wird.

Es giebt noch einen anderen Irrtum, vor dem wir uns zu hüten haben: das ist die Annahme, dass Esras Buch lediglich ein Gesetzbuch war. Das Gesetzeselement herrschte allerdings vor, aber das Gesetzbuch wurde eingeleitet oder begleitet durch eine Geschichte von dem Ursprung des Gottesvolks nnd der göttlichen Eiurichtungen. Man wird bei Betrachtung dieser Geschichte überrascht durch den sehr schwach entwickelten, obwohl keineswegs ganz fehlenden Sinn für die Volksüberlieferung und durch das Fehlen des wahren geschichtlichen Interesses. Andererseits macht der tiefe religiöse Ernst der Verfasser auf uns Eindruck, denn ihr Gottesbegriff ist höher und reiner als der der früheren Erzähler, und ihre Verehrung für die heiligen Einrichtungen ist eine derartige. dass sie von einer derselben (dem Sabbat) behaupten, sie sei bei der Schöpfungeingesctzt worden und cineandere (die Beschneidung) sei so alt wie Abraham. Ferner tragen die Patriarchen 
nicht mehr jene Mängel an sich, welche die frühere Überlieferung ihnen belassen hatte. Sie sind Vorbilder jenes vollkommen'n Charakter's, nach welchem jedes Glied der Theokratie strebt, und ihr verdienstvolles Leben gehört zu den Kleinodien des erneuerten Israel.

Es ist wahr, man hat dabei ebensogut verloren wie gewonnen. Auf der einen Seite treten die $\mathrm{Pa}$ triarchen mit einem gewissen Schauer zu ihrem Gott in Beziehung, auf der andern besitzt der Charakter dieser heiligen Männer etwas Unbegreifliches, das einen modernen Leser anmutet, als wenn sie gar keine sittliche Entwicklung durehgemacht hätten. Aber jener Schauer ist keinesfalls Gleichgültigkeit, es ist nur der Ausdruck des beteiligten Gefühls. Ein Priester ist kein Dichter; es bedarf eines Dichters. um die verborgene Wärme der jüdischen Religion zu Esras Zeit an das Licht zu bringen. Und das Unbegreifliche, woron ich sprach, verschwindet sofort, wenn man Abraham, Isaak und Jakob als Muster oder Vorbilder des neuen Israels betrachtet. Denn das nene Israel ist von dem alten durch eine tiefe Kluft getrennt: die Kluft nationalen Untergangs, über welche die Bestrebungen Ezeehiels, des Propheten und Gesetzgebers, und seiner Nachfolger bis zur Zeit Esras herab eine Brücke geschlagen hatten. Diese Brücke bildete das neu ausgelegte Gesetz. Aber diese Brücke zu überschreiten stand nur denen frei, welche die Lehren der Tergangenheit sich zu Herzen genommen hatten. Solche Leute sind die einzig echten Israeliten. Sie erkennen an, dass 
ihre alten Ideale und ihre alten Hoflnungen falsch waren, und dass sie neue'im Gesetz finden. Die Religion hat ihre Charaktereigenschaften umgebildet; sie hat sie auch gelehrt, nicht auf Wagen und Rosse zu trauen, sondern auf die Stärke, welche dem gläubigen Gehorsam grewährt wird ${ }^{1}$ ). Der einzige Mangel, den ein rechtgläubiger Jude im Leben Abrahams finden konnte, war der, dass er kein Gesetzbuch besass, um es zu studieren. Aber Job, welcher, abgesehen von einigen leicht auszuscheidenden Einzelheiten, ein dichterischer Doppelgänger Abrahams ist, beweist durch seine grosse Unschuldsbeteuerung (Job 31), dass alle Elemente des Sittengesetzes ihm bekannt und massgebend waren im Geiste demütigen Gehorsams. Der Mangel an Poesie bei den priesterlichen Verfassern des Gesetzbuches wurde durch spätere Schriftsteller, nicht am wenigsten durch den Dichter des Job, ergänzt.

Eine Eigenschaft entbehrte Job unzweifelhaft eine Zeitlang, welche der priesterliche Verfasser äusserst scharf bei Abraham hervorhob, das ist die Demut. Demut ist das hervorstechende Merkmal des nach dem Gesetz umgebildeten jüdischen Charakters. Sie ist an und für sich eine Beziehung auf Gott, und sie ist die Wurzel, aus welcher nicht allein Israels Vorrechte hervorgehen, sondern alle seine Gerechtigkeit. Daher die bemerkenswerte Erscheinung, dass Gerechtigkeit und Demut in der nachexilischen Periode zusammengestellt werden. ..Siehe, dein König kommt zu dir.

1) Vgl. den Ausdruck: „Alles hat Hilfe nötig (vom Himmel)“ (Midraš zu Ps. 20). 
Er ist gerecht und siegreich, demütig ist er und reitet auf einem Esel" (Zach. 9, 9). Und wiederum wird in einem Psalm von den Kriegen des Messias gesagt, sie würden unternommen „für die Wahrheit, Gerechtigkeit und Demut" (Ps. 45, 4 [5]). Das eine grosse Vorrecht, das in Zukunft dem "Demütigen" gewährleistet wurde, war die Gegenwart Gottes unter seinem Volk oder mit andern Worten, die offensichtliche Annahme der Königswürde von seiten Jehovahs. Als der Priestercodex ursprünglich entworfen wurde, lebte man der Hoffnung, dass dies "grosse himmlische Ereignis" bald eintreten werde. Das ist der Grund, warum man im Leviticus so oft die Mahnung vernimmt: "Ihr sollt heilig sein, denn ich bin heilig" (Lev. 11, 44 u.s. w.). Das ist auch der Schlüssel zu all jenen ins Einzelne gehenden Vorschriften, welche den meisten unter uns lästig erscheinen, aber denen, welche "das Joch des Himmelreichs ${ }^{\boldsymbol{1}}$ ) auf sich genommen hatten, Freude brachten. Die allzufrüh verwischte Heiligkeit des alten Israel wurzelte in einer vorhergehenden That Jehovahs (Auszug aus Ägypten), in Zukunft sollte der Erlösungsakt von seiten Gottes durch eine gründliche Heiligung seines Volkes eingeleitet werden. Diese zu sichern waren Esra und seine Genossen bemüht, und wenn man sie von ihrem Standpunkt aus beurteilt, so thaten sie allerdings ibre Pflicht in der seibstverleugnendsten und ehrenwertesten Weise.

Die Masse von alten Elementen in der priester-

1) Der Ausdruck erklärt die Worte Jesu: „Nehmet auf euch mein Joch .... deun mein Joeh ist leieht-.

Cheyne, Religiöses Leben der Juden. 
lichen Gesetzgebung hindert uns aber, wie gesagt, dieselbe im buchstäblichen Sinne des Wortes ein neues, d. h. ein durchaus ursprüngliches Gesetzbuch zu nennen. Sie stellt die Gestalt dar, welche die ältere Gesetzgebung unter gründlich veränderten Umständen annahm, und sie unterscheidet sich in vieler Hinsicht deshalb so sehr von der älteren, weil Israel eine grosse äussere Umwälzung durchgemacht hatte, und diese allmählich sich auswirkte in einer ebenfalls bedeutenden Unwandlung am inwendigen Menschen. In jener andern Umwälzung gab es neben Esra und den Gesetzesschreibern viele andere treibende Factoren. Priester, Propheten, Psalmisten und Weise, neben den weniger hervortretenden Gläubigen des täglichen Lebens, alle hatten ihren Anteil an der Ausgestaltung der Umwandlung Israels. Auf einige derselben darf ich des Lesers Aufmerksamkeit lenken, aber keiner derselben ist solch hohen Ansehens würdig wie Esra der Schriftgelehrte, weil ohne sein Gesetzbuch ihrem Vorgehen die grundlegenden Voraussetzungen gefehlt haben würden. Die jüdische wie die zoroastrische Gemeinde haben jahrhundertelange Verfolgung durchgemacht; sie waren dazu im stande, hauptsächlich weil sie ein geschriebenes religiöses Buch besassen. Die Verfasser jenes Gesetzes, mag ihr Name bekannt sein oder nicht, sind grössere Männer denn Staatengründer. 


\section{Dritte Vorlesung.}

\section{Religiöse Ideale der Juden; Hindernisse für ihre volle Entfaltung.}

Die jüdische Volksgemeinde in Palästina war jetzt wieder errichtet. Mochte kommen, was da wollte, sie hatte ein Band, stärker als der Tod, das sie mit dem Gott Himmels und der Erde verband. Freilich durfte sie für die nächste Zukunft nicht viele Erfolge erwarten. Esra und Nehemiah haben wohl gewusst, dass eine Zeit des Aufatmens zwischen einer Reihe von Stürmen das einzige war, worauf man hoffen durfte $^{1}$ ). Aber sie wussten ebenfalls, dass sie den besten Trost für ihr heimgesuchtes Volk beschafitt hatten, indem sie innerhalb desselben ein Gefühl für das wahre israelitische Ideal erregten. Dies Bild war nicht dasselbe, wie es David und Salomo vorgeschwebt hatte. Es war nicht in erster Linie äusserliches Wohlbefinden, sondern es bestand einfach darin, als Gemeinde so zu sein und zu handeln, wie es einem gerechten Gott wohlgefiele. Ein Mann voll Zartgefühls,

1) Das war ein unglückliches Ergebnis der Politik des Cyrus, der so viel wio mŏglich bestrebt war die Eigenart der unterworfenen Völker zu achten. Er meinte es gut, aber er sah nicht, dass diese Eigenart sich in einer Reihe von Aufständen, welche seine Nachfolger nur mit Iühe dämpfen konnten, Luft marhen würde. Recht oft brachen diese Aufstände in der Nachbarschaft Judäas aus, und jenes kleine nnd arme Land hatte infolge dessen viel Ungemach zu erdulden. 
Eifers und Begeisterung stellte seine Feder in den Dienst dieses Ideals. Er schilderte einige von seinen schönsten Erscheinungen in einem Kranz von Liedern, welche irgend ein gleichgestimmter Herausgeber an verschiedenen Stellen in die erweiterte Wiederherstellungsweissagung (d. h. Jes. 40-55) einfügte. Diejenigen, welche die geheiligten Bestrebungen einiger der besten Juden in dem durch Esra eingeleiteten Zeitalter verstehen wollen, müssen diese schönen Verse wieder und wieder lesen.

Wir beginnen mit einem Liede, das am bestimmtesten in seinen Wendungen ist und am augenscheinlichsten durch gleichzeitige geschichtliche Thatsachen veranlasst ist. Ich will den mittleren Teil hersetzen ${ }^{1}$ ). Mögen diese Worte ehrfurchtsvolle und aufmerksame Leser finden:

„Er ging auf wie ein Reis

„Er hatte keine Gestalt noch Majestät

"Verachtet (war er) und vergessen von den Menschen,

„Ja gleich einem, vor dem man das Antlitz verbarg, -

"Aber unsere Krankheit (allein) trug er,

r. Während wir ihn für geschlagen hielten,
Und wie ein Spross aus der Wurzel in trockenem Grunde, Und keine Schönheit, dass wir sollten Gefallen an ihm finden".

Ein Mann der(vielen) Schmerzen und mit Krankheit wohl vertraut;

Verachtet, und wir achteten ihn für nichts".

Und unsere Schmerzen, - er ertrug sie,

Gezüchtigt von Gott und niedergeschmettert".

1) Jes. 53, 2-9. Diese und die folgenden Übersetznngen sind fast ausschliesslich der Polyehrome Bible entnommen und beruhen auf einem Text, der in einigen Pankten von dem landläufigen abweicht. 
nAber er (allein) wurde erniedrigt wegen unserer $\mathrm{Ab}$ trünnigkeit,

„Eine Züchtigung, alles für unsern Frieden, war auf ihm,

"Wir alle waren wie Schafe in

die Irre gegangen,

„Während Jehovah auf ihn warf

„Er wurde mit Härte behandelt,

aber er ergab sich drein

"Wie ein Lamm, das zum Wür-

ger geführt wird,

„Durch ein dumpfes Schicksal ward er hinweggenommen, "Dass er gefällt ist ans dem

Lande der Lebendigen hinweg,

„Und sein Grab wurde bestimmt

bei den Abtrünnigen

"Obgleich er keine Ungerech.

tigkeit gethan hatte,
(Er allein wurde) zermalmt wegen unserer Sünden;

Und uns kam Heilung aus seinen Striemen".

Wir hatten uns jeder auf seinen eigenen Weg gewandt,

Die Schuld unser aller".

Und that seinen Mund nicht auf,

Und wie ein Schaf, das verstummt vor seinem Scherer".

Und sein Geschick, wer gedachte daran, -

(Dass) für meines Volkes Abfall er zu Tode getroffen ist?"

Und bei den Gottlosen sein Grabmal,

Noch Trug in seinem Munde erfunden ist."

Wie natürlich war die Frage des äthiopischen Kämmerers in der Apostelgeschichte: "Von wem sagt doch der Prophet dies? von sich selber oder von jemand anders?" (Act. 8, 34). Denn das ist augenscheinlich kein reines Phantasiebild, sondern eine tiefempfundene Betrachtung über gewisse betrübende Thatsachen, die dem Dichter und seinen Lesern wohl bekannt waren. Wenn man Abfassung des Liedes am Ende des Exils annehmen will, dann ist man geneigt, es aufzufassen als Beschreibung der Verfolgung und des Todes des Propheten Jeremiah, der nach glaubwürdiger Überliefe- 
rung von seinen ungläubigen Landsleuten zu Tode gebracht worden sein soll. Doch lässt sich mehr vorbringen für das Zeitalter Esras als Abfassungsdatum, und in diesem Falle werden die vom Dichter angedeuteten Thatsachen wahrscheinlich ${ }^{1}$ ) mit den in einer' späteren Weissagung des Buches Jesajah (Jes. 57, 1) in dem folgenden Zusammenhang erwähnten Martyrien zusammenhängen:

„Der Gerechte kommt um, und niemand nimmt sich's zu Herzen; ,Fromme Leute werden weggerafft, aber niemand achtet darauf, „Dass für die Verkehrtheit (der Zeit) der Gerechte weggenom. men wird."

Man darf meines Erachtens nicht überrascht sein, Klagen wie die angeführten in den Jahren vor Esras Ankunft zu vernehmen. Der religiöse Fortschritt unter den Juden war nicht umsonst erkauft. Die meisten Juden in der ersten Hälfte des fünften Jahrhunderts waren Kinder der von Nebukadnezar Zurückgelassenen und keineswegs überzengte Anhänger des Deuteronomischen Gesetzes. Niemand, weder reich noch arm, hätte eine sehr scharfe Gerichtsprobe bestehen können. Damals wie später waren die Reichen besonders geneigt zu Sünden der Gewaltthätigkeit und Unmenschlichkeit, während die Armen ebensosehr altem und neuem Aberglauben fröhnten. Sicherlich gab es jedoch Ausnahmen. Maleachi nennt solche Leute „Gottesfürchtige" und dentet an, dass sie zu

1) Doch wiril miglicherweise das von der Überlieferung berichtete Martyrium des Jeremiah in einer sehr spät nachexilisehen Weissagung als grōsste Stinde der Gemeinde erwāhnt, In der Stelle Zach. 12, $10 \mathrm{kann}$ : .Sie werden sehen (mit verlangendem Bedanern) auf mich, den sie durchbohrten" nicht richtig sein. Es ist nicht unmöglich,

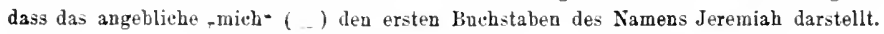


der ärmeren Klasse gehörten. Diese armen, aber frommen Leute scheinen von ihren Nachbarn gering geachtet worden zu sein, indem dieselben deren ungünstige und sogar traurige Lage einem Gottesgerichte zuschrieben, während die gewaltthätigen Reichen, um sich der unruhigen Eiferer zu entledigen, zuweilen sie ohne Ursache vor dem Richter anklagten, ja gar ihre Verurteilung zum Tode durchsetzten. Aber der grosse Denker und Dichter des Esrazeitalters, den ich erwähnt habe, sah beim Rückblick auf diese traurigen Ereignisse sie im hellen Lichte eines göttlichen Plans. Er verschmolz die verschiedenen ungenannten Blutzeugen und Bekenner zu einer einzigen Gestalt ${ }^{1}$ ) und setzte diese ideale Persönlichkeit mit dem wahren Volke Israel gleich. Dabei mag er sehr wohl an den Propheten Jeremiah gedacht haben, der sicherlich sich selbst und seine Schüler im Verein als einzige Vertreter des wahren Israel betrachtete.

Beim Rückblick darauf erkannte, wie gesagt, der Dichter den vollen Wert eines solchen Lebens und ahnte den Wohlgeruch seines Endes in den Augen Gottes. Dieser zweite Jeremiah konnte dem ersten an religiöser Einsicht nicht nachstehen und muss erkannt haben, dass diese geduldig ertragenen Leiden zur Bekehrung und endlichen Verherrlichung seines Volkes mehr beitragen würden, als irgend ein gesetzliches

1) Ein Volk den Knecht dieses oder jenes Gottes zu nennen, ist ein durchaus semitischer Gedanke. Robertson Smith hat arabische Parallelen beigebracht, und Stellen wie Deut. $4,19: 6,13 ; 10,12.20$ belegen denselben Sprachgebrauch unter den Israeliten, obwohl er augenscheinlich nicht so landlänfig war, wie die Anwendung der Ausdrücke auf einzelne Personen. 
Opfer. In einem bekehrten und wiedergeborenen Israel musste alles, was zu dem Edelsten in ihm gehörte, leben, und so musste er fortfahren, die allweisen Pläne des einen wahren Gottes ins Werk zu setzen, das fühlte er.

Dieses wundervolle Gedicht, welches das Allerheiligste im Tempel des Alten Testaments bildet, steht an letzter Stelle in dem Liederkranz über den Knecht Jehovahs. Die drei vorangehenden Gedichte schildern die Erlebnisse dieser grossen Persönlichkeit vor ihrem Martyrium oder vielmehr die Erlebnisse derjenigen Märtyrer und Bekenner, die die besondere Aufgabe hatten, zu lehren und zu predigen. Wer nur immer in irgend einer Weise für Jehovah Zengnis ablegte, gehörte zum wahren Israel, dem Knecht Jehovahs; aber besonders passend konnte man unter der letzten Bezeichnung die befassen, welche mit dem Amte der Verkündigung betraut waren. In Jes. 42, 1-4;49, 1-6 und 50, 4-9 wird der Knecht Jehovahs dargestellt als ernster und sich aufopfernder religiöser Lehrer, den zuweilen ein Erfolg belohnt, aber dem zu andern Zeiten Gleichgültigkeit oder Verfolgung begegnet. Sein Werk für Israel besteht im „Zurückbringen" des Volkes in Jehovahs Land, und das Mittel, mit dessen Hilfe er dieses Ziel zu erreichen sucht, ist eine geschickt sich anpassende Beredsamkeit, scharf wie ein Schwert, wenn eindringliche Mahnung an die Gewissen nötig ist $(49,1)$, aber sanft wie Milch, wenn die Müden und Trostlosen wieder aufgerichtet werden müssen $(50,4$ vgl. 42,3$)$. Sie befasst in sich zu- 
nächst eine lockende Auseinandersetzung der Hauptforderungen des Gesetzes und dann für die Juden der Diaspora eine Schilderung der mannigfachen Segnungen, deren die Bewohner der heiligen Stadt teilhaftig seien. Das war in der That ein grosser und ehrenvoller Auftrag, und wahrscheinlich würde er den Ehrgeiz des Schriftgelehrten Esra befriedigt haben ${ }^{\mathbf{1}}$ ). Aber er befriedigte den Verfasser dieser Lieder nicht, der den Geist der mit weiterem Blick begabten Lehrer in sich aufgenommen hatte. So ehrenvoll anch der Beruf sein mochte, Jehovahs Volk wieder aufzurichten, er war nicht der ehrenvollste, und so stellt er den Knecht Jehovahs dar, wie er sich bei dem geringen Erfolg unter dem Volke Israel mit dem Gedanken an eine noch grössere Aufgabe tröstet.

„Und nun, (so) spricht Jehovah, Er, der mich vom Mutterleibe an gebildet hat, ein Krnecht für ihn zu sein,

„Damitich Jakob zu ihm zurück- Und Israel versammeltwürde - : brächte,

„Es ist eine zu geringe Sache, Und die Geretteten aus Israel dass du solltest die Stämme von Jakob wiederaufrichten "So setze ich dich zum Licht Damit meine Erlösung reichen der Völker, möge bis an die Enden der Erde (Jes. 49,5 f.)."

Es ist die Botschaft an die andern Völker, die den Gegenstand des sehr schönen Liedes bildet,

1) Man beachte, dass nicht einmal die einleitende Erzählung des esranischen Gesetzbuches irgend eine Hindeutung auf die weltumspannende Mission der Nachkommen Abrahams enthalt. 
welches die Reihe der Lieder über den Knecht eröffnet. Diesmal spricht nicht der Knecht, sondern Jehovah selbst: "Siehe, mein Knecht, den ich Mein Auserwählter, an dem erhalte; meine Seele Wohlgefallen hat; "Ich habe meinen Geist auf Er wird das Gesetz den Völkern ihn gelegt, zutragen".

„Er wird nicht laut schreien noch brüllen (wie ein Löwe) „Ein geknicktes Rohr wird er nicht zerbrechen,

Noch seine Stimme vernehmen lassen auf der Strasse.

Und einen glimmenden Docht wird er nicht anslöschen".

"Treulich wird er mit dem Gesetz sich aufmachen;

Er wird nicht lau werden noch zagen,

„Bis er das Gesetz über die

Und auf seine Lehre warten die Erde verbreitet hat, fernen Länder (Jes. 42, 1-4)."

Kann es eine schönere Schilderung des echten Missionars geben? Er darf nicht das Geringste von den berechtigten Forderungen der Wahrheit, welche für ihn keine blosse Anschaumg. sondern ein Gesetz bilden, nachlassen; er muss im Gegenteil den Hauptnachdruck legen auf die Fähigkeit jenes Gesetzes, die tiefsten Bedürfnisse der menschlichen Natur zu befriedigen, indem es Stärke bringt dem ,zerstossenen Rohr" und Licht dem "glimmenden Docht". Überredung, nicht Gewalt, muss das Mittel sein: wie andersartig ist doch die mit einiger Übertreibung Esra zugeschriebene Art des Vorgehens:

Und wer ist denn dieses Urbild eines Predigers und Missionars? Ist es eine geschichtliche Einzelperson, die der Erwähnung im Heiligenkalender der Juden verlustig gegangen ist? Nein. In den ersten drei 
Liedern ist der Knecht noch eine ideale Verschmelzung vieler Einzelner, und die Personen, welche hier zu einem organischen Ganzen gleichsam verbunden werden, sind die edlen Lehrer und Prediger der jüdischen Religion zu und nach der Zeit Esras. Diese setzt der Dichter augenscheinlich als zahlreiche Schar voraus, denn um seine Schilderung zu verwirklichen, mïssen einige auf ihrer apostolischen Mission nach Babylonien gehen, andre nach Ägypten und wieder andre nach den Küstenländern des Mittelmeeres. Das kann keinesfalls wunder nehmen. Das prophetische und missionierende Streben der Juden wird wiederholt in den späteren Schriften uns vor Augen gestellt (siehe Vorlesung VI) und muss in einigen hochbegabten hellen Köpfen seinen Ursprung genommen haben. Ich kann mir kaum denken, dass das Buch Jona uns den rechten Ausgangspunkt bietet. Die Vorstellung von dem Missionarpropheten Jona, der auch ein Bild Israels ist, wurde sicherlich hervorgerufen durch irgend ein Werk, in welchem dieselbe Idee ausdrücklicher dargestellt war.

Aber ist das wirklich die Vorstellung der jetzt in Rede stehenden Lieder? Gewiss. Diese ersten Lehrer des Gesetzes, in der Heimat so gut wie draussen -wer kann das anders sein als die Apostel oder Boten einer grossen centralen Körperschaft: der durch Esra gebildeten jüdischen Gemeinschaft? Es mögen besonders die Lehrer sein, welche sagen: "Ich habe gearbeitet (wie es scheint) für umsonst, aber mein Lohn ist bei Gott"; und doch ist es die Gesamtheit des gläu- 
bigen Israels, welche laut Jes. 52, 13-15 an dem verheissenen Lohn Anteil haben wird. Ohne die Unterstützung der Gemeinde, was würden die Lehrer ausrichten können? „Die ganze Gemeinde“, wie der priesterliche Erzähler sagt, ,.ist heilig, und Jehovah ist unter ihnen" (Num. 16, 3), und es war das Bestreben Zions, dass alle ihre Söhne „Schüler Jehovahs" sein möchten (Jes. 54, 13), und dass das ganze Volk Jehovahs aus Propheten bestehen möchte (Num. 11, 29). Einige mochten berufen sein zu einem Leben missionierender Thätigkeit, und andere mochten einfach für die Wahrheit Zeugnis ablegen, indem sie „Gerechtigkeit thaten, Barmherzigkeit liebten und demütig mit ihrem Gott wandelten " (Mi. 6, 8). Beiderlei Weisen der Thätigkeit waren gleich passend und notwendig, wenn jener erhabene Ausspruch: .. Ich will dich bilden und dich machen zu einem Bunde für das Volk ${ }^{1}$ ), einem Licht der Völker" (Jes. 42, 6) erfüllt werden sollte.

Die Einfügung dieser Lieder war die zweite Erweiterung, welche die ursprüngliche Wiederherstellungsweissagung erfuhr. Es ist klar, dass diese Einfügung den Einfluss der Weissagung bedeutend verstärkte. Denn als man daran dachte, diesem Werke in seiner erweiterten Form einen frischen Anhang beizufügen, da führte der Verfasser an drei Stellen den Gottesknecht im Monolog ein $\left.{ }^{2}\right)$. Hier jedoch ist

•) Ein Bund fur da; Volk, weil der hnecht Jehorahs, der so grtindlich seinen Willen kennt und im stande ist, ihn auszuführen, gleich einer Verkōrperung seiner Verheissung oder seines Vertrages (berith) ist. Vgl. Kor. B 3, 2: "thr seid unser Brief". - 2) Jes. 61, 1-3; 62, 1. 6 f. Siehe Polychrome Bible. 
der Knecht augenscheinlich gedacht als Personifikation der Prophetengenossenschaft, zu welcher natürlich auch der Verfasser selbst gehört. Die Weissagung setzt ein mit jenen begeisternden Worten, welche so schön die prophetischen Ideale der Zeit zum Ausdruck bringen:

„Der Geist des Herrn Jehovah ist auf mir, weil Jehovah „mieh gesalbt hat und mieh gesandt, den Betrübten frohe Bot„schaft zu bringen, die gebroehenen Herzens sind, zu verbinden, „den Gefangenen Freiheit auszurufen und die Augen der Blinden „zu öffneu, das Jahr der Gnade Jehovahs anszurnfen und den "Tag der Rache unseres Gottes, alle Leidtragenden zu trösten, „ihnen statt der Asehe einen Kranz zu geben, Frendenöl statt „des Trauergewandes, einen Lobgesang für einen matten Geist (Jes. 61, 1-3)."

Ein Psalmist wurde ebenfalls zum Enthusiasmus entflammt durch die Lieder über den Knecht Jevovahs. Er lebte in einem jener dunklen Zeitabschnitte, welche der Verwaltung des Nehemiah nachfolgten, und welche ihren Eindruck in so vielen Psalmen des ersten Buches des Psalters hinterlassen haben. Er ist der Verfasser des ersten Teiles von Psalm 22, dem wie es scheint von andrer Hand ein Schluss beigefügt worden ist. Auf die formell dichterische nnd inhaltliche Schönheit dieses schönen Bruchstücks will ich nicht eingehen. Es mag genügen zu sagen, dass sie nie hätten geschrieben werden können ohne jene Quelle der Poesie und Religiosität: das Buch Deuterojesajah in seiner erweiterten Form, und dass unter den inhaltlichen Schönheiten am meisten in die Augen fällt die Energie, mit welcher der Verfasser die Gemeinschaft aller 
wahren Israeliten zum Ausdruck bringt. Der Knecht Jehovahs, wie er wenigstens den Ausdruck auffasst, ist gewiss nicht eine Prophetengilde oder -gesellschaft, sondern die ganze Gemeinde gläubiger Juden in Judäa. Und daher stammt ein bemerkenswerter Unterschied zwischen diesem Psalmbruchstück und Jes. 53. Nämlich während nach dem letzten Liede der Knecht Jehovahs leidet mit vollem Bewusstsein über Zweck und Ausgang seiner Anfechtungen, scheint nach dem ersteren Gott seinen Knecht dem Tode überliefert zu haben; dessenungeachtet aber weigert sich dieser, seines Gottes zu vergessen. Kurz, Psalm 22 führt uns eine ganz neue Gestalt des jüdischen religiösen Gedankens vor Augen. Vor dem Exil hatten die Menschen ihren Gott verlassen, wenn er sich unfähig oder abgeneigt zeigte, sie zu beschützen. Aber die Gemeinde gläubiger Israeliten. die Esra gegründet hatte, war willens, ihrem Gott und Vater auch in der Finsternis zu vertrauen.

Ich gehe jetzt zu einer andern Form des israelitischen Ideals über, welche in der Person des Messias gipfelt. Der Ursprung der jüdischen Messiashoffiung ist an der Hand der Überlieferung nicht festzustellen. Die ersten leuchtenden Spuren derselben finden sich Jes. 9, 2-7 und 11, 1-8. Diese beiden Stellen sind wahrscheinlich nachexilisch und zwar nicht einmal frühen Datums. Es scheint, dass die Vorstellung nur allmählich die religiösen Führer erfasste. Ezechiel hegte sie eine Zeitlang (siehe Ez. 17, 22-24), gab sie aber thatsächlich wieder auf. Denn obwohl er äusserlich 
die Gestalt eines zweiten David in sein späteres eschatologisches Gemälde ${ }^{1}$ ) aufnimmt, so entäussert er doch diesen David von allem, was in alter Zeit das Leben eines Königs wünschenswert machte. Er gestattet ihm keine Freiheit der Bewegung und verurteilt ihn thatsächlich dazu, der Nährvater der Kirche zu sein, mit der Aufgabe, die äusseren Bedürfnisse des Tempelrituals zu beschaffen. König will er ihn nicht nennen. Der zweite David darf nur Häuptling oder Fürst sein. Ich vermute jedoch, dass Ezechiel in den Augen vieler seiner Leser zu weit ging. Die volkstümliche messianische Hoffnung konnte durch einen einzelnen bedeutenden Lehrer nicht ausgelöscht werden. Es bestand ein tiefgewurzelter Glaube, dass ein Tag bevorstehe, für den die Lose der Unterdrücker und der Unterdrückten aufbewahrt blieben. Und wie sicher es auch immer sein mochte, dass Jehovah der Goël - der Erlöser Israels - sei, so schien doch ein König, der sowohl regierte als herrschte, den meisten Juden unerlässlich als Krönung des Gebäudes. Es gab nur wenige Gesinnungsgenossen Esras, die sich zu dem Gedanken einer Volksgemeinde aufzuschwingen vermochten, eines Volkes, das da gänzlich aufginge in Religion, dessen Speise und Trank es wäre, Jehovahs Willen zu thun. Und so finden wir die Werke Jesajahs und Jeremiahs infolge der Arbeit von Herausgebern, die nicht lediglich litterarische Specialisten waren, aber wohl vertraut mit dem Volk und seinen geistlichen Bedürfnissen, mit dem durchsetzt, was man in verschie-

1) Ezech. $3 t, 23$ f.; $37,24 f$. 
denem Sinne des Wortes messianische Weissagungen nennen kann.

Eine von diesen übte eine sehr bemerkenswerte Wirkung aus. Wir besitzen sie in zwei Gestaltungen. Keine von ihnen ist ganz richtig überliefert. Aber wenn wir die besten Lesarten aus jeder entnehmen, dann erhalten wir diejenige Gestalt der Prophetie, welche ich, obwohl ich mir der dagegen möglichen Einwürfe wohl bewusst bin, wenn auch nicht Jeremiah selbst, so doch einem Mitgliede der Schule jenes Propheten zuzuschreiben geneigt bin:

„Siehe der Tag kommt, spricht Jehovah, da ich David einen „Spross rechter Art erweeken will; er wird herrsehen als ein „König und weise handeln und Recht und Gerechtigkeit im „Lande aufrichten. $\mathrm{Zu}$ seinen Tagen wird Juda erlöst sein, "und Jerusalem sieher wohnen, und das ist der Name, der ihr „gegeben werden wird: Jehovah ist unsere Gerechtigkeit ${ }^{1}$ )

$$
\text { (Jer. 23, 5 f.; 33, 14-16)." }
$$

Mit Recht bezeichnete ein Herausgeber des Jeremiah diesen Ausspruch als ,jenes gute Wort, das Jehovah geredet hat" (Jer. 33, 14). Es mag das erste geschriebene derartige Wort gewesen sein, und sicher hat es an Wirkung gewonnen, indem es Jeremiah zugeschrieben wurde. Glaubte der prophetische Schriftsteller in Wirklichkeit seine Hoffnungen zum Besseren oder Schlimmeren an die Davidische Familie anknüpfen zu sollen oder gebrauchten sowohl er als Ezechiel "David" als bildlichen Ausdruck für einen idealen Herrscher? Die Frage ist schon aufgeworfen im Zu-

1) Vgl. den Namen Jerusalems an Schluss des Ezerhielbuchs (Ez. 48, 35). 
sammenhang mit einer Episode im Leben Nehemialıs. Ich bin geneigt, anzunehmen, dass der Prophet sich um die Antwort nicht bemüht haben würde. Thatsächlich konnte der Erfolg allein lehren, wer der auserwählte Messias war. Und als es nun Jehovahs Wille zu sein schien, seinen "wahrhaftigen Eid gegen David" (Ps. 132, 11) nicht in der Person eines auserlesenen Israeliten zu erfüllen, da muss eine Zeitlang ein tiefes Schweigen auf die Propheten des Messias gefallen sein. Der Verfasser der Lieder vom Knecht Jehovahs nimmt auf keinen messianischen König Bezug, thatsächlich geht er so weit, Ausdrücke, die vorher allgemein auf einen messianischen Eroberer angewendet worden waren, in einem neuen übertragenen Sinn zu verwenden. Er sagt, dass der Knecht Jehovahs, das wahre oder geistliche Israel, einen ihm zugewiesenen Anteil bei den Grossen haben wird und Beute teilen wird mit den Starken (Jes. 53. 12); und in demselben Sinne lässt der Verfasser des ersten Anhangs an die Wiederherstellungsweissagung Jehovah zu dem Volk in Zion sagen:

„Ieh will einen ewigen Bund mit euch maehen, "Die sichere Verheissung der Gnade Davids."

Er fügt hinzu, dass, wie in der vergangenen Zeit auf den Ruf Davids, so jetzt auf den Ruf Israels die Völker herzuströmen werden, um sich in das israelitische Reich aufnehmen zu lassen (Jes. 55, 3-5). Mit andern Worten, die Idee eines persönlichen messianischen Königtums hat für diese religiösen Denker 
ihre Bedeutung verloren, jeder Israelit ist ein Fürst, and die Gesamtgemeinde ist Jehovahs Gesalbter.

Die Gedankengänge waren jedoch zn dieser Zeit veränderlich, und so dürfen wir nicht überrascht sein, wenn wir die Funken der messianischen Hoffnung neu aufflammen sehen. Von Jeremiah glaubte man fest, er sei ihr Träger gewesen, und der nachträgliche Einfluss dieses Propheten war gross. Wir können nicht umhin, gerade diesem Zeitpunkt einige der jetzt in den Büchern Jesajahs und Michas sich findenden messianischen Stellen zuzuweisen. Kein Geschichtsschreiber der Erscheinungen der altjüdischen Religion darf diese übersehen; einige von diesen wenigstens halten wir - - und sie sind es wert - fest in Gedächtnis und Herz. Wir dürfen unsere Hoffnungen nicht an ihren buchstäblichen Sinn heften, aber ihr vieldeutiger Klang ermutigt zu einer höheren und weitergehenden Anwendung.

Die prophetischen Lieder Jes. 9, 2-7 und 11, 1-8 finden wir am Schluss zweier Sammlungen von Weissagungen des Jesajah, in welchen auf ein schweres Gericht ïber Jerusalem Bezug genommen wird.

Um diese etwas anstössigen Stellen für den nachexilischen Gebrauch verwendbar zu machen, hängte ein Heransgeber zwei neue prophetische Stellen daran. im Sinne der vielgelesenen tröstlichen Weissagungen des Jeremiah und des Deuterojesajah. Man scheint das Gefühl gehegt zu haben, alle alten Weissagungen bedürften einer solchen Anpassung. Der litterarische Wert der Einschübe ist sehr verschieden, aber die 
Weissagung von dem "König der vier Namen“" ist ein Werk von nicht geringer Bedeutung. Ich will mich bemühen, sie darzulegen.

Es ist eine Trostprophetie, an solche gerichtet, die des Trostes sehr bedürftig waren. Propheten des alten Schlages straften lieber, als dass sie trösteten; ihr Geist findet seinen Ausdruck in den IVorten des Amos: "Kann eine Trompete geblasen werden in der Stadt, und die Leute erschrecken nicht" (Am. 3, 6). Aber unser Prophet gehört seinerseits zu der Schule derer, deren wohlthuende Aufgabe so schön dargestellt wird in den Worten Jes. 61: "Er hat mich gesandt zu verbinden, die zerbrochenen Herzens sind", und welche die Friedensschalmei der Trompete vorziehen. Unser Prophet ist so zart und anziehend wie der Engel des Herrn in jenen köstlichen Erzählungen, die den Anfang des dritten Evangeliums bilden. Natürlich ist er sich wohl bewusst, dass Israel gesündigt hat, aber er weiss nicht minder, dass der Zuchtmeister die Grenzen seines Auftrags überschritten hat. So geht er in einer Nacht, als weder Mond noch Sterne scheinen, fort. Er ahnt weit mehr, als dass er sieht, wie früh aufgebrochene Reisende auf den dunklen Bergen umherstolpern und ängstlich nach den ersten Streifen der Dämmerung ausschauen. Plötzlich ändert sich die Scene. Viel schneller als die Chormusik in Händels "Messias" sich ändert, verschwindet die Dunkelheit. Die Somne geht auf am Horizont; ndas Volk, das im 
Finstern wandelte, hat ein grosses Licht gesehen". Es ist ein Schauspiel, wie man es in Palästina an jedem Sommermorgen sehen kann. Aber diesmal weist der Seher zuweilen mahnend darauf hin, dass eine gewissermassen sakramentale Bedeutung damit verbunden ist. Es ist ein Unterpfand für die langersehnte Erlösung, eine Weissagung ohne Worte vom Ewigen. Fortan will er warten in der Geduld der Hoffnung, denn die Erfüllung "wird sicherlich kommen, sie wird nicht säumen". Er kann jetzt die düstern Schatten im letzten Jahrhundert der Perserherrschaft beinahe mit Freuden begrüssen, denn wie in alter Zeit ist Mitternacht der Zeitpunkt, wo der göttliche Erlöser erscheinen wird. Die Erlösung selbst wird Jehovahs Werk sein, aber die Arbeit, welche auf die Erlösung folgt, wird dem Messias gehören. Der Prophet, ich möchte sagen: der Dichter, erinnert sich der alten Weissagung ron Immanuel, den er für den Messias ${ }^{1}$ ) nimmt, und aus der Prüfung der ganzen Sammlung ron Weissagungen, wozu er einen Anhang beschaffen will, schliesst er, dass, wenn der Unterdrücker (d. h. die Perserherrschaft) niedergeworfen sein wird, dann der Messias das Alter haben wird, die Last der Regierung auf die eigene Schulter zu nehmen.

„,Denn ein Kind ist uns geboren, ein Sohn ist uns gegeben,

,Und Herrschaft ist auf seine Schulter gelegt;

, Sein Name ist Wunderbar an Rat,

,Mächtiges güttliches Wesen, Vater der Ehre²), Friedensfürst.

1) ¿̈ber die wahrseheinliehe Bedeutung von Immanuel rgl. die Polychrome Bible ("nglisch-hebraische Ausgabe). - 2) D. h. ruhmroller Vater der israelitischen Volksfamilie. 
„Die Herrschaft nimmt zu, und der Friede nimmt kein Ende, „Auf dem Throne Davids und durch sein ganzes Reich hindurch, „Es aufzurichten und zu stützen durch Recht und Gerechtigkeit „Von num an bis in Ewigkeit; Jehovahs Eifer wird das verrichten (Jes. 9, 6 f.)."

So sieht eine von den gangbaren Vorstellungen von Israels Wiederherstellung aus. Die Gesellschaft soll gipfeln in einem mächtigen und unbesiegbaren, aber ebenso friedfertigen König etwa wie der Nebukadnezar der babylonischen Inschriften. Sein Reich soll jedoch viel kleiner sein als das Nebnkadnezars. Jedenfalls hat unser Dichter nur Interesse für die Wiederherstellung eines Königreichs, das nicht ausgedehnter ist als das dem David zugeschriebene. Wir finden eine ähnliche Erwartung in dem nachexilischen Anhang zu Amos $(9,11 \mathrm{f}$.), aber sie wird nicht ausgedrückt mit derselben Inbrunst und rhythmischen Schönheit, welche an dem vorliegenden Liede so bewunderungswürdig sind.

Und doch, wenn wir nur von dem Lichtglanz, mit der frühzeitige Gedankenverbindungen dieses Lied umkleidet haben, uns nicht blenden lassen, dann müssen wir zugeben, dass es keinen Augenblick den Vergleich mit der Schilderung des Knechtes Jehovahs aushalten kann; sein sittlicher Gehalt tritt mehr hervor als sein religiöser. Der Verfasser des letzteren ist im wesentlichen über das Ideal eines persönlichen Messias hinausgeschritten, obwohl er noch Zuneigung für dasselbe empfindet und vielleicht hofft, durch Annahme einiger vergeistigter Züge von demselben seiner eigenen edleren Auffassung Eingang zu verschaffen. Es war ein Schritt. 
den die grössten Lehrer der Folgezeit nicht zurückthun konnten - ein Schritt, den ganz unabhängig davon die älteren Buddhisten thaten, als sie den demütigen Buddha mit dem in der Volkshoffnung lebenden gerechten und mächtigen König zusammenstellten - ein Schritt, den die Jünger Jesu sich nicht abhalten liessen von nenem zu thun, und dessen Bedeutung der Gang der göttlichen Erziehung des Menschengeschlechts modifiziert hat. Denn, wie Professor Rhys-Davids mit Recht gesagt hat: „Der christliche Messias ist ebensoviel höher und edler als die frühere jüdische Auffassung des ersten Jahrhunderts, wie der buddhistische König der Gerechtigkeit höher und edler ist als die vorangehende hinduistische Auffassung vom König der Könige* 1).

Der zweite der beiden messianischen Einschübe ist der, welcher anhebt:

„Und eine Rute soll aufgehen aus dem Stamm Jesse,

Und ein Schössling aus seiner Wurzel emporwachsen."2)

Er: stammt möglicherweise von demselben Verfasser, wie das erste Bild, das, wie Sie sich erinnern werden, mit einem Hinweis auf die Gerechtigkeit und Geradheit des Königs schliesst. Freilich trägt es nicht denselben Rhythmus, noch pulsiert es mit solcher Bewegung. Aber der neue Rhythmus und die neue Stimmung mochten augenscheinlich dem neuen Gegenstand sich besser anpassen. Und ich denke, dass wir dieselbe Modulation in der Schilderung des Messias, welche wir in dem ersten Bilde finden, hier ebenfalls nachweisen können - eine Veränderung, welche unbedenklich

1) Hibbert Lectures for 1881 p. 136. - 2) Jes. 11, 1. 
dem jesajanischen Einfluss zugeschrieben werden kann. Denn ich kann keinesfalls mich der Annahme entziehen, dass diese beiden poetischen Schilderungen als Anhang bezw. zu der zweiten und dritten prophetischen Sammlung Jesajahs geschrieben wurden $\left.{ }^{1}\right)$. Und gewiss ist als eine der Quellen beider Stellen anzusehen das Wort Jesajahs: „Und ich will dir deine Richter zurückbringen wie vorher und die Männer deines Rats wie im Anfang; hernach wirst du genannt werden Burg der Gerechtigkeit, getreue Stadt" (Jes. 1, 26).

Der Gesamtinhalt der Prophetie oder des Gedichtes ist höchst interessant. Es ist eine jener Visionen, die die Welt mit sittlicher Kraft erfüllen. Sie wirft Ruhm auf die Kreise zurück, aus denen heraus sie entstand. Sie ist jedoch eine scharfe Satire auf die Könige der vergangenen Geschichte, was vielleicht die Thatsache erklärt. dass der neue König nicht Sohn Davids, sondern Sohn Jesses genannt wird. Die Person des Messias wird in der That mit einem Geheimnis ungeben. Irgendwo befindet er sich zweifellos, aber ganz ohne Bewusstsein von seiner zukünftigen Grösse. Nicht eher, als bis der rechte Augenblick gekommen, werden sich die göttlichen Gaben, die ihn zu seinem Amt befähigen, auf ihn herniederlassen. Dann wird jenes Wort eines späteren Propheten erfüllt werden, dass das Haus Davids sein werde „wie Gott" (Zach.12, 8); der ideale König wird eine Gottheit sein nicht allein

1) Hierdurch mag die seltsame Thatsache erklart werden. dass der Verfasser von Jes. 11, 1-8 weder die Wendung -sprossen" nowh den Ausdruck ..Spross" rerwendet. Jiese Worter wurden den Einfluss von Jer. 23, 5 rorausgesetzt haben. 
an Macht, sondern anch an Weisheit. Wie ein Richter wird er Wahrheit und Recht auf den ersten Blick erkennen, und seine richterliche Energie wird ihn in den Stand setzen, die ersten Triebe des Bösen anszurotten ${ }^{\mathbf{1}}$ ). Einige von uns mögen das für ein beschränktes Ideal halten. Aber man kann überzengt sein, dass der Dichter mehr meint, als er sagt. Denn was fügt er num seinen Worten hinzu? Wie Vergil ${ }^{2}$ ) in der messianischen Ecloge, singt er von dem Wolf, der neben dem Lamme weidet und dem Leopard, der neben dem Zicklein ruht $\left.{ }^{3}\right)$. Das ist keine blosse Allegorie. Das bedentet vielmehr, dass Friede eines Tages in der ganzen Tierwelt herrschen wird. Aber ist das überhaupt möglich? Gewiss; denn was sollte dieser Zug der Schilderung bezwecken, wenn er nicht die Ertötung des wölfischen Elements in der menschlichen Natur voranssetzte? Sicherlich setzt er das voraus; mithin setzt dieses messianische Bild ebenfalls ein geordnetes System sittlicher und religiöser Belehrung voraus. Denn ob der Messias auch den gottlosen Tyrannen mit Gewalt niederwerfen konnte, so vermochte er doch einen $\mathrm{T}_{\mathrm{y}}$ rannen nimmermehr zu veranlassen, die Sanftmut eines Lammes anzunehmen. Jehovah ist ohne Zweifel der grosse Lehrer. Aber Propheten, Sittenlehrer und Gesetzeserklärer sind seine Abgesandten, und unser weit

1) - Mit dem Hauch seines Mundes wird er den Gottlosen erschlagen* (Jes. 11, 4).2) In der Kathedrale zn Zamora in Spanien wird Vergil unter den bebräischen Propheten dargestellt [rgl. H'iper, Evangelischer Kalender 1862. S. $17 \mathrm{fr} .-\mathrm{S}_{0}$..$-{ }^{3}$ ) In einem grossen indischen Epos wirl gesagt, dass. ., Wiesel mit sehlangen spielen und Tiger mit Hirselen, durch die Macht von Heiligen erhabener Gewalt (Mahabharata citiert bei lluir, Ancient Sanserit Texts 1V. 152). 
ausblickender prophetischer Schriftsteller sctzt ihre Thätigkeit als Bedingung der idealen Zukunft voraus.

Aber bevor wir näher auf diesen auziehenden Gegenstand eingehen, müssen wir einige andere Äusserungen der messianischen Hoffnung betrachten. Zu diesem Zweck wenden wir uns naturgemäss zum Psalter, der als ein Gemeindebuch höchstwahrscheinlich doch auf einen so volkstümlichen Glauben Bezug nehmen muss. Was wir aber finden, ist ziemlich überraschend. Die Tempeldichter gingen so weit, Psalmen aufzunchmen, welche einen mächtigen, kriegerischen und gerechten davidischen König als schon auf dem Throne sitzend voraussetzen. Wahrscheinlich latten die vorexilischen Psalmisten die Israeliten an den Gebrauch von Psalmen zu Ehren des regierenden Königs gewöhnt, und die späteren Psalmisten gaben die Sitte nicht auf; bot sie ihnen doch überdies die Möglichkeit, dem inbrünstigen Glauben an Gott, der sie erfüllte, herzandringenden Ausdruck zu geben. Ton einer ehrenvollen Zukunft, die der Volksgemeinde vorbehalten sei, waren sie so fest überzeugt, wie von ihrem eigenen Dasein. Wenn sie darum beteten, dann bezergte ihnen eine innere Stimme, dass die Antwort schon unterwegs sei; alles, was sie zu thun hatten, war, in Hoffnung zu warten. Das erklärt nicht allein den unvermittelten Wechsel zwischen brünstigem Gebet und überschwänglicher Danksagung, sondern auch die seltsamen Wendungen an einen zur Zeit doch noch nicht existierenden König. Ich muss einräumen, dass das dem Anspruch der Psalmen auf lyrisehe Natürlichkeit Eintrag thut. Ein 
Ansleger. der an die sogenamnten Königspsalmen zum erstenmal herantritt, muss auf die Fermutung kommen, dass sie an einen gleichzeitigren geschichtlichen König sich richten. Der äussere Eindruck wirkt sehr stark zu Gunsten dieser Ansicht; sie macht gleichzeitig die Psalmen sogar für einen nicht religiös gestimmten Leser lebensvoll und anziehend. und doch sind die Eindrïcke hier meistenteils auf Selbstäuschung beruhend. Wrahrheit ist Wahrheit; selbst dann. wenn sie sich gegen irgend einen unserer Lieblingswünsche richtet: wie z. B. die Erweckung eines stärkeren litterarischen Interesses am Psalter: wir miissen sie ehrlich auf- und annehmen.

Ich wage daher, als meine These aufzustellen, dass wir lediglich im letzten Teile des Psalters Hindeutungen aufeinen geschichtlichen Herscher mit Sicherheit voraussetzen dürfen, und dass in den zwei Psalmen, die so aufgefasst werden müssen. Ps. 101 and 110, trenergebene Unterthanen so sehr ihren Fürsten idealisiert haben, dass man sehr bald zu einer messianischen Auffassung kommen musste. Die Auslassung des Schlussteils von Ps. 110 mag durch den Wunsch veranlasst sein, eine solche Auffassung zu erleichtern. Ich möchte gern einige Minuten bei jedem dieser Psalmen mich aufhalten. Denn trotz ihrer Kürze sind sie ausserordentlich interessant, wenn man sie in Lichte der frïhmakkabäischen Zeit liest, und sie erzählen uns Thatsachen. welche wir aus den Blättern der Geschichte nicht erfahren oder wenigstens nicht erkannt haben würden. Ihr religiöser Gehalt allerdings ist dürftig. Der 2. Psalm wirft mehr Licht auf 
den messianischen Glauben, Psalm 15 und 24 handeln mehr von der besten jüdischen Sittlichkeit.

Wir gehen über zu den unerwarteten Erseheinungen, die uns entgegentreten. Zwei der seltsamsten messianischen Psalmen sind der 20. und 21. ${ }^{1}$ ). Beide nehmen Bezug auf den messianischen König, der als Inhaber des Thrones betrachtet wird. In ersterem sieht man ihn gerade ausziehen zum Kampf gegen die Feinde Israels. Das ist vielleicht sein erster Feldzug, denn in Psalm 21 setzt die Volksgemeinde, indem sie Gott für des Königs Sieg lobt, die totale Niederwerfung der Feinde als noch zukïnftig voraus. Aber noch auffälliger ist Psalm 45. Der Messias, der unter dem Bilde des idealisierten Salomo dargestellt wird, hat den Thron bestiegen. Um sein Glück vollständig zu machen und seinen Stamm fortzusetzen, steht er auf dem Punkte mit eines „Königs Tochter" oder vielmehr mit einer „königlichen Jungfran“" sich zu vermählen (v. 14). Der Psalm ist ein Brautlied auf das königliche Paar, dessen Zusammenführung als eben erfolgt vorausgesetzt wird. Der Dichter besitzt eine zügellose Phantasie. Aber er hält fest an dem hauptsächlichen Inhalt der messianischen Hoffnung, die nicht in blossem privaten Glück, sondern in Verleihung von Wohlthaten an die Volksgemeinde besteht.

„Gürte dein Schwert um deine Lenden, o Held,

"Lege deinen Ruhm und deine Pracht an.

„Er leitet dich und lässt deinen Lauf gelingen

1) Diese beiden Psalmen haben zahlreiche Berühruugspunkte mit unleugbar nachexilischen Psalmen (siehe (heyne, Origin of the Psalter). Sie mit Bezug auf einen vorexilischen König zu erklaren, ist daher nicht ratsam. 
„Behufs der Wahrheit, der Gerechtigkeit und der Demut; ... Schrecklich wird seine rechte Hand dieh führen,

"Während Völker niedergestreckt unter dir hinstürzen ${ }^{1}$ ) (Ps. 45, 4f.)."

Vom sittlichen Standpunkt aus rerdient diese Stelle besondere Beachtung. Hier ist ein siegreicher König, dessen Thaten nicht seinem eigenen Vorteil dienen, sondern wie die Arthurs in der grossen moralischen Dichtung Tennysons, „der Wahrheit, Gerechtigkeit und Demut", das sind eben jene Eigenschaften, man beachte es wohl, deren Verschwinden von der Erde fromme Juden zuweilen fürchteten. Ich glaube hinzufügen zu sollen, dass dieser Auffassung Nabopolassar, Nebukadnezar und Neriglissar, Könige des neubabylonischen Reiches, nahe kommen, da jecler von ihnen sich die unerhörte Bezeichnung „demütig“" giebt²).

Ein anderer messianischer Psalm, der 7\%., welcher thatsächlich eine Ergänzung zu dem 45. bildet, giebt dem idealen Könige genau denselben Charakter, nur malt er den schlagenden Widerspruch zwischen der kriegerischen Tapferkeit und der Herzensdemut des Königs nicht aus, wie denselben umgekehrt, wie Sie sich erinnern werden, eine berïhmte messianische Prophetie im Buch Zachariah (9, 9) auf die Spitze treibt. Die Worte des 72. Psalms sind folgende (v. 13 f.):

„Er hat Mitleid mit den Elenden und Armen,

,Die Seelen der Armen befreit er;

"Ton Gewalt erlöst er ihre Seelen,

..Ja knstbar ist ilhr Blut vor seinem Angesicht"

1) Jit ('bersetznng ist hier wie auch sonst der gerade erscheinenden zweiten Auflage eines Werkes iber die Psalmen ron dem Verfasser dieses Buches entnommen. - 2) Suhrader, Keilinsthr. Bibl. $111 \%$ ๖. 3. 7. 7 . 
d. h. nicht aus reinem Pflichtgefühl sondern aus Mitleid stellt er seinen starken Arm in den Dienst derer, die in Not sinc. Statt die Armen zu verachten, betrachtet er ihr Blut doch als zu kostbar, um vergossen zu werden.

Ich darf bei diesem interessanten Liede nicht länger verweilen. Aber ich muss noch die Eigentümlichkeit der Anfangsstrophe betonen, wo der Messias nicht allein als König bezeichnet wird, sondern als "Königssohn". Das stimmt zu einer Stelle aus Psalm 45, in welcher die "Väter" d. h. die königlichen Väter des Messias erwähnt werden. Die Psalmisten übergehen die Zwischenzeit zwischen dem letzten Könige von Juda und der Thronbesteigung des Messias und stellen den letzteren dar als Sohn all der Könige, welche ihm vorangegangen sind.

In Wahrheit ist der Messias lediglich eine dichterische Verkörperung des davidischen Königtums, und das davidische Königtum ist in Ermangelung irgend eines politischen Interesses lediglich ein Vertreter des jüdischen Volkes ${ }^{1}$ ). In der idealen Demokratie ist jeder Bürger ein König; in dem idealisierten jüdischen Staat ist jeder wahre Knecht Jehovahs ebenso heilig wie der Messias. Diese Anschauung erklärt die auffällige Thatsache, dass im 89. Psalm das Volk

1) Hier sehen wir uns genütigt, anderer lleinung zu sein als R. H Hutton trotz seines sehünen Wortes (Essays 1, 274), dass die jüdischen Propheten einzusehen begannen, dass es z wischen dem Vater und der mensehlichen Natur ein Wesen geben müsse, niedrig wie die letztere, vollkommen wie der erstere, dessen Königsherrsehaft nicht bestehen sollte in blosser gereehter Iacht, sondern in gerechter Demut". Gerechte Demut und Gottesnahe sinū ebenso bezeichnend fur das Volk wio für seiner: idealen Herrscher und Vertreter. 
Israel thatsächlich den Titel .Jehovahs Gesalbter" annimmt ${ }^{1}$ ). Gestatten Sie mir jetzt, Thre Aufmerksamkeit auf diesen Psalm zu lenken, wenigstens auf die Verse 19-51, welche ursprünglich für sich gestanden zu haben scheinen. Diese Stelle setzt ein mit einer dichterischen Umschreibung einer Weissagung, die in der Perserzeit die Aufmerksamkeit vielfach auf sich zog: Nathans Weissagung (Sam. B 7):

„Meinen Bund will ich nicht entheiligen,

„Noch ändern, was über meine Lippen gegangen ist;

„Ein für allemal habe ich geschworen bei meiner Heiligkeit, "Ich will nimmer Darid trenlos sein."

"Sein Same soll ewig dauern

„Und sein Thron wie die Sonne vor mir;

„Er soll für ewig anfgestellt sein wie der Mond,

,(Ja) standfest sein wie der Versammlungsplatz in dem Himmel."

Der Versammlungsplatz in Himmel ist (wenn die Worte so richtig überliefert sind) der „Berg der Versammlung“, wo nach einer alten Mythe die „Söhne Gottes" (oder übernatürliche Wesen, vgl. das Buch Job) sich versammelten; dessen Spitze bis an den Himmel reichte, und dessen Wurzel im Ocean ruhte, der die Erde umgiebt. Welch treffenderes Bild von Unerschütterlichkeit kömnte es geben!²) Aber nachdem der Psalmist die Weissagung angeführt hat, befällt ihn tiefe Niedergeschlagenheit. Er beklagt, dass die prophetische Verheissung zu den Thatsachen in ge-

1) Vgl. dieselbe Erscheinung Ps. 28, 7 [8]; 84, 10; Hab. 3, 13. - ${ }^{2}$ ) Genau dasselbe Bild wird seitens des Ezechiel angewandt $(28,13 \mathrm{f}$.$) , um das Selbstbewusstsein$ des Kunigs ron Tyrus zu sehildern. 
waltigem Gegensatz steht. Die Königsherrschaft des davidischen Hauses hat aufgehört und das Volk Israel, das hier mit dem Messias identifiziert wird, erfährt seitens seiner Nachbarn Schlimmeres denn Verachtung.

Der 18. Psalm ist nicht weniger auffällig. Ich fürchte, dass er bisweilen auf unstichhaltige Gründe hin bewundert worden ist. Es geht nicht an, ihn mit dem glänzenden an Thutmes III. gerichteten Siegeshymnus zusammenzustellen: die Sprache dieses ist ebenso lebhaft und urwüchsig, wie die des 18. Psalms farblos und gekünstelt. Um letzteren würdigen zu können, müssen wir ihn lesen als Ausdruck jener „überweltlichen" Gesinnung, welche kein Volk in solchem Mass besessen hat wie das jüdische. Von Anfang an versetzt der Psalmist uns in das messianische Zeitalter. Das Gericht über die Völker hat stattgehabt $^{1}$ ); Israel mit einem davidischen Könige an der Spitze ist bis zum Gipfel des Erfolges gestiegen. Gerade dieser davidische König redet im Psalm. Er besitzt keinen persönlichen Ehrgeiz und kann daher die Gedanken der Gemeinde vertreten; in der That vergisst der Psalmist zuweilen den König und spricht in der Rolle des personifizierten Volkes²). Alles dieses ist psychologisch höchst wunderbar. Wenn es sich nicht auf das Bündigste beweisen liesse, würden wir es ïberhaupt nicht für möglich gehalten haben.

1) Ps. 18, 4-19: vgl. 97, 1-6. - 2) Daher werden in Ps. 144, 1-11, einer lediglich nach fremden Vorlagen angefertigten Arbeit, die Worte aus Ps. 18 einfach libernommen seitens der personifizierten Gemeinde, welche hier sich deutlich ron Lavid unterscheidet. 
Ähnlich muss Psalm 2 erklärt werden. Wie der 18. ist er ein Versuch einer lebensvollen Darstellung auf Grund der mehr ausgeprägt messianischen Weissagungen. Im 18. Psalm redet der messianische König, als wenn er auf dem Throne sässe und unter Jehovah die Schicksale der Nation leitete. Im zweiten redet er, als wenn die verbündeten Könige einen $\mathrm{Ab}$ fall von Jehovah und seinem Gesalbten planten. Der Messias, der hier redet, trägt weniger menschliche Züge als sein Gegenstück im Parallelpsalm. Dort stellte das ihm übertragene Werk grosse Ansprüche an seine Energie; er bedurte (wie alle grossen religiösen Streiter des Orients das Bedürfnis empfanden) einer Machthilfe von oben, um den Erfolg zu erringen. Hier braucht er nur sein eisernes Scepter aufizuheben. um die Heiden wie Thongefässe zu zertrümmern. Sittlich steht der Psalmist höher als sein Held. Er wünscht den Königen der Erde nichts Böses. Der messianische König kann keine Schritte gegen sie unternehmen, bis Jehovahs Zorn entbrennt. Bis dahin haben die Könige Zeit, Busse zu thun und sich wieder zu unterwerfen.

„Nun zeigt darum eure Weisheit, ihr Könige;

.,Nehmt Warnung an, ihr Richter der Erde.

.,Dienet Jehovah mit Furcht,

.,Und huldiget mit Zittern.

.$\left.{ }^{1}\right)$ Damit er nicht zornig werde, und ener Lauf in Verderben ende.

1) Hier sehalten die Iandaufigen l'bersetzungen fin: -Kusset den sohn*, was jedoch auf einem Nissterstantris beruht. - husset-, d. h. .Iluldiget- muss bestimmt fur .Frenet euch- (siehe die Iandiautige l̈bersetzung) in der roranstehenden Zeile pingesetzt werden: alen sohn" ist l'bersetzung aut Gruble tiner Vermutung; in Wirklichkeit 
„Denn bald entbrennt sein Zorn;

"Wohl allen denen, die zu ihm ihre Zuflucht nehmen (Ps. 2, 10-12)."

Ein Gedanke, fürchte ich, wird sich Ihnen aufdrängen: der nämlich, ob es denn überhaupt eine Wohlthat für die Heiden bedeutet, unter das Joch des Messias gebracht zu werden; ist es doch eine Wohlthat, die die schmerzlichsten Opfer von ihnen verlangt. Die Schärfe des messianischen Vorgehens gegen die auswärtigen Völker kann, das müssen wir hervorheben, sittlich nur gerechtfertigt erscheinen bei der Anschauung, dass die Heiden gründlich schlecht sind, und dass ihre dauernde Unabhängigkeit die höchsten menschlichen Ideale bedroht. Das war in der That die Ansicht frommer Juden, wenn es einmal irgend eine Reibung zwischen ihnen und ihren Herren gab, und das kam noch bestimmter zum Ausdruck in den Liedern, welche sie im Tempel sangen. Doch werden wir sehen, dass die Psalmisten von den auswärtigen Völkern nicht immer in demselben harten Tone sprechen. Ebensowenig die prophetischen Schriftsteller. Aber wir müssen uns, meine ich, das Recht, an den sanfteren Stellen uns zu freuen, gleichsam erkämpfen, wenn wir uns zuerst an der Hand der Psalmisten in den schrecklichen Zustand der Spannung hineinversetzen, in dem die Juden zu oft lebten.

Ich weiss wohl, dass ein hervorragender jüdischer

steckt darin ein Bruchstück des durch -mit Zittern* wiedergegebenen Wortes (siehe des Verf. Book of Psalms 2. Aufl.).

Cheyne, Religiöses Leben der Juden. 
Schriftsteller (Isidor Loeb) die objektive Genanigkeit der Psalmisten bestritten hat; er betrachtet den Psalter lediglich als Ausfluss eigentümlicher und absonderlicher Gemütszustände. Nach seiner Auffassung sind die Psalmisten idealistische Dichter, die die Kunst erfunden haben, ihr Elend möglichst sich zurecht zu legen, und die den Geschmack der Sorge nicht gänzlich bitter finden. Sie sind die Narren und Spielbälle ihrer Einbildung; sie leben in Träumen und haben für die Wirklichkeit keinen Sinn. Darin steckt ein Körnlein Wahrheit, aber kein grosses. Wie die Propheten haben die Psalmisten eine Neigung. zu übertreiben. Ihre Empfindungen sind so stark, dass sie sich verleiten lassen, die Farben zu dick aufzutragen. Sie lieben die ihnen überlieferten Ideale so sehr, dass sie denen gegenüber, welche diese Ideale in den Staub treten wollen. nicht ganz kühl bleiben können. Aber es giebt gewiss ein schmerzstillendes Etwas in ihrem Leiden, dass ein Unbeteiligter nicht erfassen kann; denn je unglücklicher sie sind, desto mehr vertranen sie darauf, dass einer, der stärker ist als die Starken, für sie sorgt. Anch sind sie nicht alle ohne eine wenn auch nur schwache Vorstellung von den Tröstungen der Kunst, obwohl die Kunst derartig sein mag. dass sie unsern Geschmack enttäuscht: ich meine Musik und Gesangim Tempel. Sie haben eine grosse Freude, die besteht in dem Lobsingen Jehovahs. Der blosse Gedanke daran ist ihnen ein Trost in ihrem Exil. Einer cler Psalmisten, der fern von Jerusalem weilt, sagt schön: 
„Dies stelle ich mir vor die Seele, indem ich derweil mein „,mattes Herz ausschütte,

"Wie ich in Gemeinschaft mit den Edlen zum Hause Gottes ,wallte

„Inmitten des tönenden Lobgesanges, der Musik derer, welche ein Fest feierten (Ps. 42, 4 [5])."

Man mag ferner zugeben, dass die Frommen in gewisser Hinsicht die Urheber ihres eigenen Unglücks waren. Sie hatten kein politisches Verständnis und waren eines praktischen Verkehrs unfähig; sie waren von unüberwindlichem Widerwillen gegen Handel erfüllt, und die Künste des Marktes waren ihwen fremd. Das Ergebnis war, dass sie sowohl staatspolitisch wie handelspolitisch an die Wand gequetseht wurden, nicht nur von seiten Fremder sondern auch durch Leute ihres eigenen Stammes. Das war es allerdings, was ihre Gefühle so verbitterte: dass jene Leute, die sich Juden nannten, sich zu den Heiden stellten und deren weltliche Grundsätze annahmen; dass aller Eifer und alle Kraft Nehemiahs und Esras es nicht durchsetzte, das edle Ideal der Volksgemeinde zu verwirklichen. Dass die nichtjüdischen und halbjüdischen Bevölkerungen in Palestina Aufregung zeigen würden bei den religiösen Anmassungen der Juden, das liess sich bestimmt erwarten; dass die persischen Machthaber der freundlichen Nachsicht eines Cyrus und Darius überdrüssig wurden, war wenigstens nicht ganz unverständlich; aber dass Glieder der Familie Israels den Bund ihres Gottes verachteten, das war mehr, als fromme Juden zu ertragen vermochten. Allen diesen Menschenklassen: lauen oder treulosen Juden, die nur für ihren 
eigenen Vorteil sorgten und keine Skrupel empfanden ihre Brüder zn betrügen und auszusaugen, gereizten und boshaften Nachbarn, herzlosen und tyrannischen Machthabern schleudern die Psalmisten die stärksten Bezeichnungen entgegen: „schlecht", ,gottlos"“, „Übelthäter", "Blutmenschen", nstolz", "Prahler", „Räuber". "Spötter", "Feinde Jehovahs". „Abtrïnnige", „die ohne Ursach feind sind“, „die da Böses für Gutes vergelten".

Von religiösem und sittlichem Standpunkt aus konnten sie keinen Unterschied unter ihnen sehen. Weder der ungläubige Jude noch der heidnische Tyrann glaubt an die göttliche Weltherrschaft. Er vergisst Gottes, ruft ihn nicht an, fürchtet ihn nicht (Ps. 9, 18; 14, 4; 36, 2; 50, 22); er denkt in seinem Herzen. wiewohl er es nicht laut ausruft: "Es ist kein Gott". (Ps. 14,1; vgl. 10, 4; 36, 1 [2]). Er kamn die schneidendsten Hohnworte anwenden gegen die, welche nicht wagen dürfen, sie ihm znrückzugeben; denn "wer hört es" (Ps. 59, 7 [8])? Er kann die grössten Frevelthaten begehen, denn "Jehovah sieht's nicht" (Ps. 10, 11; 94, 7). Er kann sogar (wenn er äusserlich ein Jade ist) die hergebrachten religiösen Formen verrichten. .,indem er sein Haupt neigt, wie ein Rohr" (Jes. 58, 5) bei den öffentlichen Bittgebeten. Aber er thut das, mm Gott zu hintergehen: so unglaublich oberfächlich ist nach der Meinung des Psalmisten seine Auffassung von Grott. Er hat thatsächlich seine religiösen Anschanungen den Forderungen des täglichen Lebens angepasst; er glaubt, dass Gott ebenso einer sei 
wie er selbst (Ps.50,21); er hat ein trügerisches Orakel in seinem Herzen, das ihm gerade das sagt, was er zu hören wünscht. Dieser Psendogott ist die Sünde in ihm, welche den Platz jenes göttlichen Lehrers, der in jedem Gliede der gläubigen Gemeinde wohnt, an sich genommen hat. Man höre den Psalmisten:

„[Dass kein Gott ist, das ist] das Lïgenorakel der sünde „An den gottlosen Menschen in seinem Herzen;

„Heine Gottesfurcht ist vor seinen Augen.

„Denn er schmeichelt Jehovah in Falschheit:

„Jehovah wird doch nicht die Gottlosigkeit seiner Zunge entdecken.

,Die Worte seines Mundes sind Unheil und Arglist;

„Er hat aufgehört, weise und gerecht zu handeln (Ps. 36, 1-3)."

So seltsam es klingen mag, eine ähnliche Darstellung wird seitens des alten und engherzigen Eliphaz von dem gerechten Job gegeben:

„Ja du zerstörst die Gottesfurcht

,Und lässest fromme Gedanken fahren.

„Denn deine Bosheit lehrt deinen Mund, „Und du erwähltest die Zunge des Falschen ${ }^{1}$ ) (Job 15, 4 f.)."

Der einzige Unterschied ist, dass Job nach Eliphaz scinen gottlosen Thaten eine theoretische Rechtfertigung seiner Gottlosigkeit hinzufügt, während die Sünder in den Psalmen als überhaupt nicht verständig hingestellt werden. Nur im ersten Psalm - dem Psalm der zwei Wege - hören wir von einer Gattung Menschen, die „Spötter" genannt werden, und das beweist uns,

1) Vgl. die vierte Vorlesung 
dass wir die Psalmen nicht als umfassendes Spiegelbild der jüdischen Gesellschaft anzusehen haben.

Aber welches sind die Unthaten, deren die Gesellschaft der Bösen sich schuldig gemacht hat? Sie bestehen zum Teil im Gebrauch beleidigender Ansdrïcke gegen Israel und Israels Gott, die mit heuchlerischen Freundschaftsbetenerungen abwechseln, zum Teil in verleumderischen Anklagen gegen die Gerechten, die vielleicht an den Richter oder an den persischen oder griechischen Gouverneur gerichtet waren, zum Teil in gröblicher Unbilligkeit beim Geschäftsverkehr den armen Gerechten gegenüber, zum Teil in Thaten äusserer Vergewaltigung. Ich will einige Stellen aus den Psalmen anführen, die diese Behauptung belegen.

Zuerst will ich, was die Reden der bösen Menschen betrifft, als Erweis zwei sehr wehleidige Stellen anführen, deren Stimmung die manches verfolgten Juden in der langen Zwischenzeit ist:

„Erbarme dich unser, Jehovah, erbarme dich unser!

„Demn allzulange sind wir mit Verachtung gesättigt worden; „Ja allzulange ist unsere Seele gesättigt worden

„Mit dem Gespött der Übermütigen, „Der Verachtung durch die Stolzen (Ps. 123, 3 f.)."

Und jetzt die Parallelstelle:

„Beschimpfung hat mein Herz gebrochen;

,Sehr schwer ist die Wunde meiner Seele;

,.Ich sah mich um nach Mitleidigen, aber da war keiner,

,Und nach Tröstern, aber ich fand keinen.

,Sie gabeu mir Galle zur Nahrung.

„Und in meinem Durst gaben sie mir Essig zu trinken

(Ps. 69, 20 [21] f.)." 
Mit "Galle" und "Essig" bezeichnet der Dichter bittere, spottende Worte. Der Sprecher ist das gläubige Israel, welches beleidigt wird, weil es der" "Knecht Jehovahs" ist. Daher lesen wir in demselben Psalm: "Die Beleidigungen derer, die dich beleidigten, fielen auf mich". Es erhellt aus dem Zusammenhang, dass das Gespött der Feinde teilweise durch den jämmerlichen Zustand der gläubigen Gemeinde, die ihrem Untergange entgegenzugehen schien, hervorgerufen wurde, besonders aber durch die Formen und Bräuche der jüdischen Religion. Allerdings ist der einzige Brauch, der ausdrücklich erwähnt wird, das Fasten ${ }^{1}$ ). Das scheint hier hervorgehoben zu sein, weil es die Aufmerksamkeit eines Unbeteiligten mehr erregte als gottesdienstliche Gebete; es war in der That der eindringlichste Versuch der Gläubigen, auf ihren Gott einzuwirken. Aus andern Stellen erfahren wir jedoch, dass auch die Gebete der Glänbigen den Lachlustigen nicht entgingen. So geschwätzig erschienen diese Gebete, dass die Feinde mit einem gewissen Schein fragen konnten: "Wo ist dein Gott?" (Ps. 43, 3 [4] f.) und der böse Mensch konnte sogar sich herausnehmen zu "fluchen bei der Erfüllung seines Wunsches" and der "Räuber" „Jehovah zu verachten" (Ps. 10, 3). Die Lieblingsausdrücke der Gläubigen scheinen ebenfalls verlacht worden zu sein; wenigstens giebt es eine besonders ergreifende Stelle, welche ein fingiertes

1) Soweit wir sehen, bestanden die seitens frommer Juden am höehsten geschätzten gottesdienstlichen Formen in Lobsingen, Recitieren von Gebeten und Fasten. Sabbat und Beschneidung werden in den Psalmen uirgeuds erwähnt. 
Gespräch der Verfolger darbietet und dies zu besagen scheint. Ein Wort oder zwei in meiner Textherstellung sind allerdings nicht einwandfrei und zwar in Zeile 3, woselbst ich eine Beziehung finde auf die von seiten Deuterojesajahs in seiner Wiederherstellungsweissagung mit Vorliebe verwendete Bezeichnung Gottes. Aber der überlieferte Text kann meiner Ansicht nach nicht gehalten werden.

„Alle, die mich sehen, lachen meiner mit Verachtung;

.,Sie sperren die Lippen weit auf; sie schütteln den Kopf:

.,(Traun) sein Erlöser ist Jehorah; (also) lasst Jehorah ihn erretten:

..Lasst Jehorah ihn befreien, weil er doch einmal solches Ergötzen an ihm hat (Ps. 22, 7 [8] f.)."

Manchmal treten jedoch die verfolgten Gerechten in den Riss und begegnen ihren Feinden mit der Waffe des armen Mannes, dem Gebet, einem wirksamen, inbrünstigen Gebet, voll Zuversicht auf Erhörung.

„Verstummen mögen jene lügnerischen Lippen,

„Welche gegen den Gerechten sprechen

„Stolze Worte in Übermut und Verachtung

(Ps. 31, 18 [19]).

Der Spott der gottlosen Reichen gegen die gerechten Armen zeigt sich auf eine allerdings sonderbare Weise. Wie es scheint, zogen die Gottlosen, so oft sie konnten, die Anwendung niedriger und schändlicher Handlungsweise vor. Sie waren bestrebt, die Gerechten in falsche Sicherheit einzulullen, indem sie sich für ihre Freunde ausgaben. Terrat spielt in der Geschichte der Makkabäer eine grosse Rolle, und es 
liegt nur allzuviel Grund vor zu der Annahme, dass der Argwohn vor demselben immer in dem Gemüte des Juden verborgen lauert. Ein Psalmist sagt:

„Da ist nichts Glaubwürdiges in ihrer Rede,

„Thr inwendiges Streben ist Verderben;

„Ein offenes Grab ist ihre Kehle,

„Obwohl Sehmeichelei über ihre Zunge gleitet

(Ps. 5, $9[10])$.

Ein anderer schildert den Gottlosen wie folgt:

„Sein Angesicht ist glatter als Butter,

„Aber Krieg ist in seinem Herzen;

„Seine Worte sind sanfter als Öl,

"Und doch sind sie Wurfspiesse (Ps. ó. 21 [22])."

Daneben ist es die Verleumdung, welche einen andern Punkt in der Anklage gegen die Gottlosen bildet. Folgendes sind die Stossseufzer des frommen Israel:

„Übergieb mich nicht der Gier meiner Feinde!

„Denn gegen mich haben falsche Zengen sich erhoben,

„Und sie zischen (Worte der) Ungerechtigkeit hervor

(Ps. 27, 12).“

Und wiederum:

„Zeugen, die der Ungerechtigkeit dienen, erheben sich, „Und mit Ränken berauben sie mich (Ps. 35, 11).“

Hier haben wir eine Anspielung auf einen gewöhnlichen Kniff habsüchtiger und mächtiger Menschen: unschuldige Personen irgend eines Verbrechens anzuklagen, wie z. B. des Diebstahls, mit der Absicht, doppelten Ersatz zu erlangen. Die Richter nahmen natürlich für sich Anteil am Raube (vgl. Mi. 3, 3). Oder die Anklage mochte auf Verräterei lauten. Wie- 
viel Scheingründe eine solche Beschuldigung in den dunklen Jahren gegen Ende des Perserreiches und sogar noch später für sich haben konnte, darauf braucht nicht erst hingewiesen zu werden. Mit Recht mochte die Volksgemeinde beten:

„Erlöse meine Seele, Jehovah, von den lügnerischen Lippen, "von den trugvollen Zungen (Ps. 120, 2)"

und dann mit den Worten des schönen Psalms am Schluss des Sirachbuches ihrem Herru und König danksagen für die Befreiung nvon den Lippen, die da Lügen schmieden", weil ,ihre Seele infolge einer Anklage beim König seitens einer ungerechten Zunge beinahe dem Tode verfallen wäre" (Sir. 51, 2-6).

Unter diesen Umständen waren normale geschäftliche Beziehungen zwischen den beiden Parteien unmöglich. Selbst wenn die Psalmisten übertreiben, indem sie ihren Gegnern die letzte Spur von Ehrenhaftigkeit absprechen (Ps.12,1), so bezengt doch gerade diese Übertreibung einen socialen Misstand, bei dem Verkehr nicht bestehen kann ${ }^{1}$ ). Die genaueren Einzelheiten der Unredlichkeit im Verkehr werden natürlich nicht gegeben. Aber das wird uns mit Bestimmtheit gesagt, dass „Erpressung und Betrug vom Marktplatz nicht weichen" (Ps. 55, 11 [12]). Ohne Zweifel war diese Erpressung mit Darlchensgeschäften in besonderem Masse verbunden. Geld ohne Zinsen an gläubige Juden zu leihen war ein verdienstliches Werk (Ps. 37, 26; 112,5), wïhrend Wuchertreiben ebenso schlimm war,

1) Sogar zu den Zeiten Ben Siras waren die Beziehungen zwischen reich und arm gleich denen zwischen Wolf und Lamm (sir. 13, 17-19). 
wie gegen einen Unschuldigen Bestechung anzunehmen (Ps. 15, 5).

Dass Akte persönlicher Vergewaltigung anch seitens der jüdischen Unterdrücker vorgenommen wurden, lässt sich nicht so leicht beweisen.

Die Gottlosen jüdischen und dieheidnischenUrsprungs kann man nicht immer leicht auseinanderhalten. Wahrscheinlich wurden eingeborne Beamte unter den auswärtigen Gouverneuren verwendet. Dieso missbrauchten ihre Gewalt und wurden noch verhasster als die Fremden. Prov. 28, 3 (vgl. 5, 15) lesen wir, dass „ein gottloser Vornehmer (oder Tyrann), der das niedere Volk bedrückt, gleich einem Platzregen ist, der keine Nahrung zurïcklässt", und in Ps. 52, 1 [3] redet ein Psalmist einen ungenannten Beleidiger mit folgenden Worten an:

„Warum rühmst du dich beim Übelthun, du Tyrann!

,[Und zeigst Überhebung] dem Frommen unaufhörlich?"

In beiden Fällen ist die natürlichste Dentung die, dass eill eingeborener Machthaber gemeint ist. Noch unzweidentiger ist der Hinweis in der nunmehr von mir anzuführenden Stelle. Sie beweist, dass es sittenlose Menschen gab, Juden dem Namen aber nicht der Gesinnung nach, die sich nichts daraus machten, Blut zu vergiessen, wenn ihre Wünsche auf keine andere Weise sich befriedigen liessen. Der frömmere Teil des jüdischen Volkes bittet Gott wie folgt:

„Nimm meine Seele nicht hin mit Sündern,

"Noeh mein Leben mit Blutmensehen,

"Auf deren Händen (die Male von) Verbrechen sind, „Und ihre Rechte ist voll Bestechung (Ps. 26, 9 f.)." 
Diese Lente gehörten, wie es scheint, einer Genossenschaft an. Sie hatten gemeinsame Grundsätze und Ziele und bildeten daher eine Partei. Wenn darum das personifizierte fromme Israel in demselben Psalm (v. 5) sagt:

.,Ich hasse die Versammlumgen der Übelthäter „Und will nicht sitzen im Rat der Gottlosen,"

so will es damit zum Ausdruck bringen, dass es sich über die fundamentale Unverträglichkeit seiner eigenen Grundsätze mit denen der Gegenpartei klar war. Es hasst sie nach seinen Worten an anderer Stelle (Ps. 139, 21), weil sie Jehorah hassen und ihm widerstreben, und es ist die schwierigste Frage, die ihm aufgestossen ist, die Fortdauer ihrer Existenz mit der göttlichen Gerechtigkeit zu vereinigen.

Ich bin, wie Sie sehen werden. der Meinung. dass der Psalter eine geschichtliche Urkunde von hohem Werte ist - auch bin ich mir vollkommen klar sowohl über seine Chronologie wie über die Glaubwürdigkeit seiner ausdrücklichen Angaben oder Andentungen. mit den von mir bezeichneten Einschränkungen. Ich halte dafür, dass der nachexilische Ursprung jedes Teiles der Psalmensammlung bis zum Überfluss nachgewiesen ist. Die Glaubwürdigkeit ihrer Angaben scheint mir gestützt durch die schon erwogenen geschichtlichen und prophetischen Beziehungen. Es ist klar, dass eine starke Gemütsspannung unter den frommen Juden bestand, und diese Spannung erklärt die leidenschaftliche Sprache der Psalmisten, welche wahrheitsliebende Menschen 
waren, wenn sie auch wie die Propheten vor ihnen einigermassen zur Übertroibung geneigt waren.

Es wäre aber bedenklich, anzunehmen, dass die Teilung der Juden in gottlose Reiche und gerechte Arme, welche einen so grossen Teil der späteren Litteratur durchzieht, eine erschöpfende Einteilung ist. Die gerechten Armen bilden in ihrer Gesamtheit den sich selbst aufopfernden Jes. 53 beschriebenen Knecht Jehovahs. Sie sind der esoterische Kreis, die wirklich schönen Beeren an der Traube. Unmittelbar neben ihnen stehen - als Gesetzesbeobachter wie sie, nur nicht in so strenger. Weise, als Besucher des Tempels, nur nicht so regelmässige — in grosser Überzahl die, welche den Namen Jehovahs anrufen. Sie sind nicht vollkommen geworden in Demut und Gehorsam und noch nicht ausser stande, sich durch das böse Beispiel der Gottlosen verführen zu lassen. Sie bedürfen der Leitung und Belehrung durch die, welche fester im Glauben stehen, und gerade ihnen widmen die Gesetzeslehrer, die Verfasser der Weissagungen und diejenigen weisen Sittenlehrer, von denen einige Psalmen und bedeutungsvolle Aussprüche und eindringliche Gespräche verfasst haben, ihre rastlose Mïhe. Zu ihrem Gebrauch ist das schöne Gebet geschrieben:

„Erforsche mieh, o Gott, und erkenne mein Herz, ,Prüfe mieh und erkenne meine Gedanken „Und sieh, ob da habsüchtiges Treiben in mir sei, „Und leite mich auf der Strasse der Vorzeit $\left.{ }^{1}\right)^{\prime \prime}$;

und grade von den Lehrern der Gerechtigkeit

1) Ps. 139, 24: in den Versen 19-2: redet das personificierte Israel. 
(welchen ich mich nummehr zuwenden werde) weisssagte der Verfasser des Danielbuches. dass .: die Lehrer leuchten werden, wie des Himmels Glanz, und die, so viele zur Wahrheit weisen, wie die Sterne immer und ewiglich" (Dan. 12, 3). 
Vierte Vorlesung.

\section{Jüdische Weisheit; ihre Bedeutung; ihr Gegenstand und ihre Gestaltungen.}

Im übrigen Teil dieser geschichtlichen Skizze habe ich mich nun zu bemühen den Beweis für die reiche Entfaltung des Lebens im älteren Judentum zu vervollständigen. $\mathrm{Zu}$ allererst bitte ich Sie, mit mir die grosse lehrhafte Bewegung dieser Periode, aus welcher die einzigartige Erscheinung, welche man die jüdische Weisheit nennt, sich entwickelte, zu betrachten. Über ihren Ursprung kann man nur Vermutungen hegen. Höchstwahrscheinlich entsprang sie jedoch aus dem Bewusstsein, es sei eine neue und anziehende Darstellung der sittlichen und religiösen Wahrheiten vonnöten, wenn nicht nur Einzelpersonen sondern ganze Klassen der Gesellschaft gerecht werden sollten: was doch, wie man wusste, die Bedingung der göttlichen Gnade war. Das Ideal vieler der edelsten Gemüter ist am Eingang des ersten Psalms ausgedrückt:

„Glücklich der Mann, der an der Furcht Jehovahs sich ergötzt, "Und denkt an sein Gesetz Tag und Nacht ${ }^{1}$ ) (Ps. 1, 2)."

Aber man muss bald eingesehen haben, dass es eine grosse Anzahl gab, anf welche diese Beschreibung niemals zutreffen konnte, wegen der vielen Schwierig-

1) Nach einer einleuchtenden Verbesserung. 
keiten in der Schriftensammlung, anf welche sie sicher stossen mussten ${ }^{1}$ ). Folglich scheint die Anschauung entstanden zu sein, dass, wenn dieses Buch studiert würde von weisen Leuten, die doch in Fühlung mit dem Volke ständen, es dann möglich sein würde, einen Auszug von solchen religiösen Wahrheiten zu liefern, den sogar die Weltmenschen (wenn man sich so ausdrücken darf) verstehen und zu ilırer Lebensregel machen konnten. Ist diese Ansicht richtig, dann dürfen wir natiirlich erwarten, dass viele patriotische Lehrer sich eindringend mit der Schrift beschäftigen und doch treulich an den bestehenden Formen festhalten würden. Kurz. sie mochten Männer glühender Religiositätwerden, obgleich sie es nicht immer für passend halten mochten, ihre Inbrunst vor ihren Schülern zu zeigen. Es mochte jedoch vielleicht auch eine Minderheit auftreten, die nicht mit der gewöhnlichen Lehrthätigkeit zufieden sondern bestrebt sein würde, die verstandesmässigen Bewegungen der Vergangenheit fortzuführen. Einige von ihnen mochten in ihrer Lehre eine vollständige Verschmelzung von Sittlichkeit und Religiosität bieten und vielleicht Werke hervorbringen, auf welche die Nachwelt allerdings nicht hinblicken würde als auf Offenbarung im ïberlieferten sinne des Wortes, die sie aber doch für nicht minder köstlich, nicht minder wahrhaft göttlich halten würde als Gesetz und Propheten. Andere wieder mochten einer mehr zweifelsüclı-

1) "Der, welcher sich dem Gesetze widmet, wird davon erfüllt, aber der Weltmenseh strauchelt daruber* (sir. 3:, 15 ). 
tigen Richtung huldigen, deren Schriften nur durch einen glücklichen Zufall der Vergessenheit entzogen würden.

So finden wir thatsächlich, wie wir auf Grund des Obigen im voraus annehmen durften, drei Arten von lehrhafter und spekulierender ethischer Litteratur: zwei davon stellen eine mehr oder weniger umfassende Verschmelzung des sittlichen und des orthodox-religiösen Geistes dar, und eine andere zeigt eine ausdrücklich ungläubige und zweifelsüchtige Richtung. Wir finden ferner, dass diese spekulierende Litteratur auf hohes Alter Anspruch machte. Wie die heilige lyrische Poesie an den berühmten Namen eines David sich anknüpfte, so nahm die neve ethische Litteratur als ihren Urheber den idealisierten Salomo ${ }^{1}$ ) in Anspruch. Ein nachexilischer Schriftsteller hat sich Mühe gegeben zu zeigen, in welch mannigfaltiger Form König Salomo seine Weisheit zum Ausdruck brachte. Salomo war natürlich ein gerechter und weiser Regent: was mehr als ein alter Schriftsteller klar zum Ausdruck gebracht hatte. Aber er war anch ein viel weitherzigerer Mann als die meisten Herrscher. Man lese die schöne kleine Erzählung, in welcher dieser Gedanke Ausdruck findet:

„Und Gott gab Salomo Weisheit und Einsicht und un,gemeinen Verstand ${ }^{2}$ ). Salomos Weisheit war grösser als die „,aller Mämner des Ostens und als alle Weisheit Ägyptens. Er „,war weiser als alle Menschen, weiser als Ethan, der Esrahiter,

1) Es mag natürlich eine vorexilisehe Weisheitslitteratur gegeben haben, aber in welcher Beziehung (wenn es überhaupt eine solche Beziehung gab) sie zur Litteratur der nachexilisehen jüdischen Weisen stand, das lásst sich unmöglich angeben. 2) Einen Sinn, der an neuen ldeen Überfluss hatte (verbesserter Text).

Cheyne, Religiöses Leben der Juden. 
„und Heman und Falkol und Darda, die Söhne Mahols; und ,sein Ruf erreichte alle Völker rund umher. Und er redete „,dreitausend Sprichwörter, und seiner Lieder waren ein tausend , und fünf. Und er redete von Bäumen, von der Ceder auf ,dem Libanon bis zum Ysop, der aus der Mauer hervorwächst; ,er redete auch von Vierfüsslern und Vögeln und Reptilien , und Fischen. Und die Menschen kamen aus allen Landen, „die Weisheit Salomos zu hören, von allen Königen der Erde, „die von seiner Weisheit gehört hatten (Reg. A 4, 29-34)."

Keine Erklärung der vorstehenden Stelle ist so naheliegend wie die, welche darin einen Hinweis auf unsere Proverbien (Sprüche) ${ }^{1}$ ), auf unser Hoheslied und auf unser Buch Job findet. Es ist allerdings wahr, wir haben nur ein "Lied", dessen Titel Salomo als Verfasser in Anspruch nimmt, aber dieser Titel kann ohne Pressung so wiedergegeben werden, dass er Salomo als Verfasser einer unbestimmten Zahl von Liedern erscheinen lässt. Ungefähr zwanzig Pflanzen und dreizehn Tiere werden erwähnt in jenem anziehenden Gedicht, dem Hohenlied, und es liess sich leicht vermuten, dass in Salomos andern Liedern viel mehrPflanzen und Tiere vorgekommen seien. Vierfüssler und Vögel werden auch sehr eingehend im Buche Job beschrieben, und rer Verfasser des Lobliedes auf Salomo glaubt wahrscheinlich annehmen zu sollen, dass Salomo sogar den Verfasser jenes dichterischen Meisterwerks übertraf ${ }^{2}$ ).

Aber gab es denn in vorexilischer Zeit keine Darstellung der Weisheit, keinen Versuch die Jugend über

1) Siehe Sir. 47, 17, wo der hebraisehe Text zeigt, dass der Verfasser an Prov. 1,6 denkt. Er nimmt angenscheinlich an, dass Salomos Sprichwörter denen in unserm Buch der Proverbien genau entsprechend gewesen seien. - 2) [Siehe Sir. 47 - S.] 
Sittlichkeit zu belehren? Gewiss. Etwa im siebenten Jahrhundert wurde ein Einschub in Gen. 18 vorgenommen, um nachzuweisen, dass die Abraham verheissenen Segnungen bedingt waren durch sein Streben, seinen Kindern und seinem Gesinde rechte Religion und Sittlichkeit einzuflössen (a. a. O. v. 17-19). Und wann auch immer die Mahnungen des Deuteronomiums, Kinder die heilige Geschichte und das Gesetz zu lehren (z. B. 4, 10; 6, 7. 20 ff.; 11, 19) zeitlich anzusetzen sind, wir dürfen annehmen, dass sie im Geiste der Urheber des älteren Deuteronomischen Gesetzbuches abgefasst sind. Diese neue lehrhafte Bewegung war ein indirektes Ergebnis der Predigt Jesajahs, der als erster unter den kanonischen Schriftstellern die Vorstellung von Jehovahs Weisheit zum Ausdruck brachte (Jes. 31, 2). Wohl ist es wahr, dass ein gewisser Glaube an die göttliche Weisheit schon vor seiner Zeit bei den Kanaanitern infolge Beeinflussung seitens der Babylonier bestand ${ }^{1}$ ). Doch ist es höchst unwahrscheinlich, dass dieser Glaube ebenso rein und religiös ebenso lebensfähig war wie die Anschauung Jesajahs. Mit welch liebevoller Ehrfurcht spricht dieser Prophet von dem "Plan" des grossen Herrschers der Welt, und wie ernstlich verachtet er die lächerlichen Pläne derer, welche nicht "nach Jehovahs Munde fragen" (Jes. 30, 2)! Für seine Person ist ihm nichts darum zu thun, ein "weiser Mann" genannt zu werden. Weisheit im religiösen Sinne des Wortes wird

1) Der Gott Ea wurde genannt "Herr der Weisheit und des Verstandes". 
noch zu sehr der Geschicklichkeit in der Verrichtung überlieferter Riten oder in der Hersagung magischer Formeln gleichgestellt. Es ist besser, Jehovahs Mundstück zu sein und ihm die ganze Ehre für jene wunderbare Einsicht zuzuschreiben, die Jesajah zum weisesten Israeliten seiner Zeit gemacht hat.

Wir wollen nun in aller Kürze eine Skizze von der früheren volkstümlichen Vorstellung von der Weisheit entwerfen. Grossen Regenten, wie David und Salomo, wurde der Besitz der "Weisheit Gottes" oder ydes Engels Gottes" zugeschrieben (Sam. B 14, 17. 20: Reg. A 3, 28), weil sie unverzüglich streng rechtliche Entscheidungen zu fällen vermochten. Staatsmänner konnten ebenfalls in den Ruf kommen, göttliche Orakel darzustellen, Ahitophel ist ein Beleg dafür (Sam. B 16. 23). Wahrsager, Priester und Propheten wurden als Weise verehrt, weil sie darauf Anspruch erhoben, den Menschen den Willen Gottes zu verkündigen, obwohl Jeremiah die Feder der Schreiber, welche die angebliche Weisheit der Gesetzbücher niederschrieben, eine .lügenhafte Feder" nennt (Jer. 8, 8), weil ihr Werk seiner eigenen mehr geistigen Predigt Eintrag zu thun drohte. Ebenso müssen Dichter den Israeliten sowohl wie den Arabern als im Besitz einer überirdischen Weisheit befindlich erschienen sein; sie hatten Anteil an der Inspiration des Propheten ${ }^{\mathbf{1}}$ ). Und Verfasser von Apologien und Parabeln, wie denjenigen des Jotham und der -weisen Fran " " von Thekoa wurden

1) Man beachte, dass von Bileam dem Seher gesagt wird, er hebe eine Parabel an", oder vielmehr, er ,trage ein (iedicht (makal) vor (Num. 23 f.). - ${ }^{2}$ ) Ri. 9, 8-15; 
zweifellos als an ihrem Teile gottbegnadigt angesehen; ja selbst die überlieferte Geschicklichkeit von Handwerkern wurde fromm auf eine Gottesgabe zurückgeführt, wie die hebräischen Erzählungen über den Ursprung der Kultur beweisen. Anderseits verdient es Erwähnung, dass es als Gegenstück auch eine Erzählung gab, in der sogar die Erkenntnis von gut und böse als unrechtmässiger Erwerb dargestellt wurde. Das war ein erster Versuch, die Mischung von Erhabenheit und Dürftigkeit im Menschenleben zu deuten. Der Mensch besass Erkenntnis wie die göttlichen Wesen, aber er stand kläglich hinter ihnen zurück, weil er Übel und Tod unterworfen war. Es blieb einer späteren Zeit vorbehalten, zu der Überzeugung zu gelangen, dass wahre Weisheit ein Lebensbaum sei.

$\mathrm{Ob}$ irgend eine erspriessliche Berührung zwischen der anfänglichen Weisheit der Israeliten und der ihrer Nachbarn in vorexilischen Zeiten erfolgte, wissen wir nicht. Jeremiah spricht von der Weisheit Temans (Jer. 49, 7), und es ist durchaus möglich, dass die Joberzählung, zum Teil in ihrer moralisierenden Fassung, kurz vor dem Exil von Edom aus Eingang gefunden hat. Jedenfalls bestand (wie wir sehen werden) solche Berührung in nachexilischen Zeiten. Gerade die Geschichte von Salomos Weisheit zwingt zu dieser Annahme. Man braucht keinen Nachdruck zu legen auf die einzelnen vom Erzähler erwähnten Völker. Der Punkt, den wir im Auge behalten müssen, ist

Sam. B 14, 2. Der Ausdrack, weise Frau wird in anderem Sinne Jer. 9, 17 verwendet. 
der, dass die berühmte Weisheit Salomos kosmopolitisch war. Es gab weise Männer unter andern Völkern, gerade so wie es dort wahre, freilich unbewusste Jehovahverehrer gab (Mal. 1, 11). Salomo war ihnen überlegen, weil er nach dem Glauben der Juden den einen wahren Gott besser kannte als jene, und sie kamen daher zu ihm, um Anregung und Belehrung zu empfangen. Aus dem Prolog der Proverbien ersehen wir, dass das vollkommen der Ansicht einiger jüdischer Weisen entspricht. Einer von diesen lässt die personifizierte Weisheit ausrufen (Prov. 8, 4):

„Nach ench, ihr Menschen, rufe ich,

„Und meine Mahnung gilt dem Menschengeschlecht;"

und später erklärt sie in dem erhabensten ihrer Monologe, dass sie von allen Geschöpfen Gottes am meisten am Menschengeschlecht ihre Freude habe (Prov. 8, 31).

Allerdings machen die beiden ältesten Bücher der Weisheit keinen praktischen Gebranch von dem in diesen Stellen beschlossenen Princip. Aber die allgemeine Beziehung der Weisheit ist schon gesetzt, und es ist nur eine Frage der Zeit, dass die jüdischen Weisen zu dem Bewusstsein von der Notwendigkeit praktischer Folgerungen durchdringen. Der Verfasser der sogen. Weisheit Salomos ist der mutigste und unerschrockenste von ihnen allen, denn er will Belehrung sowohl annehmen als geben, und wie Philo glaubt er felsenfest an die Existenz heidnischer Inspiration. Aber im Augenblick müssen wir uns begnügen mit dem relativ weiten Blick, der immerhin den nachexilischen Weisen aufgegangen ist. Diesen büsste nicht einmal der Ver- 
fasser des Sirachbuches ein, obwohl er mehr Nachdruck auf religiöse Formen legt, als jener frühere weise Mann. Um seine Bildung zu vervollständigen, muss der weise Mann, wie er sich ausdrückt, „durch das Land fremder Völker reisen", muss ,gute Dinge und Übles unter den Menschen erfahren“, und "wenn der grosse Herr will“, und er "mit dem Geist der Verständigkeit erfüllt ist", dann werden die "Völker" im allgemeinen sowohl wie die Gemeinde "sein Lob verkündigen" (Sir. 39, 4. 10). Denn nicht mit den Juden als solchen, sondern mit den Menschen ,begründete die Weisheit eine ewige Stiftung und mit ihren Sprösslingen wird sie im Bunde stehen" (Sir. 1, 15). Thatsächlich haben alle weisen Leute die Vorstellung von der Menschheit als Familie erfasst. Man kann ihr auch im Psalter begegnen. Aber jenes wichtige Buch hat doch in dieser Beziehung einen sehr engen Gesichtskreis. Die Leiden der Juden und besonders der Besten unter ihnen waren gegen Ende der Perserherrschaft so gross, dass es infolge einer rührenden Selbsttäuschung schien, als ob alle Menschen ausser den Juden sittlich nichtsnutzig wären. Jene Psalmen, in denen ein Verständnis für etwas wie die Brüderlichkeit der Völker zu dämmern beginnt, sind aus verschiedenen Gründen nach 332 v. Chr. anzusetzen. Ich nenne diese Beschränktheit des Gesichtskreises eine bedauerliche. Es ist zu beklagen, dass das Bild von dem missionierenden Gottesknecht eine relativ so geringe Wirkung erzielt hatte. Doch hat man eine vollkommen angemessene Ursache für diesen mangelnden 
Erfolg angeführt: es wäre das ein psychologisches Wunder gewesen, und solche darf man nicht erwarten. Vor der Ankunft des grossen makedonischen Versöhners des Ostens und des Westens mochte es schon eine Ahnung von der Thatsächlichkeit der göttlichen Leitung geben, nicht allein Israels, sondern des Menschengeschlechts überhaupt.

Man kann nur dankbar dafür sein, dass der Psalter nicht ganz in die persische Periode gehört. Unter den Worten, welche wir den spätern Psalmen zu verdanken haben, wollen wir diese treffenden ja nicht übersehen:

„Er, der die Völker in Zueht hält, kann er nicht strafen:

„Er, der die Menschen Erkenntnis lehrt? (Ps. 94, 10)"

Sie enthalten denselben Begriff, den wir in der Erzählung von Salomos Weisheit finden, nämlich dass die Weisheit, die von Gott gegebene Weisheit allen Menschen zugänglich ist; aber sie fügen hinzu, dass das Ziel des göttlichen Lehrers nicht lediglich theoretisch, dass es vielmehr praktisch ist. Ein Sittenlehrer späterer Zeit fasst dies in eine anziehendere Form:

„Die Barmherzigkeit eines Mensehen geht auf seinen Näehsten; „Aber die Barmherzigkeit des Herrn geht auf alles Fleiseh, ,Indem er sie tadelt, züchtigt und lehrt

,Und zurück bringt, wie ein Hirt seine Herde

(Sir. 18, 13 [12])."

Ein schönes Wort, wer sollte das nicht zugeben! Und es lässt auf eines der Haupterfordernisse eines Erziehers schliessen: Zuneigung zu seinen Zöglingen. Gottes geduldige bedächtige Unterweisung ist das 
Ergebnis seiner Barmherzigkeit oder Güte, und er sucht eine ähnliche Güte unter Mitbürgern, dass sie einander erzieherisch nützlich seien. In Ermangelung dieser Güte verdient ein Mensch nicht anders genannt zu werden als ein "Thor", denn

„Ein Verbrechen zu begehen, ist einem Thoren Zeitvertreib

$$
\text { (Prov. 10, 23)." }
$$

Die jüdischen Lehrer hegten im allgemeinen wenig Hoffnung, aus solchen Leuten etwas zu machen. Einmal finden wir freilich den edlen Gedanken:

„Sogar ein unnützer Mann kann Belehrung empfangen,

„Und ein Wildeselsfüllen mag werden gefangen ${ }^{1}$ )

$$
\text { (Job 11, 12)." }
$$

Aber öfter finden wir nur Unglücksweissagungen für den "Thoren" und den Rat, keine Hiebe für seinen Rücken zu sparen. Dass ein "Thor" jemals durch diese Behandlungsweise gebessert worden wäre. hören wir nicht. Ein Sprichwort versichert uns:

„Selbst wenn du einen Thoren inmitten seiner Genossen einsperrst $\left.{ }^{2}\right)$,

"Wirst du seine Thorheit nicht von ihm fortbringen

und ein anderes:

$$
\text { (Prov. 27, 22);" }
$$

„Ein Verweis macht Eindruek anf den, der Verstand hat;

„(Aber) ein Thor, wenn er gezüehtigt wird, macht sich leicht davon (Pror. 17, 10)."

In allen übrigen Fällen jedoch halten die weisen Leute ihren Einfluss für unbegrenzt. Es ist unnütz, von vornherein zu behaupten, dass weise Regeln wenig hätten

1) Der Reim entsprieht der Assonanz im Original, gemäss einer sehr einleuchtenden Verbesserung des verderbten hebräischen Textes („Das Buch Job“, Expositor Juni 1897) - $\left.{ }^{2}\right)$ Vgl. LXX. 
dazu beitragen können, die jüdische Jugend auf der Bahn des Rechten zu erhalten. Die Erfahrung belehrte die Alten in vielen verschiedenen Ländern anders. Für uns scheinen diese hebräischen Sprichwörter auf den ersten Anblick der treibenden Kraft zu entbehren; aber eine genaue Prüfung wird diese unsere Ansicht teilweise Lügen strafen. Als Torbeugungsmittel leistete die hebräische Weisheit im täglichen Leben den wichtigsten Dienst. Sie machte naturgemäss etwas ganz anderem Platz, aber nicht ohne auf die Form der Lehre, welche darauf folgte. einen dauernden Eindruck zu hinterlassen. - Wie hätte das auch anders sein können? Denn die besten Männer der Zeit befanden sich unter den Spruchlehrern. und bei der Lektüre der schönsten Teile der Proverbien können wir sogar die Bedeutung jenes Ausspruchs ermessen:

„Die Frucht des Gerechten ist ein Baum des Lebens,

„Lnd der weise Mann ist ein Seelengewinner

(Prov. 11, 30)."

Wie sorgsam die sogenannte "Weisheit" disponiert wurde, sehen wir an dem seltsamen Element der Lebensklugheit in derselben. Wenn die Furcht Jehovahs als erster Teil der Lehre gegeben wird, dann ist die Kunst des Fortkommens in der Welt der zweite. Es wirkt fast erheiternd zu bemerken, dass derselbe Schriftsteller, der da sagt, Weisheit sei viel besser als Reichtum, ebenfalls uns belehrt, dass Weisheit der beste Weg zum Wohlstand sei (Prov. 3, 14-16; 8, 18 f.). Thatsächlich bedeutet einer der bezeichnenden Ausdrücke für Weisheit: Fähigkeit gut zu lenken, und 
der allgemeine Sinn der Worte des weisen Mannes kann kaum idealistisch genannt werden. Der Ton, welcher sie durchdringt, ist der einer ruhigen Verständigkeit; in der That wird uns an vielen Stellen gesagt, dass „der, welcher kühlen Geistes ist, ein Mann des Verstandes ist" (Prov. 17, 27). Dann und wann scheint diese "Kühle" einem Beobachter aus unserer Zeit sogar in Plattheit umzuschlagen:

„Ein gewandter Mann sieht ein Unglück kommen und ver„birgt sich,

„Während die Einfältigen ihres Weges gehen und dafür leiden (Prov. 22, 3)."

Das ist jedoch lediglich ein Überbleibsel jener alten nomadischen Vorliebe für List und Schlauheit ${ }^{1}$ ), von welcher selbst David sich nicht frei hielt.

Im ganzen empfahlen die weisen Männer energische Thätigkeit, wie sie sich für diejenigen schickt, welche des Rechten und des Besitzes der Gnade Gottes sich bewusst sind.

Aber was soll man vom religiösen Anblick dieser Spruchweisheit sagen? Man fühlt sich leicht verleitet, dieselbe zu unterschätzen. Es muss jedoch mit allem Nachdruck betont werden, dass die weisen Männer mehr voraussetzen, als sie ausdrücklich sagen. Thre Lehre könnte beim ersten Anblick fast ausschliesslich weltklug erscheinen, aber sie setzt doch als zugegeben voraus die Anschauung von der irdischen Vergeltung,

2) Sogar der streng religiöse Verfasser des Prologs zu den Proverbien macht dreimal "Schlauheit" oder "Gewandtheit" zu einem wesentliehen Teil der Weisheit (1, 4: 8, 5. 12). Anderseits werden ,Schlauheit " und schlau $^{*}$ mit üblem Nebenbegriff gebraucht im Job $(5,12$ f.; 15, 5). Vgl. dritte Vorlesung. 
welche eine grundlegende Lehre des Gesetzes ist und legt entschiedenen Nachdruck auf jene sittlichen Eigenschaften, die aus der gehörigen Erfüllung der Gebote folgen. Indem jene alten Sittenlehrer Weisheit empfahlen, glaubten sie damit bestimmt das Gesetz zu empfehlen oder doch mindestens zu zeigen, dass die orthodoxe Religion nicht nur nicht mit weltlichem Erfolge unvereinbar sei, sondern ihm im Gegenteil zuträglich. Ihre Weisheit sei es weltklug, sei es gemeinnützig (utilitaristisch) im heutigen Sinn des Worts zu nennen, würde ein Irrtum sein. Ihr religiöser Charakter wird in der That nicht selten betont. So hören wir: „Die Furcht Jehovahs ist eine Schule der Weisheit, „Und vor der Ehre steht die Demut (Prov. 15, 33)"

d. h. die dauernde Ausübung der Religion ist die rechte Schule der Weisheit, und die Demut (die nach Lehre der späteren Schriftsteller halbe Gerechtigkeit ist) wird am Ende mit Ehre belohnt werden.

„Die Fureht Jehovahs verlängert die Tage, „Aber die Jahre der Gottlosen werden verkürzt werden (Prov. 10, 27)."

„Der Weg (d. h. das Verfahren) Jehovahs ist dem Unsehuldigen eine Feste,

"Aber Verderben den Missethätern (a. a. O. 10, 29)."

„Wer in seiner Aufrichtigkeit wandelt, fürehtet Jehovah, ,Aber wer anf seinen Wegen böse ist, rerachtet ihn

$$
\text { (a. a. O. 14, 2)." }
$$

d. h. Religion und Sittlichkeit decken sich, „Wer den Armen bedrückt, veraehtet den Schöpfer des armen „Mannes,

..Aber Jehovah ehrt den, der des Bedürtigen sich erbarmt (a. a. O. 14, 31)." 
d. h. Sittlichkeit ist begründet auf dem gemeinsamen Verhältnis aller Menschen zum Schöpfer.

„Scheol und Abaddon (d. h. alle Teile der Unterwelt) sind vor „Jehovah;

„Wie viel mehr denn die Herzen der Menschen!

„Die Augen Jehovahs sind an jedem Orte

„Und beobachten Böse und Gute (a. a. O. 15, 3. 11)."

Zwei schöne Ausdrücke für die Allwissenheit Jehovahs, - eine Eigenschaft, die nach der Zeit Jeremiahs tiefer gefasst wurde; denn wir dürfen nicht daran zweifeln, dass die in Rede stehende Beobachtung sich auch auf Herz und Gewissen erstreckt. Ein Psalmist der griechischen Zeit sagt schön:

„Aus dem Himmel blickte Jehovah hernieder,

„Er erblickte alle Stämme der Menschen;

„Von seiner sicheren Wohnung aus spähte er

„Auf alle, die auf Erden wohnen -

„Er, der ihrer aller Herzen schuf,

„Der ihrer aller Werk in Obacht nimmt

(Ps. 33, 13-15)."

Ein anderer weiser Mann sagt:

„Das Opfer der Gottlosen ist Jehovah ein Greuel, "Aber das Gebet der Aufrichtigen ist sein Ergötzen

(Prov. 15, 8),“

indem er damit andeutet, dass Gebet der beste Teil des Opferdienstes und sogar ohne Opfer willkommen ist. Ein anderer geht noch weiter und sagt:

„Das Rechte und Gerechte zu thun

„Ist vorzüglicher bei Jehovah als das Opfer

(a. a. O. 21, 3. vgl. 27)."

Ich will jetzt einen der schönsten religiösen Aussprüche in den Proverbien anführen: 
„Lass offenbar sein vor Jehovah, was du thun willst,

„Und deine $Z$ wecke werden erreicht werden (a. a. O. 16, 3)."

Natürlich bezieht sich dies anch nur auf sittliche Zwecke. Der weise Mann kamn nicht roraussetzen, dass wir Gott zu unserm Mitverschwornen gegen unsere Feinde machen können. Im Gegenteil; wie ein anderer Spruch sagt:

„Freve dich nieht, wenn dein Feind fällt ${ }^{1}$ ),

,End lass dein Herz nicht froh sein, wenn er gestürzt ist,

,Damit Jehovah es wieht sehe, und es ihm missfalle,

,Und er seinen Grimm abkehre von deinem Feinde

(a. a. O. 24,17$) .6$

Der Gedanke ist, dass eine boshafte Frende am Missgeschick anderer Gott missfällt, sogar wenn jener andre ein Feind des Gerechten ist, und dass, wenn der gerechte Mann, obwohl er Gottes Willen kennt, ihn doeh nicht thut nnd so Sünde begeht, er mehr Strafe verdient haben wird, als sein Gegner.

Und wiederum:

"Wenn deinen Feind hungert, gieb ihm Nahrung;

„Oder wenn ihn dürstet, gieb ihm Wasser zu trinken!

„Denn feurige Kohlen nahnst du weg ${ }^{2}$ )

„Und Jehovah wird dich belohnen (a. a. O. 25, 21 f.)."

Der Sinn ist, dass das neue Verhältnis, das durch diese unerwartete Gastfreiheit bedingt ist, das alte verderbliche Verhältnis zwischen Unterdrücker und Unterdrücktem aufheben wird. Die "feurigen Kohlen" des Streites (siehe 26, 21) werden fest angepackt und weggeschafft werden, und die Belohnnng, die denen

1) Wenu ein Inglück inn befallt. - 2f Wir nehmen eine Textreranderung vor, die den spruchschreiber vor dem Vorwurf sittlichen Wankelmuts bewahrt. 
zukommt, welche dem Bedürftigen helfen, wird durch Jehovah zuerteilt werden. Hier giebt es eine Aussicht für die Gerechten, die harten Herzen der Gottlosen zu zerschmelzen und sie vor der sonst sicheren Vergeltung zu bewahren. Oder, wenn das ein zu hoher Gedankenflug für die meisten Geister ist, so können doch alle verstehen:

„Wenn eines Mannes Wege Jehovah wohlgefallen,

"Versöhnt er sogar seine Feinde mit ihm (a. a. O. 16, 7)."

Augenscheinlich hat die jüdische Welt einen gewissen Fortschritt gemacht seit jener Zeit, als das personifizierte Israel noch beten konnte:

„Zu Schanden und Unehren mögen die gemacht werden, die „meine Seele suchen,

„Zurückgescheucht und beschämt mögen die werden, die meinen „Schaden planen;

„Mrögen sie sein wie Spreu vor dem Winde,

„Und Jehovahs Engel sie verfolgen;

„Möge ihr Weg dunkel und schlüpfrig sein,

„Und Jehovahs Engel sie stossen (Ps. 35, 4-6).“

Wir müssen uns jedoch dessen bewusst bleiben, dass der Psalmist nicht von Einzelpersonen im allgemeinen, sondern von feindlich gesinnten Gemeinden oder Parteien spricht. Einzelne können leichter durch Güte erreicht werden, als eine Gesellschaft von Menschen. Dieselbe Sammlung von Sprichwörtern enthält auch noch diesen erschütternden Ausspruch:

„Jehorah hat jedes Ding für sein Ende gemacht;

„Ja selbst die Gottlosen für den Tag der Heimsuchung (Prov. 16, 4)."

Das erinnert uns an einen Psalmisten, der beim 
Rückblick auf die drückende Herrschaft und den plötzlichen Zusammenbruch des Perserreichs folgenden Zug zu einem tiefsinnigen Bilde Jehovahs hinzufügt, das ein "Thor" nicht verstehen kann:

,Wenn die Gottlosen emporwachsen wie das Kraut,

,Und alle Thäler der Ungerechtigkeit blühen,

„Es ist (nur), damit sie zerstört werden ewiglich,

„Während du, Jehovah, König bleibst ewiglich

(Ps. 92, 7 f.)."

Beide, Psalmist und Weiser, nehmen an, dass es menschliche Wesen giebt, welche unverbesserlich böse sind, nämlich die Juden, welche sich von der Wahrheit abgewandt haben, um der Lüge zu dienen, und die Heiden, welche sich zusammengerottet haben, das eine grosse Licht, das Gott in eine dunkle Welt gestellt - das Licht des Bundesvolkes Israel -, auszulöschen. Solche gottlose Leute sind unfähig zur Reue, sie müssen vertilgt werden. Ihre „unverhältnismässige Sünde

„Kämpft mit der Harmonie der Natur, und mit schrillem Geräusch „Durchbricht sie die reine Musik, die alle Kreatur darbringt "Ihrem grossen Herrn." ${ }^{1}$ )

Aber beide, der Psalmist wie der Weise, haben gelernt, geduldiger zu sein, als früher möglich schien. Der "Tag Jehovahs" muss abgewartet werden. Es ist nutzlos auszurufen: "Wache auf, warum schläfst du, Jehovah? (Ps. 44, 24)" Für den Augenblick duldet der Allwissende Böse sowohl wie Gute; er lässt beide miteinander wachsen bis zur Ernte. Wie ein weiser Mann sagt:

1) Miltun. -At a Solemn Musick." 
„Der arme Mann und der Erpresser stossen einander; „Jehovah erleuchtet die Augen beider (Prov. 29, 13)."

Thatsächlich macht gerade dies Nebeneinanderbestehen von gut und böse, weise and thöricht innerhalb derselben Gemeinde eine Centralautorität unentbehrlich. Wenn auch die an den Einzelnen sich wendende Methode der "weise Männer" genannten Lehrer allgemein angewandt werden könnte, so würde es doch noch schwierig sein, die zügellosen Triebe der Menge zurückzudämmen. Denn:

„Ohne einen Zaum ${ }^{1}$ ) wird das Volk unbändig; „Aber wohl dem, der das Gesetz festhält

(Prov. 29, 18)."

Der Ausdruck „das Gesetz" bedeutet hier jenen gedrängten Auszug und jene praktische Anwendung der Lehre der Schriften, die durch die weisen Männer für ihre Zöglinge vorbereitet wurde. Das Unglück war, dass die Centralgewalt sich in den Händen heidnischer Herrscher befand, und diese hatten nicht dieselben sittlichen Grundsätze wie die weisen Männer. Dennoch ist die Sprache der Proverbien betreffs des Königs etwas überraschend. Wurde der König an einigen Stellen als einheimischer Herrscher angesehen? Oder manchmal sogar als Messias? Hier sind die fraglichen Stellen:

I. ,Des Königs Gunst ist für einen verständigen Knecht, "Aber ein gemeiner erfährt seinen Grimm (a. a. O. 14,35)."

1) Hier besonders springt die Notwendigkeit eines verbesserten Textes in die Angen. Der uberlieferte Text hat ,ohne Gesicht, was vermutlich bedeutet ,ohne prophetische Offenbarung".

Cheyse, Religiöses Leben der Jaden. 
II. ,Jehovahorakel ist auf den Lippen des Königs;

,Sein Mund wird nicht gegen die Gerechtigkeit verstossen

(a. a. O. 16, 10)."

III. „Güte und Wahrhaftigkeit bewachen den König;

„Und durch Güte stützt er seinen Thron (a. a. O. 20, 28)."

IV. ,Nimm die Schlacke vom Silber weg,

,Und das Ganze kommt versehönert hervor;

„Nimm den Gottlosen weg von dem Angesicht des Königs, ,Und durch Gerechtigkeit wird sein Thron fest stehen

(a. a. O. 25, 4 f.)."

V. ,Mein Sohn, fürchte Jehovah und den König

"Und lass dich nicht mit denen ein, welche sie hassen;

,Denn plötzlich wird ihr Unglück erscheinen,

„Und der Untergang der Hasser wird unversehens kommen

(a. a. O. 24,21 f.)."

VI. ,Drei Dinge sind von stattlichem Gange,

„Ja, vier von stattlichem Schritt:

„.Der Löwe, der Held unter den Tieren,

,Den nichts zurückzutreiben vermag,

,.Der Hahn' ${ }^{1}$ ), der (stolz) sich erhebt und der Ziegenbock ..Und ein König, der Held seines Volkes (a. a. O. 30, 29-31)."

Es giebt auch eine eigentiumliche Gruppe ron Ratschlägen, bezeichnet als „Worte eines Königs; ein Spruch [oder Gedicht], womit seine Mutter ihn belehrte". Die Aussprüche sind jedoch durchweg gekünstelt und sehr späten Ursprungs, sie sollen uns jetzt nicht aufhalten.

Die Aussprüche in der vorigen Gruppe sind viel anziehender. Aber nicht einmal diese tragen ein klares Gepräge der Wirklichkeit. Ein nichtjüdischer König

2) Wean diese Übersetzung richtig ist, dann spricht sie fur oder vielmehr erfordert sie ein sehr spates Datum der Stelle. Sithe s. F. ,Coch- in Enc. Bibl. 
konnte in einem mehr oder weniger höflichen lyrischen Gedicht wohl noch idealisiert werden, aber kaum in Sprüchen, die für die volkstümliche Belehrung bestimmt waren. Sicher ist es nur das letzte Paar der oben angeführten Gruppe, das auf zeitgenössische Könige Bezug nimmt: das erste auf einen griechisch-ägyptischen, das zweite wahrscheinlich auf einen makkabäischen Fürsten. Die vier vorhergehenden müssen jedoch besonders die Aufmerksamkeit des Religionsforschers erregen. Sie stellen ein messianisches Element im Buch der Proverbien dar, das Ähnlichkeit hat mit den meisten Königshymnen im Psalter. Die Verfasser sehen mit grosser Zuversicht die baldige Erneuerung des angestammten Königtums voraus und suchen den Gemütern ihrer jungen Schüler erhabene Vorstellungen vom Charakter desselben einzuflössen. Die Aussprüche erinnern uns an Psalm 45 und 72. Dagegen kommen solche Elemente nicht im Sirachbuch vor, obwohl dieses interessante Buch ein Gebet von bemerkenswerter Schönheit für die Befreiung und Verherrlichung Israels enthält (Sir. 36, 1-17).

Spuren jedoch davon, dass die Weisen einen ausgebildeten Messiasglauben hegten, fehlen; sie scheinen die auf keimenden Anschauungen der späteren prophetischen Schriftsteller vollkommen zu übersehen. Es ist kein Weltregent, sondern ein unschuldiger, bescheidener König von Israel, den sie uns vor Augen stellen, obwohl sie, augenscheinlich auf Grund eines feststehenden Brauchs, den Namen Israel nicht einmal erwähnen. Auf diesen König warten sie geduldig, denn sie leben 
der Zuversicht, dass Jehovah sie nicht immer unter der Herrschaft der Ptolemäer lassen werde, wie lange sie auch immer im Vergleich mit der Herrschaft der letzten Perserkönige dauern möge. Sie sind damit zufrieden, dass der letzte Gerichtstag noch eine Zeitlang verschoben wird, weil sie bemerken, dass sogar jetzt die Gerechten nicht ganz und gar vergessen sind, und dass die einzelnen ziemlich alle eine entsprechende irdische Belohnung für ihre Gerechtigkeit empfangen. Auch war wohl die Mehrzahl der Weisen beschränkt in der Äusserung ihrer Ansichten durch pädagogrische Erwägungen. „Jehovah zu fürchten und das Böse zu meiden" war alles, was der gemeine Mann zu wissen begehrte.

Für einige unter den Weisen war jedoch diese streng praktische Ansicht von der Weisheit nicht ausreichend. Es giebt sogar im Buch der Proverbien eine Stelle, die ein Interesse an Erscheinungen des Weltgebäudes beweist, und andere Stellen befinden sich im Job. Allerdings findet sich erstere Stelle im Prolog der Proverbien, der ein Ganzes für sich bildet und von dem Hauptteil des Werkes in mancherlei Hinsicht sich stark unterscheidet. Hier folgt die Schilderung. Sie besteht aus fünf vierzeiligen Stanzen $\left.{ }^{1}\right)$ :

„Jehovah brachte mich hervor als Erstling seiner Schöpfung,

„Das älteste seiner uralten Werke;

„Denn von Ur an wurde ich gewirkt,

"Ton Anfang an, von den ersten Tagen der Welt." 1) C'ber den T'ext siehe den Artikel, On some obscure passages ete. IQR
Oct. 1897. $\left.{ }^{1}\right)$ C'ber den T'ext siehe den Artikel, On some obscure passages ete. IQR
Oct. 1897. 
„Als die Wasserfluten nicht waren, wurde ich hervorgebracht; „Als es keine Quellen gab, die vom Wasser übersprudelten, „Ehe die Berge tief gegründet wurden, "Vor den Hügeln wurde ich hervorgebracht. ${ }^{1}$ "

„Ehe er das Land und das Gras gemacht hatte „Und mit Grün die Schollen der Mutter Erde bekleidet hatte, „Als er die Himmel vorbereitete, war ich da, "Als er einen Bogen über den Ocean wölbte";

„Als er die Wolken droben ausbreitete, „Als er die Brumnen des Oceans festlegte, ,Als er der See ihre Ufer zuwies, „Damit die Wasser nicht sein Gebot übertreten könnten," „Da war ich täglich neben ihm als Künstlerin, „Indem ich beständig vor ihm spielte, „,Mein Spiel trieb bei der Ausarbeitung ${ }^{2}$ ) seiner Erde ,Und mein Ergötzen hatte am Menschengeschlecht

(Prov. 8, 22-31)."

Das ist gewiss eine der erhabensten Stellen in der Weisheitslitteratur. Sie besagt, dass die präexistente Weisheit der Weltbildner war, eins in Zweck und Thätigkeit mit der schöpferischen Gottheit, und im Zusammenhang betrachtet beweist sie, dass die Weisheit ihre Lehrlinge in das Studium der Erscheinungen des Weltgebäudes so gut einführt, wie in das der Sittlichkeit des täglichen Lebens. Der Anfang oder erste Teil der Weisheit besteht nach dem Verfasser in der Furcht Jehovahs; oder um unsere Erklärung zu erweitern, ohne ihre Bedeutung zu verändern: sie ist eine Verbindung der Religion mit einer gewissen praktischen Geschick-

1) Das gleicht der Beschreibung des ersten Menschen, der die personifizierte Urweisheit ist, in Job 15, 7 f. - 2) Diese Textrerbesserung ist augenscheinlich richtig. Sie entscheidet wahrseheinlich ủber die Richtigkeit der Übersetzung "Künstlerin ${ }^{\star}$ in Zeile 1 der Stanze. 
lichkeit. Aber der letzte Teil trägt einen etwas mehr verfeinerten esoterischen Zug. Es ist das die Betrachtung der Werke Gottes in der Natur, und es ist genau eine solche Betrachtung der Ideale, deren Ausdruek diese Werke sind oder, nach hebräischem Sprachgebrauche, der präexistenten Weisheit, welche Gott selbst nicht verachtete, als er die Welt erschuf. Wie denn ein anderer hebräischer Dichter, einer der Verfasser des Buches Job, schön sagt:

„Als er eine Wage für den Wind machte

„Und die Wasser mit dem Mass bestimmte,

„Damals beobachtete und prüfte er sie wohl,

,Er richtete sie auf und ergründete ihre Tiefe

(Job 28, 26).

Thatsächlich enthält das Buch Job mehr als eine Stelle, in der die weitere Fassung menschlicher Weisheit deutlich Ausdruck findet. Beispielsweise empfichlt der Verfasser der Reden Jehovahs bestimmt die Naturbeobachtung. Allerdings besitzt er nicht den modernen wissenschaftlichen Geist und blickt die Natur an in dichterischer phantasievoller Weise mit zu Grunde gelegtem lehrhaften Zweck. Aber wir dürfen die Wichtigkeit dieser Betrachtungsweise nicht unterschätzen. An der Natur Interesse hegen heisst den ersten Schritt thun zu ihrem Verständnis. Ich würde mit Freuden einige von des Verfassers schönen Bildern ans dem Tierleben anführen; aber ich habe nur Raum für eine Reihe mehr naiver Fragen, zu welchen es ziemlich auffällige Parallelen in der Zoroastrischen Litteratur giebt. Doch fehlen auch verwandte Stellen bei den Hebräern selbst 
nicht. Das erste Lied, das von einem Besuch bei den göttlichen Vorratshäusern für Schnee und Hagel redet, erinnert uns an die Geschichte Henochs, wie sie in dem nach ihm benannten Buche dargestellt wird ${ }^{1}$ ).

„Bist du jemals zu den Vorratskammern des Schnees gekonmen?

„Und hast du die Hüter des Hagels gesehen? -

„Den ich aufbewahrt habe für die Zeit der Heimsuchung,

„Für den Tag des Kampfes und Krieges?"

„Auf welchem Wege geht der Nebel aus,

„Um kalte Feuchtigkeit auf die Erde zu sprengen?

„Wer spaltete eine Rinne für den Regenstrom,

„Und eine Bahn für die Windstösse, - "

„Um Regen zu senden über ein Land ohne Menschen,

„Über die Wildnis, wo keine Leute sind,

„Um die äusserste Verödung zu befriedigen

"Und das durstige Land frisehes Kraut hervorbringen zu lassen?"

„Aus wessen Schoss kam das Eis?

,Und den Reif des Himmels, wer erzeugte ihn?

„Die Wasser schliessen sich zusammen wie ein Stein,

„Und die Oberfläche der Tiefe verbirgt sich."

„Bindest du die Knoten der Pleiaden?

„Oder lösest du die Fesseln Orions?

„Kannst du die Hyaden aufgehen lassen zu ihrer Zeit?

„Und die Bärin und ihr Junges führen?" ")

„Kennst du die Gesetze des Himmels?

„Bestimmst du seinen Einfluss auf die Erde?

„Kannst du der Wolke einen Befehl hinaufsenden,

"Dass Wassermassen dich bedecken? $\left.{ }^{3}\right)^{\prime}$

Die Ironie der Fragen ist unverkennbar. Aber sie sind nicht ausschliesslich bestimmt, Job zu

1) Henoch 60, 17; vgl. 69, 23. - ") Die Wiedergabe der Sternbildernamen ist nieht überall sicher. - ${ }^{3}$ ) Job 38, 22-27. 29-34 (naw verbessertem Text); siehe JQR Oet. 1897 . 
demütigen, indem sie ihm einen Begriff von der Beschränktheit seines Wissens geben, sondern ihn anzuregen, aus sich selbst in den grossen Bildersaal der Welt hinauszutreten. Der Dichter, der ebenfalls ein Weiser ist, stimmt weder überein mit den Ansichten Jobs und seiner Freunde, wie sie in den Dialogen dargestellt werden, noch mit denen des einen Herausgebers, der im Gegensatz zu dem Dichter, dessen Werk er bearbeitet, behauptet, das „einzig für einen Menschen sich ziemende Studium" sei praktische Religion. Man lese einen Teil der letzten Strophe des in Rede stehenden Gedichts:

„Woher geht demn die Weisheit hervor?

,Und wo ist der Platz des Verstandes?

„Da es doch verborgen ist vor den Augen alles Lebendigen

"Und rerschlossen gehalten vor den Vögeln des Himmels."

„Der Abgrund und die Unterwelt sagen:

„Thr Gerïcht hat unsere Ohren erreicht.

,Gott hat den Weg zu ihr bezeichnet,

„Er ist bekannt mit ihrem Orte ${ }^{1}$."

Die Weisheit ist demnach nicht unabhängig von Gott, der in der That ihr ursprünglicher Erfinder war. Diese Entdeckung und ihre Bedeutung für den Schöpfungsvorgang werden dargelegt in den letzten vier Zeilen, die ich schon angeführt habe ${ }^{2}$ ). Und dann erscheint ziemlich unvermittelt die folgende, nur zu strenggläubige Behauptung:

„Und er sagte zum Menschen: Siehe die Furcht Jehovahs „Das ist Weisheit, und Böses zu meiden ist Verstand." ${ }^{3}$ )

1) Job 2s, 20-23. - 2) Siebe Seite 150. - 3) Job 28, 28. 
Ich behaupte nicht, dass der Verfasser dieses Zusatzes gedankenarm war, aber ich behaupte allerdings, dass er von dem Verfasser des Gedichtes selbst sich unterschied. Dieser beabsichtigte sicherlich nicht, bei seiner grossen Lobrede auf die höhere Weisheit die Menschen vom Interesse an der Natur abzuschrecken. Dieser neue Schriftsteller besass keine dichterische Phantasie, und wie demnach zu erwarten, schreibt er in Prosa und nicht in Versen.

Wir hoben soeben hervor, dass der Weise, der die Reden Jehovahs verfasste, nicht mit all seinen Genossen übereinstimmte. Aber in einem Punkte stimmen er und all die grössten der weisen Männer überein, es giebt keine Unterbrechungen im Zusammenhang der Welt. Es giebt einen Platz, so wird uns in den Proverbien $(16,4)$ gesagt, sogar für die Bösen in Gottes Anordnung der Dinge, und es muss am letzten Ende ein Einklang zwischen Natur und Sittlichkeit bestehen. Nachdenkenden jüdischen Theisten offenbarte sich Gott als der Allweise. Es gab niemals eine Zeit, wo die göttliche Weisheit nicht da war. Es gab niemals irgend einen Zusammenstoss (wie es die Hiobdialoge vorauszusetzen scheinen) zwischen Jehovah und dem Drachen des Chaos $^{1}$ ); über das Chaos schweigt der Lobredner der Weisheit in beredter Weise. Auch vermag er die Vorstellung einer willkürlichen Allmacht nicht zu billigen. "Gott ist," wie Hooker, genannt

1) Die Beschreibung von Behemoth und Liwjathan (siehe darüber Expositor Jnli 1897 oder Ene. Bibl.) gehört nicht zu den Reden Jehovahs in ihrer ursprünglichen Gestalt. Der Verfasser der Dialoge nimint jedoch auf den Liwjathan genannten Claosdrachen Bezng. 
nder Verständige", sagte, "sich selbst ein Gesetz"; "seine Weisheit hat die Wirkungen seiner Macht eingesehränkt". Und so mächtig, so voll Leben ist dieses weise und wohlthätige Gesetz, dass es einem orientalischen Denker unmöglich ist, es nicht zu personifizieren. Und was für eine Person ist das! Arbeit bedentet für sie Zeitvertreib $\left.{ }^{1}\right)$ ! Die Ausgestaltung der Welt ist keine sechstägige Beschäftigung sondern eine dauernde und auserlesene Freude; der Schöpfer bedarf keiner Sabbatruhe, denn er kann nicht müde werden. Hier stehe auch der so wundervoll dem fleischgewordenen Wort im Evangelium des Geistes angepasste Ausspruch: „Mein Vater wirkte bisher, und ich wirke auch" 2). Das Weltall ist, wie Emerson es ausgedrückt hat, eine ,göttliche Improvisation", sein Baumeister ist der "Ewige Sohn". Zweifellos ist das einer der schönsten Gedanken im Alten Testament. Er steht lier ganz isoliert; aber ebenso ist mehr als ein Gedanke in dem Geistesevangelium des Neuen Testaments einzigartig. Das so zum Ausdruck gebrachte Ideal kann seitens derjenigen, welche eine ebenso heitere wie tiefsinnige Religion besitzen wollen, nicht ungestraft verachtet werden.

Weiter haben wir jetzt zu fragen: Welche andern Gedankenformen sind dieser seltsamen neuen Vorstellung von der göttlichen Weisheit am nächsten verwandt? Der forschende Geist, für den die veründerlichen Bilder des menschlichen Lebens doch ein zu enges Gebiet

1) Es ist naturlich ein Zufall, dass die "Weisheit* als Weib personifiziert ist (das hebraische Wort fur Weisheit - ה: - ist feminin). - ${ }^{2}$ ) Joh. 5, 17. 
bilden, ist derselbe, der die himmlischen Sphären im Buch Henoch durchwandert; er hat einen phantastischen (mythologischen) Ausdruck gefunden in der Erzählung von Henoch ${ }^{1}$ ), der durch die Engel über die Geheimnisse des dreiteiligen Weltalls belehrt wurde. Anspielungen auf diese Erzählung in ihrer frühesten Gestalt finden sich Gen. 5, 21-24 und wiederum in einer Weissagung Ezechiels (28, 3), der in seiner Anrede an den Fürsten von Tyrus sagt:

„Siehe, du bist klüger als Henoch; es giebt kein Geheimnis, "das vor dir verborgen bleiben könnte."

Ich muss zur Erklärung bemerken, dass diese Übersetzung eine so notwendige wie einfache Textverbesserung voraussetzt. Jedermann muss es zugeben, dass der Ausdruck "weiser als Daniel" in dieser Fassung und zu Ezechiels Zeit höchst auffallend ist. Anderseits muss dieser Prophet Henoch als einen Verkünder der Geheimnisse gekannt haben, und die ihm zugekommene Kunde war zweifellos verquickt mit einigen Gedanken aus der Naturphilosophie der Babylonier. Allerdings gehen die Verfasser des Henochbuchs weit über Ezechiel hinaus, aber nicht minder übertrifft die Beschreibung der göttlichen Weisheit in Teilen der Proverbien und Job bei weitem die im Deuterojesajah ${ }^{2}$ ) gegebenen dürftigen Andeutungen. Aber wir müssen uns weiter in der Ferne umsehen nach Parallelen zur personifizierten göttlichen Weisheit. Ich weiss wohl, dass einige Gelehrte dagegen Einspruch erheben werden. Sie sind der Ansicht, dass

1) Siehe s. จ. "Enoch- in Blacks Enc. Bibl. - ${ }^{2}$ ) Jes. 40, 13 f. 
fast all die seltsamen neuen Triebe der nachexilischen Periode als ächtjüdischen Ursprungs aufgezeigt werden können. Sie denken, dass diese Ansicht mit dem selbstisolierenden Streben des Esranischen Zeitalters am besten in Einklang zu bringen sei. Das ist meiner Meinung nach ein grosser Irrtum. Die Gesetze des menschlichen Denkens sprechen gegren das von diesen Gelehrten angenommene Streben nach Selbstabschliessung. Orientalische Einflüsse aller Art machten sich fühlbar, zuerst vor allem bei dem Volk und dann auch bei seinen religiösen Führern. Besonders in der griechischen Zeit, welcher der Prolog der Proverbien ganz oder nahezu sicher angehört, erfolgte eine Befruchtung des geistigen Ackers mit nenen Ideen überall in der jüdischen Welt. Viele Juden wanderten nach Ägypten, besonders nach Alexandria, und wir wissen, dass im alten Ägypten die Hypostasierung göttlicher Eigenschaften in weitem Umfange gebräuchlich war $\left.^{1}\right)$. Es ist eine irrige Annahme, dass altägyptische Ideen die griechische und jüdische Gesellschaft in Alexandria hätten nicht beeinflussen können. Und persische Einflüsse machten sich bei den Juden gar noch stärker fühlbar nach dem Eroberuugszuge Alexanders. Der gegenwärtige Stand der Forschung lässt betreffs der Geschichte des Zoroastrianismus einige Zurückhaltung gerechtfertigt erscheinen; aber nicht ohne Grund wird man annehmen dürfen, dass der Nachdruck, den der Zoroastrianismus auf die Weisheit als

1) Wiedemann. Geschiebte Ägyptens, S. 53. rgl. Brimmer, Three essays etc. p. 29 . 
die hauptsächlichste göttliche Eigensehaft und auf den Unterschied zwischen der himmlischen Weisheit ${ }^{1}$ ) und der „durch das Ohr erworbenen" legte, einigen Einfluss auf die Juden ausübte, zunächst freilich nur auf die in oder nahe bei Persien wohnenden Juden. Ich bin nicht so kühn anzunehmen, dass die Vorstellung von der himmlischen Weisheit, welche das erste von Ahura-Mazdas Geschöpfen war, geradezu übernommen und zurechtgestutzt wurde seitens des Verfassers des Prologs zu den Proverbien oder einfach dafürzuhalten, dass die weiter vorgeschrittene religiöse Philosophie des Zoroastrianismus die Entwicklung einer neuen jüdischen Religionsphilosophie beförderte, die da gipfelte in dem Glauben an ein allweises und daher im strengen Sinne des Wortes nicht allmächtiges Wesen, den Schöpfer und Lenker der Natur und der Menschenwelt. Platonische und stoische Einflüsse vorauszusetzen scheint mir so unnötig wie unsicher.

Hier möchte ich wohl abbrechen; aber darf ich das echte Buch Job, zu welchem die beiden schönen Gedichte, die ich angeführt habe, Anhänge bilden, unberührt lassen? Und wie könnte ich den Patriarchen Henoch von dem Patriarchen Job trennen: den einen als Vertreter der Naturphilosophie, den andern als den der Moralphilosophie? Der erstere trat in seine vollgiltige Stellung lange nach dem letzteren ein. Augenscheinlich übte das Leben Henochs zuerst keine starke Anziehung auf denkende Juden aus. Dass

1) Siehe Zendaresta ron Darmesteter und Mills (Sacred books of the East) and rgl. Cheyne im Expositor $Y$ (1892), p. is sq. 
nach 365 Jahren Gott einen so frommen und hochbegabten Mann nicht länger entbehren mochte, sondern ihn in seine unmittelbare Gegenwart aufnahm: dieser frühe Hingang Henochs hatte trotz seiner ausserordentlichen Umstände, und wie sehr er auch zum Nachdenken anregen mochte, doch für das Herz nichts Anzichendes. Aber die Geschichte Jobs, der von der Höhe des Glücks in die tiefste Tiefe des Elends hinabsank, indem er nicht allein sein Eigentum verlor sondern auch seine Kinder, ja selbst von der schlimmsten Art des Aussatzes heimgesucht wurde, und dem doch zur allgemeinen Verwunderung von Gott Gesundheit und Reichtum zurückgegeben wurden, sie erregte zahllose Gedanken ron tiefstem menschlichen Interesse.

Ezechiel erwähnt Henoch. wie wir gesehen haben, an einer Stelle als bevorzugrten Inhaber übermenschlicher Weisheit. In einer andern vielangeführten Stelle (Ez. 14. 14) stellt er ihn zusammen mit Noah und Job als aussergewöhulich gerechten Mann; denn die Aufaihlung "Noah, Daniel und Job" ist selbstverständlich unrichtig! Es giebt kein Anzeichen dafür, dass er jene grössere Anziehungskraft in der Geschichte Jobs, von der ich gesprochen habe, erfasst hätte, und dieser Mangel ist kein Zug an Ezechiel, der geeignet wäre, uns zu diesem strengen Propheten hinzuziehen. Was hat denn aber zuletzt den Menschen die Augen dafür geöffinct? Es waren die fortdauernden Enttäuschungen jener Periode, die man gemeiniglich die nachexilische nennt. Nachexilisch, allerdings! Denn das Exil Israels 
in seinem tiefsten Sinne ${ }^{1}$ ) hat seit der Zerstörung Jerusalems durch Nebukadnezar bis auf unsere Tage fortgedauert. Gerade das hat die Juden zu solehen Idealisten gemacht; gerade diese Bedeutung des Exils regte jenen unbekannten nachexilischen Dichter an, der der alten hebräischen Legende von Job dem Dulder die erste entsprechende Fassung gab.

Der Prolog (Kap. 1 f.) und der Epilog (42, 7-12) des Liedes müssen beide diesem Verfasser zugeschrieben werden. Der erstere ist voll zarter Psychologie und unnachahmlichen Humors; der letztere, der beginnt:

„Und Jehovah sagte zu Eliphaz von Teman: Mein Zorn ist ,entbrannt gegen dich und deine beiden Freunde, weil ihr "nicht recht von mir geredet habt, wie es mein Knecht Job "gethan"

und schliesst mit der Angabe, dass Job starb, nachdem er seine Tage erfüllt, ist trocken und prosaisch ${ }^{2}$ ) und sittlich sogar, für uns wenigstens, enttäuschend. Es war Jobs hohe Bestimmung, wie wir sehen werden, "Gott umsonst zu dienen", und indem er eine greifbare Belohnung, wie es doch der Fall war, aufgedrängt erhielt, scheint er uns in sittlicher Hinsicht herabzusteigen. Aber um dem Verfasser sein Recht widerfahren zu lassen, haben wir ihn nicht als Künstler, sondern als Lehrer anzusehen. Er sorgt sich um sein Volk viel mehr als um Job, und da bekanntlich eine

1) „In seinem tiefsten Sinn* vgl. erste Vorlesung. S. 12: ..wenn es überhaupt ein nachexilisches Zeitalter gab“. - ") Dr. Bartlett und Dr. Peters haben von asthetischem Standpunkt aus wohlgethan. den Epilog aus ihrer ausgezeichneten sammiung ausgewählter Stellen der Bibel (Seriptures, Hebrew and ('bristian, part Vl, chapt. V) fortzulassen. 
„doppelte Belohnung für Israels Unfälle" eine ständige Wendung in der späteren prophetischen Lehre ist, so fühlt er sich verpflichtet, Job als doppelt für sein unverdientes Unglück belohnt hinzustellen. Die Hauptbedeutung des Epilogs besteht darin, dass er uns in den Stand setzt, die Hauptumrisse des ausgefallenen Teiles der Erzählung wieder nachzuzeichnen. Dank ihm sind wir in der Lage, in gewissem Sinn den, der „seine Erzählung halb vollendet hinterlassen hat" (oder dessen Herausgeber uns nur eine halbe oder eine verkehrt aufgefasste Erzählung überliefert haben) "wieder zu fragen" nach der Geschichte des Geduldigsten der Menschen.

Das Ergebnis einer solchen Nachforschung würde wahrscheinlich $\operatorname{sein}^{1}$ ), dass an der Stelle von Job 3-42, 7 ursprünglich etwa folgendes, nur im Stil einer fliessenden natürlichen Beredtsamkeit, zu lesen war:

„Und diese drei Männer, bewegt bei dem Anbliek von Jobs „Herzeleid, brachen in Klagen aus und enthielten sieh nicht "leidenschaftlicher Beschwerden über die Ungerechtigkeit Gottes. „Sie sagten: Ist Erkenntnis bei dem Höchsten, und hält Gott "gerechtes Gericht? Aber Job gefiel das übel, und er tadelte "sie und sprach: Bitter ist der Schmerz, der mieh peinigt, aber „noch bitterer sind die Worte, die ihr redet. Gelobt sei der „Höehste für das, was er gab, und jetzt, da ich beraubt bin, „sei doch sein Name gelobet. Ich will ihn anrufen und spreehen: "Zeige mir, worin ieh gefehlt; lass mich nicht dahin fahren „,unter der Last deines Zornes. Denn Gott ist gütig gegen „alle die, welche ihn anrufen, und wird nieht zulassen, dass die "Gerechten auf ewig fallen. Und Job rechtete mit seinen „Freunden und gebot ihnen Busse zu thun, damit Gott nieht „,verführe mit ihnen als mit Übertretern. Und am Ende einer

1) So zuerst Macdonald im Journal of biblical litterature 1895, p. 63-71. 
„Frist erschien Gott Eliphaz in einem Traume und sprach: „Mein Zorn ist entbrannt gegen dich und deine beiden Freunde, "weil ihr nicht recht von mir geredet habt, wie mein Knecht „Job gethan."

Das stimmt, wie mir scheint, überein mit der früheren Ansicht von Job als einem vollkommen gerechten Mann, einem zweiten Abraham oder Noah. Dem entspricht auch, dass Jehovah den drei Freunden eine ernste Rüge erteilt, und dass sie einer geheimnisvollen Strafe, wovon sie nur durch Jobs Fürbitte befreit werden können, verfallen sind. Ebenso entspricht dem auch das dem Job erteilte hohe Lob, während er doch nach dem jetzigen Wortlaut des Gedichtes betreffs Gottes gewiss nicht in allen Punkten recht redet. Es stimmt auch überein mit den Ausführungen eines andern wichtigen Buches, das auf dem Original des Jobbuches zu beruhen scheint: ich meine die Schilderung des leidenden Gottesknechts in Jes. 52, 13-53, 12 .

Diese feinsinnige Beschreibung des grossen Märtyrers, welche uns schon ergötzt hat ${ }^{1}$ ), ist thatsächlich grösstenteils entworfen auf Grund des ursprünglichen Jobbuches. Bei der Betrachtung von Jobs Unglück kam der Verfasser zu dem Schluss, dass Gott dasselbe zum Besten solcher, welche im Gegensatze zu Job grosse Übertreter wären, bestimmt habe, und dass Jobs Bewusstsein hiervon dazu habe beitragen müssen, dass er seine Leiden ohme Murren trug. Gleichartig war nngefähr seine Ansicht betreffs seines eigenen Helden,

1) Siehe dritte Vorlesung.

Cheyne, Religiöses Leben der Juden. 
des Knechts Jehovahs. Er leugnet freilich nicht, dass der Knecht hinblickte auf seine endliche Rechtfertigung vor der Öffentlichkeit, aber er denkt augenscheinlich, dass der wirklich bedeutsame Beweggrund fiir den Knecht die Möglichkeit war, durch seine Leiden sein Volk von seinen Sünden zu erlösen ${ }^{1}$ ). Sein Held dient thatsächlich Gott umsonst. Und das ist es sicherlich, was der ursprüngliche Verfasser des Jobbuches als Zweck Gottes darstellte, indem er die Unfälle. die Job trafen, zuliess, nämlich den thatsächlichen Nachweis der Möglichkeit uneigennütziger Frömmigkeit. Man ist geneigt anzunehmen, dass die beiden Verfasser Freunde waren. Zum mindesten dürfen wir vermuten, dass sie Zeitgenossen waren, und dass der Verfasser dieses Jobbuches die Schilderung von Jehovahs Knecht als einen Kommentar zu seinem eigenen Buche auffasste.

Ich neige zu der Annahme, dass diese beiden Schriftsteller nach der Einführung von Esras Gesetzbuch lebten; beide interessieren sich ziemlich warm für die bestehenden religiösen Einrichtungen. Jol, wird dargestellt als unerschütterlich auf Opfer bauend und der Knecht Jehovahs als beauftragt, das wahre Gesetz des Lebens den Völkern zu bringen. Keiner von ihnen kann durch äussere Verluste von seinem felsenfesten Glauben an Gott losgerissen werden. Aber bei weitem die Überzahl der Juden war dieser erhabenen Frömmigkeit nicht fähig. Es war ein

1) Siehe Jes. 53, $10 \mathrm{f}$. in der Polychrome Bible. 
Fundamentalsatz der altisraelitischen Religion, dass jedes Leiden durch irgend ein bekanntes oder unbekanntes Vergehen gegen Gott verursacht sei, und das Wichtigste, was die alten vorexilischen Propheten thun konnten, war, das Gewissen der Menschen zu schärfen, um die Sünden, welche unbereut grosses und verdientes Unglück über die Gesamtheit bringen könnten, aufzufinden. Allerdings trugen sie auch das Gegenteil dieser Lehre vor, nämlich dass durch Gehorsam gegen Gottes Gebote die Gesamtheit sich seine Gunst und seinen Schutz sichern könne. Sittlich war diese Lehre von hohem Wert, selbst wenn sie wenig Wirkung auf die Mehrzahl der Hörer ausübte. Ihr hauptsächlicher Ausbau geschah durch die Abfassung des Deuteronomiums, welches mit einem tiefdurchdachten Gesetzbuch die oft wiederholte Versicherung verbindet, dass Gehorsam gegen Jehovahs Gebote mit Glück belohnt werden wird, und bewusster Ungehorsam bestraft durch Widerwärtigkeit und Verderben. Aber wieder und wieder traten Ereignisse ein, die diese Versicherungen Lügen straften. Die allgemeine Einführung des Deuteronomiums (in seiner ursprünglichen einfacheren Form) hatte das Unglück von Megiddo und endlich die Gefangenschaft im Gefolge, und die Einführung des Esranischen Gesetzbuchs war nur ein Ereignis wie die andern in der inneren Geschichte der Juden. Seit Nehemiahs Abgang wurde die persische Herrschaft mehr und mehr bedeutungslos, und die socialen Übelstände, unter denen die Gemeinde immer so schwer gelitten hatte, nahmen bald von 
neuem wieder zu, mochten sie auch für eine Zeitlang abgestellt worden sein. Und das ist der Grund, dass jene glückliche Heiterkeit, die Job (den urspünglichen Job) sowohl als den Knecht Jehovahs kennzeichnet, so gut wie unmöglich wurde. Ein hebräischer Pascal, der Verfasser von Psalm 73, obwohl er die Theisten mit dem erhabensten Ausdruck (worauf ich ${ }^{1}$ ) zurückzukommen habe) der uneigennützigen Liebe zu Gott beschenkte, hatte sich doch durch einen schweren Anfall von Zweifel hindurchzuringen, und wir dïrfen daher nicht erstaunt sein, dass einer der Weisen am Ende der persischen oder wahrscheinlich am Anfang der griechischen Periode die Behandlung der Leiden Jobs durch den ursprïnglichen Erzähler als für praktische Zwecke unbrauchbar erfand.

Diesem neuen Schriftsteller erschien es unglaublich, dass Job nicht von Zweifeln betreffs der Gerechtigkeit Gottes heimgesucht worden sei. Job war, wie die ursprüngliche Erzählung andeutete, ein Bild des jüdischen Volkes, und sogar die besten unter den Juden hatten Augenblicke sehmerzlichen Zweifels; diesen zurïckzudrängen war alles, was sie thun konnten. Würde nicht das Buch Job der Gemeinde nützlicher sein, wenn sein Held mehr in Fühlung mit der jüdischen Durchschnittsstimmung gebracht wurde? Auf diese Weise wurde der leidende Job ungeduldig. Es lag noch ein anderer Grund vor, weshalb dieser Schriftsteller daran dachte, die Originalgestalt des Job 
zu ändern. Er war augenscheinlich ein gebildeter Mann, der die „noch gedämpfte Musik des Universalismus" auf vielen Lebenspfaden in sich aufgenommen hatte. Seine Interessen waren auf Judäa nicht beschränkt, und so wurde Job unter seinen Händen ein Bild nicht mehr des jüdischen Volkes allein sondern der Menschheit überhaupt. Ferner drängt sich die Beobachtung auf, dass dieser neue Verfasser mehr Individualist war als sein Vorgänger d. h. dass er die sittlichen und religiösen Rechte der Einzelperson als solcher, abgesehen von dem Volk, zu dem er gehörte, betonte. In der alten Zeit hätte sogar ein guter Mensch nicht erwartet, dass es ihm gut ginge, wenn er bloss vereinzelt in einer Gemeinschaft schlechter Menschen lebte. Aber seit Ezechiel gelehrt, dass der Sohn das Unrecht des Vaters nicht trage, noch der Vater die Sünde des Sohnes, seitdem begann das alte Gefühl der Gemeinsamkeit einem neuen Gefühl für die sittlichen Rechte des Einzelnen Platz zu machen. Der Verfasser des Job hatte nach meiner Auffassung gelernt mit den Einzelnen zu leiden und mit ihnen zu fühlen. Und die Frage, die ihn beschäftigte, war nicht lediglich: "Warum leidet das gerechte Israel?" sondern: "Warum leiden gerechte Menschen überall ohne Ursache, und selbst angenornmen, dass einige Strafe verdient sei, warum steht sie so oft im Missverhältnis zu der vorauszusetzenden sittlichen Ursache?"

Die Folge war, dass die Rollen Jobs und seiner Freunde bis zu einem gewissen Grade vertauscht 
wurden. Es waren nicht mehr, wie im Original, die drei Fremnde, welche vom Höchsten unehrerbietig sprachen, sondern es war Job selbst. Freilich wurden Jobs harte Worte unter äusserster Provokation ihm abgezwungen. Sie dürfen keinesfalls aus kühlem, verständig überlegendem Geist heraus erklärt werden. Und seltsam genug: diesem kühnen hebräischen Prometheus kommt allmählich eine versöhnende Vorstellung von etwas, das beinahe ein Übergott genannt werden kann d. h. von einem Gott, der liebt und geliebt werden kamn, hinter dem Gotte der mitleids- und unterschiedslosen Gewalt. Und dieser Lichtstrahl der Erkenntnis kommt ihm (so stellt es der Dichter, zweifellos auf Grund eigener Erfahrung, dar) grade da, als alles irdisehe Gut ihm abgenommen zu sein scheint. Zuerst scheint Gott für seinen Sehrei taube Ohren zu haben, und er wendet sich um Trost an seine Freunde. Aber die Freunde fïhlen sich unter dem erstarrenden Einfluss der ïberlieferten Vergeltungslehre gedrängt, einem so grossen Siinder, wie es Job ihrer Ansicht naeh sein muss, ihr Mitleid vorzuenthalten. Dann, als ihre Sprache heftiger wird, wird die Jobs ruhiger und würdiger. Er beginnt gleichsam ein doppeltes Angesicht in Gott zu entdecken. Von dem Gott der Gewalt, den er in den zahllosen trüben Erscheinungen der WVelt erblickt, hinweg beruft er sich auf einen Gott der Liebe und der Barmherzigkeit, der im Himmel wohnt, und er kommt zu der Überzeugung, dass Gott ihm irgendwie Gerechtigkeit zukommen lassen wird. Beinahe dringt er durch zu dem Glauben, dass Gott ihn von der Unterwelt, 
wohin er himuntersinkt, auf die Daner zurückrufen wird; aber er lässt den allzu verführerischen Gedanken schnell fahren. Diese hervorragende Stelle hoffe ich später zu besprechen. Aber selbst wenn er denn durch die unverbrüchlichen Gesetze über Leben und Tod zu einer ewigen Gefangenschaft im Šseol verurteilt wird, so ist doch ein göttliches Zengnis für seine Unschuld nicht ausgeschlossen.

„O Erde, bedecke nicht mein Blut,

"Und lass meinen Schrei keine Ruhstatt finden"

d. h. lass nicht die Erde mein ungerecht vergossenes Blut verschlingen, sondern lass es wie das Abels laut nach Sühne schreien. Denn, so fährt er fort:

,Selbst jetzt ist mein Zeuge gewisslich im Himmel,

, Und der für mich bürgt ist in der Höhe.

,Mein Fleisch dürstet nach Gott,

„Nach Eloah hin vergiessen meine Augen Thränen,

,Dass er seinen Spruch fälle zu gunsten eines Mannes, der mit Gott rechtet,

,Und zwischen einem Sterblichen und seinem (göttlichen) Frennd $\left.{ }^{1}\right)$."

Später drückt er nochmals dieselbe bestimmte Hoffnung aus, und diesmal verbindet er sie mit der Bestrafung seiner Freunde. Bildad hat sich gerade so weit vergessen, dass er thatsächlich Job mit den Bösen, welche Gott nicht kennen, auf eine Stufe stellt. Diese Rede ist es, welche in Jobs innerer Entwicklung eine Wendung hervorruft. Er kann die Oberflächlichkeit seiner Freunde, welche ihm gegenüber so grausam un-

1) Job 16, $18[19]-21$ (siehe JQR. Oct. 1897, p. 1łf.). 
gerecht sind, nicht lïnger dulden. Noch einmal jedoch beruft er sich auf ilure besseren Gefühle:

"Habt Mitleid mit mir, habt Mitleid mit mir, o meine Freunde, „Denn die Hand Gottes hat mich getroffen.

"Warum verfolgt ihr mich - wie Gott,

"Und könnt nie satt werden meines Fleisches? ")"

Aber er sieht an ihren Mienen, dass sein Wort umsonst an ibre Ohren klingt. Er sehnt sich danach, dass seine Worte in irgend einer dauernden Form verewigt werden möchten: die Worte nämlich, mit denen er seine Unschuld beteuert. Aber kaum hat er dies gesagt, als er sich auf eine weit bessere Rechtfertigung, die seiner wartet, besinnt. Es ist das dieselbe Vorstellung von dem göttlichen Zengen, der wir schon begegnet sind. Und diesmal verbindet Job die Idee mit der Bestrafung seiner grausamen Freunde. Seine Berufung geht nicht von dem Gott der Gewalt an den Gott der Liebe; demn er ist im stande, durch eine neue sittliche Anstrengung den Begriff eines geteilten Gottes ein für allemal zu überwinden. Was er jetzt wïnscht, ist einfach der Erweis seiner Unschuld und die Bestrafung seiner hartherzigen Verfolger. Allerdings versteht er seine Behandlung seitens Gottes nicht, aber nicht länger beschuldigt er Gott der Ungerechtigkeit. Gerade seine Freunde sind ungerecht, und sie müssen bestraft werden, damit seine eigene Rechtfertigung vollkommen sei:

„Aber ich weiss, dass mein Rächer lebt,

,Und dass er endlich über meinem Grabe erscheinen wird;

1) Job $19,21 \mathrm{f}$. 
„Mein Zeuge wird meinen Wunsch zur Ausführung bringen, „Und Flueh wird meine Feinde erfassen."

„Mein inwendiger Menseh wird verzehret von Sehnsueht, „Denn ihr sagt: Wie (seharf) wollen wir ihn verfolgen!

„Empfindet Sehreeken vor dem Schwert, „Denn der Zorn (Gottes) fällt auf die Ungereehten ${ }^{1}$ ).

Die Krisis ist überwunden. Jobs intellektuelle Unruhe dauert fort, aber er bezweifelt nicht das Dasein eines sittlichen Gottes, obwohl er sein Thun nicht enthüllen kamn:

„Ieh mag vorwärts gehen, aber er ist nicht da, "Und rückwärts, aber ich kann ihn nicht erfassen 2)."

Die Freunde jedoch haben nichts gelernt, und nachdem sie Jobs Antwort auf die dritte Rede Zophars gehört haben - dieselbe scheint nicht erhalten zu sein -, dürfen wir erwarten, dass das ältere Werk: den Abgang von Jobs falschen Freunden brachte. Es blieb nun noch übrig, für dieses grosse Drama einen passenden Schluss zu finden: einen Schluss, der, wenn er keine andere Bedeutung hatte, noch einmal bekräftigen sollte, dass ein Dulder zu sein kein Beweis der Schuld war. Der Instinkt des Dichters leitet ihn richtig. Er beginnt damit, dass er unser Interesse durch einen Rückblick erweckt, der unser Mitleid wachrufen soll. Job sucht seinen Geist von der Bitterkeit des Streites zu reinigen (Kap. 29 f.). O dass doch jene schönen Tage wiederkehren könnten, wo der Allmächtige sein Freund war, und seine Kinder ihn um-

1) Job 19, 25-29 (siehe den schon angeführten Artikel in JQR). - ") Job 23, 8. $-{ }^{3}$ ) D. h. jene Gestalt des Gedichts, welehe zwisthen dem Uriob und der jetzigen Gestalt des Buches in der Hitte liegt. 
gaben: Dann geht er auf einmal über in eine grosse Beteuerung seiner Unschuld (Kap. 31), welche eins der sehönsten Kompendien altjüdischer Sittenlehre bildet, und verlässt endlich den Schauplatz mit einem wunderbaren Muster sittlicher Selbstsetzung, welche beinahe die am meisten unhebräische Stelle im ganzen Alten Testament ist.

Es war ein wahres Kleinod lehrhafter Poesie, untermischt mit Leidenschaft, was dieser neue Dichter hervorbrachte. Das durch das Leiden des Unschuldigen gesetzte Problem war zu schwer für ihn, aber er benutzte mit dem grössten Geschick alle widerstreitenden Ansichten der ihm bekannten Sittenlehrer. Es war ihm (das muss seine Anschaumng gewesen sein) ziemlich gelungen, die verderbliche Lehre, dass wir von grossen Leiden auf das Vorhandensein schwerer Schuld schliessen dürfen, abzuweisen. Und er hatte Job dargestellt als endlich angelangt auf einem Zustand der Resignation und so grosser Ruhe, wie sie mit änsserster Erschütterung wegen der Verstandesfrage an Ende überhaupt verträglieh war. Aber er befriedigte seine Mitforscher nicht mehr, als sein Vorgänger ihn befriedigt hatte. Verschiedene Einschiebungen wurden durch spätere Schriftsteller vorgenommen (denn die Annahme eines dauernden Schwankens des Verfasser's selbst ist unnatürlich) mit der Absicht, Teile seines Werkes zu ändern oder zu widerlegen. Die Einschübe sind von verschiedenem Wert. Die Reden des jungen Elihu sind unaussprechlich dürftig, obgleich sie als Denkmal einer Zeit intel- 
lektueller Decadence nicht ohne Bedeutung sind. Aber ich kann nicht umhin, das feine Lob der Weisheit (Kap. 28) noch einmal rühmend hervorzuheben, abgesehen von dem Schlussverse, der es in eine Missbilligung freier Forschung umgewandelt hat. Einen noch grösseren Anteil an Lob muss ich den Reden Jehovahs zusprechen, welche auf den ersten Anblick uns viel zu fein scheinen, als dass sie einen späteren Einschub bilden könnten. Ich selbst neige sehr zu der Ansicht, dass der Verfasser der Dialoge der Freunde mit seinem eigenen Werk unzufrieden geworden war und die Reden Jehovahs als Gegengewicht einfügte. Eine rein litterarische Kritik kann kaum umhin, einer solchen Vermutung sich hinzugeben, aber ich fürchte, dass die Regeln der wissenschaftlichen Kritik uns nötigen sie zu verwerfen. Die einzig sichere Ansicht ist meines Erachtens die, dass irgend ein grosser Dichter — der das ältere Jobbuch für religiös unvollkommen hielt - diesen Anhang hinzufügte. Der Grundgedanke dieses Abschnitts ist der, dass eine kleinliche Kritik der göttlichen Regierung (wie die seitens Jobs geübte) ebenso nutzlos ist, wie die Betrachtung der Naturwunder nutzbringend. Job muss lernen, sich selbst zu vergessen inmitten der herrlichen Schöpfung, wovon er ein Stück bildet. Freilich ist das nicht gradeaus gesagt. Alles, was der Dichter Jehovah in den Mund legt, ist das, Job habe durch unverständige Worte den Plan der göttlichen Regierung verdunkelt $(38,2)$. Die augenscheinliche Freude jedoch, die der Dichter an den Schöpfungsgemälden 
empfindet, berechtigt uns zu der Annahme. dass er die Naturbetrachtung als Heilmittel gegen selbstquälerische und oberflächliche Zweifelsucht betrachtet. Wie wir anch urteilen mögen über seine Haltung gegen freies Denken, er hat uns ein glänzendes litterarisches Denkmal von einer der ältesten Stufen der Liebe zur höheren Weisheit unter den Juden gegeben, und wir können nur dankbar sein, dass dieses Denkmal einen so hervorragenden und ehrenvollen Platz in der biblischen Litteratur gefunden hat. 
Fünfte Vorlesung.

\section{Orthodoxe und ketzerische Weisheit; gleichzeitige levitische Frömmigkeit.}

Kaum wird jemand leugnen können, dass die jüdische Religion Babel und Persien Dank schuldet. Nicht allein heilsame religiöse Anregung, sondern auch einige leieht verarbeitete Vorstellungen und Glaubenssätze kamen ihr von dort zu. Ieh fürchte, dass wir von der ersten Berührung zwisehen jüdisehem und griechisehem Denken nieht ebenso günstig reden dürfen. Ein ganz fremdartiger Geist des Zweifels beginnt jetzt im Judentum sich bemerkbar zu maehen. Das Buch der Proverbien jenes sorgfältig bearbeitete Handbuch volkstïmlicher religiöser Belehrung - enthält sehon wenigstens eine Stelle (Prov. 30, 2-4), die der frommen Lobrede auf die Weisheit Prov. 8 gradezu widerspricht. Hier folge dies einzigartige skeptische Gedicht. Es führt uns zurüek in die Zeit, bevor irgend ein Werk unter der Weisheitslitteratur als heilige Schrift galt. Die bemerkenswerte Thatsache ist, dass es in einen ganz andersartigen Zusammenhang, der die Natur eines Gegengiftes hat, hineinverwoben ist. Es besteht aus zwei Stanzen zu je sechs Zeilen, und folgendes ist, wenn ich richtig lese, die ihm vorangestellte Überschrift: „Die Worte Agurs ben Jakeh, des Diehters". Ob das des Ver- 
fassers wirklicher oder ein angenommener Name ist, kann ich nicht sagen.

„Eine feierliche Rede des Mannes, der nach Gott fragt:

„Ich habe nach Gott gefragt, aber ohne Erfolg.

„Denn ich habe minderen Verstand als andere Menschen,

„Und menschlicher Verstand ist nicht in mir,

,Und ich habe keine Weisheit gelernt,

"Dadurch ich die Kenntnis der Heiligen erlangen möchte".

„Wer kann aufsteigen zum Himmel und herniederkommen?

„Wer kann den Wind sammeln in seinen Fäusten?

"Wer kann die Wasser in ein Gewand binden?

„Wer kann alle Enden der Erde zusammenraffen?

.,(So einen wollt' ich dann nach Gott fragen.) Welches ist sein Name?

„Und welches sind die Namen seiner Söhne, weun du sie kennst?

Ich bin über das Gedicht folgender Ansicht. Der Sprecher ist ein Jude, aber mit starkem Anstrich griechischen oder modernen Geistes. Er ist ein Urbild von Goethes Faust. Sie kennen jene schönen Verse, die der deutsche Dichter seinem Helden in den Mund legt:

.Wer darf ihn nennen?

, Und wer bekennen:

„Ich graub" ihn.

"Wer empfinden

„Lnd sich unterwinden

,Zu sagen: Ich glaub' ihn nicht?

„Der Allumfasser,

„Der Allerhalter,

,Fasst und erhält er nicht

"Dich, mich, sich selbst?

"Wölbt sich der Himmel nicht da droben? 
„Liegt die Erde nicht hier unten fest?

„Und steigen freundlich blinkend

„Ewige Sterne nicht herauf?

„Ich habe keinen Namen

„Dafür! Gefühl ist alles;

"Name ist Schall und Rauch,

.,Umnebelnd Himmelsglut ${ }^{1}$ ).

Diesen Gedanken in etwas verwandt, nur mit weniger Gefühl und Anschaulichkeit des Ausdrucks, ist das, was der hebräische Dichter meint. Er hat schöne Worte sagen hören über Gott als Schöpfer und Herrn der Welt, und verschiedene Namen und Titel sind diesem grossen Wesen gegeben worden z. B. Jahweh (so sollte das so vertraute Jehovah richtig ausgeprochen werden), Adonai, Elohim, El Šaddai, Jahweh Sebaoth, Gott der Allmächtige, Hirte Israels. Welcher von diesen ist der richtige Name, der Name, welcher voll die göttliche Natur oder den göttlichen Charakter zum Ausdruck bringt, und welcher fasst im Klange weniger Laute den Unendlichen zusammen? Der Dichter hat auch vernommen in beliebten Erzählungen und in Tempelhymnen von den ,Söhnen Gottes": ein Ausdruck, der ihm kaum im Einklang zu stehen scheint mit jenen transcendentalen Anschauungen von der göttlichen Natur, die mit Recht den Platz der naiven Gedanken des Altertums eingenommen haben. Was sind das für Söhne Gottes, die sich vor einem Jahweh genannten Gott zu bestimmten Zeiten einfinden, und welches sind ihre Namen? Eine beliebte Erzählung

1) Goethes Faust. Erster Teil. 
besagt, dass einer von ihnen der ...Satan“ d. h. „der Feind" genannt wird, und eine andere Urkunde ${ }^{1}$ ) sagt uns ron sieben hauptsächlichen Söhnen Gottes: Uriel, Raphael, Raguel. Michael, Saraqael, Gabriel, [Remiel]. Haben diese Angaben, gegen welche ein denkender Mensch allerlei einzuwenden hätte, irgend eine zwingende Kraft für den Terstand?

Dieser forschende Denker stellt sich selbst dar als einen, der nach Gott geforscht hat. Wenn er nur eine massgebende Autorität finden könnte. würde er an dieselbe appellieren zwecks Lösung dieser Fragen, fïr welche er in seinem eigenen Gehirn keinen Schlüssel finden kann. Es ist ihm bekannt, dass es eine Weisheit oder Theosophie giebt, welche den Menschen die Kenntnis der Heiligen oder Himmlischen zu geben verheisst. A ber kann diese Weisheit ihre Versprechungen einlösen? Thre Vertreter reden in der That sehr zuversichtlich. Einer von ihnen hat in fesselnden Versen die ursprüngliche Geburt der Weisheit und ihren urprünglichen Aufenthalt bei Gott beschrieben. Aber, du vollendeter Theosoph, wie erwarbst du diese Kenntnis?

,Warst du der Erstgeborne der Menschen?

.,Wurdest du hervorgebracht, ehe denn die Berge?

,Lauschtest du im Rate Gottes,

., Und holtest (daher) die Weisheit zu dir? $\left.{ }^{2}\right)^{4}$

Denn so viel ist klar, dass kein gewöhnlicher mensch-

1) Buch Henoch, siehe Charles' (englische) l'bersetzung [120, 7 (der Grieche giebt sieben, der Äthiopier nur sechs Namen)]. - ") Job 15, 7 f.: eine Ansicht rom ersten Menschen, die weit von der in Genesis 2 vertretenen abweicht. Er ist nichts weniger als die verkörperte Weisheit, ein grisserer Henoch. Vgl. Prov. 8, 25. 
licher Verstand diese feinen Dinge ergründen kann. Ich, der Dichter, mag weniger Verstand haben als andere Menschen, aber selbst wenn es anders wäre, wenn ich nicht zum Himmel auffahren kann und wieder herunterkommen, wenn ich nicht den Wind zwischen meinen beiden Fäusten sammeln kann, wenn ich nicht die Wasser des Ozeans in einem Gewande zusammenbinden kann, wenn ich nicht alle Enden der Erde halten kann, wenn ich nicht ein zweiter Henoch bin und Umgang mit den weisen "Heiligen" (d. h. den Engeln) beanspruchen kann, dann will ich meine Anmassungen nicht als Weisheit betrachtet wissen.

Sind Sie überrascht durch diese Äusserung des Zweifels? Erinnert dieselbe Sie mehr an arische als an semitische Gedanken? Und verspüren Sie nicht starke Neigung, meiner Erklärung ein wenig Zweifel entgegenzubringen? Aber können Sie in den Kommentaren eine ansprechendere Erklärung finden? Die älteren nehmen sämtlich die wesentliche Richtigkeit des einleitenden Verses im überlieferten Text und die Einheit des Ganzen in Prov. 30 an. Diese Annahmen sind kaum haltbar, und die darauf gegründeten Erklärungen sind viel gekünstelter als die meinigen, lassen auch viele Schwierigkeiten stehen. Dass Sie von dem Zweifel jenes jüdischen Dichters überrascht sind, ist vollkommen natürlich. Aber Sie müssen bedenken, dass wir jetzt in der griechischen Periode stehen, und wenn wir im Rig Veda einen Ausdruck ehrlichen Zweifels finden wie den, welchen ich jetzt anführen will, warum sollten wir Cheyne, Religiöses Leben der Juden. 
denn überrascht sein, dass derselbe charakteristische arische Geist von den erobernden Griechen auf die unterworfenen Juden übergegangen sein sollte. „Wer weiss?" sagt der ungenannte Sanskritdichter:

„Wer weiss, wer kann hienieden erklären, woher entstanden „,ist - ja woher, diese Schöpfung? . . Woraus die Schöpfung „entstanden ist, und ob sie gemacht ist (von jemandem) oder „nicht; er, der im höehsten Himmel wohnt, ist ihr Herr, er ",weiss es wahrlich, oder (sogar) er weiss es nicht ${ }^{1}$ )."

Zu einer späteren Zeit (2. Jhd. n. Chr.) mochte es scheinen, dass der zweifelsüchtige Dichter Agữ von den Toten auferstanden sei in der Person des Eliša ben Abujah, der ein so tiefsinniger Theosoph wurde, dass er von der geoffenbarten Religion $\mathrm{abfiel}^{2}$ ) oder, wie jüdische Schriftsteller sich ausdrücken, in das Paradies eindrang und die dort wachsenden Pflanzen zerstörte; ein feinsinniges Gleichnis, nicht wahr? Man möchte es abstrakteren Ausdrücken bei weitem vorziehen. Die Rabbinen sprechen mit Schmerz von Elišas Abfall und geben ihrem verlorenen Führer den Namen Acher „ein Fremder, einer, der nicht zu uns gehört".

Es erscheint beinahe als ein Wunder, dass dieses seltsame zweifelsüchtige Gedicht Agurs der modernen Welt sicher übermittelt worden ist. Das würde aber nicht geschehen sein ohne den frommen Protest, in den es eingeschachtelt wurde. Auf diesen Protest der Orthodoxie will ich jetzt Thre Aufmerksamkeit lenken.

1) Muir, Aucient Sanserit Texts $Y$, 356. _. 2) Es wird uns überliefert, er sei in seiner lrreligiösitat bestarkt worden durch den Anblick der harten Anfechtungen derer, welche nach dem Gesetz wandelten, und die nichtslestoweniger ihre Hoffnung auf Gluck stutzten auf ihre Gesetzesgerechtigkeit. 
Der Verfasser des Protestes spricht zunächst seinen Glauben an die göttliche Offenbarung aus, er sagt: „Jegliches Wort Gottes ist frei von Schlacken; "Es ist ein Schild für alle, die zu ihm ihre Zuflucht nehmen."

Das besagt, die reinste Weisheit ist zu finden in Gottes Buch. Der Beweis dafür ist der Schutz, dessen die sich erfreuen, die Gott vertrauen. Frömmigkeit und ihr Lohn sind, das wird angedeutet, auf die beschränkt, welche jede Angabe der Bibel als massgebend annehmen. Dann fährt er fort:

"Siehe zu, dass du nichts zu seinen Worten hinzuthust, „Damit er dich nicht überführe, nnd du als Lügner erwiesen werdest."

Das besagt: was nicht offenbart ist, das ist nicht wahr. Der Freidenker, der den Titel "feierliche Rede" an die Spitze seines Gedichts gesetzt hat, als wenn sie eine Weissagung wäre, wird seinem Unglück nicht entgehen.

„Zwei Dinge erbitte ich von dir,

„Halte sie nicht von mir zurück, ehe denn ich sterbe.

„Leichtsinn und das Spreehen (von Thorheit

„Und) Lügen halte ferne von mir.

„Lass mein Los weder Armut sein noch Reichtum,

„Nähre mich mit dem Brot, das mein Teil ist;

„Sonst, wenn ich voll wäre, möchte ieh ein Gottesleugner werden „Und sagen: Wo ist Jehovah?

„Oder wenn ieh verarmt wäre, dann möchte ieh so sehr des Verstandes beraubt werden,

„Dass ich mich am Namen meines Gottes vergriffe ${ }^{1}$,",

Diese beiden Wünsche bilden in Wahrheit bloss einen. Es ist der Dichter Agur, auf welchen dieser

\footnotetext{
1 Prov. 30, 5[7]-9.
} 
brave Mann anspielt: Agur, der bekannt hatte, den rechten Namen Gottes nicht zu wissen, und der, wie der orthodoxe Widersacher vielleicht vermutete, geleugnet hatte, dass es irgend ein Wesen gebe, selbst im Himmel, das die Wasser zusammenbinden und den Wind einfangen könne. Kurz der orthodoxe Kämpe bittet, dass er nicht werden möge wie Agur. Er sieht ein, dass wenn er an irgend einem sozialen Extrem stände, er in Versuchung kommen könnte, den Gott Israels zu leugnen; denn der Reiche scheint Gottes nicht zu bedürfen, und der Arme scheint von ihm vergessen zu sein. Er verachtet daher Reichtum: eine ziemlich auffüllige Erscheinung; die andern Veisen sind im Gegenteil weit davon entfernt. Allerdings ist dieser Weise teilweise beeinflusst durch seinen Wunsch, die Worte Agurs zu widerlegen; wenn er auf die Probe gestellt wäre, hätte er vielleicht Reichtum nicht ganz unerwünseht gefunden.

Die anderen Spruchgedichte Agurs, die in demselben Kapitel der Proverbien stehen, gehen uns nichts an. Es genügt, dass wir ein versprengtes Beispiel skeptischer Litteratur gefunden haben. Ieh nehme keinen Anstand, diese Wendung zu gebrauchen, denn ein solches Gedicht kann nicht für sieh allein gestanden haben. Homer erzählt uns allerdings, dass es in dem griechisehen Heere vor Troia nur einen Thersites gab. Glüeklicher Achilleus und Agamemnon! Gewiss gab es nicht wenige Agurs zu Jerusalem vom dritten vorehristlichen Jahrhundert an abwärts. Den Naehweis dafür liefert ein Werk einer ganz anderen Schule: das Buch Henoch. 
Die Stelle, die ich anführen will, gehört zu den ältesten Teilen dieses Buches:

„Und mun kenne ich dies Geheimnis, dass viele Sünder die „Worte der Wahrheit ändern und verkehren werden und gott.lose Worte reden werden und lügen und grosse Trügereien "verüben werden und Bücher schreiben betreffs ihrer Worte ${ }^{1}$ ). "

Der angebliche Sprecher ist eine von denselben Personen, auf die Agur wohl anspielt, wenn er sagt: . Wer ist hinaufgefahren gen Himmel und wieder herniedergekommen?" - der Patriarch Henoch. Aber diese Worte sind die eines Verfassers aus der Zeit Johann Hyrkans (135--105 v. Chr.). Diese Annahme wird belegt durch den Anhang, den ein Herausgeber einer der spätesten Schriften des Alten Testaments hinzugefügt hat, worin nachdrücklich Verwahrung eingelegt zu werden scheint gegen philosophische Bücher einer mehr "vorgeschrittenen" Art als die, welche im Kanon stehen. Ich will eine Stelle aus dem Anhang anführen:

„Die Worte des Weisen sind wie Stacheln und wie fest „eingetriebene Nägel. Sie wurden niedergeschrieben [d. h. herans. ,gegeben] durch Verfertiger von Sammlungen, aber gegeben .,seitens eines andern Lehrers ${ }^{2}$ ). Und allen gegenüber ausser ,diesen sei auf deiner Hut, mein Sohn. Des Verfertigens vieler „Bücher ist kein Ende und zuviel Lesen ermüdet den Leib $\left.{ }^{3}\right)$."

Diese kurze gedrungene Redeweise ist nach der Art der spätjüdischen Schriftsteller, die an die Fassungskraft ihrer Leser grosse Ansprüche stellen. Die Stelle soll, wie es scheint, folgendes zum Ansdruck

1) Henoch 104, 10 (ed. Charles p. 299). - ${ }^{2}$ L Liese Auffassung les Textes ist. jedoch nur wahrscheinlich. - ${ }^{3}$ ) Koh. 12, $11 \mathrm{f}$. 
bringen: „Aussprüche weiser Männer, wie die in Proverbien und Kohelet, müssen dringend empfohlen werden, denn sie regen das Gemüt an und belästigen nicht das Gedächtnis. Sie sind ohne Zweifel durch dazu berufene Personen herausgegeben, aber sie wurden jedenfalls ursprünglich abgefasst durch einen vom Herausgeber verschiedenen Lehrer. Sie können vertranensvoll gelesen werden, es giebt keinen berechtigten Anspruch, den sie nicht befriedigen. Aber daneben laufen noch viele andere litterarische Erzeugnisse um, Ich ermahne meine Schüler, gegen diese auf der Hut zu sein. Keinen Vorteil hat man von ihrem Studium, nur nutzlose Mühe." Die Bücher, an welche der diese Warnungen enthaltende Epilog angehängt ist, sind die Proverbien (mit den Bruchstiicken der Gedichte Agurs) und Kohelet. Diese werden als für die Lektïre gläubiger Israeliten nicht zu vorgeschritten bezeichnet.

Es ist der Prediger, der jetzt unsere Anfmerksamkeit auf sich zieht: jenes höchst sonderbare Buch, das Heinrich Heine das Hohelied des Skepticismus und Franz Delitzsch — sehr fraglich ob mit mehr Recht - das Hohelied der Religion nannte. Ich würde unbedingt mein Thema lückenhaft behandeln ohne Rücksichtnahme auf den Prediger. Allerdings muss ich zu meinem Bedanern hinzufügen, dass er in der uns überlieferten Form für das Verständnis eines der schwierigsten Bücher ist. Die Widersprïche, die das Buch bietet, sind viel zu auffallend, als dass wir sie bei Annahme der unversehrten Überlieferung des Buches zwangslos erklären könnten. Die Wider- 
sprüche bei Montaigne sind die eines unbefangenen und in der Entwicklung begriffenen Geistes, die des Predigers sind derartig, dass sie in einem verständigen Denker nicht neben einander bestehen können. Ich gebe zu, dass sehr ähnliche Widersprüche sich im Buche Job befinden, und dass wir, wenn wir von der Einheit des Buches Job uns hätten zu überzeugen vermocht, die Verteidigung der Integrität des Buches Kohelet nicht für aussichtslos $z u$ halten brauchten. Haben wir dagegen gefunden, dass das Buch Job nicht aus einer, sondern aus zwei oder drei einander widerstreitenden Schulen herstamme, dann ist uns das Auge dafür geöffnet, dass mehr als eine Schule auch im Kohelet vertreten ist. Und wenn ferner der Inhalt des Kohelet, abgesehen von gewissen vollkommen rechtgläubigen Stellen, noch mehr auffällt, als selbst die schwerverständlichsten des Buches Job, dann leuchtet uns die Erkenntnis ein, dass noch durchgreifendere Mittel angewandt wurden, um den Anstoss, den Kohelet dem Leser erregte, abzuschwächen. Endlich wenn später sowohl Proverbien als auch Hoheslied Salomo zugeschrieben wurden, dann werden wir nicht überrascht sein, dass nachdem der Kohelet in rechtgläubigem Sinn überarbeitet worden war, ein noch späterer Schriftsteller ihn in den Bannkreis der Legende von Salomos Busse stellte. Diese drei Vorgänge haben sich, wie ich glaube, ereignet. Kohelet ist in orthodoxem Interesse überarbeitet worden ${ }^{1}$ ).

1) Das ist keine unerhörte Ansicht. Die dagegen vorgebrachten Einwürfe scheinen dem Verfasser keine Beweiskraft zu besitzen. Die Frage entsprechend zu 
Entweder Zufall oder gewaltsamer Eingriff hat den Zusammenhang beinahe vollständig zerstört, und der Sprecher, Kohelet (unsere Bibelübersetzung giebt es mit "Prediger"; der Name bezeichnet einen Vertreter der Klasse der öfentlichen Redner ohne Bezugnahme auf irgend eine Einzelperson) ist thatsächlich mit Salomo identifiziert worden: ein Vorgang, der naturgemäss nene Einschübe veranlasst hat. Es ist eine äusserst schwierige Aufgabe, die ursprüngliche Reihenfolge der Aussprüche vermutungsweise wieder herzustellen. Wie mir scheint, sind Stellen sowohl gestrichen als eingefügt, und ich fühle mich nicht ganz sicher, ob nicht Gustav Bickell in seiner Wiederherstellung vielmehr zuängstlich bedacht gewesen ist, eine vollständige Abhandlung über hebräische Philosophie herzustellen. Nach diesem römisch-katholischen Gelehrten ist der echte Kohelet eine sorgsam erdachte Antwort auf eine uns selbst genügend vertraute Frage: Ist das Leben des Lebens wert? Er lässt es in zwei Teile zerfallen: einen kritisch-spekulativen und einen praktisch-sittlichen Teil, von denen der erstere nachweist, dass die angeblichen absoluten Güter (alles, was ein Mann hat oder weiss oder kann) ergebnislos und unbefriedigend sind, der letztere hingegen als wenigstens in etwas schätzbar Weisheit und den heiteren Lebensgenuss empfiehlt.

Beianstandsloser Annahme dieserAnsicht würdeman

untersuchen. wurde nur angangig sein in einem Kommentar über den Kohelet ron -vorgeschrittenem ${ }^{*}$ kritischen Staudpunkt aus. Die Einschübe wurden dabei auszuscheiden sein. 
kaum sicher gehen, um so weniger als bald eine andere Wiederherstellung aus amerikaniseher Feder zu erwarten ist $^{1}$ ). Was ich allein betonen möchte ist: die gegenwärtige Unordnung herrschte innerhalb des Buches nicht von Anfang an. Der Verfasser ist gewiss in Anbetracht der Dunkelheit seiner Zeit als Schriftsteller nicht gering zu schätzen. Der Takt, mit dem er gelegentlich Stücke in metrischen Versen einführt, ist ein Beweis dafür. Es ist nicht wahrseheinlich, dass er ein so ungleichartiges Machwerk. wie den uns vorliegenden Kohelet. in die Welt gesetzt und so seinen eigenen Ausführungen soviel Eintrag gethan haben würde. Gerne würde ich bei dieser Frage noch verweilen, aber ich darf mich von meiner Hauptanfgabe, der nämlich, festzustellen, welche Rolle die Religion für den Verfasser spielte, nicht abziehen lassen. Ich will eine Blütenlese aus seinem Werke später anführen.

Dass ex ein warmes und tiefes Gefühl besitzt, wird auf den ersten Blick klar, und ein sorgsames Studium wird zeigen, dass er auch Religion besass: er ist weder theoretisch noch praktisch Atheist. Aber man vergleiche den Gott, an den er glaubt, mit dem Jehovah der Psalmisten! Welch ein Unterschied! Dass er nie den Namen Jahweh oder Jehovah nennt, ist Nebensache; das Traurige aber ist, dass sein Gott so fern von der Erde und so unbarmherzig ist. Er ist ein Gott, den man klugerweise fürchtet, dem man gehoreht, selbst wenn man auf Lohn für seinen Ge-

1) Die von Professor Haupt zu rerfassende Arbeit wirl einen Teil der Polychrome Bible bilden. 
horsam nicht zählen kanı, aber den man nicht so leicht lieben und in gewisser Beziehung unmöglich begreifen $\operatorname{kann}^{1}$ ). Lange sehon hat dieser Gott alles vorher bestimmt ${ }^{2}$ ), was sich ereignen soll; die Klugheit rät uns daher, mit verschränkten Armen uns in das Unvermeidliche zu fügen. So hält demnach der Verfasser an dem grundlegenden Hauptsatz des älteren Judentums, dem Glauben an einen Gott, fest; dieser Glaube erfüllt ihn nicht mit Frende, nicht mit Begeisterung, aber er rettet ihn vor dem Abgrund. Anderseits hat er (und so zweifellos auch Agur der Freidenker) einen nur um weniges nebensächlicheren Grundsatz aufgegeben: den von einer ellsprechenden Vergeltung auf Erden für Gerechte und Gottlose. Er lehnt sogar das von den meisten Juden festgehaltenesüsse Linderungsmittel eines grossen Vergeltungstages in der Zukunft ab, wo es eine Scheidung zwischen Gerechten und Gottlosen, zwischen dem, der Gott dient, und dem, der das nicht thut, geben wird. Ich will nicht behaupten, dass der Verfasser irgendwo leugnet, dass Gott zuweilen den Sünder bestraft. Aber von irgend etwas, was dem Satz von der vergeltenden Gerechtigkeit in der göttlichen Regierung ähnlich sieht, bemerkt er keine Spur. Er sagt mit vieler Bitterkeit:

„Es giebt manchen gerechten Mann, der trotz seiner Ge„,rechtigkeit umkomrnt, und manchen gottlosen Mann, der lange ,"lebt trotz seiner Gottlosigkeit ${ }^{3}$ "“

und ferner:

„Es giebt eine Eitelkeit (eine getäuschte Hoffnung oder 1) hoh. \&, $17-2$ Koh. 6, 10. $-{ }^{3}$ ) Koh. 7, 15. 
„Enttäusçhung), welche auf Erden Platz hat, nämlich dass es ,gerechte Nensehen giebt, denen es ergeht nach dem Werk ,der Gottlosen, und dass es gottlose Mensehen giebt, denen es „nach dem Werk der Gerechten ergeht. Ich sage, dass das auch "Eitelkeit ist $\left.{ }^{1}\right)$.

Solche Ansichten, ungemildert durch irgend eine Beziehung auf ein endliches Gericht, erfüllten die Frommen mit tiefem Schmerze. Sie fürchteten für die jungen Leute, die durch die Kühnheit des Verfassers angezogen und auf die falschen Pfade des Unglaubens geführt werden könnten. Daher nalımen fromme Herausgeber ihre Zuflucht zu dem Mittel der Einschübe. Ein ziemlich durchgreifender Erfolg wurde erzielt. Im Schlusswort wurde der Verfasser als einfach frommer Mann geschildert und im Text selbst liess man ihn bekennen, dass die Gottlosen in Wirklichkeit hier bestraft würden und hernach bestraft werden wïrden. Später ging die Targum genannte volkstünliche Übersetzung ziemlich viel weiter, indem sie das Buch der voll ausgestalteten Eschatologie des späteren Judentums anpasste. Aber wenn Sie einen Kohelet, in welchem die Ergebnisse der Kritik angemerkt sind, vor Augen haben, dann werden Sie, denke ich, sehen, dass es nur zwei unzweifelhaft echte Stellen giebt, in welchen die sittliche Handlungsweise und die äusseren Schicksale der Menschen zu einander in Beziehung gesetzt werden. Ich will diese Stellen anführen und erklären. Eine von ihnen lautet, wie folgt:

"Sei nicht allzu gottlos und sei nieht zu thöricht, warum ,wolltest du vor deiner Zeit sterben? 2)"

1) Koh. 8, 14. - ${ }^{2}$ ) Koh. 7, 17 [18]. 
Die andere:

"Wenn du Gott ein Cielübde geleistet hast, so verschiebe ,die Einlösung nicht. Lass deinen Mund nicht Strafe über "deinen Leib bringen und sage nicht ror dem Boten: Es ,war in Übereilung ausgesprochen: warum sollte Gott zornig ..werden über deine Stimme und zerstören das Werk deiner „Hände? ${ }^{1}$ "

Die erste dieser Stellen scheint auszudrücken, dass es gewisse äusserst gottlose Thaten giebt, die die Langmut Gottes erschöpfen und nufehlbare Strafe über den Bösewicht bringen. Aber das kann kaum die wahre Bedeutung sein, denn ein verwandter Ausspruch liegt vor, der nicht weniger klar aussagt:

.Sei nicht allzu gerecht und mache dich nicht im Über"mass weise, warum solltest du dich selbst zerstören? ${ }^{2}$ )"

Es ist doch klar, dass das nicht bedenten kann. die, welche Gerechtigkeit und Weisheit zu ihrem Hauptstreben machten, missfielen Gott. Die beiden Aussprüche müssen vom Standpunkt eines praktischen Mannes aus gemünzt worden sein, und die Ansdrücke .gerecht" und .,verkehrt" müssen gefasst werden, wie sie gewöhnlich in der religiösen Welt verstanden werden d. h. in pharisäischem Sinn. Gerechtigkeit bezeichnet demnach die Beobachtung und Verkehrheit die Vernachlässigung der mehr nebensïchlichen Einzelheiten des Gesetzes. Gesetzesgehorsam bis zum Punkte der Selbstquälerei zu treiben, war nicht minder selbstmörderisch, als einem über solche Kleinlichkeit erhabenen Geist zu erlauben, einen Menschen zu sinn-

1) Fih. 5. 4. 6 [?. 5] (Neue [̈bersetzung). - ? Koh. 7, I6 [17]. 
licher Zügellosigkeit zu reizen. In beiden Fällen ist die entsprechende Strafe einfach die, welche aus der Übertretung von Naturgesetzen hervorgeht. Wer zugleich mit Massen fromm und mit Massen weltfröhlich ist, wird nach Kohelet ein wahrhaft weiser Mann sein.

Die zweite Stelle scheint zu beweisen, dass sogar dieser rationalistische Denker nicht ganz frei von überlieferten Vorurteilen war. Eine Übertretung gab es, welche der Strafe nicht entgehen konnte, und das war, ein Gelübde zu leisten und es nicht zu halten. Wenn du das thust, sagt der Verfasser. wirst du an deinem eigenen Leibe zu leiden haben. und wenn du dem Boten des Priesters sagst, dass du das Gelübde unüberlegt ausgesprochen, dann wird nicht er, sondem Gott zum Zorne gereizt, und Gott wird dich mit dem Verluste des Eigentums strafen. So glaubt derselbe Mann, der nicht an den Messias glaubt, doch an eine göttliche Rache wegen unerfüllter Gelübde.

Mankann nicht umhin, unsern Verfasser zu bedanern. Natürlich gebot ihm sein Gewissen Zweifel am Gericht, und doch konnte er nicht wohl am Zweifel festhalten. Ich bestreite nicht, dass es zu jener Zeit Juden gab, die der uneigennützigen Liebe zu Gott so fähig waren wie der heilige Bernhard. Als Beispiel diene der grosse Lehrer Antigonos von Soco, der sagte: „Seid nicht wie Sklaven, die um Lohn dienen, sondern seid wie die, welche ohne Eigennutz dienen und lasst die Furcht des Himmels (d. h. Gottes) ïber ench sein!" Allerdings gebrancht er den Ausdruck „Furcht", aber was er meint, ist ehrfurchtsvolle Liebe. Wir dürfen 
jedoch nicht vergessen, dass Antigronos ein Schüler Simeon des Gerechten war, dessen bezeichnenden Ausspruch er, was man nicht ausser acht lassen darf, voraussetzt. Der Ausspruch Simeon des Gerechten lautete:

„Die Welt besteht auf drei Dingen: auf dem Gesetz, auf ,dem Gottesdienst und auf Thaten der Güte."

Wenn der Verfasser des Kohelet dem Gesetze und dem gottesdienstlichen Kult ebenso zugethan gewesen wäre wie Antigonos von Soco: wenn er sie als absolute Güter, deren Erstrebung eine Belohnung an sich ist, betrachtet hätte — dann hätte er mit Fug die Messianische Hoffnung aufgeben können. Aber das war zweifellos nicht der Fall. Er glaubte an keine absoluten Güter, schwärmte nicht einmal für das Gesetz und hielt es für nötig überschwängliche Frömmigkeit zu missbilligen. Weniger daher als andere Leute durfte er ungestraft den Glauben an Gottes vergeltende Gerechtigkeit fahren lassen. Allerdings wenn er eine gewisse neue damals gerade in den Volksglauben eindringende Lehre, die von der Unsterblichkeit, übernommen hätte, damn hätte alles gut gehen können. Aber niemand konnte zu seiner Zufriedenheit beweisen, dass der Geist des Menschen nach oben ginge und lediglich die Geister der Tiere nach unten in die $\operatorname{Erde}^{\mathbf{1}}$ ). Da ist es noch ein Wunder, dass er solche Sittlichkeit und einen solchen Glauben an Gott, wie er sie besass, behaupten konnte. „Fürchte Gott ${ }^{2}$ )!" sagt er mit vollem Ernste. Wenn er die Freuden der Tafé empfiehlt,

1) Koh. 3, 21. - 2) koh. 5, i. 
so thut er das aus reiner Ironie; erfreue dich ein wenig an diesen Vergnügungen, sagt er, weil sie nicht die schmerzlichen Folgen höherer Vergnügungen haben, und weil die Zeit für diese Freuden so kurz ist, ausserdem - fügt er seltsamerweise hinzu - sind sie die Gabe Gottes. Für ihn selbst hatten sie unbedingt lange ihren Reiz verloren. Aber Jugend bleibt Jugend, und er missgönnt den jungen Leuten, für welche er besonders schreibt, nicht die Gelegenheit, diese Freuden zu schmecken, ehe sie dieselben als blosse Sodomsäpfel verschreien.

Er verweilt auch eingehend bei dem Glück eines reinen Ehestandes. Seine Aufrichtigkeit hierbei ist über allen Zweifel erhaben. Und hier wenigstens ist er ein echter Jude; hier wenigstens zeigt er seine Abneigung gegen eines der bezeichnendsten Laster des Hellenismus. Dass er selbst eine üble Erfahrung mit Frauen gemacht hat ${ }^{1}$ ) und augenseheinlich jenen Preis, der "die Rubinen übertrifft", nicht erlangt hat, lässt ihn andere um ein höheres Glück nicht beneiden. Freue dich des Lebens, sagt er, mit einem Weibe, das du liebst, alle deine vergänglichen Tage ${ }^{2}$ ) und wiederum:

"Gieb keinen Raum der Sorge in deinem Gemüt, „Von deinem Leibe halte Not fern;

"Auf deine Cisterne gieb gut acht "In den 'Tagen des Jugendalters ${ }^{3}$ )."

Was Cisterne in einem semitischen Gedicht be-

$\left.{ }^{2}\right)$ Koh. 7. $\left.27 \mathrm{f} .-{ }^{2}\right)$ Koh. 8, 9. $-{ }^{3}$ ) Koh. 11, 10a: 12. 1a.; rgl. Cheyne, Job and Solomon pp. 227. 300 . 
deutet, hat Mr. Lyall in einer Anmerkung zu einer seiner Übersetzungen altarabischer Gedichte gut ausgedrückt: .Die "Cisterne" ist eines Mannes Haus und Familie und was immer ihm teuer ist."

$\mathrm{Zu}$ den Lesern reiferen Alters spricht unser Verfasser in mehr gedämpfter Stimmung:

"Besser zu gehen zum Tranerhanse,

"Als in ein Haus des Festfeierns.

"Demn dort ist das Ende aller,

„Der Lebende wird es zu Herzen nehmen.

„Besser ist sorge als Gelächter,

"Bei cinem düstern Gesicht ist das Herz heiter ${ }^{1}$ )."

Ich bin jedoch nicht ganz fest überzeugt davon, dass der Terfasser seinen eigenen Rat, Leidtragende zu besuchen, befolgte. Hätte er das gethan, dann würden wir sicher etwas zu hören bekommen über die Pflicht, den Elenden durch die That Mitleid zu bezeigen. Er hegte augenscheinlich wahres Mitgefühl für den Jammer der Menschen, aber es scheint niclit, dass er sich selbst viel um das Elend der Einzelnen bekümmerte. Die Verfasser des Buches der Proverbien trifft dieser Tadel nicht. Einer von ihnen sagt beispielsweise, indem er von Hohn auf die Menschlichkeit spricht:

"Befreie die, welche zum Tode geschleppt werden,

"Lnd die, welche hinwanken, um erschlagen zu werden, halte zurück $\left.{ }^{2}\right) .6$

Aber ich fürchte, dass unter solchen Umständen unser Verfasser sich begnügt hätte mit blossem Zusehen, und dass er mit einem Seufzer gesagt hätte: "Das ist auch Eitelkeit." Vielleicht ist er durch sein

1) Koh. 7, 2[3] f. - " Prov. 24, 11. 
vorgerücktes Alter entschuldigt, oder vielleicht hat gerade seine Lebensanschauung seine wohlthätigen Triebe abgeschwächt, denn er sagt uns:

"Ich habe alle Werke gesehen, die unter der Sonne gethan "werden; und siehe, alles ist eitel und Plage des Geistes. Was „krumm ist, kann nicht grade gemacht werden, und ein Fehl"betrag kann nicht eingerechnet werden ${ }^{1}$ )."

Und daher begegnen wir diesem bemerkenswerten Eingeständnis tiefgewurzelter Selbstsucht:

"Und ich hasste alle meine Plackerei, die ich unter der "Sonne verrichtet habe, weil ich die Friichte derselben einem, "der nach mir kommen wird, werde hinterlassen müssen. Und "wer weiss, ob es ein Weiser oder ein Thor sein wird? Und "er wird verfügen über alles, was ich mit Plackerei und Weis"heit unter der Sonne erworben habe; das ist auch Eitelkeit $\left.{ }^{2}\right)$."

Kein Gedanke daran kommt ihm in den Kopf, sein Geld Jehovah zu leihen, wie die Verfasser der Proverbien sagen, oder alle seine Güter herzugeben zum Bau von Schulen und zur Gründung von Spitälern; und es ist bezeichnend für die Dürftigkeit seines Buches vom Standpunkt des Menschenfreundes aus, dass eine Stelle, welche in Wirklichkeit eine Aufmunterung zu kühnen Geschäftsunternehmungen enthält („Schicke dein Brot auf das Wasser, denn du wirst es nach vielen Tagen wiederfinden "), durch christliche Prediger in eine Empfehlung der Wohlthätigkeit verwandelt worden ist. Die Wahrheit ist, dass der unglückliche Verfasser nur ein schwaches Gemeingefühl besitzt. Aus alter Gewohnheit und dem Einfluss seiner rechtgläubigen Erziehung folgend, mag er in

1) Koh. 1, 14f. $\left.-{ }^{2}\right)$ Koh. 2, $18 \mathrm{f}$.

Cheyne, Religiōsas Leben der Juden. 
vielen Dingen wie irgend ein Durchschnittsjude handeln, aber das Band der jüdischen Nationalität übt fast gar keinen innern Einfluss auf ihn aus, und er hat seinerseits nicht jenes Gemeinschaftsgefühl der Humanität gewonnen, das von dem Stoiker unter den römischen Kaisern so scharf und klar ausgesprochen wird. DieMenschheit bedeutet für ihn nur eine Sammlung von Millionen wertloser Atome. Glücklicher waren Saul und Ahab und so mancher andere, der sein Leben für das Volk opferte ohne Hoffnung, es wieder zu gewinnen, weit glücklicher als dieser trübsinnige Egoist, der in sich ohne Zweifel den Keim schöner Eigenschaften trug, deren Gedeihen aber rauh unterbrochen worden war durch übermässige Hingabe an den Geist des Zweifels. Gewiss war er kein schlechter Mensch, und doch muss in seiner sittlichen Entwicklung eine Verkümmerung eingetreten sein, sonst wäre sein Nationalgefühl feiner, sein Widerstand gegen totalen Pessimismus leistungskräftiger gewesen. Man denkt auch unwillkürlich, dass seine Denkkraft mangelhaft gewesen sei, sonst hätte er sich unwiderstehlich lingezogen gefühlt entweder zu der hebräisch-persischen Lehre von der Auferstehung oder zu der neueren griechischen Lehre von der Unsterblichkeit der Seele. Der eine oder der andere von diesen Begriffen wïrde ihn vor geistigem Hungertode bewahrt und ihn in den Stand gesetzt haben, das durch eine Reihe von Schriftstellern in jenem feinen Sammelgedicht, dem Buche Job, so nutzbringend begonnene Werk fortzuführen.

Es ist kein Wunder, dass die Meinungen über 
dieses wunderbare Buch vielfach geteilt waren. Viele wurden abgestossen, aber beinahe ebensoviele (so scheint mir) angezogen durch dasselbe. Zweifler bleiben dem Verfasser, der kräftig und in gewissem Sinn auch künstlerisch den Gedanken, welche in ihnen sich regen, Ausdruck zu geben vermag, immer dankbar. Dass der Zweifel unter den Juden der späteren nachexilischen Zeit weit verbreitet war, ist gewiss; freilich sind naturgemäss die Anzeichen davon knapp. Der Umsturz des Perserreiches durch Alexander war an und für sich eine ergiebige Quelle des religiösen Zweifels. Lange schon hatte der Todeskampf jenes Reiches gedauert, und die Juden hatten sich in ihrem vielfältigen Elend an dem Gedanken aufgerichtet, dass, wenn nun der Sturz einträte, das wieder aufgerichtete Königreich Israel ebenfalls erscheinen würde. Aber es erschien nicht, und nun begannen einige Leute den Gedanken zu hegen, dass das Schicksal auf seiten der griechischen Macht und die Wahrheit auf der der griechischen Philosophie sei. Sogar dem makkabäischen Aufstand gelang es nicht, die Neigung zum Zweifel auszulöschen. Die radikalen Hellenisten, die Zeus an Jehovahs Stelle setzen wollten, wurden zweifellos durch denselben hinweggefegt. Aber die Besserung in der Lage der Juden war keine derartige, dass sie den religiösen Zweifel unmöglich gemacht hätte. Die alte Vergeltungslehre und die neuere Messiaserwartung waren gleich schwer mit den Thatsachen zu vereinigen, und die zunehmende Kenntnis der grossen Welt machte die Engherzigkeit der jüdischen Orthodoxie für viele 
Denker mehr und mehr ungeniessbar. Auf solche Leute wirkte der tiefempfundene und mit Nachdruck vorgetragene Zweifel des Kohelet mit grosser Gewalt. Das Buch zu unterdrücken war unmöglich. Alles, was die auf dem religiösen Gebiet tonangebenden Männer thun konnten, war, seineLehre unschädlich zu machen. Das bewirkten sie(wie wir gesehen haben) zum Teil durch Versetzung gewisser Abschnitte und dadurch bedingte Zerstörungdes Zusammenhangs und zum Teil durch Einschiebung gewisser auf das Zukunftsgericht und auf den übersättigten und reuigen König Salomo bezüglicher Stellen. Für uns ist die Beziehung auf Salomo äusserst anstössig, aber eine frühere Zeit hatte (wahrscheinlich) schon eine ebenso überraschende Umbildung der Geschichte in den Büchern der Chronik erlebt. Der Schluss seinerseits erhielt folgenden merkwürdigen Anhang:

"Das Schlussergebnis, nachdem alles vernommen ist: Fürchte "Gott und halte seine Gebote. denn das ist die ganze (Pflicht) „eines Maunes. Denn jedes Werk wird Gott in das Gericht „bringen, (welches kommen wird) ïber alles Verborgene und "alles Offenbare, es sei gut oder böse $\left.{ }^{1}\right)$."

So wurde der Terfasser zum Verkündiger einer Lehre gemacht, an die er nicht glaubte und zur Säule einer Orthodoxie, die er geprüft und mangelhaft erfunden hatte. Er wurde sogar idealisiert zu einem bussfertigen „retraktierenden“ König, und unter dem Deckmantel des Namens jenes Königs hat sein Buch den Weg in den Kanon gefunden.

Und nun zur Datierung des Buches. Wir wissen 
natürlich, dass es ein nachexilisches Werk ist; kein Kritiker würde Anstand nehmen, es in einer geschichtlichen Skizze, wie der vorliegenden, zu benutzen. Aber in welchen Abschnitt der nachexilischen Zeit gehört es? Die Frage ist von hohem Interesse und verlangt eine Beantwortung. Dass Geist und Zweck des Buches Beeinflussung seitens der griechischen Philosophie voraussetzen, ist genügend klar. Man nehme die erste biographischeStelle(natürlich lasse ich dieeingeschobenen Worte , war (oder: bin gewesen) König über Israel in Jerusalem" aus).

„Ich, Kohelet (oder Prediger), widmete meinen Sinn, Unter"suchung und Forschung anzustellen mit Hilfe der Weisheit "betreffs alles dessen, was unter dem Himmel geschieht; es ist „böse Plage, welche Gott den Menschen zu tragen gegeben hat. "Ich sah alle Werke, die unter der Sonne geschehen $\left.{ }^{1}\right) . "$

Das bedeutet, dass Kohelet die Lage des Menschengeschlechts kritisch erforscht haben will oder es thatsächlich gethan hat. Kann es etwas weniger Hebräisches, etwas weniger Orientalisches geben als die Vorstellung, wenn es nicht die Ausdrucksform ist? Und welcher nicht philosophisch denkende hebräische Schriftsteller hätte wohl diese Wendung verstanden:

"Auch hat er die Welt ihrem Verstande aufgeschlossen, nur "dass man von Anfang bis zu Ende das Werk, das Gott ge"macht hat, nicht ergründen kann ${ }^{2}$ )?

Gewisse Stellen erschliessen die Möglichkeit, dass der Verfasser Berührungspunkte mit dem Stoicismus hatte. Ebenso könnte es scheinen, dass der an anderer

1) Koh. 1, 12-14. - ") Koh. 3, 11 [Vigl. aber Anmerkung am Schluss]. 
Stelle angeführte Ausspruch des Antigonos von Soco über uneigennützigen Gehorsam stoische Verwandte hat. Auch ist es wohl begreiflich, dass die Ansichten anderer philosophischer Schulen zu unserem Verfasser durchgesickert sind. Jedoch würde es bedenklich sein, bestimmte Aufstellungen darïber zu machen wegen des Fehlens unleugbar technisch-philosophischer Wendungen im hebräischen Text des Kohelet. Indirekter griechisch-philosophischer Einfluss ist mit Bestimmtheit vorauszusetzen.

Es ist wenigstens etwas, zu wissen, dass zeitlich unser Terfasser später anzusetzen ist als die Eroberungszüge Alexanders. Aus sprachlichen Gründen ist er allem Anschein nach später als 290 v. Chr. anzusetzen. Das ist der früheste Zeitpunkt, der je für die Entstehung des Kohelet vorgeschlagen worden ist. Ist dem aber so, dann können wir, da weder der Makkabäeraufstand noch die vorhergehende Zeit einen passenden geschichthichen Hintergrund darbietet, nicht Halt machen vor der Zeit Johannes Hyrkans (135 bis 105 v. Chr.). Dieser Zeit hat Renan den Kohelet zugewiesen. Dagegen lässt sich zweierlei einwenden: Zunächst war die Herrschaft Hyrkans eine glänzende und liess die meisten Juden stolz sein auf ihr Land ${ }^{\mathbf{1}}$ ). Und ferner, obwohl Hyrkan königliche Gewalt besass, begnügte er sich mit dem Titel eines Hohenpriesters. Die Herrschaft des Alexander Jannäus (104-78 v. Chr.), eines Sohnes von Johamnes Hyrkan, kommt demnächst

1) Wir ersehen das aus einer bemerkenswerten stelle in Pseudojonathans Targum zu Deut. $33,11$. 
in Betracht. Es war eine Zeit trauriger Bürgerkriege, und das Thun des Königs war ein derartiges, dass es ihm alle hochgesinnten Juden entfremdete. Es war ebenfalls eine Zeit sehr starken griechischen Einflusses. Josephus erzählt uns, dass der Bruder und Vorgänger des Königs, Aristobul, den Titel Philhellen führte. Aber wie seltsam würde es sein, wenn ein in jener Zeit entstandenes Buch von dem damals zwischen Sadducäern und Pharisäern wütenden Streit gar kein Anzeichen böte. Gehen wir daher ein wenig weiter herab und lesen wir Josephus' Bericht über die Regierung des mit Unrecht "der Grosse" genannten Herodes. Es war eine Zeit, so sagt er uns, voll allgemeinen Schreckens und allgemeiner Unsicherheit. Die Bürger von Jerusalem durften nicht einmal zusammengehen oder -essen, weil der Tyrann alle grösseren Menschenversammlungen verboten hatte. Spione waren überall ausgestellt, sowohl in der Stadt selbst als in ihrer Umgegend. Herodes selbst soll sich in Verkleidung unter das Volk gemischt haben, nicht um wie ein berühmter Kalif ausfindig zu machen, ob es glücklich wäre ${ }^{1}$, sondern um Ausdrücke des Missvergnügens aufzuschnappen. Seine erklärten und unversöhnlichen Widersacher verfolgte er, und wenn sie Widerstand leisteten, dann nahm er ihnen das Leben. Ein allgemeiner Treueid wurde dem Volke abverlangt, wovon nur die Essener, denen Herodes günstig gesinnt war, ausgenommen waren. Über 6000 Pharisäer verweigerten den Eid und wurden mit Geldstrafe belegt;

1) Die Erzählung von Ilarun al Raschid ist jedoch sagenhaft. 
einige von ihnen wurden nachher aus Rache erschlagen ${ }^{1}$ ). Ich gestehe, dass ich zur Zeit keine Periode ausfindig machen kann, die die Anspielungen im Kohelet so befriedigend erklärt, wie diese. Wird es uns nicht klar, dass die Hauptquelle des in ihm geschilderten Elends das allgemeine Gefühl der Unsicherheit ist? Man vernehme folgenden Rat des Verfassers:

„Fluche nicht dem König, selbst nicht auf deinem Lager, "Und fluche nicht dem Reichen in deinem Schlafgemach; „Denn die Vögel des Himmels könnten den Laut forttragen, "Und die Geflügelten die Rede berichten ${ }^{2}$ ). "

Er sagt uns auch, dass dieser argwöhnische Herrscher keine hoch geborne Persönlichkeit ist, sondern die tyrannische Weise eines Emporkömmlings besitzt. „Wehe dir, Land, wenn dein König ein Knecht ist!

„Glücklich bist du, Land, wenn du einen freigebornen König hast $\left.{ }^{3}\right)$."

Eigentümlicherweise giebt es eine talmudische Legende ${ }^{4}$ ), welche einen berühmten von Herodes seines Augenlichts beraubten Rabbi grade diese Stelle in einer Unterredung mit dem König anführen lässt. Ich muss noch hinzufügen, dass Herodes eine Verkleidung angelegt hatte und den Rabbi zu verleiten suchte, bittere Worte gegen den Mann auszusprechen, der ihn geblendet hatte. Die Geschichte gehört zu einer Gattung von Erzählungen, die offensichtlich ungeschichtlich sind, aber

1) Jos. Ant. XV 10, 4; XVll 2,4. - 2) Koh. 10, 20. „Schlafgemach * ist eine notwendige Vermutung. $-{ }^{3}$ ) Koh. 10, 16a. 17a. Die angeführte Stelle erinnert uns an Jes. 34; der nichtangetuhrte Teil an Jes. 5, 11. Der Verfasser findet in diesen prophetischen Stellen eine Anspielung auf seine eigene Zeit. - *) Baba bathra 4a. Gewōhnlich wird diese Geschichte als historisch behandelt. Doch siehe die Pemerkung am Schluss des Paragrayhen. 
wenigstens zeigt diese Auffassung einer späterenZeit, dass die Tyrannei des Herodes durch Kohelet gut geschildert war. Man erkläre das ganze Buch von diesem Standpunkt aus, dann wird es wahrhaft Leben gewinnen. Warum bemitleidet beispielsweise der Verfasser ein Land, dessen König ein Knecht ist? Weil Herodes zu einem Stamm gehörte, der erst kürzlich von den Juden unterjoeht und sogar gezwungen worden war, seine Religion zu wechseln. Im Talmud erhält er wirklich den Titel „Sklave der Hasmonäer" (der an Kohelet erinnert), weil die Idumäer dureh Johann Hyrkan unterworfen worden waren. Man vergleiche auch folgende Stelle: "Ich sah Sklaven zu Pferde und Fürsten wie Sklaven auf dem Erdboden gehend ${ }^{\mathbf{1}}$ ). "

Das mag bedeuten, dass Herodes die Hasmonäer und ihre Freunde absetzte und seine eigenen Parteigänger (Emporkömmlinge und vielleicht Idumäer) in alle vorzüglichen Posten einsetzte. Hier folge noch eine andere deutliche Anspielung auf politische Verhältnisse:

"Lass dich nicht verwickeln in eine böse Sache;

„Denn er kann alles thun, was ihm gefällt,

"Weil des Königs Wort entscheidend ist.

"Wer kann fragen: Was machst du? $\left.{ }^{2}\right)^{\text {" }}$

Spüren wir nicht die schwüle Luft der Herodeisehen Gewaltherrschaft? Die Erfahrung hat den Verfasser gewarnt vor den verhängnisvollen Folgen der Verwicklung in revolutionäre Aufstandsversuche. Man höre wieder:

„Der weise Mann beachtet des Königs Gebot

"Wegen des Eides bei Gott ${ }^{3}$ )."

1) Koh. 10,7. ${ }^{2}$ ) hoh. 8,3 f., vgl. 10,4. $-{ }^{2}$ ) Koh. 8, 2 (nach Bickell). 
Das scheint eine Anspielung zu sein auf jenen erzwungenen Eid, von dem Josephus uns erzählt hat. Eine ähnliche Anspielung liegt vielleicht vor in der folgenden Stelle:

„Es ist ein und dasselbe Geschick für jedermann, für den "Gerechten und den Gottlosen, für den Reinen und für den „Unreinen, für den, der opfert, und den, der nicht opfert. Dem „guten Manne ergeht es gerade so, wie dem Sünder und dem, "der da sehwört, wie dem, der einen Eid fürchtet ${ }^{1}$ ).

Hier scheint Bezug auf die Essener genommen zu sein, die nach Ansicht des Josephus der gewöhnlichen Opfer sich enthielten, da sie wirksamere Reinigungsmittel für sich selbst hatten und den Eid untersagten, weil ein Mann. dessen einfacher Versicherung nicht getrant werden könne. schon verurteilt sei. Zum Glück für sie berücksichtigte Herodes ihre Abneigung gegen den Eid. Aber unser Verfasser setzt die Gesellschaft der Nichtschwörenden augenscheinlich herab. Vermutlich rechnet er die Essener (welche auch. wie man sich erinnern wird, die Ehe verwarfen) unter die ,ultrareligiösen": Leute, welche, wie er kräftig sagt, ,sich selbst vernichteten."

Es giebt eine Beschreibung der Essenischen Askese im Buch Henoch ${ }^{2}$ ), welche, obwohl von ganz anderem Standpunkte aus geschrieben, die hier vertretene Meinung bestätigt, nämlich dass der Verfasser des Kohelet auf die Essener anspielt. Dort werden die sich selbst verleugnenden Menschen dargestellt als solche, die mehr den Himmel lieben als ihr

1) hoh. 4, 2. - 2) Henoch 108, rgl. 102. 
irdisches Leben und den Gericht und Auferstehung leugrnenden Sündern gegenübergestellt. Der Gegensatz zwischen Kohelet und Henoch kann nicht schärfer sein ${ }^{1}$ ).

Wir dürfen nicht überrascht sein durch diesen weitgehenden Unterschied zwischen den Verfassern der beiden Bücher. Der eine giebt uns das einfache Licht der Erfahrung und Philosophie; der andere beleuchtet die Thatsachen des Lebens mit dem Licht der Gesichte und Träume. Der eine glaubt an göttliche Lenkung der Schicksale Israels, der andere hat fast allen nationalen Sinn verloren, ohne das umfassendere Weltbürgertum gewonnen zu haben. Der Verfasser dieses Teiles des Henoch ist im Geist, wenn nicht thatsächlich, Essener; der Verfasser des Kohelet ist mehr geneigt mit den Sadducäern es zu halten als mit irgend einer andern der wichtigsten Denkerschulen. So haben wir in ihren bezüglichen Schriften Denkmäler von zwei oder drei grossen Richtungen des spätern Judentums. Ich meine natürlich nicht, dass der Verfasser des Kohelet ein ausgesprochener Sadducäer war. Wahrscheinlich war Ben Sira, der weise Verfasser des Ecclesiasticus, dem sadducäischen Durchschnittstypus näher verwandt sowohl nach seinem Priestertum, wie nach seiner Theologie ${ }^{2}$ ). Aber in der sadducäischen Partei war, wie ich vermute, Platz für Leute der verschiedensten Stufen von Kultur und Konservativität. Ich darf hinzufügen, dass wir in

1) Siehe sechste Vorlesung. - ${ }^{2}$ ) Das wird belegt dureh die Thatsache, dass die Bücher der Sadducaer und das Buch Ben siras nebeneinander auf dem alten judischen Index expurgatorius stehen. Siehe Sanhedrin 100b. Taylor, Jewish fathers p. 129. 
den sogenannten Psalmen Salomonis (siehe sechste Vorlesung) einen unanfechtbaren Bericht über die Religion der Pharisäer haben. Es ist vortrefflich, dass wir jede Schule oder Partei in ihren fähigsten Vertretern kennen lernen, und so ist Jüngern der Wissenschaft nur zu raten diese Bücher zu lesen, was nicht verfehlen wird, die schiefen Anschauungen zurechtzurücken, mit welchen sie, wenn ihre Erziehung christlich gewesen ist, natürlicherweise an die neutestamentliche Zeitgeschichte herantreten.

Gewisslich ist es nicht unbegreiflich, wenn wir weniger religiöse Vorliebe für Kohelet haben als für die beiden andern Bücher, und ich bin fest überzeugt, dass wir beim Rückblick auf das Buch Job und sogar auf die Proverbien und das Buch Sirach uns enttäuscht fühlen werden wegen des auffälligen Fehlens des grossen Strebens nach Weisheit. Aber wir wollen daran denken, dass der Schriftsteller, mit dem wir in religiöser Hinsicht am wenigsten übereinstimmen mögen, der einzige ist, mit dem wir aus andern Gründen nicht umhin können das zu thun. Seine Freimütigkeit und die Weite seines Blickes ziehen uns gleichzeitig an, und wenn wir den Jammer der Zeit, in welcher er lebte, uns vor das Auge rufen, dann macht unsere Kritik seiner religiösen Mängel dem aufrichtigsten Mitgefühl Platz. Er hätte sich zweifellos seine religiöse Inbrunst erhalten können, wenn er an die Pharisäer oder Essener sich angeschlossen hätte. Aber um das zu ermöglichen, hätte er den Begriff einer allgemeinmenschlichen Kultur, den das Griechentum 
ihm geschenkt hatte, aufgeben müssen. Es war nötig, dass der Versuch gemacht wurde, diesen Begriff auf das Gewächs des jüdischen Denkens aufzupfropfen und so jüdischen Theismus mit hellenischem Rationalismus zu verbinden. Der, welcher zuerst den Versuch machte, musste für seine Kühnheit büssen, aber wir, die wir das Hinschwinden gewisser Teile seines höheren Strebens beklagen (ähnlich dem, welches der berühmte Darwin nach seinem eigenen Willen zu ertragen hatte) und es doch nicht tadeln dürfen, können dem edlen, wenngleich erfolglosen Streben des Verfassers des Kohelet unsere Aufmerksamkeit nicht vorenthalten.

Denn nach allem wäre es ein mnendliches Missgeschick gewesen, wenn der jüdische Theismus ausschliesslich und dauernd dem Pharisäismus anheim gefallen wäre. Späterhin wurde das jüdische Volk in Palästina allerdings durch den Pharisäismus thatsächlich in Beschlag genommen, aber das Vorhandensein des Kohelet selbst in seiner überarbeiteten Gestalt im Kanon war ein Einspruch dagegen, und wenn nicht die Welt dauernd zwischen Juden und Nichtjuden geteilt werden sollte, dann war es notwendig, dass der Versuch, die jüdische Religion zu hellenisieren, wieder aufgenommen wurde. Welche Haltung unser philosophischer Sadducäer einer solchen Wiederaufnahme gegenüber eingenommen hätte, darüber sich Vermutungen hinzugeben, ist nutzlos. Aber man darf füglich annehmen, dass sein Blick weit weniger pessimistisch gewesen wäre, und dass eine gewisse elementare Form des Entwicklungsgedankens ihn für den 
Verzicht auf den für ihn nicht annehmbaren Messiasgedanken des Pharisäismus schadlos gehalten hätte. Gerade das Fehlen dieser belebenden Vorstellung macht seine Bekenntnissezu einer so grossenEnttäuschung in sittlicher Hinsicht. Ein Schriftsteller mag den Sünden und Thorheiten der Gegenwart gegenüber so strenge sein wie er will, sofern er nur der Hoffnung für die Zukunft eine Thür offen lässt. Carlyle hält man gewöhnlich für einen pessimistischen Schriftsteller, aber er wirkt wahrhaft erbaulich, weil er im ganzen, wenigstens gilt das für die Zeit seiner Blüte, an Fortschritt glaubte. Wer wird nicht sittlich aufgerichtet durch jene schöne Stelle seines Sartor resartus:

"Geschlechter sind wie die Tage des arbeitenden Menschen"geschlechts; Tod und Geburt sind die Abend- und Morgen"glocken, die die Menschheit mahnen, schlafen zu gehen und „erfrischt zu neuem Fortschritt sich zu erheben."

Und dagegen nun jene schöne, aber ganz und gar entmutigende Stelle des Kohelet:

"Ein Geschlecht geht, das andere kommt, „Atber die Erde bleibt immer;

„Die Sonne geht auf, und die Sonne geht nieder

"Und keucht nach dem Orte, wo sie aufgeht.

"Der Wind geht nach Süden und dreht sich rund nach Norden, Indem er ohne Unterlass sich dreht,

"Cnd auf seinen Kreislauf kehrt der Wind wieder.

"Alle Ströme fliessen in die See. und noch ist die See nicht voll;

„Zu dem Ort, wohin die Ströıne gegangen sind, dahin gehen sie wieder.

"Alle Dinge sind voll Mühe, kein Mensch kann es aussprechen; „Das Auge wird nicht gesättigt durch Sehen, noch das Ohr angefüllt durch Hören. 
"Der Tag, der gewesen ist, ist derselbe, der sein wird, "Und was sich ereignete, ist dasselbe, was sich wieder er. eignen wird, "Und es giebt nichts Neues unter der Sonne ${ }^{1}$ )."

Welch lahmer und schwächlicher Schluss! Nun, Montaigne kann uns etwas Besseres lehren als das; denn er erklärt, dass „der menschliche Geist ein grosser Wunderthäter ist!" Und es ist sicher, dass solche Wunder nur durch die befähigende Kraft jener höchsten Weisheit herausgepresst werden können, jener, die im Anfang bei Gott war und „ihre Freude am Menschengeschlecht" hat, die nicht gehemmt werden kann, rüstig ist Gutes zu thun, gütig gegen die Menschen ist, fest, sicher, frei von Sorge, im Besitz aller Macht, alle Dinge übersieht ${ }^{2}$ ). So etwa war der Glaube der bedeutenderen hebräischen Weisen, und obwohl diese erhabene Vorstellung, die zum Teil vielleicht aus Persien stammte, jetzt infolge griechischen Einflusses seitens eines tonangebenden Schriftstellers aufgegeben war, so war sie doch bestimmt, in nicht ferner Zeit auf dem gastlichen Boden eines hellenistischen Winkels in Ägypten zu neuer Blüte gebracht zu werden.

Aus verschiedenen Gründen würde ich froh sein, hier abbrechen zu dürfen. Jener eigenartige Charakter des Verfassers des Kohelet hat einen gewissen Reiz für mich, und ich möchte lieber, dass der Zauber für den Augenblick ungebrochen bliebe. Aber die geschichtliche Gerechtigkeit zwingt mich, a uf die Gefahr hin, den Eindruck der vorstehenden Darstellung ab-

1) Koh. 1, t-9. - ') Sap. Sal. 7, $22 \mathrm{f}$, vgl. Prov. 8, 22-31. 
zuschwächen, dem Leser einen weniger interessanten, aber doch kaum weniger wichtigen Freund der Weisheit vorzuführen. Ich meine den Verfasser der Weisheit des Jesus Sirach, denn ich darf Sie nicht bei der Annahme belassen, dass alle Weisen späterer Zeit dem unglücklichen Verfasser des Kohelet glichen, oder dass die Ketzerei ein höheres Ansehen hatte als die orthodoxe Weisheit.

Die Weisheit Jesu des Sohnes Sirach (oder Ben Sira, wie ich ihn nennen werde) wurde wahrscheinlich um 200 v. Chr. abgefasst. Von den religiösen Ansichten eben dieses Verfassers habe ich nunmehr zu reden. Ich werde meine Ausführungen möglichst auf den kürzlich aufgefundenen hebräischen Teil des Textes begründen.

Und zwar muss uns von vornherein meines Erachtens eine entschiedene Abnahme des allumfassenden Blicks der hebräischen Weisheit auffallen. Der Verfasser des Ecclesiasticus nimmt luäufig Bezug auf Israel und seinen geistigen Vorrang vor den Völkern ${ }^{1}$ ). Und im Lobe der Weisheit, das er nach dem Vorbilde von Prov. 8 zu geben sich verpflichtet fühlt, geht er über seine Torgänger hinaus mit der Erklärung, dass sie, obwohl sie auf der ganzen Erde Besitz habe, democh ihre dauernde Wohnstätte in Jerusalem habe; er sagt sogar, dass sie identisch sei mit "dem Buch des Bundes, dem Gesetze, das Mose uns auferlegte 2)." Das ist ein Satz, den kein alexandrinischjüdischer Gelehrter aufgestellt haben würde, und die

$$
\text { 1) Sir. 17, 17: 24. \&: 36, 12: 37, 25. - 9) Sir. 24. } 23 .
$$


bestimmt zoroastrische Beziehungen hat, denn Dîn oder Daêna, die Personifikation des zoroastrischen Gesetzes wird als eine der himmlischen Schöpfungen Ahuramazdas, "des vieles wissenden Herrn, " bezeichnet ${ }^{1}$ ). Späterhin wurde es ein jüdischer grundlegender Satz, dass die präexistente schöpferische Weisheit nichts anderes sei als das Gesetz ${ }^{2}$ ).

Ben Sira verehrte demnach das Gesetz und fühlte sich veranlasst, das offener zu äussern als die Sittenlehrer vor ihm. Wenn er unter den berühmten Männern der Vorzeit Esra nicht erwähnt, so unterbleibt die Erwähnung einfach aus dem Grunde, weil die nur öffentlichen, dem Esra im Bericht beigelegten Ämter derartige waren, dass ihre Erwähnung vielleicht Sirach peinlich gewesen sein und seine Schüler verletzt haben würde $\left.{ }^{3}\right)$. In der Praxis jedoch wird seine Achtung vor dem Gesetze gemässigt durch seinen Blick auf die andern religiösen Klassiker seines Volkes, aus denen insgesamt er ohne Auswahl Wendungen entlehnt. Dass er sich viel um äusserliche Einzelheiten kümmerte, ist nicht wahrscheinlich. Allerdings äussert er, dass die verordneten Opfer nicht vernachlässigt werden dürfen, aber er sagt ebenfalls, dass Thaten der Barmherzigkeit die echten Dankopfer bilden, und dass Unrecht vergessen ein Sühnopfer ist $\left.{ }^{4}\right)$. Im Tempeldienst ist es der äussere Pomp einschliesshich der Musik und des Gesanges, der ihn anzieht. Zweifellos verehrt er die

1) Siehe Din Yast im Zendavesta (Oxforder Ausgahe) II, 264 ff. - ${ }^{2}$ ) Esra 7,27 dentet darauf hin. Vgl. auch das sehon angetuhrte Wort simeon des Gerechten. - ${ }^{3}$ ) Sogar von Nehemiah weiss Ben Sira nur zu berichten, dass er die Manern hergestellt und die Thore wieder aufgeriehtet habe (Sir. 49, 13! - - ${ }^{4}$ ) Sir. 35, 1-6.

Cheyue, Religiöses Leben der Juden. 
Priester, die Söhne Aarons, hoch; ihre Ehrenrechte vergleicht er mit denen der Familie Davids. Er stellt jene höher als diese ${ }^{1}$ ). Das folgt natürlich aus seiner Achtung vor dem Gesetz. Aber er verehrt die Priester viel mehr als Wächter des sichtbaren Mittelpunktes der jüdischen Volksgemeinde, denn als Opferer.

Die Messiashoffnung ist für unsern Verfasser weniger lebendig als für die älteren Weisen ${ }^{2}$ ), aber seine Eschatologie ist ausgeprägter als die ihrige. Da er fest an diesseitige Vergeltung glaubt, so kann er nicht ohne endliches Gericht auskommen, und jene seltsame Weissagung Maleachis betrefts der Wiederkunft des Propheten Eliah, welche sogar jetzt noch eines so bedeutenden Ansehens in der jüdischen Welt geniesst, wird seitens des Ben Sira mit zweifelloser Zuversicht angeführt. Bei dem Erscheinen Eliah's wird die Wendung im Schicksal des jüdischen Volkes eingetreten sein. Alle andern eschatologischen Weissagungen werden dann in der seligen Wirklichkeit erfüllt werden.

"Selig, wer dich (nämlich Eliah) sieht und stirbt,

"Denn er wird nicht sterben, sondern wahrlich leben ${ }^{3}$ )."

Allerdings verbürgt Maleachi's Weissagung das an sich nicht, aber in Verbindung mit einer andern grossen Weissagung genommen, gewährt sie doch jene Gewissheit. Im Buche Jesajah lesen wir, dass auf dem Berge Zion Gott „den Tod auf ewig vernichten wird ${ }^{4}$ ". Daher wird der Gerechte, den Eliah am

$\left.{ }^{1}\right)$ Sir. 45, 25: Darids Erbe erstreckte sich nur , von Geschlecht zu ('reschlecht (so Hebr. Text). - ${ }^{2}$ ) Siehe vierte Vorlesung. $-{ }^{3}$ ) Sir. 48. 11. - t) Jes. 25, 8. 
Leben findet, ohne den Tod zu schmecken mit einem Schlage in das neue Leben übergehen; dass Ben Sira in der zweiten Zeile eine Wendung der ersten aufhebt, erzielt eine schöne rednerische Wirkung.

Der Verfasser des Sirachbuches hat keine Spur von Dualismus und Pessimismus an sich. "Wenn der gottlose Mensch Satan flucht", sagt er, "dann flucht er seiner eigenen Seele ${ }^{1}$ ). " Denn der Satan benannte Versucher ist einer und derselbe mit dem angebornen Versucher, der im Herzen wohnt: dem schwachen oder verderbten Willen. Von aller lästigen Träumerei fort flüchtet sich der Siracide zu jenem Bilderbuch der Werke Jehovahs, das uns schon aus dem Buche Job bekannt ist. Hier ist für einen Widersacher oder für das Gespenst der Enttäuschung kein Platz. Am Schluss seiner Aufzählung der Naturwunder sagt der Siracide mit frommer Einfalt:

"Mehr von der Art dieser Worte wollen wir nicht hinzufügen; „Das Ende der Rede ist da. Er ist alles.

"Wenn noch mehr enthüllt würde, würden wir ihn (noch) nicht ergründen,

„Denn grösser ist er, als alle seine Werke.

„Welcher Mann hat ihn gesehen, dass er's uns erzählen möge? "Welcher Mensch kann ihn gebührend preisen?

„Es giebt noch viele Dinge, die grösser sind als diese;

"Aber wenige von seinen Werken habe ich gesehen.

"Jehovah hat alles gemacht, was ist,

"Und seinen Frommen hat er Weisheit gegeben 2)."

Jedoch darf ich von dem Siraciden nicht Abschied nehmen, ohne ihn mit einem andern Schriftsteller ver- 
glichen zu haben, der eine wenig abweichende Gestalt der Frömmigkeit vertritt. Der Verfasser und Kompilator der Chroniken (die genau genommen Esra und Nehemiah mit umfassen sollten) war seinem Beruf nach unzweifelhaft ein levitischer Musiker. Er ist 50 oder 60 Jahre früher anzusetzen als der Siracide. Der Verfasser ist oft anziehender als sein Werk, oder vielmehr, das Buch ist oft höchst anziehend als verschleiertes Bild seimes Verfassers. Der Chronist wird natürlich mehr angezogen durch die Einzelheiten des Opferdienstes als der Siracide, der Laie. Es macht ihm Freude, ziemlich eingehende Beschreibungen des Tempeldienstes und sogar der Tempelgeräte zu liefern, ebensowenig zeigt er Geringschätzung des Tieropfers. Er hätte der opferlosen Religion kaum soweit sich nähern können, wie der Siracide und einige Psalmisten.

Augenscheinlich hegt er besonderes Interesse für diejenigen Verrichtungen seiner eigenen Berufs genossen, die zum Opfer in keiner Beziehung stehen. Er erwähnt einen levitischen Schreiber schon zur Zeit der Regierung Davids und giebt an, dass Jošafat in alle Städte Judas levitische Gesetzeslehrer entsandte. Das waren Verrichtungen, die auch durch Laien versehen werden konnten und die den Priestern eigentümlichen an Bedeutung überragen sollten. Noch mehr Interesse zeigt er am Psalmengesang im Tempel, er setzt als selbstverständlich voraus, dass die bestehenden Einrichtungen bis in das zehnte Jahrhundert zurückreichen. Dies sein Interesse wurde seitens des Siraciden in vollem Masse geteilt, wie wir aus dem Lob- 
preis frommer Menschen in seinem Buch ersehen. Doch übte wahrscheinlich keiner dieser beiden Schriftsteller den ungeheuren geistigen Einfluss der Psalmisten aus.

Dass der Siracide eine diesseitige Vergeltung annimmt, haben wir schon gesehen. Der Chronist gewährt jedoch noch stärkere Belege für die erneute Kraft dieses Glaubens im dritten Jahrhundert. Ich brauche nicht all die erstaunlichen Verschiebungen und Erfindungen von Thatsachen aufzuzählen, worauf den Chronisten seine fromme Phantasie geführt hat. Über den Chronisten als Geschichtsschreiber ist des langen und des breiten geredet worden; man gestatte mir aber noch eine Würdigung des Chronisten als Menschen. In jenem Zeitalter war ein so fester Glaube an die Gerechtigkeit Gottes eine Leistung für die Sittlichkeit, wofür wir wohl eine Menge von Verstössen gegen die geschichtliche Zuverlässigkeit mit in den Kauf nehmen können. Und die Idealisierung Davids ist ebensogut eine Weissagung einer zukünftigen besseren Zeit wie das Gesicht vom Fürsten des Friedens und dem Spross aus der Wurzel Jesse. Für eschatologische Schilderungen hat der Chronist keinen Raum. Aber die Freigebigkeit, mit der er früheren Zeiten angebliche Propheten zuschreibt, legt uns Zeugnis ab für seine brennende Sehnsucht nach einem wahren Propheten guten alten Schlages; gerade so wie sein Festhalten an der göttlichen Gerechtigkeit uns zeigt, dass er täglich um die Ankunft des wahren israelitischen Königs Jehovah gebetet haben muss. 
Noch ein weiterer Berührungspunkt mit dem Siraciden und noch mehr mit dem Psalter muss zum Schluss hervorgehoben werden: die Zartheit seines Gefühls. Ich stelle seine Theologie beiseite und rede nur von seinem Gefühl, wie es Ausdruck findet in den Reden, die er seinen Gestalten in den Mund legt. Die Worte, mit denen David Jehovah vor der ganzen Gemeinde dankt (Chron. A 29, 10-19) mögen genannt werden. Allerdings sind sie nicht so, wie David möglicherweise gesprochen haben könnte, aber mit einigen Kürzungen hätten sie seitens eines frommen Leviten beiLeitung der Andacht von demütigenjüdischen Gläubigen wohl geprochen werden können. Hier wie an anderen Punkten seiner verkehrten Geschichtskonstruktion schüttet der gute Chronist sein Herz aus. Und kein Besitz von Terstandesweisheit ist soviel wert, wie jene liebende Elrfurcht vor Gott, in der er lebte und webte. 
Sechste Vorlesung.

\section{Das Judentum:}

Seine Anziehungskraft auf Fremde, seine Auffassung des Verhältnisses zu Gott als solchem, seine Beziehungen zu Griechenland, Persien und Babel.

In der dritten Vorlesung betrachteten wir jene ausgezeichneten Gedichte über den Knecht Jehovahs, die eine vollständige Vermischung der gesetzlichen und prophetischen Religion darstellen. Der Knecht Jehovahs d. h. die Gesellschaft religiöser Lehrer, die den Kern des jüdischen Volkes bildete, hatte zuerst die lauen oder gleichgiltigen Juden und dann die andern Völker zur wahren Religion zu bekehren. Der Geist seiner Predigt war prophetisch, die Grundlage seiner Botschaft gesetzlicher Natur. Dass Jehovah (erklärt als nder, welcher ist" d. h. Grund und Quelle alles Seins, aller wahren Erkenntnis und Macht) der Gott der ganzen Menschheit ist, das ist ein Glaube, der schon dem allerersten Abschnitt der priesterlichen Erzählung zu Grunde liegt (Gen. 1), und wie ernst der Erzähler das gemeint wissen will, das erhellt aus der Thatsache, dass er einen "ewigen Bund" zwischen dem wahren Gott auf der einen Seite und der durch Noah und seine drei Söhne vertretenen Menschheit auf der 
andern erwähnt (Gen. 9, 1-12). Gerade diesen „ewigen Bund" haben, wie ein späterer Prophet erklärt, die Bewohner der Erde gebrochen ${ }^{\mathbf{1}}$ ). Und ebendenselben Bund fasste eine "Säule" der alten Christengemeinde als Grundlage des neuen Elementargesetzes des neuen Heidenchristentums auf ). Der priesterliche Erzähler in der Genesis meint natürlich nicht, dass die einfache Vorschrift der Achtung vor dem Leben, besonders vor dem Menschenleben, genügen kann als alleinige Grundlage der bürgerlichen Gesellschaft, aber er ist sich klar darüber, dass die Verletzung derselben den Zorn Gottes über die sündigen Völker bringen wird. WVirft das nicht unverhofftes Licht auf jene sonst überraschende Wendung des neunten Psalms'):

"Die Gottlosen werden zur Unterwelt fahren:

"All die Völker, die Gottes vergessen"?

Gerade die Barbarei der fremden Zwingherren der Juden treibt diese kühne Drohung über die Lippen der Unterdrückten. Das personifizierte Israel weiss, dass Gott sein Gebot nicht ungestraft übertreten lassen wird; am allerwenigsten, wenn sogar das Dasein seines Volkes bedroht wird. An einer andern Stelle desselben Psalms (Ps. 9, 11 f.) zeigt der Psalmist die Innigkeit seines Glaubens, indem er sich in die glückliche Zeit versetzt, wo Jehovah schon dazwischen getreten sein wird. Er sagt:

"Lobsinge Jehovah, dessen Thron in Zion ist, „Künde von seinen Thaten unter den Völkern,

"(Sage,) dass der Rächer des Blutvergiessens ihrer gedacht hat "(Und) hat nicht rergessen des Schreis der Dulder."

1) Jes. 24, 5. - 3) Act. 15, 20. - 3) P's. 9, 17. 
Wir sehen jetzt, dass für die nichtjüdische Welt das Vorhandensein zweier Menschengattungen angenommen wird. Es giebt solche, die Gottes und seiner Uroffenbarung "so weit vergessen haben", dass sie selbst seinen Augapfel (d. h. die fromme Gemeinde Israel) antasten ${ }^{1}$ ), und es giebt solche, die trotz ilnrer augenblicklichen Unwissenheit keineswegs für Belehrung unempfänglich sind ${ }^{2}$ ). Der ersten Gattung gegenüber ist für einige Psalmisten (siehe dritte Vorlesung) kein Ausdruck der Feindschaft zu stark, aber gegen die letzteren besitzen wir die freundlichsten Worte seitens des Dichters und Lehrers, der die Lieder über den „Knecht" schrieb. Der letztgenannte Schriftsteller besass einen Mitarbeitęr in jenem vollendeten Erzähler, der zum Teil auf Grund der Volkssage die Jonaerzählung abfasste. Jona, der Sohn des Amittai, war ein missionierender Prophet, der zuerst seiner Berufung widerstrebte, hernach aber nach Niniveh ging und nicht ohne Erfolg die blutdürstige Einwohnerschaft dieser Stadt zur Busse zu bewegen suchte. Er wird aufgefasst als Bild des Volkes Israel, das in der vergangenen Zeit seines Missionsberufs vergessen hatte, zur Strafe dafür durch den Drachen Babel verschlungen worden, aber jetzt befreit war und noch einmal ermahnt wurde, seine Pflicht zu erfüllen.

Ein leichter erreichbares Ziel jedoch als das im Jona vorgeführte erschien vor dem Auge eines andern ernstlich frommen Mannes. Es bezog sich auf die Fremden, auf welche die Religion Jehovahs ihre An-

1) Zach. 2, 8. $-^{2}$ ) Jes. 42, 4. 
ziehungskraft auszuüben begonnen hatte. Diese Proselyten waren über sittlichen oder religiösen Vorwurf erhaben; sie waren eifrig in Erfüllung aller ihnen bekannten gesetzlichen Pflichten und besonders eifrig bei der Heilighaltung des Sabbats. Ihr Hauptwunsch war, was ein Psalmist ${ }^{1}$ ) so schön ausdrückt: $\eta^{\mathrm{zu}}$ wohnen im Hause Jehovahs alle Tage ihres Lebens" d. h. in Jerusalem sich niederzulassen und den Tempel zu besuchen. Aber sie kannten nur zu gut die Stärke des Widerspruchs, der sich gegen ihr Verlangen zu regen im Begriff war. Ihr unbekannter Freund suchte sie daher durch eine Weissagung ${ }^{2}$ ) zu unterstützen, lant welcher Gott ausdrücklich die grösste Weitherzigkeit forderte gegen jene frommen Ausländer, welche geneigt waren, den gesetzlichen Forderungen nachzukommen, aus dem Grunde, weil sein Haus als aligemeines Bethaus betrachtet werden sollte. Obgleich als Schriftsteller nicht reich begabt, besass dieser gute und weise Mann ein ziemlich gesundes religiöses Urteil, und die jüdische Kirche hat allen Grund, dankbar zu sein, dass Priester und Schriftgelehrte wie Esra nicht ihre alleinigen Leiter waren.

Und wiederum unterstützt der Geschichtsschreiber den Propheten. Es gab in Jerusalem einen andern Freund der bedrückten Proselyten, welcher eine idyllische Erzählung schrieb zwecks Rechtfertigung der Aufnahme fremder Frauen, welche von Herzen Nationalität und Religion ihrer jüdischen Ehemänner annahmen, in die Gemeinde. Über die liebliche Geschichte von

1) $1 \mathrm{~s}, 27,4 .-2$ Jes, $56,1-8$. 
der Ruth hätte ich vieles zu sagen, wenn nicht ein hoch angesehener amerikanischer Gelehrter ${ }^{1}$ ) das Buch vor den amerikanischen Lesern schon in das rechte Licht gerückt hätte. Die Existenz dieses unzweifelhaft nachexilischen Buches ist eine ebenso bedeutungsvolle Thatsache wie die strenge Denkart Esra's. Das Buch beweist, dass wir Recht haben mit unserer Annahme, dass jener grosse Priester und Schriftgelehrte einen ganz vollständigen Sieg über die Freunde der Mischehen nicht davongetragen hatte. Wären die Ehen zwischen Juden und Moabitern ganz unmöglich gemacht worden, dann hätte eine solche Erzählung nicht geschrieben werden können. Aber obwohl dieser Brauch durch die Rechtgläubigen nicht ganz ausgerottet worden war, so wurde er zweifellos ihrerseits mit schelen Augen angesehen. Unser Verfasser, der mit den unterdrückten Moabiterinnen fühlte, wie Maleachi mit den unterdrückten Jüdinnen, widmete seine gewandte Feder ihrer Sache. Das ist nicht alles. Ein trockener mit Interesse für Genealogien begabter Schriftsteller fügte dieser volkstümlichen Erzählung einen kurzen Zusatz hinzu ${ }^{2}$ ), dessen Zweck war, die moabitische Heldin unter die Ahnen Davids einzuführen. Ich bedaure, dass ein so schreiblustiger Mann wie der Chronist diesen Faden nicht aufnahm. Wir blicken in seiner Genealogie Darids umsonst nach dem Namen der Ruth uns um. Vielleicht nahm er Anstand, dieses angebliche moabitische Weib des Boas

2) Ruth 4, 18-2.2.

1) Prof. C. A. Briggs im North American fieview Jannar 1897. - 
anzuerkennen, da ihr Vorhandensein möglicherweise auf ihre Nachkommenschaft einen Makel werfen konnte; denn wir dürfen kaum zweifeln, dass er die Thorheit des Königs Rehabeam auf die ammonitische Abstammung der Mutter jenes Königs zurückführt ${ }^{1}$ ).

Die Weitherzigkeit der Propheten und Geschichtsschreiber darf jedoch nieht übersehätzt werden. Wie stolz ein Fremder auch immer sein mochte auf Geburt oder Rejehtümer oder Weisheit, er hatte alles beiseite zu legen, wenn er Proselyt wurde. Der einzige des Besitzes werte Adel bestand darin, jüdischer Religion zu sein, und die beste Verwendung des Reichtums darin, .den Platz des Heiligtums Gottes zu verschönern und den Schemel seiner Füsse ruhmwürdig zu machen "2)." Wieviel Freiheit auch auf dem Gebiet der Woisheit einem Juden, der nach einem längeren auswärtigen Aufenthalt nach Palästina zurückgekehrt war, eingeräumt werden mochte, fiu einen Proselyten, der so viel zu lermen hatte, ehe or mit den Sehriften vertraut war, passte allein die Stimmung, die in folgenden Worten ihren Ausdruck fand:

"Nicht stolz ist mein Herz, Jehovah,

"Nicht hochmütig blicken meine Augen;

"Auch befasse ich mich nicht mit grossen Dingen "Und dem, was zu schwer für mich ist $\left.{ }^{3}\right) . "$

Freilich ist es nicht wahrscheinlich, dass es viele Proselyten in Judäa gab, selbst als die Beziehungen zwischen Persien und den Juden die allerfreundlichsten waren. In späteren Tagen muss der zerrüttete Zu-

1) (hron. B 12, 13 f. - ") Jes. 60, 13. - 3) Ps. 131. 1. 
stand des Perserreiches einer kräftigen judaistischen Propaganda in Palästina so gut wie anderswo ungünstig gewesen sein. Die Juden ihrerseits wurden auch mehr und mehr den Fremden abgeneigt, und wenn die beiden gegen Götzendienst eifernden Stellen, die ein nachexilischer Herausgeber in den ursprünglichen Text des Deuterojesajah ${ }^{1}$ ) eingefügt hat, in die persische Zeit gehören, dann dürfen wir uns kaum wundern, dass die Heiden ihre Abneigung gegen das Judentum beibehielten, denn der Ton ist unversöhnlich und beissend, und es ist keine bestimmte religiöse Lehre da, die denkende Fragesteller hätte anziehen mögen. In der That waren die Umstände dem Missionsgedanken der grossen „Knechts“" Lieder höchst ungünstig, obwohl man gern hervorhebt, dass im 51. Psalm das fromme Israel seine Verpflichtung anerkennt, die Sünder und Abtrünnigen Gottes Wege zu lehren:

„Erfreue mich wieder mit deiner Erlösung

"Und stütze mich mit einem eifrigen Geist.

„Dann will ich Abtrünnige deine Wege lehren,

"So dass sich die Sünder zu dir bekehren ${ }^{2}$ )."

Unter "Sündern“" und "Abtrünnigen" versteht der Psalmist ungläubige Juden.

Im 119. Psalm dagegen (einem Werk der griechischen Zeit) finden wir die Stellen, in welchen der Gedanke einer Mission innerhalb der nichtjüdischen Welt zu keimen scheint. Sie finden sich in zwei nebeneinanderstehenden Strophen: 
"Lnd reisse nicht das Wort der Wahrheit heraus aus meinem Munde,

"Denn ich harre auf deine Rechte."

"Und ich will von deinen Ermahnungen reden vor Königen "Und mich nicht schämen ${ }^{1}$ )."

Die erste Strophe erinnert uns an den „Bund" im Jesajah $(59,21)$, nach welchem die Worte, die in den Mund des wahren Israel gelegt sind, niemals aus demselben weichen sollen d. h. Israel soll ewig erhalten bleiben, um der gläubige Verkünder des Gesetzes Jehovahs zu sein ${ }^{2}$ ). In der letzten Strophe will der Sprecher (das personifizierte fromme Israel) vielleicht sagen, dass er sich als Missionar vor das Angesicht heidnischer Könige wagen wird, wie Jona gethan haben soll. Das ist möglicherweise reranlasst durch einen schon vorher gemachten Versuch, das Judentum ror einem Könige von Ägypten oder Syrien in vorteilhafteres Licht zu rücken. Ich selbst fasse die Stelle jedoch als weniger weittragend auf. Israel drückt seine Bereitwilligkeit aus, unter veränderten Unständen vor Königen für die geoffenbarte Wahrheit Zeugnis abzulegen. Augenblicklich ist ein solch heroisches Wagestück unstatthaft. Gegenwärtig verlangt Israel zu ungeduldig nach der Vollstreekung des Urteilspruchs über seine Verfolger") und hat zu viel zu thun mit den Versuchen heidnischer Lehrer, seine eigenen Volksgenossen zum Heidentum herüberzuziehen, als dass es seinerseits ernstlich an missionierende Unternehmungen

1) Ps. 119, 43. 46. - ${ }^{2}$ ) Es findet sich dort eine Anspielung auf die Monologe jenes vorbildlichen Missionars: des Tinechts Jehovahs. - ${ }^{3}$ ) Ps. 1I8, St. 
unter den Heiden denken könnte. Alles, was es thun kann, ist, dass es den Glauben an die Vollendung der wahren Religion pflegt.

"Ich habe mehr Einsicht, als alle meine Lehrer, "Denn deine Ermahnungen sind meine Betrachtung. "Das Gesetz aus Gottes Munde ist besser für mich "Als Tausende von Gold und Silber ${ }^{1}$ )."

Wir finden jedoch bestimmte Bezugnahme auf Proselyten in zwei Psalmen ${ }^{2}$ ), welche mit dem 119. Psalm eng verbunden sind. Eine Aufforderung, auf Gott zu vertrauen und von seiner Güte Zeugnis abzulegen, wird an drei Gruppen von Personen gerichtet: an Israel, das Haus Aarons und die Gottesfürchtigen. "Israel" wird sonst als Bezeichnung für die Laien gebraucht; das "Haus Aarons" sind die Priester; die "Gottesfürchtigen" sollen zweifellos die Proselyten sein, eine Gleichsetzung, für welche der spätere Sprachgebrauch spricht. Beanstanden können diese Auffassung nur diejenigen, welche Psalm 115, 118 und 135 als Zeugnisse der persischen Periode betrachten, eine Annahme, die wenig Wahrscheinlichkeit für sich hat.

Man darf daher meines Erachtens annehmen, dass zu irgend einem Zeitpunkt der griechischen Periode, wahrscheinlich während der Herrschaft der Ptolemäer und wiederum nach den ersten Siegen der Makkabäer eine Anzahl von Fremden sich der jüdisch-palästinensischen Gemeinde anschloss. Ihre Beweggründe waren zweifellos verschiedener Art. Es gab viele, welche

1) Ps. 119, 99. 72. $-{ }^{2}$ ) Ps. 116. 118. 
nach dem „lebendigen Wasser" dürsteten, welches keine andere Religion besass ${ }^{1}$ ). In der That darf man mit Fug behaupten, dass die verhältnismässige Reinheit des jüdischen Monotheismus einem Bedürfnis des Zeitalters entsprach ${ }^{2}$ ). Andere gab es vielleicht, welche ein noch dringenderes Bedürfnis nach einem Gemeinschaftsbande empfanden, das stärker wäre als die zersplitternden Einflüsse drückender despotischer Herrschaft. Ein solches Band schien mit Reeht die jüdiische Gemeinschaft mit ihren vielfach sich verzweigenden Beziehungen zu bieten.

Aber die bemerkenswertesten Belege für das Vorhandensein Fremderinder nicht mehrausschliesslich nationaljüdischen Kirche sind vor allen die, welche in dem Anhangzu Jes. 19 (v. 18-25) und in Psalm 87 sich finden. An beiden Stellen wird der Erwartung Ausdruck gegeben, dass nicht bloss vereinzelte Heiden, sondern ganze Gemeinschaften in den jüdischen Verband eintreten werden. Ohne Zweifel war das eine starke Selbsttäuschung; aber sie setzt voraus, dass zahlreiche Bekehrungen schon stattgehabt hatten, und dass nicht allein Bašan und Galiläa ${ }^{3}$ ) sondern Städte und Distrikte in den verschiedenen erwähnten Gegenden in bemerkenswertem Grade judaisiert worden waren. Ich will die zweite Stelle anführen in einer hoffentlich dem, was der Verfasser hat sagen wollen, sich annähernden Fassung. Es ist ein Gedicht in drei Stanzen:

1) Ps. 65, 2: „Lu, der du (iebete erhorst! Alles Fleisch kommt zu dir!* - ") [0b wir zu Gunsten unserer Anschauung aus der Benennung "Tobiah der Ammouiter" irgend eine Folgerung ziehen dürfen, ist ungewiss. Siehe die Schlussanmerkung über sanballat und Tobiab.] - ${ }^{3}$ ) Ps. 68, 22 (?); Makk. A 5, 14-54. 
"Wohl der Stadt, deren Fundamente

"Ruhen auf den heiligen Bergen!

„Jehovah liebt die Thore Zions

„Über alle Wohnungen Jakobs (hinaus).

"Lass sie ihn preisen und ihn loben ohne Unterlass

"In der Stadt Gottes."

"Assyrien, Rahab und Babel

"Schliessen sich ihr an;

"Philistäa, Musur und Kus' ${ }^{1}$ ):

"Israel ist ihr Name;

"Und Zion nennen sie "Meine Mutter"

"Und Israel "Meinen Vater".

„Jehovah verzeichnet im Buch der Völker

"„Israel ist ihr Name"."

"Wohl der Stadt, deren Fundamente

"Ruhen auf den heiligen Bergen!

"Jehovah, unser Gott, richtet sie auf,

„Der Allerhöchste trägt sie.

"Lobt ihn mit Singen and mit Reigen

"In der Versammlung der Armen ${ }^{2}$ )."

In vorstehenden Worten müssen wir einen Lobgesang auf Zion als den Mittelpunkt einer idealen katholischen Kirche erblicken. Der Psalmist hat alle grossen Vorstellungen Deuterojesajahs und der "Knechts"-Lieder in sich aufgenommen und findet sie nun im Begriff in seiner eigenen seligen Erfahrung erfüllt zu werden. Das einst so verachtete Israel ist nun sei es durch seine Predigt sei es, indem es ein-

1) Zwei nordarabische Gegenden, deren Namen, wie Winckler mehr als wahrscheinlich gemacht hat [Altorientalische Forschungen 1. - S.), mit den ähnlich klingenden Namen Ägyptens und Äthiopiens verwechselt worden sind. - 2) (Die vorstehende Übersetzung nebst der dazu gehörigen vorstehenden Anmerkung, sowie die nachstehend im Text in eckige Klammern eingeschlossene Stelle sind Ergebnisse der neuesten Forschung des Herrn Verfassers, durch welche er guitigst die vorliegende Übersetzung bereichert hat. $-s$.

Chөyдө, Religiöses Lebeu der Juden. 
fach sein Licht leuchten lässt, drauf und dran Philister und Araber, Assyrer und Babylonier zu sich herüber zu ziehen und zwar in solchen Massen, dass ein Tag bevorzustehen scheint, an dem alle Menschen Juden sein werden d. h. da die Religion mehr verbinden wird als die zufälligen Verschiedenheiten der Sprache oder des Volkscharakters trennen.

Diese Stelle und der Anhang zu Jesajah 19 (v. 16-25) stellen die Flutmarke religiöser Weitherzigkeit in Palästina dar. Für einen Augenblick schien es möglich, dass die juidische Theologie von ihren minderwertigen Elementen gesäubert werden könnte. Aber das sollte nicht sein. Die Ursachen dafür aufzuzeigen würde mich zu lange aufhalten. Ich muss mich vielmehr einem noch interessanteren Gegenstande zuwenden, der uns in den Mittelpunkt der jüdischen Lehre von Gott als solchem und dem Terhältnis zu ihm führt. Man wird darauf gebracht durch [folgende schöne Worte in Jes. 12: „Mit Freuden werdet ihr Wasser schöpfen aus dem Brunnen des Heils"].

Was sind das für Brunnen in Zion, möchte ich fragen, die so viele fromme Proselyten anzogen? Das Bild ist bedeutungsvoll. Wer gedenkt nicht jenes schönen alten hebräischen Liedes in der älteren Geschichte, das da anfängt: „Steige auf Brunnen, singet demselben $\left.{ }^{1}\right)^{4}$, als wenn durch das Lied das in der Erde verborgene Wasser an den Tag gelockt werden könnte? Aber das Wasser, das die liebreiche Mutter Zion ihren Kindern giebt, ist kein gewöhnliches lebendiges

1) Num. 21, $17 \mathrm{f}$. 
Wasser. Wer immer aus dem Abana und Pharphar trinkt, den wird wieder dürsten. Aber wer aus Zions Quellen trinkt, den wird nie wieder dürsten; jenes köstliche Wasser wird ihm ein Brunnen sein, der in das ewige Leben quillt ${ }^{1}$ ). Hier folge eine schöne Stelle, die diesen Gedanken sehr klar zum Ausdruck bringt und erklärt, wie die in der ersten Strophe angedeuteten geistlichen Vorrechte allen Menschen eröffnet werden.

"(Auf dich setzen) die Geschlechter der Menschen (ihre Zuversicht), „Im Schatten deiner Flügel finden sie Zuflucht.

„Sie feiern Feste ob der Süssigkeiten deines Hauses,

"Und aus dem Strom deiner Wohlthaten giebst du ihnen zu trinken.

"Denn bei dir ist der Quell des Lebens,

"Durch dein Licht sehen wir Licht 2)."

Die letzte Strophe ist ebenfalls wichtig. Sie zeigt, dass es zwei Arten von Licht und Leben giebt, und dass nur im Tempel das höhere Licht und Leben erlangt werden kann. Was das für die edelsten Juden bedeutete, werden wir später sehen. Es ist klar, dass die alte Ausdrucksweise erweitert wird, um neue Gedanken aufzunehmen. Ohne Zweifel müssen wir uns hüten, allzuviel zu vergeistigen. Die Segnungen, auf welche fromme Gläubige hoffen, sind noch in bedeutendem Grade materiell. In gewissem Sinne wird allen Menschen, sogar denen, die jetzt leben und noch mehr denen, die am grossen Gerichtstage leben werden, materielles Glück zugesichert als Lohn gläubigen Gehorsams.

1) Siehe Joh. 4, 13 f. - $\left.{ }^{2}\right)$ Ps. 36, 8-10. 
Aber die neue Sehnsucht nach sittlichem Einssein mit Gott strebt ebenso gewiss danach, über die alte Sehnsucht nach materiellem Glück die Oberhand zu erlangen.

Doch wir wollen uns bestimmter ausdrücken. Gab es denn keine dämmernde Ahnung von einem zweiten Leben nach dem Todesschlafe, einem zweiten Leben, das nach Hunderten von Jahren gemessen werden konnte oder vielleicht garnicht? Gewiss begannen nach dem Ende des Perserreiches einige Leute "zaghaft die grössere Hoffnung zu hegen". Zu dieser Zeit wurden die folgenden scheinbar einander widersprechenden Sätze seitens eines prophetischen oder apokalyptischen Schriftstellers ausgesprochen:

„Die Toten werden nicht leben; die Schatten werden nicht „auferstehen; daher bestraftest, daher zerstörtest du sie, und "liessest all ihr Andenken vergehen." (Das bezieht sich auf "die toten Unterdrücker Israels, die nicht länger schrecklich "sind, weil die heidnischen Toten nicht wieder aufleben können.) "Deine Toten werden anferstehen; die im Staube wohnen, "werden erwachen und singen vor Frende. Denn dein Tau "ist ein Tau des Lichts, und das Land wird die Schatten "hervorbringen ${ }^{1)}$."

Die zweite Stelle ist an Israel gerichtet und beweist, dass der Glaube an die Auferstehung der frommen Juden schon ziemlich in Aufnahme gekommen war. Es scheint sogar, dass mystische Ausdrücke ausgeprägt worden waren, diesen Glauben zu symbolisieren. Die Auferstehung wird einem Tau zugeschrieben, der

1) Jes. $26,14.19$. 
vom höchsten Himmel hernieder kommt. Dort sind jene blendenden glänzenden Lichter, inmitten derer Gott wohnt. Es ist in der That möglich, dass diese grosse Gnade auf diejenigen beschränkt blieb, die um ihres Glaubens willen gestorben waren. Aber selbst wenn das zuerst der Fall war, so dürfen wir annehmen, dass die gewöhnlichen Bekenner des täglichen Lebens bald nach demselben Vorrecht strebten wie die Märtyrer.

Etwa 170 Jahre später fand dieser Glaube noch bestimmteren Ausdruck. Der Verfasser des Danielbuches sagt, dass in einer Zeit unvergleichlicher Wirren das jüdische Volk befreit werden wird und ebenso, dass "viele von denen, die im Staube des Erdbodens schlafen, erwachen werden, etliche $z u$ ewigem Leben und etliche zu Schande und ewigem Abscheu", endlich, dass eine Belohnung von besonderem Glanze für die Lehrer der Gerechtigkeit aufbehalten wird ${ }^{\mathbf{1}}$ ). Nach dieser Zeit sind die Gründe für das Vorhandensein des Auferstehungsglaubens überwiegend, obwohl die Sadducäer wie der philosophische Verfasser des Kohelet noch gegen diese fremd aussehende Neuerung sich ablehnend verhielten.

Es giebt jedoch keine frühen Anzeichen für die Thatsächlichkeit eines Glaubens an bewusste Gemeinschaft der Seele mit Gott zwischen Tod und Auferstehung, und es dauerte lange, ehe die Aufhebung des Todes für gerechte Juden im messianischen Zeit-

) Dan. 12, 1-3. 
alter allgemeine Annahme wurde. Das vorletzte Kapitel des Buches Jesajah, das einzige, das der Zeit Nehemiahs entstammt, sagt in einer Schilderung des messianischen Glücks weiter nichts, als dass Weinen und Klagen nicht mehr sein wird, und dass der jüngste Mann, der in Jerusalem stirbt, ein Alter von hundert Jahren ${ }^{1}$ ) erreichen wird. Kurz darauf finden wir, dass ein anderer prophetischer Schriftsteller in gewählterer Sprache der bestimnten Hoffnung auf Aufhebung des Leides Ausdruck giebt. Er nemnt Leid die „Hülle, die über alle Völker gebreitet ist" und fügt hinzu, dass „Gott die Thränen von allen Angesichtern abwischen wird ${ }^{2}$ ". Mehr vermag dieser fromme Optimist nicht zu sagen. Aber ein späterer Schriftsteller, dessen Glaube an Gott so fest ist, dass er kühnlich auf die wunderbarste aller Gaben hofft, hat folgenden kurzen Ausspruch eingefügt, der allerdings den Zusammenhang unterbricht, aber den Lesern sich durch seinen Wohlklang aufgedrängt haben muss: „Er wird den Tod vernichten für immer ${ }^{3}$ )." Das ist die logische Schlussfolgerung aus dem Glauben an die Auferstehung. Sobald die Juden das erfassten, wetteiferten sie mit ihren Zoroastrischen Brüdern in der Folgerichtigkeit, mit der sie ihn annahmen.

Daher dürfen wir nicht überrascht sein, wenn wir in Job, Proverbien, Sirach und dem Psalter von den neuen Glaubenssätzen mehr oder weniger bestimmte Spuren finden. Keinesfalls kann irgend eines ron diesen

1) Jes. $65,19 \mathrm{f} .-{ }^{3}$ ) Jes. 25,7 f. $-{ }^{3}$ ) Jes. 25. 7 (Zeile 1). 
Das Judentum: Seine Anziehnngskraft auf Fremde u. s. w. 231

Büchern älter sein als die Zeit Nehemiahs, und ein grosser Teil des Psalters muss sogar jünger sein als dieser Zeitabschnitt. Aber sogar der Siracide, der frommgesinnte Verfasser des Ecclesiasticus, empfiehlt, obwohl er theoretisch der Ansicht ist, dass "das; was vom Himmel herniederkommt, zum Himmel zurïckkehrt ${ }^{1}$ ), " doch als praktischer Mann die Übung des Frohsinns; denn es giebt "keine Wiederkehr" aus dem Grabe ${ }^{2}$."

Wenden wir uns damn den Proverbien zu, so finden wir, dass keine einzige von den angeblichen Belegstellen dieses Buches für die Unsterblichkeit der Prüfung Stich hält. Die unzweideutigste Stelle, wenn anders sie auf richtiger Lesung beruht, würde folgende sein (ich führe sie nach der revidierten [englischen] Übersetzung an):

"Auf dem Wege der Gerechtigkeit ist Leben, "Und auf dem Pfade von dort aus ist kein Tod ${ }^{3}$ )."

Aber wir haben guten Grund anzunehmen, dass die zweite Zeile vielmehr zu lesen ist wie folgt:

"Aber der Weg des Abschenlichen führt zum Tode."

Die wirkliche Ansicht der Verfasser der Proverbien ist in folgender Strophe ausgedrückt:

„Die Furcht des Herrn verlängert die Tage, "Aber die Jahre der Gottlosen werden verkürzt werden ${ }^{*}$ )."

Trotz dessen, was im Buch Job bemerkt ist,

1) Sir. 40, $\left.11 \mathrm{f} .-{ }^{2}\right)$ Sir. 38, $20 \mathrm{f}$. Allerdings giebt es eine Stelle, die besagt. dass, die, welche liott wohlgefallige Werke thun, die Frucht des Baumes des Lebens empfangen werden ${ }^{4}$. Aber sie findet sich nicht in den besten griechischen Handschriften und steht innerbalb eines späteren Einschubes. - ${ }^{3}$ ) Prov. 12, 28. - ${ }^{4}$ ) Prov. 10,27 , vgl. 3,2 . $16: 9,11$. 
glaubten sie, dass Religion das Leben verlängere und Irreligiösität es verkürze, während der endgültige Erweis der sittlichen Weltregierung bei einer grossen Krisis (dem messianischen Gericht) geliefert werden würde, wenn das Verderben über die Gottlosen käme wie ein Wirbelwind ${ }^{1}$ ). Allerdings mag diese Haltung der Weisen begreiflicherweise durch erzieherische Erwägungen veranlasst worden sein. Sittliche Argumente einer unbewiesenen Vorstellung ganz neuerlichen Ursprungs zu entnehmen, mochte nicht ganz ratsam erscheinen, da sie möglicherweise zu einer zu enthusiastischen Gemütsverfassung Anlass bieten konnte. Aber doch kann nichts die Kraft folgender eindrucksvoller Zeilen aus einer Rede Jobs abschwächen:

„Denn (Hoffnung) besteht für einen Baum, „(Und für einen Feigenbaum bleibt) eine Zukunft;

"Wenn er gefällt wird, wird er wieder ausschlagen, "Und seine Schösslinge werden nicht fehlen."

"Aber wenn ein Mensch stirbt, dann geht er hinweg, "Er thut seinen letzten Atemzug, und wo ist er? "Solange der Himmel hält, wird er nicht erwachen, "Noch sich erhebeu von seinem Schlafe ${ }^{2}$ )."

Und um so erschütternder wirkt die Leugnung eines zweiten nachfolgenden Lebens, da der Redner hinzufügt, dass er bei dem entgegengesetzten Gedanken sich so glücklich fühlen würde. Es giebt in der That keine Stelle in der ganzen Bibel, die klarer die Kongenialität dieser grössten aller Hoffnungen mit der Natur wenigstens des semitischen Menschen beweist.

1) Prov. 1. 27. - $\left.{ }^{9}\right)$ Job 14, 7-12. Die erste Stanze des überlieferten Textes ist wahrscheinlich unvollstandig, 
Natürlich brauche ich nicht hervorzuheben, dass Arier und Semiten in dieser wie in anderer Hinsicht eng miteinander verwandt sind.

„O, dass du mich doch in Verwahrung legen wolltest in den S̀eol hinein,

„Dass du mich verbergen wolltest, bis dein Grimm vergangen wäre,

"Dass du mir eine Zeit bestimmen wolltest und dich meiner erinnern,

"(Und) dass ein Mann trotz seines Sterbens wieder leben könnte!"

"Meine lange, harte Mühe hindurch wollte ich dann harren, "Bis meine Hülfe käme,

"Bis du rufen würdest und meine Antwort empfangen,

„Bis du dich sehnen würdest nach dem Werk deiner Hände."

"Aber nun zählst du jeden Schritt, den ich mache,

„Du willst meine Sünde nicht übergehen;

"Du hast meine Übertretung im Beutel versiegelt,

"Du hast meine Ungerechtigkeit mit Wachs verwahrt ${ }^{1}$ ).

Die Schönheit dieser Stelle besteht darin, dass die von Job ausgesprochene Sehnsucht, ich möchte nicht sagen: so unpersönlich, aber doch: so uneigennützig ist. Er bittet dringend wieder leben zu dürfen, um das Glück der bewussten Gemeinschaft mit Gott zu geniessen, und er würde gerne in der öden Stadt des Todes warten, bis der göttliche Ruf an ihn ergeht, wenn ein zweites Leben für den Menschen auch nur zu den Möglichkeiten gehörte. Freilich weiss er (oder glaubt zu wissen), dass die Vorstellung der Begründung ermangelt. Und doch kann er nicht umhin in ihr einen Augenblick zu schwelgen, denn sie ist so süss.

3) Job 14, 13-17. 
Aber es ist bezeichnend, dass er nie wieder auf sie zurückkommt. Die angebliche Hindeutung auf die Auferstehung im neunzehnten Kapitel (siehe fünfte Vorlesung) beruht zum Teil auf Textrerderbnis, zum Teil anf dem naiven Glauben der Juden, dass eine so köstliche Hoffnung auch in dem weisen alten Jobgedicht ihren Platz gefunden haben müsste. Da die Stelle verstïmmelt war, so war der Herausgeber bestrebt, so gut ihm das gelingen mochte, sie in ihm passend erscheinender Weise zu ergänzen. Aber sein Werk ist sicherlich des Verfassers des Jobbuches als Vertreters der hebräischen Litteratur unwürdig.

Dieses Ergebnis darf uns nicht allzusehr überraschen. Die Forscher und Lehrer als solche haben eine Scheu, dem religiösen Enthusiasmus das Thor zu öfinen. Aber in den für den Gemeindegebrauch bestimmten Hymnen mag eine grössere Empfünghichkeit für neue Dogmen vorausgesetzt werden. besonders in der griechischen Zeit. Um über den Wahrscheinlichkeitsgrad dieser Erwartung zu entscheiden, dürfen wir uns mit der Gestalt, in welcher der hebräische Psalter auf uns gekommen ist, nicht zufrieden geben. Weiterer Fortschritt auf exegetischem Gebiet ist nur möglich auf Grund eindringender Prüfung des Textes der Psalmen. Eine solche Prïfung anzustellen, bin ich unter Berticksichtigung der Arbeiten meiner Vorgänger bemüht gewesen. Ich werde jetzt die erarbeiteten Ergebnisse vorfïhren.

Die Stellen, die hauptsächlich erwogen werden müssen, finden sich in den Psalmen 16 f.: 49; 73. 
Diese sind äusserst bedeutungsvoll. Wie sie im übrelieferten Text stehen, machen sie den Eindruck, dass die Verfasser eine Vorstellung von einem zweiten persönlichen Leben gehegt haben müssen. Besonders ist das der Fall, wenn wir die Stellen in Verbindung mit verwandten Stellen in den Psalmen Salomos und mit Andeutungen im Buche Henoch nehmen. In diesem Falle scheint die Hindeutung auf ein zukünftiges Leben allerdings schwer bestritten werden zu können.

Wenn wir aber diesen Stellen im Laufe einer eindringenden Textesrevision uns zuwenden, dann wird unsere Znversichtlichkeit bei der angedenteten Schlussfolgerung bedenklich erschüttert werden. Nehmen wir beispielsweise Psahm 49. Wenn der Text hier auch nur annähernd richtig überliefert ist, dann ist dieser Psalm eng verwandt mit den Kapiteln $102 \mathrm{f}$. des Henochbuches ${ }^{1}$ ). Diese Stellen enthalten eine Verwahrung gegen den althebräischen Begriff des šeol oder der Unterwelt, welche die gottlosen Reichen bei ihrer Unterdrückung der gerechten Armen ermutigt. Und genau eine solche Verwahrung finden wir nach dem überlieferten Text im Psalm 49. Der reiche Mann, der für sich ein grosses Grab aushaut, denkt, dass er einen entsprechend grossen Ruheplatz im Šeol haben werde. An Strafe für seine Unterdrückung der Armen denkt er nicht. Im Leben wie im Tode wird er in gleicher Weise das verzogene Kind des Glücks sein, der Erbe so viel guter Dinge, wie zu finden sind. Der

1) Vgl. fünfte Vorlesung. 
Psalmist sieht sich veranlasst daranf zu erwidern, dass der gottlose Reiche sich gründlich irrt. Das Verhältnis seines eigenen Standes zu dem des gerechten Armen wird umgekehrt werden. Der Reiche wird hinunterfahren, um sich zu seinen Vätern im Šeol zu gesellen, aber ohne seine Pracht, während der arme aufrichtige Mann aus den Krallen des Šool befreit wird, und die Genossenschaft, zu der er gehört, wird auf die Gräber der Gottlosen mit Füssen treten, wenn die Dämmerung des grössten der Tage anbricht.

So ansprechend auch diese Erklärung ist, so fürchte ich doch, dass sie unrichtig ist. Die Textkritik zeigt. dass der im Vordergrund stehende Widerspruch nicht besteht zwischen dem Schicksal aller Reichen als Einzelner und dem aller armen Menschen, sondern zwischen dem aller Reichen insgesamt und dem der Gesamtheit aller Armen, ohne besondere Beziehung auf diesen oder jenen Einzelnen. Über das Schicksal des einzelnen Armen wird nichts gesagt ${ }^{1}$ ). Die Gemeinschaft würde fortleben, selbst wenn alle ihre gegenwärtigen Glieder sterben sollten. Geistigpersönliche Selbstverneinung liegt einem frommen Juden ob; er geht auf in der Wohlfahrt der Gesamtheit, der er angehört. Die Gemeinschaft wird ewiges Leben geniessen, davon ist er fest überzeugt. Folgendes sind, wenn ich mich nicht irre, die Worte des Psal-

3) Eine zufiallige Anspielung mag sich noch in v. 10 finden. Die ,Weisent, die, wie ausdrucklich gesagt wird, sterbent, sind natülich gerecht und vermutlich arm. 
misten oder vielmehr der frommen personifizierten Gemeinde:

„Dies ist der Weg zu ihrem Straucheln, "Und die Strasse zu ihrem Fall, die sie laufen."

Mit diesen Worten beginnt der Dichter einen neuen Abschnitt. Er schildert, wie die gottlosen Reichen sorglos in die Arme des Verderbens rennen. Dann fährt er fort:

"Wie Schafe sinken sie in den Š̀eol,

„Der Tod beherrscht sie, Schrecken erfassen sie;

"Sie gehen hinunter stracks in das Grab hinein,

"S̀eol ist ihr Aufenthalt für immer.

"(Aber) sicherlich wird Gott meine Seele freilassen,

"Denn er wird mich aus der Hand des S̀̀eol nehmen ${ }^{1}$."

Dem 49. Psalm ist der 73. nahe verwandt. Er bietet keine so eingehende Schilderung des Schicksals der Gottlosen, sondern nach dem überlieferten Text führt er den Gegensatz aus zwischen der Zukunft des einzelnen Reichen und der des einzelnen Armen. Die jüdische Übersetzung (Paraphrase) (Targum) findet darin thatsächlich eine Hindeutung auf die Auferstehung, und christliche Exegeten haben darin, keineswegs ohne Grund, eine solche auf eine selige Anschauung Gottes unmittelbar nach dem Tode gefunden. Die letztere Ansicht scheint besonders viel für sich zu haben. Die Henochgeschichte war, wie wir wissen, in der nachexilischen Zeit volkstümlich, und es würde durchaus natürlich sein, dass in einer Zeit zunehmender Betonung des Wertes des Einzelnen fromme Anbeter Gottes das Vorrecht Henochs

1) Ps. 49, 14-16. 
für sich in Anspruch nahmen. Nach der Überlieferung "verschwand" er bekanntlich, "denn Gott hatte ihn hinweggenommen ${ }^{1}$ ). ${ }^{\text {" }}$

Die Worte:

„Du wirst mich nach deinem Rate führen

"Und hernach mieh zur Ehre aufnehmen ${ }^{\text {g). }}$."

scheinen des Dichters nicht unwürdig, da er kurz darauf sagt, dass der Gläubige, selbst wenn seine änssere Gestalt verfallen wäre, doch noch Gott als seinen unverlierbaren Anteil haben würde. Und doch muss diese anziehende Auftassung, die die Angrifte exegetischer Gegner überlebt hat, auf Grund der Textkritik, so fürchte ich, aufgegeben werden. Ich will eine Übersetzung der wichtigsten Verse geben, die auf einem meines Erachtens unanfechtbaren Texte beruht. Es findet sich dort, wie man sehen wird, ein Widerspruch zwischen den Geschicken der Gerechten und Gottlosen.

"Wie werden sie [d. h. die Gottlosen] in einem Angenblick zunichte gemaeht,

„Günzlich weggefegt inrch Schreeken (des Todes)!

"Wie ein Tranm, wenn jemand erwaeht ist,

"So wirst du, Herr, weun du dieh erhoben hast, ihre schemenartige Gestalt verachten."

"Und doch bin ich beständig bei dir;

„Du hast meine rechte Hand ergrifien:

"Nach deinem Rat wirst dn mich führen

"Lnd mieh den Weg der Ehre kennen lehren ")."

1) Gen. 5, 24. - ") Nach Kautzsch' Neuer (deutscher) Übersetzung des Alten Testaments. - ${ }^{3}$ ) Ps. 73, $19 \mathrm{f}$. $23 \mathrm{ft}$. Die C̈bersetzung ron Wellhausen und Furness in der Polychrome Bible beruht auf' zu wenig durchgreifender Verbesserung. 
Wer der Sprecher ist, und was der "Weg der Ehre" bedeutet, das will ich jetzt erörtern. Aber schon jetzt muss klar sein, dass die zweite Zeilc der letzten Strophe der ersten verwandt ist, und dass beide Zeilen auf einzigartig wichtige Erfahrung auf dieser materiellen Erde sich beziehen.

Wir wenden uns nunmehr dem 17. Psalm zu, dessen überlieferter Text eine Beziehung auf die Anschauung Gottes nach dem Tode zulässt. Ja ich möchte sogar sagen, dass er eine solche Beziehung begünstigt, denn ein Gegensatz scheint ausgemalt zu werden $^{1}$ ) zwischen dem Sprecher, der Gott „beim Erwachen" zu sehen hofft und "dem Weltmenschen, dessen Teil in diesem Leben ist". Und doch nötigt uns eine sorgfältige Textkritik zur Aufgabe dieser Ansicht. Was der Psalmist ursprünglich schrieb, ist nicht mehr festzustellen. Aber das Nachstehende giebt, des bin ich sicher, keine unrichtige Anschauung von dem, was ausgedrückt werden soll:

„Auf Jehovah, stelle dich ihm entgegen, beuge ihn nieder;

"Rette meine Seele vor dem Gottlosen, Jehovah!

,Thr Teil gieb ihnen: ihren Anteil an (deinem) Grimm;

„Fülle ihren Bauch mit deinen aufgehäuften Strafen!

"Ich aber, ich werde in meiner Unschuld dein Angesicht schamen,

"Ich werde meine Augen weiden, wenn dein Eifer erwacht ${ }^{2}$ )."

Das Wort ergreift jetzt nicht ein einzelner Israelit,

1) So jedenfalls in der englischen C̈bersetznng [auch in der Lutherischen. $-\mathrm{S}$. . - 2) Ps. 17, 13-15. 
sondern das jüdische Tolk, über welchem Jehovah nach seinem Wort wacht wie über seinem ".Augapfel $\left.{ }^{1}\right)^{4}$.

Nur eine Stelle erübrigt noch: Ps. 16. $10 \mathrm{f}$. Der Text ist hier ganz untadelig überliefert. Er kann so übersetzt werden:

„Du wirst meine Seele nicht der Unterwelt übergeben, „Noch wirst du zulassen, dass dein Frommer die Grube sehe. "Du wirst mich den Pfad des Lebens kemnen lehren;

"Vor deinem Angesicht ist Überfluss an Frenden, „Ergötzen ist zu deiner Rechten für ewig $\left.{ }^{2}\right)$."

Nun ist es immer aufgefallen, dass der Anlass zu dem, was ich mystische Erklärung nennen möchte, an dieser Stelle weniger geboten war als an den bisher betrachteten. Der Ausdruck ,der Weg des Lebens" in den Proverbien ${ }^{3}$ ) bedeutet nach allgemeiner Annahme jenes Thun, das zu einem glücklichen Leben führt: und gewiss werden .:Freude vor dem Angesicht Jehovahs" und Gaben von seiner Hand im 21. Psalm einem irdischen Könige beigelegt ${ }^{4}$ ), während vom Šeol befreit zu werden lediglich bedeuten mag: der Todesgefahr zu entrinnen. Daher haben viele Kritiker angenommen. dass die Bedeutung der Stelle folgende sei: der Einzelne dem das Wort in den Mund gelegt wird, wird aus seiner gegenwärtigen Not erlöst werden und das selige Bewusstsein von der Gnade Gottes wieder erlangen. Andere haben gefühlt, dass diese Erklärung der Erhabenheit und Feierlichkeit der Stelle Eintrag thut. Darin stimme ich so vollkommen mit

10. 17. - 4) Ps. 21. 6. 
ihnen überein, dass ich, wenn der landläufige Text der drei andern Stellen richtig überliefert wäre, keinen Anstand nehmen würde, in allen vier Stellen in gleicher Weise eine Hindeutung auf die Unsterblichkeitshoffnung zu finden. Es besagt nichts gegen diese Auffassung, dass sie die Vermutung voraussetzt, der Psalmist übersehe den Tod des Gerechten und stelle alles zukünftige Heil dar als Folge gegenwärtigen Gehorsams und Glaubens. Denn wenn der Tod nur besteht in Zulassung zu Gottes erhabener Gegenwart, nach der gewöhnlichen Erklärung von Psalm 73, 24, dann liegt kein Grund vor, warum der Tod nicht ganz übergangen werden könnte, und es ist bestimmt der Fall, dass die Vorstellung einer Abschlagszahlung an Belohnungen und Strafen vor dem Endgericht den späteren Juden geläufig war. Aber wir, haben gesehen, dass die drei andern Stellen, wenn richtig gelesen, die mystische Erklärung nicht zulassen, und der Zusammenhang nötigt uns, für die vierte ebenfalls darauf zu verzichten. Das bedingt jedoch nicht die Annahme der eben bezeichneten heute bei den Gelehrten durchweg gültigen Annahme. Denn der "Weg des Lebens* ist selbst in den Proverbien meines Erachtens nicht lediglich der Weg zum Glück, und noch weniger ist das im 16. Psalm der Fall. "Weg des Lebens" und "Weg der Ehre" bezieht sich beides auf das messianische Zeitalter, wenn nach dem Ausdruck eines anderen Psalmisten "Ehre in unserm Lande wohnen wird $\left.{ }^{1}\right)^{*}$. Die göttliche Ehre ist gemeint,

1) Ps. 85, 9 [10].

Cheyne, Religiöses Leben der Juden. 
und "Leben" ist nicht bloss das, was wir in unseren banausischen Tagen "Glück" nennen, sondern ein so hochgespanntes Leben, wie es in folgenden Worten eines späteren Propheten beschrieben wird:

„Und ich will mich freuen über Jerusalem und über mein Volk frohlocken;

"Und der Schall des Weinens soll nieht mehr darin vernommen werden, noch der schall des Geschreis.

"Sie werden nicht banen, und ein anderer wird bewohnen, sie werden nicht pflanzen, und ein anderer wird essen; „Denn wie die Tage der Bäume, sind die Tage meines Volkes ${ }^{1}$ )."

Gewiss sind Wendungen, wie die in den letzten beiden Zeilen vom 16. Psalm im 21. auf einen irdischen König bezogen. Aber was ist das für ein irdischer König? Nicht irgend ein geschiclitlich bekannter König von Israel, sondern der erwartete messianische König, der thatsächlich nur Führer und Tertreter der Gemeinde ist, so dass, was von ilm gesagt wird, ebensogut vom personifizierten Israel gesagt werden kann und sogar in erweiterter Ausdentung von jedem frommen Israeliten. Gewiss über einen frommen Israeliten werden Jehovah seitens eines Psalmisten folgende Worte in den Mund gelegt:

"Ieh will ihn erretten und ihn ruhmtoll machen;

„Teh will ihn mit Länge der Tage sättigen

"Und ihn meine Erlösung schauen lassen 2),"

wo unzweifelhaft die bezeichneten Segnungen die des Ideals oder der messianischen Zeit sind.

So enthält demmach der Psalter in keiner der

1) Jes. 65, 19. 22. - 2 ) Ps. 91. $15 \mathrm{f}$. 
angeführten Stellen und wemn dort nicht, dann gewiss nirgendwo anders irgend eine Hindeutung auf die Auferstehung oder die Unsterblichkeit des Einzelnen, woraus sich ergiebt, dass bis zur Zeit Simon des Makkabäers diese beiden eng verwandten Glaubenssätze für die Mehrheit der Frommen keine Rolle spielten. Doch muss dieser Glaube seitens einer wichtigen Minderheit gehegt worden sein. Diese Vorstellungen lagen sozusagen in der Lutt; sie entsprachen einem mehr und mehr empfundenen religiösen Bedürfnisse, besonders während der scharfen Verfolgung durch Antiochus Epiphanes. Wir dürfen daher überzeugt sein, dlass die bemerkenswerten, aber doch immerhin vieldeutigen Wendungen der vier besprochenen sowie anderer Stellen, die auch hätten angeführt werden können, sehr früh auf das Individuum angewandt und auf, wie wir es nannten, mystische Weise gedeutet wurden. Diese Stellen und nicht clie trübe Strophe:

"Welcher Mensch mag wohl aufleben und nicht den Tod sehen "Oder für seine Seele aus der Hand des S̉eol die Flucht ermöglichen ? 1)"

müssen die geistige Nahrung der am tiefsten gegründeten Juden der griechischen Zeit gebildet haben: jener Juden, deren Nachfolger die Mitglieder der grossen und wichtigen Schule der Pharisäer und der Sekte der Essener wurden.

Und jetzt wollen wir die Zwischenzeit zwischen Simon dem Makkabäer und dem römischen Feldherrn

1) Ps. 89, 48 (jedoch wahrscheinlich Einschub). 
Pompeius, der der hasmonäischen Königsherschaft 63 v. Chr. ein Ende machte, überspringen. Das Dogma, das früher nur eine Minderheit unter seine Anhänger zählte, ist jetzt allgemein übernommen worden. In der Zeit zwischen 63 und etwa $45 \mathrm{v}$. Chr. wurden achtzehn neue Psalmen verfasst und gesammelt. die das sogenannte Psalterium Salomonis ausmachen. Hier werden ohne das geringste Schwanken Auferstehung und Unsterblichkeit der Gerechten als gewiss hingestellt ${ }^{1}$ ). Beweise dafür liegen im Überfluss vor. Wir finden beispielsweise folgenden Ausspruch: „Das Leben der Gerechten dauert ewig, aber die Sünder werden weggerafft werden ins Verderben, und ihr Gedächtnis wird man nicht mehr finden ")". Und wiederum: "Das Verderben der Sünder dauert ewig; aber die den Herrn fürchten, werden auferstehen zum ewigen Leben; ihr Leben wird im Lichte des Herrn stehen und nicht aufhören $\left.{ }^{3}\right)$." Es findet sich auch eine bezeichnende Stelle in diesem späten Psalter, worin fromme Israeliten als „Bäume des Lebens" geschildert werden. Sie "leben ewig", nicht wie das Buch Henoch von den Auserwählten sagt, indem sie ambrosische Früchte geniessen, sondern indem sie ,wandeln in dem Gesetz, dass uns Gott befohlen hat")". So erklärt auch das Targum Jonathan (zu Gen. 3), dass das Studium des Gesetzes einen sichereren Weg zur Unsterblichkeit biete als der Genuss

1) Wahrscheinlich i*t der zweite dwr 18 Lobpsalmen, der Gott als den, der die Toten zum Leben bringt ${ }^{*}$, schillert, etwas alter als diese Zeit. - ") Ps. Sal. 13, 9 f. [11 ed. Gebhardt - S.] $-{ }^{3}$ ) A. a. 0. 3. 15 f. [3, 12 ed. Gebhardt - S.] $-{ }^{\text {t) }}$ A. o. 0. 14, 1 f. [14, 2 ed. Gebhardt $-\mathrm{s}$.$] ; Henoch 25. 5$. 
der Frucht vom Baum des Lebens, und der Anhang zu den Sprüchen der Väter ${ }^{1}$ ) sagt, die Weisheit, welche „ein Baum des Lebens ist für die, die sie ergreifen" (Prov. 3, 18), sei das Gesetz.

So erfüllen die späteren Schriftsteller (immer mit Ausnalme solcher Ketzer wie der Verfasser des Kohelet) die alte Ausdrucksweise mit umfassenderer Bedeutung. Sie thun das ganz einfach als etwas Selbstverständliches, und ich gebe zu, dass ihre Ansicht mir die passendste Erklärung der heiligen Worte zu bieten scheint. Gleichzeitig muss ich die Thatsache zugeben, dass die alten Psalmisten etwas andres zum Ausdruck bringen wollten und meiner Bewunderung Ausdruck geben für diese edlen Denker, welche, um in Brownings Sprache ${ }^{2}$ ) zu reden, der Seele viel weniger versichert waren als Gottes: beispielsweise für den Verfasser des 73. Psalms, welcher sagt:

"Wen habe ich (zu schätzen) im Himmel?

"Und wenn ich dich habe, freue ich mich keines Dinges auf Erden,

"Und wenn mir selbst mein Fleisch und mein Herz verschmachtet wäreu,

"Grott würde mein Fels und mein Teil für ewig sein."

Könnte man diesen Psalmisten nach seiner Theologie fragen, so würde man ihn wahrscheinlich auf seiten des Antigonus, jenes schon erwähnten jüdischen Predigers der uneigennützigen Sittlichkeit, gefunden haben. Aber wenn man nun weiter liest, dann wird

1) Yirke Aboth 6, 7. - ") Siehe La Saisiaz. 
man sehen, dass er an der Schwelle einer klareren Anschauung steht. Denn er fährt fort:

"Sicherlich werden die sich von dir entfernen umkommen;

„Du vemichtest alle, die dich mutwillig verlassen.

"Aber ich, die Nähe Gottes ist mein Glück;

"Auf den Herrn Jehovah habe ich meine Zuversicht gesetzt ")."

Uns mag es so scheinen, als ob die Verheissung des Untergangs der Gottlosen eine Bürgschaft für die Errettung der Gerechten bildete. Aber dieser selbstlose Denker ist zufrieden mit der gegenwärtigen Wonne der Gemeinschaft mit Gott, welchem nahe zu sein sein ganzes Glück ausmacht. An Israels Errettung kann er nicht zweifeln. Ob auch der Verderber den letzten der Bekenner mit dem kalten Stahl zum Schweigen bringen könnte, dann würde der Odem Gottes über die dürren Gebeine hauchen, und sie würden leben. Gott würde doch noch Israels Fels sein und sein Teil für immer.

Aber was bedeutet "Gottesnähe" nach der älteren jüdischen Frömmigkeit? Ezechiel spricht von den Priestern, den ,Söhnen Zadoks", als die allein berufen sind, zu Gott zu führen. Aber die Erfahrung des Psalmisten beschrïnkt sich nicht auf die Priester allein, denn wie einer der jüngsten Psalmen sagt, die Frommen insgesamt sind , das Volk derer, die ihm nahe sind ${ }^{2}$ ". Nach jüdischer Anschauung wird die Nähe Gottes besonders im Tempel gefühlt, wo Kunst und Religion zusammenwirken, den geringsten Gläubigen über sich selbst zu erheben. IVie konnte die

$$
\text { 1) Ps. } 73,27 \text { f. }-2 \text {, Ps. } 148,14 .
$$


tägliche Ausübung des gesetzlichen Gehorsams lästig empfunden werden, wenn sie versüsst wurde durch eine wirkliche, selbst mystische Anschauung Gottes und verherrlicht durch den grossartigen Psalmengesang des Tempels. Das Ergreifende der Tempelgottesdienste kann man sich vorstellen auf Grund der Schilderungen des Chronisten und nach den begeisterten Worten des Siraciden im Ecclesiasticus. Natürlich wären sie unserem Geschmack nicht alle angemessen gewesen, aber sie passten für den Geschmack des Volkes, das ihrer bedurfte, bewunderungswürdig. "Wie fein", sagt einer der Psalmisten:

"Wie fein sind die Festzüge Gottes,

„Die Festzüge meines Gottes, meines Königs, im Heiligtum.

"Sänger gehen voran, Chöre ziehen am Ende,

"In der Mitte sind Jungfrauen, die auf Pauken spielen.

"Im vollen Chore loben sie Gott,

r(Ja) den Herrn, den Führer Israels $\left.{ }^{1}\right)$."

Und dann wende man sich zu dem .Finale des geistigen Konzerts" des Psalter's: dem 150. Psalm, den ich nur aus dem Grunde nicht wörtlich anführe, weil er unter die bestbekannten aller Psalmen gehört. Gewiss hielten die Juden Musik und Gesang für das, was die abendländischen Christen als "Gradenmittel" zu bezeichnen gewohnt sind.

In einem ausgeprägten rituellen System wie dem jüdischen bestand natürlich grosse Gefahr des Aberglaubens. Ohne Zweifel meinten viele Juden, dass ihre Verbindung mit Gott durch eine rein äusserliche

1) Ps. 68, 24-26. 
Ausübung der heiligen Riten ernenert werden könne. Aber die besten Lehrer protestierten beständig gegen diese Anschauung. Nur ein "gerechtes Volk" konnte zu Gott hingezogen und gesegnet werden durch die sakramentalen Riten, und unter Gerechtigkeit versteht der Psalmist in erster Linie religiöse Sittliehkeit. Hier stehe eine Stelle, in welcher die jüclische Kirche feierlich alle Gemeinschaft mit der Partei der Gottlosen zurüekweist:

"Ich hasse die Gemeinschaft der Übelthäter

"Und sitze niemals in der Versammlung der Gottlosen;

"Ich wasche meine Hände in Unschuld,

"So will ich gehen (im Festzug) um deinen Altar, Jehovah!

„Damit ich möge verkündigen mit lanter Danksagung

"Und anserzähle alle deine Wunder! ${ }^{1}$ "

Wir besitzen ebenfalls in den Psalmen 15 und 24 zwei dichterische kirchliche Katechismen, die die Bedingungen für die Zulassung zu dem höchsten aller Vorrechte darstellen. Die erwähnten Bedingungen sind sittlicher Natur, und das dargebotene Vorrecht besteht in unbedingter Sicherheit unter göttlichem Schutz. Eine besondere Bezeichnung für dieses Vorrecht ist "Gastrecht". "Wer mag ein Gast sein in deinem Zelte, Jehovah? 2" " fragt die fromme Gemeinde, und bei dem messianischen Gericht werden die Sünder, so wird uns gesagt, zitternd fragen:

.Wer kann wohnen als Gast neben dem fressenden Feuer?

"Wer kanu wohnen als Gast neben den ewigen Bränden ? ${ }^{3}$ "

Die alte Auffassung des Gastrechts war eine sehr

1) Ps. 26, 5-7. - 2) 1's. 15. 1. - 3) Jes. 33, 14. 
verschiedene. Die Gäste Baals und Astartes waren nichts Besseres als Schmarotzer, die da schwelgten bei den Opfermahlzeiten, aber keine ansserordentlichen sittlichen Verpflichtungen zu erfüllen hatten ${ }^{1}$ ). Aber die Gäste Jehovahs (des Jehovahs der Psahmisten) hatten von ihm ein neues sittliches Vorbild empfangen, und so hoch auch ihr Streben ging, immer sahen sie das Vorbild noch über sich, denn „dein Gebot ist weit ausgedehnt $\left.{ }^{2}\right)^{\prime}$. Dann und wann mochten die Gäste Jehovahs wohl fürchten ihm lästig zu werden; sie mochten glauben eine Wolke auf seinem Angesicht zu sehen und ihn mit Thränen an ihr. Gastrecht erinnern $^{\mathbf{3}}$ ). Aber das war in Zeiten ungewöhnlicher Bedrängnis des Volkes der Fall, der normale Gemütszustand für einen "Gast Jehovahs" war gewiss ein heiterer.

Der neue und geläuterte Begriff eines Gastes Jehovahs war eine der wichtigsten religiösen Ergebnisse der Zerstreuung der Juden. Es war unstatthaft geworden, die Vorteile des Gastrechts als auf die Bewohner Jerusalems beschränkt festzuhalten. Zehntausende frommer Leute konnten Jerusalem nur einmal in ihrem Leben besuchen; bei weitem mehr konnten dass überhaupt nicht. Und doch waren sie überzeugt, dass ihre Verbindung mit Jehovah nicht gelockert sei, weil sie das Geheimnis des Herzensgebets kennen gelernt hatten. In ihrem Kämmerlein und in der Synagoge hatte eine überraschende neue Erfahrung ihnen gezeigt, dass die liebende Fürsorge ihres Beschützers

\footnotetext{
1) Renan, Histoire d'lsrael II, 35 - 2) Ps. 119, 96. - ") Ps. 39, 12.
} 
thatsächlich von Zion her ansstrahlte aufjeden , trockenen und durstigen ${ }^{\mathbf{1}}$ ". Winkel von Gottes Welt, in dem sie zufällig sich befanden. Mochte immerhin eine höhere Wirkungskraft mit solchen Gebeten verbunden sein, die in Verbindung mit den Tempelopfern gesprochen wurden, so dienten doch die liturgischen Gottesdienste auf Zion zum Besten jüdischer Leute in allen Landen. Man nahm sogar gemeiniglich an, dass ein Jude in Persien oder Ägypten dadurch, dass er dreimal am Tage ${ }^{2}$, einfach ein Gebet nach Jerusalem hingewandt sprach, derselben Vorteile teilhaftig werden könnte wie ein Jucle, der im Tempel betete. Dieser wachsende Glaube an die Macht des Herzensgebets beeinflusste sicher die Juden in Jerusalem, von denen viele in der That Gelegenheit gehabt haben mussten, in der Ferne seine Wirkungskraft durch die That zu erproben. Und so war zu dem Begriff eines geistigen Israel, den man aus Deuterojesajah gewonnen, der eines geistigen Tempels hinzugekommen. Für die, welche fern von Jerusalem den 23. Psalm lasen, müssen die Worte:

"Ich werde wohnen in Jehovahs Haus "Für alle kommenden Tage ${ }^{3}$ "

einen tieferen Simn gewonnen haben, als der Dichter beabsichtigt hatte. Der Tempel, den sie im Sinne

1) P.. 63, 1. - 2) I Ian. 6, I0, vgl. lieg. 1 \&, 48. Das war eine Zoroastrische Sitte mit Ausnahme natürlich der Wendung narh Jerusalem zu. Die Zoroastrische Vorsehrift Iautete: - Dreimal am Tage muss mau aubeten der soune zugewandt (Pahlevi Texts in Sacred Books of the East, Part III). Thas erste Gebet war bei Tagesanbruch zu sprechen. Waher stammt ziemlich wahrscheiulich die jüdische Sitte, das erste Gebet bei Tagesgrauen zu sprechen. Fgl, auch Koran, Sure 17, 80. $-{ }^{3}$ ) Ps. 23, 6. 
hatten, war ein solcher, den keine ungläubigen Verehrer entweihen konnten, und der ein höheres Dach und weitere Höfe besass, als man in Zion sehen konnte. Der religiöse Sinn verbot ihnen, diesen Gedanken auszusprechen, aber in ihrem innersten Herzen stimmten sie ziemlich vollständig überein mit jenen Worten Brownings:

"Was braucht's noch Tempel, wenn der Weltenrund ein Tempel ist?

„Was soll der Wechselsang levit'scher Chöre, Priesterruf, Trompetenschall?"

Der Gedanke eines geistigen Tempels führt natürlich auf den geistiger Opfer. Der Ursprung dieses Gedankens, der im Psalter klar zum Ausdruck gelangt, kann mit Sicherheit bis Jeremiah hinaufverfolgt werden. Dieser Prophet lehnt im Gegensatz zu den Buchstabenknechten seiner Zeit mit Bestimmtheit den Gedanken $a b$, dass Gott den alten Israeliten irgend eine andere Anweisung gab als diese: "Gehorchet meiner Stimme, und ich werde ener Gott sein, und ihr sollt mein Volk sein $^{1}$ )!" Wie der Zusammenhang zeigt, meint er das Sittengesetz. Nun gab es eine Schule von Denkern nachexilischer Zeit, die mit Jeremiah eines Sinnes waren. Unter ihre älteren Glieder gehören die Verfasser von Psalm 40 (erster Teil), 50 und 51, 1-17. Man braucht nicht mit Notwendigkeit anzunehmen, dass diese Schriftsteller ebenso eifrig wie Jeremiah dem Opfersystem widersprachen. Es ist sehr wohl möglich, dass sie bei dem Gedanken sich beruhigt haben, Opfer

1) Jer. 7, 22. f. Amos hatte lem Sinne nach $(5,25)$ dasselbe gesagt. 
seien provisolisch eingerichtet um der .: Menschen Herzenshärtigkeit willen". Aber sicher haben sie darauf bestanden, dass die einzig wesentlichen Satzungen die überwiegend sittlichen seien, die im Dekalog zusammengefasst sind. Ich will die am meisten in Betracht kommenden Psalmenstellen anführen. Bei der ersten sah ich mich genötigt zur Vervollständigung des Sinnes einige Worte hinzuzufügen:

„An Opfer und Darbringung hast du kein Ergötzen,

..(Aber) Ohren hast du für mich geschaffen.

„Brandopfer und sündopfer verlangst du nicht,

"[Mein Herz hast du ernent.]

. $\mathrm{Zu}$ verrichten deinen Willen

„Ergötzt mich, o mein Gott;

...[Deine Verordnung] und dein Gesetz

"sind in meinem Herzen ${ }^{1}$ ). "

Die Schlussworte erinnern uns wiederum an Jeremiah. der uns versichert, dass in der letzten Zeit Gott sein Gesetz in Israels Inneres legen und es in ihre Herzen schreiben" wird"): Worte, die den weitesten Ausblick der vorexilischen Prophetie bezeichnen.

In der nächsten Stelle erhalten die Juden, die den Tempel besuchen, aber Jehovahs grundlegende Satzungen übertreten, einen seharfen Tadel. Dieser ist num nicht verbunden mit einem Befehl, die gebräuchlichen Riten in besserer Gesinnung zu verrichten, sondern mit folgender überraschender Einschärfung:

"Opfere Gott Danksagung

"Und bezahle deine Gelübde dem Allerhöchsten

$\left.{ }^{2}\right)$ Ps. 40, 6. 8 [Die Übersetzung ist nur provisorisch]. - ${ }^{2}$ ) Jer. 31, 33. 
Das Judentum: Seine Anziehungskraft auf Fremde u. s. w. 253

"Und rufe mich an am Tage der Not:

"Ich will dich erretten, und du sollst mich preisen ${ }^{1}$ )."

Die Schlussworte des Psalms lauten:

„Wer da Dank opfert, der preist mich,

"Und dem, der tadellosen Lebens ist, will ich die Erlösung Gottes zeigen $\left.{ }^{2}\right)$. "

Hier finden wir nicht nur Opfer, sondern sogar Gelübde, die in das täghche Leben noch tiefer eingriffen als Opfer, abgeschafft durch ihre Vergeistigung. Die allein richtigen Gelübde bestehen darin, dass man Lebensbesserung gelobt; das allein rechte Opfer besteht in Danksagung für Gottes unzählige IVohlthaten an Israel. Die Kritik, die der Verfasser des Kohelet (siehe fünfte Vorlesung) an den volkstümlichen Opfern und Gelübden seiner eigenen Zeit übt, beleuchtet und rechtfertigt die Sprache des Psalmisten. Zuletzt von allen höre man folgende Verse aus Psalm 51:

„Du hast kein Gefallen an Opfern und Gaben;

"An Brandopfern (und Ganzopfern) hast du kein Ergötzen.

„Die Opfer für Gott sind ein zerbrochenes Herz;

„Ein zerbrochenes und zerknirschtes Herz, o Gott, kamnst du "nicht verachten $\left.{ }^{3}\right)$."

Hier haben wir in kurzen Worten die Lehre des späteren Judentums, dass Busse ebensoviel wert ist wie Brandopfer. Ein späterer Verfasser war jedoch damit unzufrieden und fügte einen ziemlich dürftigen Anhang hinzu ${ }^{4}$ ). Er leugnet nicht, dass Gott gegenwärtig die Opfer ganz gleich gïltig seien - das Missgeschick Israels bewies das zu klar - ; aber er dachte, dass, wenn die

1) Ps. 50, 14f. $\left.-{ }^{2}\right)$ Ps. 50, 23. $-{ }^{3}$ ) Ps. $\left.51,16 \mathrm{f.}-{ }^{4}\right)$ A. a. $0.18 \mathrm{f}$. 
zerstörten Manern Jerusalems wieder aufgebaut wären, er wiederum an „rechten Opfern“ Grefallen finden würde: ein vieldentiger Ausdruck, der zu besagen scheint: Opter, die nieht mit der Absicht dargebracht werden, Grottes Vorhaben zu ändern, sondern aus Gehorsam gegen seimen erklärten Willen. Er gehörte, so viel steht fest, einer theologischen Schule an, die das Opfersystem kritiklos als göttliche Bestimmung übernalım. aber ihm eine neue symbolische Deutmg gab. Dieser scheint der Verfasser von Jesajah 53, der von der Selbstaufopferung eines Märtyrers als einem wahren "Sündopfer" redet, ebenfalls angehört zu haben.

So gab es also andere Plätze neben dem Tempel, wo man sich Gott nahe fühlte: das Kämmerlein und dieSynagoge. Wer Gott hier nur fand, mochte mit Fug und Recht den Psalm singen: „Der Herr ist mein Hirte, mir wird nichts mangeln". Gebete und Lobgesänge waren hier die Opfer. - Aber es gab noch einen Gottesdienst, der nur deshalb nicht Opfer genannt wurde, weil er mit dem Tempel nicht in Verbindung stand: das Schriftstudium. Kam es Esra zum Bewusstsein, dass er dem Opferdienste das Grab schaufelte, als er den Gedanken einer geschriebenen Offenbarung anerkannte? Jedenfalls war das das Ergebnis der allmählichen Kanonisation von Gesetz, Propheten und Schriften; inspirierte Bücher müssen notwendig Träger des Gottesgeistes sein. und mit ihnen umzugehen ist gleichbedeutend mit dem Umgang mit Gott. Erst in der griechischen Zeit (wohin die vom Gesetze handehden Psalmen zu gehören scheinen) begann diese Hochschätzung 
Das Judentum: Seine Anziehungskraft anf Fremde u. s .w. 255

der Schriften vorherrschend zu werden. Je gefährlicher der Hellenismus wurde, desto mehr suchten die frommen Juden ein Gegengift dagegen in ihrer Bibel. Nach dem Makkabäeraufstande wurde die Verehrung für die Schriften eine derartige, dass die Juden "meinten, in ihnen das ewige Leben zu haben $\left.{ }^{1}\right)^{\text {. }}$. Sie empfanden, dass hier etwas sittlich Erhabenes vorlag, wozu Griechenland kein Gegenstïck bieten konnte, und ein Band, welches die zerstreuten Glieder ihres Stammes weit wirksamer vereinigen konnte als der Tempel zu Jerusalem. Und die Geschichte gab ihrer Überzeugung Recht. Mehr und mehr nahm der Anstoss zu, der allen hochsinnigen Juden geboten wurde durch die obersten Diener des Heiligtums. Und als dann die Rache des unversöhnlichen Rom die endliche Zerstörung des schon entweihten Altars forderte, da war das Bewusstsein, dass ihr grösster Schatz gerettet sei, für die Juden ein Trost. Der goldene Leuchter mochte durch die Sieger fortgeschafft werden, aber die Sonne des Geisteshimmels strahlte fort „und es blieb nichts verborgen vor ihrer Hitze ${ }^{2}$ ".

Wie es dazu kam. dass der Besitz eines heiligen Buches nicht ausreichte, die jüdische Religion vor Veränderung zu bewahren, dass kann ich hier nicht auseinandersetzen. Es mag genïgen darauf hinzuweisen, dass die Veränderungen, die sich vollzogen haben und die noch sich vollziehen mit den religiösen Gedanken des Judentums, nicht bedeutender sind als die, welche

1) Joh. 5, 39. - ${ }^{2}$ ) Ps. 19, 6 [7]. 
während der biblischen Zeit mit denselben sich vollzogen haben.

Es ist mir unmöglich gewesen, sogar diese kurze Skizze der nachexilischen Religion zu geben, ohne von Zeit zu Zeit anf answärtige Einflüsse hinzuweisen. Der Einfluss des griechischen Denkens kann in der frühgriechischen Zeit nicht dentlich nachgewiesen werden; wir finden ihn zuerst im Kohelet. Aber der Forschergeist, der jenes bemerkenswerte Buch hervorgebracht, war zweifellos auch vorher thätig; das Buch Job, obwohl hebräisch in seinen Ausdrücken. stellt einen neuen Ansatz im jüdischen Denken dar, der vom griechischen Einfluss nicht getrennt werden kann. Der persische Einfluss begann sich bei den palästinensischen Juden nicht so früh stark fühlbar zu machen, wie man angenommen hat. Der Ahura-mazda des Aresta besitzt zweifellos eine enge Verwandtschaft mit dem Jehovah der späteren jüdischen Schriftsteller, aber der alte Zug nach Babel hin verhinderte diese neu entdeckte Verwandtschaft anf lange Zeit noch an der Hervorbringung grosser Wirkungen. Wohl muss ein gewisser Einfluss von Persien ans ansgeübt worden sein, aber wir sind nicht in der Lage, seine Ansdehmung abschätzen zu können. Vor der Ankunft Esras war er wahrscheinlich ausschliesslich beschränkt auf die grossen jüdischen Kolonien östlich des Euphrat und Tigris. und sogar in babylonisch - jüdischen Werken wi dem Priestercodex, beispielsweise in der Kosmogonie (wo wir etwas anderes erwartet hätten) kann babylonischer Einfluss viel eher als persischer klar 
nachgewiesen werden. Freilich die Vorstellung der präexistenten himmlischen Weisheit im Prolog zu den Proverbien hat dem Zoroastrianismus verwandte Züge. und zu einer früheren Zeit begegnen wir einem Auferstehungsglauben, der kaum ohne persischen Einfluss sich entwickelt haben kann. Allein der Prolog der Proverbien ist ein Werk der frühgriechischen Zeit, wo man persischen Einfluss ohne Schwierigkeit voraussetzen darf. und der Auferstehungsglaube war nicht (wie es scheinen könnte) urprünglich begleitet vom Unsterblichkeitsglauben ${ }^{1}$ ), obwohl die beiden Dogmen im gemeinen Zoroastrianismus neben einander vorkommen.

In Wahrheit sind wir nicht in der Lage, zwischen den beiden beeinflussenden Gedankenkreisen. dem persischen und babylonischen. scharf trennen zu können. Altpersien und Altisrael wurden beide durch Babel beeinflusst, und der Einfluss Babels auf Persien setzte wahrscheinlich viel früher ein. als man angenommen hat. Babylonische Verträge belegen, dass Perser in Babel sich aufhielten noch vor der Eroberung durch Crrus, und die Ahura-mazda-Religion, obwohl der des Jehovah näher verwandt als der des Marduk oder Nerodach, mag sehr wohl durch die letztere ebenso wie ihre jüdische Schwester beeinflusst worden sein. Es scheint mir sicher. dass sie so beeinflusst wurde. und dass jene Gelehrten, die alle jüdischen oder alle

1) Die beiden Dogmen wurden durch die Essener verkuüpft. wenn der Bericht des Josephus über diese sekte (Ant. XVIII 1, 5, rgl. XIII 5, 9) zurerlassig ist. Ihre Lebre ron der Seele rereinigt zwei Elemeute: ein babylonisches und ein persisches. the hebraisiert (Cheyne, Origin of the Psalter, p. 419 .

Cheyne, Religiöses Leken der Juden. 
persischen Gedanken aus rein inneren Bewegungen erklïren wollen, in Unrecht sind. Die Entwicklung sowohl der jüdischen als der persischen Religion ist zweifellos durchweg auf vollkommen natïrlichem Wege erfolgt: aber sie würde doch ganz denselben Verlauf nicht genommen haben ohne gewisse, wenn ich so sagen darf, in der Luft liegende Einflüsse, die von Babylonien kamen. Daher ist es oft schwierig, für das, was Judentum und Zoroastrianismus Babel verdanken, durchans überzengende Beweise vorzulegen, und aus einem ähnlichen Grunde gilt das anch von dem. was das Judentum dem Zoroastrianismus verdankt. Einige augenscheinlich unvermittelte Entlehnungen giebt es; aber im allgemeinen müssen wir uns mit dem Nachweis der Wahrscheinlichkeit indirekter religiöser Beeinflussung begnügen. Es wird aber gewiss nicht schwierig sein, das denen nachzuweisen, welche mit dem vergleichenden Studinm der Religion irgendwie vertraut sind. Und ohne noch durch weitere Einzelheiten Sie zu verwirren, behaupte ich, dass als Gegenbilder für die durch den Psalter dargestellte Richtung des jüdischen Denkens die alten Zoroastrischen, Gîthâs ${ }^{1}$ ) genannten Hymnen belehrender sind, als irgendwelche unter den religiösen Änsserungen in den älteren oder jüngeren babylonischen Inschriften. Sie sind ganz genan so frei von abergläubischen Cärimonienwesen und ebenso einwandfrei in ihren sittlichen Forderungen") wie die

1) Siehe Zent-Aresta 111 (Sacred Books of the East). -- ") Die Ausdebnung der Sittlichkeit auf die Gedankeu (ngute Gedanken, gute Worte, gute Werke ${ }^{*}$ ) int elen $\rightarrow 0$ hazeichnend für die Găthâs wìe tür die Psalmen. F̆gl. Ps. 17, 3-5. 
hebräischen Psalmen, und man kann kaum bestreiten, dass den Dialogen zwischen Gott und Zarathustra (der in Wirklichkeit die Personifikation der frommen Gemeinde ist) an Vergeistigung nur die allerschönsten Teile des Buches der Tempellieder an die Seite gestellt werden können.

Das sind die geschichtlichen Ergebnisse, die ich nach Entledigung derselben von störendem rein gelehrten Ballast mich veranlasst gefühlt habe Ihnen vorzulegen. Aber ehe ich schliesse, lassen Sie mich Sie ermahnen, die Beschäftigung mit diesen geschichtlichen Forschungen nicht liegen zu lassen. Wenn es andere Stimmen giebt, die den Männern und Frauen unserer Zeit verlockender klingen, so folgt mit nichten daraus, dass sie wichtiger sind als der Ruf, die Schriften zu untersuchen. Religiöse Reform ist eine notwendige Vorbedingung des socialen Fortschritts, und im Hinblick auf diese muss der Ursprung und die Natur des Urehristentums und - darf ich das hinzufügen? -- des Urjudentums von nenem erforscht werden. Da sie unsere Anfmerksamkeit tief erregt, so sollte keiner von uns es ablehnen, nach bestem Können an dieser wichtigen Erörterung Anteil zu nehmen. Ich unterschätze das Studium der altisraelitischen Religion nicht; in der That möchte ich, ich hätte ihre Urkunden in diese meine Übersicht aufnehmen dürfen. Aber gerade das Studium derjenigen religiösen Erscheinung, die sich ans derselben entwickelte, hat den grössten Anspruch auf unsere Aufmerksamkeit wegen seiner engen Beziehung zu den geschichtlichen Fragen des 
ältesten Christentums. Es selbst ist nicht ohne seine dornigen Striche; aber mitten unter den Dornen werden wir überrascht durch ergötzliche Blumen, das Autblühen des religiösen Geistes des Judentums. Ich habe innerhalb der notwendigen Grenzen gethan. was ich konnte, um einige dieser kleinen Blüten möglichst vorteilhaft zusammenzustellen. Wenn die Lieder von dem Knecht Jehovahs, das zusammengesetzte Buch Job, der Psalter, das Buch der Weisheit, von Esras Gesetzbuch wenigstens die Erzählungen und die Erzählung des Chronisten nach einigen Seiten hin meinen Lesern zu lebensvollen Erscheinungen geworden sind, dann werde ich inne werden, dass mein Besuch in Amerika. der nunmehr zu einer lieben Erimnerung geworden ist, nicht ganz nutzlos war. 


\section{Noten.}

\section{Sanballat und Tobiah}

(zu Seite 46).

Trutz Wincklers scharfsinnigen Aufsatzes über Nebemiahs Reform (Altorientalicche Forschungen Band II, Heft I 1899) halte ich doch fest an der Ansieht, dass Sanballat kein Moabiter sendern aus Horon d. h. Beth Horon gebürtig war. Das geht hervor aus dem berichtigten Text der Stelle Neh. 3, 34 (siehe LXX Vatic.). Tobiah mag aus Kephar Ammoni (Jos. 18, 24) gebürtig gewesen sein; seine vertrauten Beziehungen zu hochgestellten Juden lassen es schwierig erscheinen, anzunehmen, er sei ein Ammoniter gewesen, Rawlinsouns Ansicht, er sei vormals ein ammonitischer Sklave gewesen, den Sanballat zu seinem Geheimschreiber und Kanzler ernannt habe, ist nur wenig unwahrscheinlicher als die Ryssels, er werde Neh. 2, 10. 19 "der Knecht" genannt, weil er ein Beamter unter der persischen Regierung gewesen sei. Der wahre Anlass der seltsamen Bezeichnung "der Knecht" ist meines Erachtens überseben worden. Sie entstand aus der Verwechslung des hebräischen Wortes für "Araber" mit der Bezeichnung für "Knecht". Der Abschreiber schrieb zufallig Neh. 2, 19 „đer Araber" für „der Ammoniter", indem er Tobiah mit Gašmu verwechselte. Aus 2, 19 ging ,der Araber, der Ammoniter" in 2, 10 und 4,1 über. In 2, 10 und 19 wurde „der $A$ raber" verderbt zu ,der Knecht", aber in 4,1 überdauerte es eine mehrfache Überarbeitung. In der letztgenannten Stelle ist aus "der Araber, der Ammoniter" geworden "die Araber, die Ammoniter", und dazu hat ein Schreiber in übelangebrachter Erinnerung an Neh. 13, 23 „die Asdoditer" hinzugefügt.

\section{Zu Koh. 3, 11}

(zu Seite 197).

Obwohl ein späteres Datum des Kohelet die auf Seite 197 vertretene Ansicht nicht so unwahrscheinlich macht, wie sie sonst gewesen sein würde, so bin ich doch aut Grund erneuter Untersuchung der Stelle zu dem Schluss gekommen, dass der Text einer Verbesserung bedart. Es giebt nur eine Verbesserung, die gleichzeitig paläographisch nahe liegt und in rollem Einklang mit dem Zusammenhang steht, und das ist die, das. wir ha'injan für ha'olam lesen, indem wir dann die Stelle wiedergeben wie folgt:

„Und ich betrachtete die Arbeit, welche Gott den Menschen gegeben hat, um sich „damit abzumühen. Alles hat er schön gemacht zu seiner Zeit; auch all die Arbeit „hat er ihrem Herzen eingegeben, nur dass der Mensch das Werk, welches Gott "von Anfang bis zu Ende wirkt, nicht ausfindig machen kann."

So hat Gott alles der Zeit, zu welcher es nützen soll, angepasst; durch den Anblick all der harten Forscherarbeit, welche der Prediger beobachtet hat, wird sein 
Geist durch bott laraut gefürt. Man muss es laher aneibunen und nicht verwerfen. obwohl das dje Kehreeite dazu ist. lass Gottes Werk alle menschliche Fasungskraft weit vibersteigt. Die andern Ansichten findet man bei Cheyne, Job und Solomon p. 210. Profeson Siegfrieds Wietergabe von ha colam mit ..Das Zukünftige" seheint mir nicht shr naturlich: uberdies hit es den sprachgebranch im fobelet nicht fur sich.

\section{Anmerkung zu Seite 152.}

Betreft's einer neluen l'bersetzung von Job 2-, $29-34$ durch dea Verfasser dieses Buches siehe Journal of Biblical Litterature (Loston) 169?. Di. Namfn der sternbilder -ind lort vielleicht richtiger wiedergegeben. 


\section{Z̈bersicht iiber die Datierung der betrachteten Quellenlitteratur.}

Zur Bequemlichkeit der Leser wird hier eine Übersicht gegeben über die Daten der in vorliegendem Werke besprochenen juidischen Litteratur.

Haggai und Zachariah. Haggai September bis Dezember $520 \mathrm{v}$. Chr.;

Zachariah 1, 1-6 ว20; 1, 7-6, $15519 ; 7$ f. 518.

Klagelieder. Klag. $1 \mathrm{f}$.; $4 \mathrm{f}$. in ihrer jetzt vorliegenden Gestalt aus dem letzten Abschnitt der persischen Zeit, doch wahrscheinlich auf älteren Elegien beruhend.

Jesajah 1-39, Micha u. s. w. Messianische Stellen nachexilischen Ursprungs. Vorexilische Stellen möglicherweise Jer. 23, 5 f. (33, 15 f.) und exilische sicher Ezechiel 17, 22-24; 34, 23 f.; $37,24 \mathrm{f}$.

Jesajah 40-66. Jes. 40-48 (grösstenteils) die ächte Weissagung des prophetischen Schriftstellers, der gewöhnlich, obwohl nicht sehr passend, Deuterojesajah genannt wird. Verfasst bald nach $\check{\jmath} 46$ (?), dem Jahre, in welchem Cyrus Sardes verliess. Kap. $49-5 \check{5}$ ein Anhang zur vorstehenden Weissagung, verfasst (wie Kap. 40-48) in Babylonien, aber im Hinblick auf die jerusalemitischen Verhältnisse. Der Liedercyklus über den Knecht Jehorahs $(42,1-4 ; 49,1-6 ; 50,4-9$; ว2, 13 - ๖3. 12) stand wahrscheinlich zuerst für sich, wurde aber dann durch einen friih anzusetzenden Schriftsteller in die erweiterte Wiederherstellungsweissagung (d. h. Kap. 40-55) eingefügt. Kap. 56-66 bilden thatsächlich kein besonderes Werk als selbständiges Ganzes, sondern gehören wahrscheinlich (mit Ausnahme rou 63. $7-64,2$, welches noch späteren 
264 Übersicht ïb. d. Datierung d. betrachteten Quellenlitteratur.

Datums ist) alle in versehiedene Teile des Zeitalters Nehemiahs und Esras.

Maleachi. Kurz vor Nehemiahs Ankunft (445\%).

Genesis-Josua. Priestercodex zunächst ausgearbeitet durch Esra und seine Genossen in der ersten Hälfte des う. Jahrhd.

Esra. Die Crkunden in Esra 5 f. beruhen auf echten amtlichen Berichten. Esra 7, 27-8,34 aus den Memoiren Esras (5. Jhd.) entnommen.

Nehemiah. Neh. 1, 1-7. 5; 13, 6-31 gehört zu den Alemoiren Nehemiahs (5. Jhd.).

Ruth und Jona. Nicht lange nach Nehemiah und Esra.

Psalnen. Das Gesangbuch der durch Esra begründeten orthodoxen Gemeinde, zum Teil aus der spätpersischen, zum Teil aus der griechischen Zeit.

Job. Ein zusammengearbeitetes Werk der spätpersischen oder (wahrscheinlicher) frühgriechischen Zeit.

Proverbien. Ein zusammengearbeitetes Werk der persischen und griechischen Zeit.

Chronik (einschl. Esra und Nehemiah in ihrer jetzt rorliegenden (iestalt). L'm 250.

Daniel. Zeitalter des Antiochus Epiphanes.

Koheleth. Nicht unwahrseheinlich aus dem Zeitalter Herodes des Grossen. Weitere Lntersuehung nötig.

Henoch. Zusammen gearbeitet; 2. und 1. Jhd. v. Chr.

Psalmen Salomonis. Zwischen 63 und $45 \mathrm{v}$. Chrr.

Fïr weitere Einzelheiten siehe Drivers Introduction to the Olu Testament, ein ausgezeichnetes Werk mit einer Fülle von Thatsachen, aber oft nicht durehgreifend genug in seiner Kritik Cornills Einleitung in das Alte Testament u. a. - S.] und vgl. die Polvchrome Bible [Regenbogenbibel - i.] herausgegeben von Haupt [Leipzig, J.C.Hinrichs"sche Buchhandhung], sowie die Encyclolaedia Biblica: A Dictionary of the Bible (London, A.\& C. Black). 
Verlag von Alfred Töpelmann (vormals.

\section{Professor D. Karl Budde:}

Die biblische Urgeschichte ( (x) $1-12,5)$

Anhang:

Die älteste Gestalt der biblischen Urgeschichte, versuchsweise wiederhergestellt. hebräischer Text und C̈bersetzung
$-1883-$
Gr. 8". XIV u. 539 s.
M. $111 .-$.

\section{Die Bücher Richter und Samuel,} ihre Quellen und ihr Aufbau
$-1890-$
Gr. 8". VIII u. 276 $\mathrm{S}$.
M. i...

Der Kanon des alten Testaments Ein Abriss
$-1900-$
Gr. 8". VIII 11. 80 $\rightarrow$
II. 1.40.

\section{Die Ebed-Jahwe-Lieder}

und die Bedentung des Knechtes Jahwe's (in Jes. 40-5i) Ein Minoritätsvotum
$-1900-$
Gr. 8". TI แ. 41 S.
II. $1 .-$.

Das Alte Testament und die Ausgrabungen Ein Beitrag zum Streit nm Babel und Bibel Zweite Auflage mit vielen Anmerkungen und einem Vorwort statt des Nachworts 


\section{Die Religion \\ Babyloniens und Assyriens \\ von}

Morris Jastrow, jr.

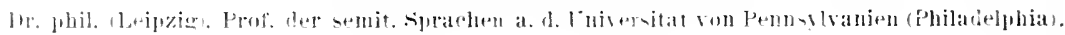

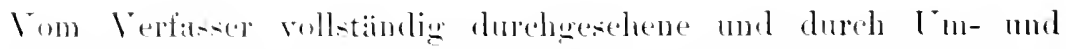

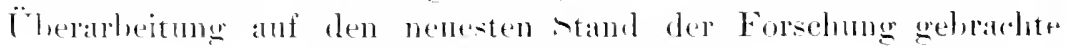

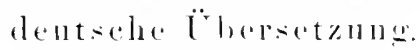

Vollständig in etwa 13 Lieferungen (zus. 65 Bogen) zu je M. 1.50 oder n zwei Bänden zu etwa je $10 M$. und in einer Mappe mit Abbildungen.

Fieben biefermugen, die zugleidh den arsten Band hilılen, liegren

- fertigr vor.

Prois des 1. Bandes: Geheftet M. 10.50; eleg. grebunden M. 1:3-. [her sub-kriptionspreis erliselut mit der Ausgabe der letzten Licfermus.

\section{Die Astronomie im Alten Testament} von

\section{Giovanni Schiaparelli}

Direktor a. D. des Breva-Observatoriums in Mailand

Chersetzt ron 1)r. plil. Willy Lüdtke, Hilfshindiothekin in Kiel

Mit if Ml,ildungen im 'lext

VIII 1. 137 s. (ielueftet M. 3.20; geb. M. 4.- 